\title{
Drug-induced torsade de pointes arrhythmias and sudden cardiac death in the remodeled canine heart
}

Citation for published version (APA):

van Opstal, J. M. (2002). Drug-induced torsade de pointes arrhythmias and sudden cardiac death in the remodeled canine heart. [Doctoral Thesis, Maastricht University]. Universiteit Maastricht. https://doi.org/10.26481/dis.20021108jo

Document status and date:

Published: 01/01/2002

DOI:

10.26481/dis.20021108jo

Document Version:

Publisher's PDF, also known as Version of record

\section{Please check the document version of this publication:}

- A submitted manuscript is the version of the article upon submission and before peer-review. There can be important differences between the submitted version and the official published version of record.

People interested in the research are advised to contact the author for the final version of the publication, or visit the DOI to the publisher's website.

- The final author version and the galley proof are versions of the publication after peer review.

- The final published version features the final layout of the paper including the volume, issue and page numbers.

Link to publication

\footnotetext{
General rights rights.

- You may freely distribute the URL identifying the publication in the public portal. please follow below link for the End User Agreement:

www.umlib.nl/taverne-license

Take down policy

If you believe that this document breaches copyright please contact us at:

repository@maastrichtuniversity.nl

providing details and we will investigate your claim.
}

Copyright and moral rights for the publications made accessible in the public portal are retained by the authors and/or other copyright owners and it is a condition of accessing publications that users recognise and abide by the legal requirements associated with these

- Users may download and print one copy of any publication from the public portal for the purpose of private study or research.

- You may not further distribute the material or use it for any profit-making activity or commercial gain

If the publication is distributed under the terms of Article $25 \mathrm{fa}$ of the Dutch Copyright Act, indicated by the "Taverne" license above, 


\section{Drug-Induced Torsade de Pointes Arrhythmias and Sudden Cardiac Death in the Remodeled Canine Heart}


(c) Jurren M. van Opstal, Maastricht, 2002 ISBN 90-9016217-8

Vormgeving en druk: Datawyse / Universitaire Pers Mastricht Illustraties: Jet Beekman en Roel Spätjens 


\title{
Drug-Induced Torsade de Pointes Arrhythmias and Sudden Cardiac Death in the Remodeled Canine Heart
}

\author{
PROEFSCHRIFT \\ ter verkrijging van de graad van doctor \\ aan de Universiteit Maastricht, \\ op gezag van de Rector Magnificus, \\ Prof. dr. A.C. Nieuwenhuijzen Kruseman, \\ volgens het besluit van het College van Decanen, \\ in het openbaar te verdedigen \\ op vrijdag 8 november 2002 om 12.00 uur \\ door \\ Jurren Marie van Opstal \\ geboren op 2 november 1972 te Utrecht
}




\section{Promotor}

Prof. dr. H.J.J. Wellens

\section{Co-promotor \\ Dr. M.A. Vos}

\section{Beoordelingscommissie}

Prof. dr. H.J.G.M. Crijns (voorzitter)

Prof. dr. M.A. Allessie

Prof. dr. D. Escande (Université de Nantes, France)

Prof. dr. M.J. Janse (Universiteit van Amsterdam)

Prof. dr. H.A.J. Struijker Boudier

Financial support by the Netherlands Heart Foundation and the Stichting RESCAR Maastricht for the publication of this thesis is gratefully acknowledged

Additional support was granted by: Procter \& Gamble Pharmaceuticals Inc, Sanofi-Synthélabo Nederland B.V., Medtronic Bakken Research Center B.V. and St. Jude Medical Nederland B.V. 
Dankzij mijn vader en moeder Voor Annelette 



\section{Content}

9 CHAPTER 1

Introduction

31 CHAPTER 2

Azimilide and Dofetilide Produce Similar Electrophysiological and Proarrhythmic Effects in a Canine Model of Torsade de Pointes Arrhythmias

49 CHAPTER 3

Probing the Contribution of $\mathrm{I}_{\mathrm{K}}$ to Canine Ventricular Repolarization

73 CHAPTER 4

Chronic Amiodarone Evokes No Torsade de Pointes Arrhythmias Despite QT Lengthening in an Animal Model of Acquired Long-QT Syndrome

89 CHAPTER 5

The JT area Indicates Dispersion of Repolarization in Dogs with Atrioventricular Block

105 CHAPTER 6

Electrophysiological Parameters Indicative of Sudden Cardiac Death in the Dog with Chronic Complete AV Block

119 CHAPTER 7

General Discussion

135 SUMMARY

139 SAMENVATTING

143 DANKWOORD

147 CURRICULUM VITAE

149 PUBLICATIONS 



\section{CHAPTER 1}

\section{Introduction}

Content

1.1 Sudden Cardiac Death and Ventricular Arrhythmias in the Remodeled Heart

1.2 The Ventricular Action Potential and Electrocardiogram

1.3 Mechanisms of Arrhythmias

1.4 Torsade de Pointes Arrhythmias and the Long-QT syndromes

1.5 Proarrhythmic Properties of Antiarrhythmic Drugs

1.6 Ion Channel Blockade in Relation to Proarrhythmic Potential

1.7 The Chronic Complete-AV Block Dog

1.8 Aims of the Thesis 


\subsection{SUDDEN CARDIAC DEATH AND VENTRICULAR ARRHYTHMIAS IN THE REMODELED HEART}

Sudden cardiac death (SCD) describes the unexpected death from a cardiac cause within a short time period, generally within one hour after the onset of acute symptoms, in a person known or unknown with heart disease. ${ }^{1,2}$ SCD is a common manifestation of heart disease, ${ }^{1,2}$ being in many cases the first and only symptom, ${ }^{2}$ and claims 1-2 deaths per 1000 persons annually. ${ }^{1,3,4}$ Such an unforeseen death is often attributed to a cardiac arrhythmia, but only an (ambulatory) electrocardiogram (ECG) or ventricular electrogram recorded from an implanted device at the time of death can provide definite information. ${ }^{1}$

Important risk factors for arrhythmia-related SCD comprise ventricular hypertrophy and heart failure, ${ }^{5-9}$ which have been related to remodeling processes, ${ }^{10-13}$ and a 3-5 times higher risk of SCD. ${ }^{14,15}$ The incidence of ventricular hypertrophy increases with age, having a prevalence of approximately $20 \%$ in the total adult population. ${ }^{16-18}$ Ventricular hypertrophy is regarded as an adaptive response of the heart to maintain cardiac output in situations, which increase the workload of the heart. Such conditions occur during hypertension, valvular disease such as aortic stenosis, or after a myocardial infarction. ${ }^{16}$ Patients with hypertrophy can remain in a compensatory phase with no symptoms and (near) normal exercise reserve for years. However, sustained hypertrophy is a leading cause of heart failure, ${ }^{19}$ afflicting at least 5 million patients in the European Union. ${ }^{20}$

Changes in electrophysiological properties of the heart, such as a prolonged repolarization of the heart, are thought to play an important role in the genesis of ventricular arrhythmias and SCD in ventricular hypertrophy and heart failure. ${ }^{21,22}$ Also, the administration of repolarization prolonging drugs, frequently antiarrhythmic ones, may favor the occurrence of repolarization-dependent tachyarrhythmias in these patients. The classical term Torsade de Pointes arrhythmia (TdP, Figure 1), ${ }^{23}$ will be used as a pars pro toto for repolarization- dependent tachyarrhythmias in this thesis. In the following pages, the genesis of the ECG will be discussed, concentrating on the role of ion currents in generating the ventricular action potential. Secondly, an overview is given about the different mechanisms of arrhythmias. Thirdly, the underlying electrophysiological changes related to remodeling processes, causing the increased susceptibility to (drug-induced) ventricular arrhythmias and SCD are explained. Finally, the proarrhythmic properties of antiarrhythmic drugs in relation to ion channel blockade are discussed, emphasizing the use of the chronic complete-AV block dog model to study the proarrhythmic properties of such drugs. 


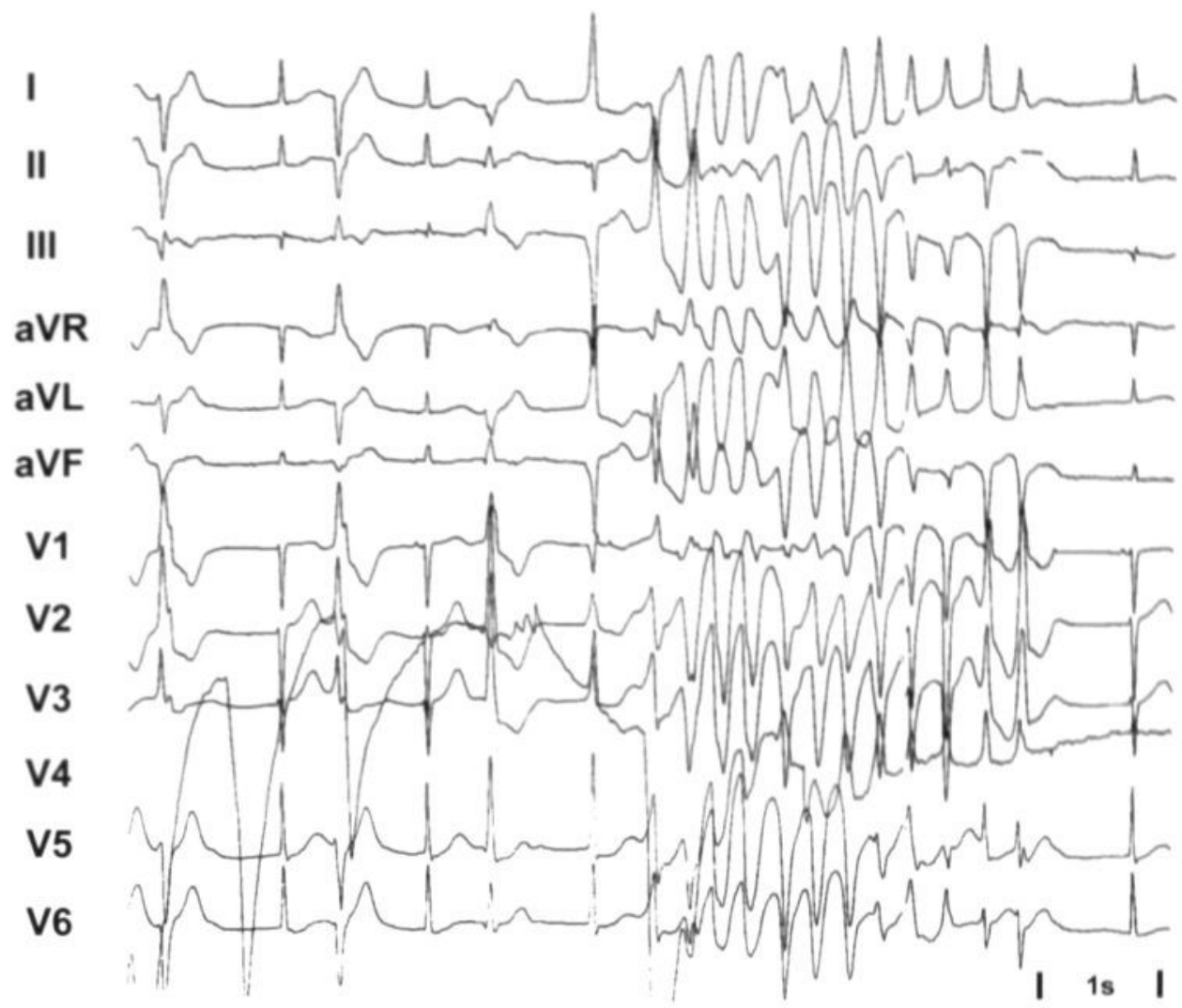

Figure 1 - Torsade de Pointes arrhythmia in a 79-year old female patient. Ibutilide was administered intravenously to terminate an atrial tachycardia. The patient had significant left ventricular hypertrophy and severe aortic stenosis with a normal ventricular ejection fraction. Lead V4 was detached during a preceding TdP episode.

\subsection{THE VENTRICULAR ACTION POTENTIAL AND ELECTROCARDIOGRAM}

The heart continuously pumps blood throughout the body, roughly three billion times in an average lifetime. To achieve this, relaxation of the heart muscle precedes contraction so that the cardiac chambers can fill with blood, and then contract to propel the blood throughout the body. This cycle of relaxation and contraction occurs in a single heartbeat. Each heartbeat is initiated by an electrical impulse, generated by a group of specialized pacemaker cells located in the sinus node area and spreads through the heart using a specialized conduction system.

The electrical activity of each cardiac cell is made possible by electrochemical currents, carried by ion channels and exchangers, which give rise to the cardiac action potential (Figure 2). The depolarization (phase 0) in ventricular tissue is caused by an inward current of sodium ions $\left(\mathrm{I}_{\mathrm{Na}}\right)$ from the extracellular to the 
Ventricular Action Potential
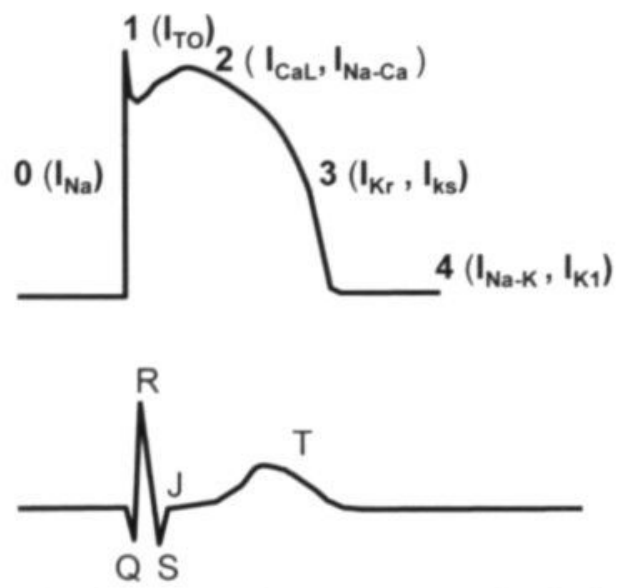

Figure 2 - The different phases (0-4) of the ventricular action potential with the underlying principal ion currents and exchangers in relation to the surface electrocardiogram (ECG) (see text for details).

intracellular space. Repolarization consists of three phases. A transient egress of outward currents (mainly $I_{\mathrm{TO}}$ ) is responsible for the first phase of repolarization (phase 1). This is followed by a plateau phase (phase 2), which duration is determined by the delicate balance between inward and outward currents through competing ion channels and exchangers (important ones are the $\mathrm{I}_{\mathrm{CaL}}$ and the $\mathrm{Na}^{+}-\mathrm{Ca}^{2+}$ exchanger). Phase 3 of the repolarization process is caused mainly by inactivation of inward calcium currents together with increasing outward potassium currents. The main outward potassium currents are the rapidly $\left(\mathrm{I}_{\mathrm{Kr}_{\mathrm{r}}}\right)$ and the slowly activating component $\left(\mathrm{I}_{\mathrm{Ks}}\right)$ of the delayed rectifier current. After completion of repolarization, outward $\left(\mathrm{I}_{\mathrm{K} 1}\right)$ and pump currents $\left(\mathrm{I}_{\mathrm{Na}-\mathrm{K}}\right)$ are responsible for maintaining the resting membrane potential at approximately $-90 \mathrm{mV}$ (phase 4).

The process of electrical myocardial activation and recovery can be recorded noninvasively by placing electrodes on the body surface. These electrodes register potential differences throughout the cardiac cycle, representing the surface ECG (Figure 2). The summation of the different ventricular action potentials in the heart represents the electrocardiographic QT interval. The QT interval can be divided into the QRS complex, which reflects depolarization within the His-Purkinje system and the ventricles, whereas the JT interval is a measure of ventricular repolarization (Figure 2).

\subsection{MECHANISMS OF ARRHYTHMIAS}

The sinoatrial node, which serves as the normal cardiac pacemaker, consists of an area of hundreds of pacemaker cells located in the wall of the superior part of the 
right atrium close to the entrance of the superior vena cava. Spontaneous depolarization of the sinoatrial node normally initiates the wave of the depolarization that activates the atria, AV node, the ventricular conduction system and the ventricles. Normally, the sinoatrial node is the fastest pacemaker with the steepest slope of diastolic depolarization. Slower subsidiary pacemakers can be located in the atrium, the AV junction and the Purkinje fibers. ${ }^{24}$

When the heart beats too slow (bradycardia) or so fast that it cannot fill and expel blood adequately (tachycardia), it may lead to circulatory collapse, and in the extreme case, sudden death. The mechanism of arrhythmias can be based upon 1) abnormal impulse formation and/or 2) abnormal impulse conduction. ${ }^{25}$

Abnormal impulse formation can be divided into: abnormal automaticity or triggered activity. Abnormal automaticity refers to spontaneous impulse generation from a reduced diastolic potential in cardiac fibers, which normally show a high diastolic membrane potential. ${ }^{25}$ Afterdepolarizations are oscillations of the membrane potential that depend on the preceding action potential for their generation, and can give rise to new action potentials, i.e. triggered activity, when reaching a critical threshold membrane potential. ${ }^{26}$ Two types of afterdepolarizations can be distinguished: early afterdepolarizations (EADs) and delayed afterdepolarizations (DADs). Early afterdepolarizations appear during the action potential and have been defined as "depolarizing afterpotentials that begin prior to completion of repolarization and cause an interruption of normal repolarization". ${ }^{26}$ Delayed afterdepolarizations have been defined as "oscillations in membrane potential that obligatory follow an action potential ". ${ }^{26}$

Disturbances in impulse conduction may lead to reentrant arrhythmias. When a propagated impulse is able to reenter a conduction pathway, part or all of the heart can be reexcited producing an "echo" or re-entrant beat. Perpetuation of this mechanism leads to a continuous arrhythmia. For reentry to occur, cardiac tissue: 1) has to be or to be brought into a state of inhomogeneity in refractory period duration (dispersion) with 2) unidirectional block in one pathway of cardiac tissue, and 3) sufficient slowing of impulse conduction in the other pathway, to enable the impulse to reenter the distal end of the proximally blocked pathway. ${ }^{27}$

The mechanism underlying TdP, with its distinct electrocardiographic phenotype (Figure 1), is still controversial. The two main hypotheses for the mechanism of TdP are: 1) multifocal abnormal impulse formation, as already been suggested by Dessertenne, who described the arrhythmia as "une tachycardie ventriculaire à deux foyers opposés variables", which he called Torsade de Pointes, ${ }^{23.28,29}$ 2) reentrant circuit(s) in the setting of spatial dispersion of repolarization (the substrate) initiated by abnormal impulse formation (the trigger). ${ }^{28,30-32}$

An EAD-induced ectopic beat, originating (sub) endocardially at the site where the action potential duration (APD) is long, ${ }^{33}$ is probably often the trigger for TdP arrhythmias. Whether this focal origin is also involved in the perpetuation of the arrhythmia is still under investigation. 
normal

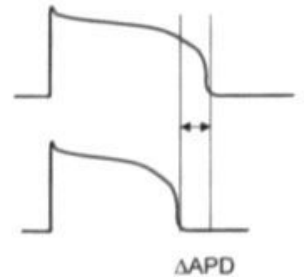

net-repolarization current $\downarrow \downarrow$

(e.g. $I_{K \downarrow \downarrow)}$

EAD triggered EB

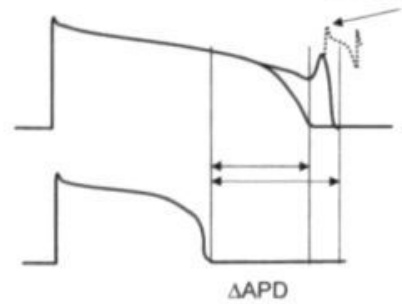

Figure 3- On the left panel two hypothetical ventricular action potentials from a normal heart are shown. The difference in duration between the two action potentials (dispersion of repolarization) is referred to as $\triangle A P D$. On the right panel the situation is shown when electrical remodeling has taken place and the net-repolarization current is diminished (e.g. when $I_{k}$ is reduced). The action potential duration prolongs which can give rise to early afterdepolarizations (EADs) and triggered ectopic beats (EBs). Furthermore prolongation of action potential duration can be inhomogeneous, which can be caused by EADs, thereby increasing $\triangle \mathrm{APD}$.

\section{net-repolarization current $\downarrow \downarrow$}

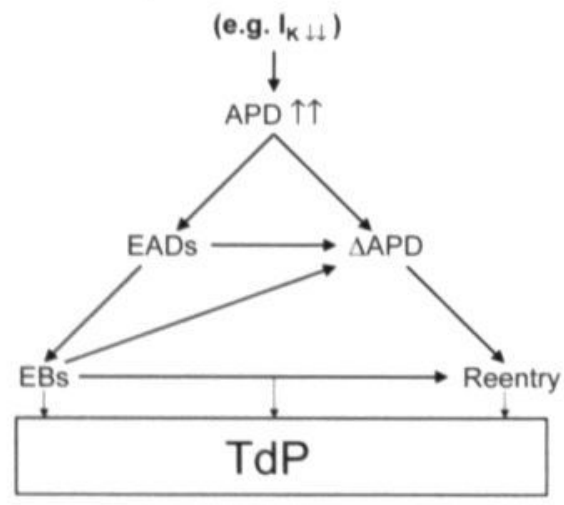

Figure 4 - Hypothetical scheme for TdP occurrence. If the net-repolarization current is diminished (e.g. by $\mathrm{I}_{\mathrm{k}}$ downregulation by electrical remodeling and/or repolarization prolonging drugs, mainly $\mathrm{I}_{\mathrm{k}}$ blockers), the APD increases, thereby creating early afterdepolarizations (EADs) and dispersion of repolarization ( $\triangle A P D)$. EADs themselves can 1) increase dispersion if their occurrence is non-homogeneous and 2) trigger (multiple) ectopic beats (EBs). Subsequently, EBs can increase $\triangle A P D$ and/or trigger reentry. TdP has been related to multifocal-triggered EBs and/or reentry. 


\subsection{TORSADE DE POINTES ARRHYTHMIAS AND THE LONG-QT SYNDROMES}

TdP arrhythmias occur often, but not necessarily, ${ }^{34.35}$ in the setting of a prolonged QT interval. ${ }^{36-38}$

The long-QT syndrome can either be acquired, for example as a result of electrical remodeling processes such as in ventricular hypertrophy and heart failure, 10-13.21.39-45 or be inherited because of a gene mutation of ion channels. ${ }^{46-53}$ The ion channel changes underlying the prolonged-QT times in hypertrophy and heart failure are still under investigation, but seem to be related to a downregulation of outward potassium currents $\left(\mathrm{I}_{\mathrm{TO}}, \mathrm{I}_{\mathrm{K}_{r}}, \mathrm{I}_{\mathrm{Ks}}\right)$ or an upregulation of inward currents or exchangers, thereby reducing the net repolarization current (Figure 3), 21,54-62

The longer QT time, respectively the longer APD, and the diminished net repolarization current results in a more labile repolarization process, which can be further aggravated by $I_{K}$ blocking drugs such as antiarrhythmics. 22,63,64 Action potential lability may become manifest as variability in duration and/or the occurrence of secondary depolarizations that interrupt the action potential repolarization, such as EADs. This process may initiate triggered arrhythmias including Torsade de Pointes ventricular tachycardia (Figures 1,3 and 4). ${ }^{65}$ Furthermore, the occurrence of EADs and/or prolongation of repolarization can be inhomogeneous, leading to dispersion of repolarization, which can serve as a substrate for reentry (Figures 3,4). ${ }^{40-42,44,66-75}$

Remarkably, the acquired-long QT syndrome and other electrophysiological changes in hypertrophy and heart failure show similarities with the congenital long-QT syndrome, in which mutations in genes encoding for ion channel proteins are related to Torsade de Pointes arrhythmias and SCD. ${ }^{22,64}$ Importantly, the contribution of some of these genes to normal cardiac repolarization had been elucidated prior to their identification as long-QT syndrome disease genes. Thus, the information gained by these molecular genetic approaches not only has implications for patients with the long-QT syndrome, but also serves as a Rosetta stone for the analysis of other clinical situations, such as seen in hypertrophy, heart failure, and sudden infant death syndrome in which ion channelopathies and abnormal repolarization have been linked to SCD. ${ }^{21,22,64,76,77}$

To date, mutations in at least 6 genes, of which at least 5 encode an ion channel protein, have been identified as causes of the inherited long-QT syndrome (Table 1). KVLQT1, MinK, HERG and MiRP1 encode for subunits in the $I_{K r}$ and $I_{K s}$ channel, respectively. SNC5A encodes for the inward cardiac $\mathrm{Na}$ channel. ${ }^{46-52}$

Patients with SNC5A mutations appear to have particularly prolonged QT intervals at night and have a higher incidence of sudden death under resting or sedentary conditions. In contrast, arrhythmic events in patients with a KVLQT1 mutation develop during, or following exercise and under conditions of emotional stress. In patients with HERG lesions, arrhythmias have occurred under conditions of exercise, emotion and rest. ${ }^{78}$ 
Table 1 - Genes and currents in the long-QT syndromes

\begin{tabular}{lll}
\hline & gene & current \\
\hline LQT 1 & KVLQT1 & $\downarrow \mathrm{I}_{\mathrm{Ks}}$ \\
LQT 2 & HERG & $\downarrow \mathrm{I}_{\mathrm{Kr}}$ \\
LQT 3 & SNC5A & $\uparrow \mathrm{I}_{\mathrm{Na}}$ \\
LQT 4 & Unknown & Unknown \\
LQT 5 & MinK & $\downarrow \mathrm{I}_{\mathrm{Ks}}$ \\
LQT 6 & MiRP1 & $\downarrow \mathrm{I}_{\mathrm{Kr}}$ \\
\hline
\end{tabular}

\subsection{PROARRHYTHMIC PROPERTIES OF ANTIARRHYTHMIC DRUGS}

Important mechanisms of antiarrhythmic drugs are 1) slowing or blocking cardiac conduction or 2) delaying cardiac repolarization, thereby slowing, terminating, or preventing cardiac arrhythmias.

Quinidine, the first antiarrhythmic drug, was introduced in cardiovascular therapy in 1918 followed by procainamide, and lidocaine in the 1950's. ${ }^{79,80}$ Their clinical use increased in the 1960's for the suppression of ventricular arrhythmias complicating myocardial infarction in the coronary care unit (CCU). The perceived success of lidocaine in suppressing premature ventricular contractions in the CCU led to the development of oral congeners of lidocaine, such as tocainide and mexiletine. This was followed by the synthesis and characterization of highly potent sodium-channel blockers such as flecainide, encainide and propafenone. These were near-perfect ventricular premature beat suppressants, thereby presumably taking away the trigger for arrhythmias. That hypothesis provided the basis for testing the use of these drugs to reduce arrhythmic mortality after a myocardial infarction. The finding that flecainide and encainide in the Cardiac Arrhythmia Suppression Trial (CAST) significantly increased mortality while suppressing premature ventricular contractions was unexpected, and had a profound impact on the selection of antiarrhythmic drugs for the control of cardiac arrhythmias in patients with heart disease. ${ }^{81,82}$

Therefore, attention shifted towards class III drugs, which lengthen repolarization as their most prominent antiarrhythmic mechanism. In 1962, sotalol had been synthesized as a $\beta$-blocker and amiodarone as an antianginal compound with coronary vasodilator properties. The latter agent was later found to exhibit non-specific antiadrenergic blocking actions as well. Both drugs exhibited strong antifibrillatory and antiarrhythmic properties. The perception that, while being powerful sympathetic antagonists, sotalol and amiodarone acted predominantly by prolonging the APD, led to the search for pure APD prolonging compounds devoid of other associated properties. ${ }^{83.84}$ Such compounds may preferentially target a single ion current (e.g. dofetilide) or multiple currents (e.g. ibutilide, azimilide). However, the clinical utility of these repolarization-prolonging compounds appears 
to be restricted by their property to induce arrhythmias, especially TdP. As shown by the SWORD and the DIAMOND trial, this is clearly the Achilles' heel of this class of drugs. ${ }^{85,86}$ The antiarrhythmic, but also proarrhythmic, effect of these drugs is related to prolongation of repolarization by augmenting inward current or diminishing outward current, which reduces the net repolarization current. A hallmark of every class III drug is the blockade of the $\mathrm{I}_{\mathrm{Kr}}$ as, part of, the strategy to achieve prolongation of the repolarization. ${ }^{37,87}$

Variation in occurrence of arrhythmias in relation to the number of the $\mathrm{I}_{\mathrm{Kr}}$ channels which are blocked, can be linked to variability in absorption, distribution, metabolism or excretion of the drug (i.e. pharmacokinetics), but can also have different pharmacodynamic causes, ${ }^{88}$ that refer to the drug-target interaction. For example, the genes encoding the proteins making up the $\mathrm{I}_{\mathrm{Kr}}$ channel might be modulated by mutations or variants in HERG or in other factors that regulate HERG function, which in turn determines the extent of $I_{K r}$ block. Mutations in MiRP1, which is a function-modifying subunit of HERG, have been identified in patients with $\mathrm{I}_{\mathrm{Kr}_{r}}$-associated TdP..$^{52.89}$ Also, mutations or allelic variants in other channels, e.g. $\mathrm{I}_{\mathrm{K}}$, can diminish the repolarization reserve and predispose to TdP. Patients with a phenotypically normal QT time but having a mutation in the KVLQT1 gene, the so called "forme fruste" long QT syndrome, are more prone to drug-induced TdP. ${ }^{90,91}$

Similarly, in ventricular hypertrophy and heart failure there is a downregulation of repolarizing currents or an upregulation of inward currents, which will contribute to a decrease in net repolarizing currents and a reduction in the repolarization reserve. ${ }^{21,44,56}$ Further reduction of the repolarization current by an $\mathrm{I}_{\mathrm{Kr}}$ blocker can then result in failure to repolarize and TdP (Figures 1,3 and 4). ${ }^{43,64,92-95}$

The first report of syncope and sudden death occurring shortly after initiation of the $\mathrm{I}_{\mathrm{Kr}}$ (and $\mathrm{I}_{\mathrm{Na}}$ ) blocker quinidine, dates back to the early 20 's of the last century. ${ }^{96}$ Then it was noted "that patients with large hearts, especially with multiple valve lesions, are unfavourably predisposed and they be treated with caution". The electrocardiographic basis of these adverse effects was reported in 1929 when Kerr and Bender described syncope during "paroxysmal ventricular fibrillation" in a patient with heart failure, "auricular fibrillation and complete heart block while under quinidine sulphate therapy". ${ }^{77}$ Today, a large number of drugs, including more than 50 non-cardiac ones, have been associated with prolongation of the QT interval and $\mathrm{TdP}$ of which virtually all are blockers of the $\mathrm{I}_{\mathrm{Kr}}$ channel (those drugs can be found at: www.torsades.org). ${ }^{38,98}$ Therefore, drugs that exert even modest QT-prolonging activity are now under increasing regulatory scrutiny because of their possible proarrhythmic potential. 


\subsection{ION CHANNEL BLOCKADE IN RELATION TO PROARRHYTHMIC POTENTIAL}

To allow prediction of the Torsadogenic potential of class III drugs, it is imperative to determine the electrophysiological characteristics of individual class III compounds. It is known that selective $\mathrm{I}_{\mathrm{Kr}}$ blockers, like almokalant and dofetilide (Table 2), show rate-related prolongation of the APD. At very slow rates the APD lengthens markedly and may become associated with the generation of EADs. This is presumed to be (one of) the bases for the development of the clinically observed TdP. Conversely, at increasing heart rates, the APD shortens. At such rates, there is a corresponding decline in antifibrillatory action of the compound. This phenomenon, called reversed use dependency, is characteristic of potent $\mathrm{I}_{\mathrm{Kr}}$ blockers, ${ }^{99}$ that has been ascribed, in guinea pig, to incomplete deactivation of the $\mathrm{I}_{\mathrm{Ks}}$ at fast rates. ${ }^{100}$ Furthermore, differences in $\mathrm{I}_{\mathrm{Ks}}: \mathrm{I}_{\mathrm{Kr}}$ density ratio between epicardium, midmyocardium and endocardium as well as between left and right ventricle play an important role in the dispersion of repolarization. ${ }^{101,102}$ Due to a weaker $\mathrm{I}_{\mathrm{Ks}}$ in the midmyocardium, attenuation of $\mathrm{I}_{\mathrm{Kr}}$ alone, results in a preferential APD prolongation of the midmyocardium. ${ }^{103}$ Therefore, (additional) $\mathrm{I}_{\mathrm{K} s}$ blockade, e.g. azimilide or HMR 1556 (Table 2), could induce an approximately equal percentage increase in the APD over the entire range of frequencies and result in more homogeneous APD prolongation. ${ }^{79,80,104}$

Another ion channel, the $\mathrm{I}_{\mathrm{Cal}}$ channel, is suggested to play a pivotal role in EAD formation, ${ }^{105}$ and as a consequence $\mathrm{I}_{\mathrm{Cal}}$ channel blockade would counteract proarrhythmia. ${ }^{106}$ Similarly, agents preventing intracellular $\mathrm{Ca}^{2+}$ overload appear favorable in the prevention of proarrhythmic effects, which could be related to less EAD formation. ${ }^{107-109}$

Still, the only antiarrhythmic drug, which demonstrates a low incidence of TdP in the clinical setting, is amiodarone (Table 2). Unfortunately, amiodarone demonstrates adverse non-cardiac effects, which have been attributed to iodine in the molecule, and furthermore needs weeks of oral administration to reach therapeutic plasma concentrations. The drug has unique properties as it blocks multiple ion channels and inhibits thyroid hormone activation in cardiac muscle when administered chronically. ${ }^{110}$ Dronedarone, its proposed successor and devoid of iodine, is suggested to have a similar electropharmacological profile, but its chronic effects on cardiac ion channels are unknown. ${ }^{111}$

\subsection{THE CHRONIC COMPLETE-AV BLOCK DOG}

The medical community and regulatory agencies have become increasingly concerned about drug-induced QT prolongation, TdP and SCD. ${ }^{120}$ Apart from the growing number of proarrhythmic non-cardiovascular drugs, regulatory concerns 
Table 2 - Ion channel and $\alpha / \beta$ receptor blockade of (proposed) antiarrhythmic drugs

\begin{tabular}{|c|c|c|c|c|c|c|}
\hline & $I_{K r}$ & $I_{K S}$ & $I_{\text {Cal }}$ & $I_{N a}$ & $\begin{array}{l}\alpha / \beta \\
\text { blockade }\end{array}$ & $\begin{array}{l}\text { clinical TAP } \\
\text { incidence }\end{array}$ \\
\hline Almokalant & +++112 & & & & & $6 \% 113$ \\
\hline Dofetilide & +++100 & & & & & $3-5 \%{ }^{86}$ \\
\hline Azimilide & +++114.115 & $+114,115$ & & & & $?$ \\
\hline HMR 1556 & & +++116 & & & & ? \\
\hline Amio chron & +117 & +++117 & +110 & +110 & ++110 & $<0.5 \%{ }^{118}$ \\
\hline Dron chron & ? & ? & ? & ? & ++119 & ? \\
\hline
\end{tabular}

$+1+++++$ : relative block of ion channels / receptors

are growing because of the increasing size of the population at risk. This applies to the elderly who frequently receive multiple drugs with the potential for interaction, and to patients with cardiac, renal, hepatic or other predisposing diseases, which may increase the risk of abnormal drug metabolism and excretion and create the potential for increased susceptibility to proarrhythmia. Also, patients with myocardial hypertrophy or heart failure with or without visible abnormalities in repolarization represent high-risk groups. ${ }^{94,98,121}$

To test drugs preclinically for their Torsadogenic potential, in-vivo animal models stand closest to the human. ${ }^{122}$ The dog with chronic complete AV block (CAVB) is a very suitable model to study (drug-induced) arrhythmias and SCD, as the demonstrated electrophysiological alterations in the hypertrophied CAVB heart show similarities with human forms of long-QT syndrome. Because of its high sensitivity to (antiarrhythmic) drug-induced TdP, the model has recently been accepted by the US Food and Drug Administration for testing proarrhythmic properties of drugs.

In the model, the bradycardia-induced hemodynamic overload created by complete AV block initiates a number of adaptation processes to compensate for the decreased cardiac output and the increased end-diastolic ventricular pressure. These remodeling processes have reached a stable situation after 4 weeks of $\mathrm{CAVB}^{123}$ and include 1) the development of biventricular hypertrophy, ${ }^{44}$ 2) compensated cardiac hemodynamics, ${ }^{44,124}$ and 3) heterogeneous prolongation of the ventricular repolarization, resulting in increased dispersion of repolarization. ${ }^{44}$ The (mal)adaptations increase the risk of EAD- and DAD-dependent triggered arrhythmias and druginduced arrhythmias. ${ }^{93,124,125}$ Moreover, a considerable number of dogs die unexpected, suddenly, in their cages.

At the cellular level increases in cell size and APD prolongation have been found as well as an increased propensity to triggered activity. ${ }^{45}$ Changes in ion channel (density), $\mathrm{I}_{\mathrm{Kr}}, \mathrm{I}_{\mathrm{Ks}}$, and the $\mathrm{Na}^{+}-\mathrm{Ca}^{2+}$ exchanger could form the ionic basis for the described alterations. ${ }^{56,59}$ On the molecular level, a downregulation of the expres- 
sion of KVLQT1 and MinK, the genes encoding for the $\mathrm{I}_{\mathrm{Ks}}$ channel, has been demonstrated. 126 Thus, the environmentally imposed alterations, which impact both the molecular, ion channel and intact organ level, render the heart susceptible to (drug)-induced arrhythmias and SCD.

\subsection{AIMS OF THE THESIS}

The first aim of the thesis was to compare several drugs with different modes of ion channel blockade in relation to their proarrhythmic properties and the electrophysiological parameters predictive for drug-induced TdP.

Azimilide is a blocker of both $\mathrm{I}_{\mathrm{Kr}}$ and $\mathrm{I}_{\mathrm{Ks}}$ channels (Table 2). ${ }^{114,115}$ The (addition of) $\mathrm{I}_{\mathrm{Ks}}$ blockade has been suggested to prolong the APDs more homogeneously than selective $\mathrm{I}_{\mathrm{Kr}}$ channel blockade. In a random crossover design in the CAVB dog, azimilide was compared to dofetilide (Chapter 2) to see whether similar QT prolongation could be reached with azimilide but without an increase in dispersion of repolarization and proarrhythmic effects.

In the next study, specifically the role of the $\mathrm{I}_{\mathrm{Ks}}$ channel was investigated by using selective $\mathrm{I}_{\mathrm{Ks}}$ blockers (Table 2). Administration of these drugs did not result in the desired QT lengthening, which excluded proarrhythmic testing in the CAVB dog. Therefore, we studied the physiological role of the $I_{K s}$ channel to ventricular repolarization in normal sinus rhythm dogs using both cellular and in-vivo investigations. The role of $\mathrm{I}_{\mathrm{Ks}}$ was quantitatively assessed in conditions relevant for the action potential, including the $ß$-adrenergic contribution and autonomic status.

Amiodarone is currently the only antiarrhythmic drug demonstrating QT prolongation with a low clinical incidence of TdP. Consequently, we were interested whether and why this drug would have a low proarrhythmic potential in the CAVB dog. Because a clear difference exists in acute versus chronic administration of these drugs with regard to QT prolonging effect, the CAVB dog model was extended, and the animals were tested serially under anesthesia before and after 4 weeks of chronic treatment. Possible proarrhythmic consequences of chronic amiodarone treatment were compared to a control group and to a group in which dronedarone was administered. Dronedarone was selected because it has been suggested to be similarly effective, but devoid of the unwanted side effects of amiodarone.

As dispersion of repolarization can only be assessed invasively by catheters or needle electrodes, the next aim of the thesis was to explore if dispersion of repolarization could be visualized non-invasively, on the surface ECG. Therefore, we investigated in chapter 5 whether the area of the JT wave on the surface ECG represented changes in interventricular dispersion of repolarization.

Another aim of the thesis was to assess if sudden death in the model unrelated to drugs, could be attributed to ventricular tachyarrhythmias. Furthermore, we 
attempted to identify retrospectively the electrophysiological parameters that could predict susceptibility to sudden cardiac death and to drug-induced TdP (Chapter 6).

The final aim of the thesis was to demonstrate that observations on druginduced TdP in the anesthetized CAVB dog are also relevant for drug-induced TdP and SCD under conscious circumstances. Using Holter recordings and the internal cardioverter defibrillator, arrhythmias were studied after oral administration of the $\mathrm{I}_{\mathrm{Kr}}$ blocker dofetilide in the conscious CAVB dog.

\section{REFERENCES}

1. Zipes DP. Wellens HJ. Sudden cardiac death. Circulation. 1998;98:2334-51.

2. Myerburg RJ, Castellanos A. Cardiac arrest and sudden cardiac death. In: Braunwald E, Zipes DP, Libby P, ed., Heart disease: a textbook of cardiovascular medicine. New York: WB Saunders Publishing Co. 2001:890.

3. de Vreede-Swagemakers JJ, Gorgels AP, Dubois-Arbouw WI, van Ree JW, Daemen MJ, Houben LG, Wellens HJ. Out-of-hospital cardiac arrest in the 1990's: a population-based study in the Maastricht area on incidence, characteristics and survival. J Am Coll Cardiol. 1997:30:1500-5.

4. Zheng ZJ, Croft JB, Giles WH, Mensah GA. Sudden cardiac death in the United States, 1989 to 1998. Circulation. 2001;104:2158-63.

5. Nikolic G, Bishop RL, Singh JB. Sudden death recorded during Holter monitoring. Circulation. 1982;66:218-25.

6. Bayes de Luna A, Coumel P, Leclercq JF. Ambulatory sudden cardiac death: mechanisms of production of fatal arrhythmia on the basis of data from 157 cases. Am Heart J. 1989;117:151-9.

7. Olshausen KV, Witt T, Pop T, Treese N, Bethge KP, Meyer J. Sudden cardiac death while wearing a Holter monitor. Am J Cardiol. 1991;67:381-6.

8. Pye MP, Cobbe SM. Mechanisms of ventricular arrhythmias in cardiac failure and hypertrophy. Cardiovasc Res. 1992;26:740-50.

9. Knight BP, Goyal R, Pelosi F, Flemming M, Horwood L, Morady F, Strickberger SA. Outcome of patients with nonischemic dilated cardiomyopathy and unexplained syncope treated with an implantable defibrillator. J Am Coll Cardiol. 1999;33:1964-70.

10. Beuckelmann DJ, Nabauer M, Erdmann E. Intracellular calcium handling in isolated ventricular myocytes from patients with terminal heart failure. Circulation. 1992;85:1046-55.

11. Beuckelmann DJ, Nabauer M, Erdmann E. Alterations of $\mathrm{K}^{+}$currents in isolated human ventricular myocytes from patients with terminal heart failure. Circ Res. 1993;73:379-85.

12. Bailly P, Benitah JP, Mouchoniere M, Vassort G, Lorente P. Regional alteration of the transient outward current in human left ventricular septum during compensated hypertrophy. Circulation. 1997;96:1266-74. 
13. Oikarinen L, Nieminen MS, Viitasalo M, Toivonen L, Wachtell K, Papademetriou V, Jern S, Dahlof B, Devereux RB, Okin PM. Relation of QT interval and QT dispersion to echocardiographic left ventricular hypertrophy and geometric pattern in hypertensive patients. The LIFE study. The Losartan Intervention For Endpoint Reduction. J Hypertens. 2001;19:1883-91.

14. Kannel WB. Left ventricular hypertrophy as a risk factor: the Framingham experience. J Hypertens Suppl. 1991;9:S3-8; discussion S8-9.

15. Haider AW, Larson MG, Benjamin EJ, Levy D. Increased left ventricular mass and hypertrophy are associated with increased risk for sudden death. J Am Coll Cardiol. 1998;32:1454-9.

16. Levy D, Anderson KM, Savage DD, Kannel WB, Christiansen JC, Castelli WP. Echocardiographically detected left ventricular hypertrophy: prevalence and risk factors. The Framingham Heart Study. Ann Intern Med. 1988;108:7-13.

17. Levy D, Garrison RJ, Savage DD, Kannel WB, Castelli WP. Prognostic implications of echocardiographically determined left ventricular mass in the Framingham Heart Study. N Engl J Med. 1990;322:1561-6.

18. Priori SG, Aliot E, Blomstrom-Lundqvist C, Bossaert L, Breithardt G, Brugada P, Camm AJ, Cappato R, Cobbe SM, Di Mario C, Maron BJ, McKenna WJ, Pedersen AK, Ravens U, Schwartz PJ. Trusz-Gluza M, Vardas P. Wellens HJ, Zipes DP. Task Force on Sudden Cardiac Death of the European Sociery of Cardiology. Eur Heart J. 2001;22:1374-450.

19. McKee PA, Castelli WP, McNamara PM, Kannel WB. The natural history of congestive heart failure: the Framingham study. N Engl J Med. 1971;285:1441-6.

20. Remme WJ, Swedberg K. Guidelines for the diagnosis and treatment of chronic heart failure. Eur Heart J. 2001;22:1527-60.

21. Tomaselli GF, Marban E. Electrophysiological remodeling in hypertrophy and heart failure. Cardiovasc Res. 1999;42:270-83.

22. Marban E. Heart failure: the electrophysiologic connection. J Cardiovasc Electrophysiol. 1999;10:1425-8.

23. Dessertenne F. La tachycardie ventriculaire à deux foyers opposés variables. Arch Mal Coeur Vaiss. 1966;59:263-72.

24. Surawicz B. Normal and abnormal automaticity. In: Rosen MR, Janse MJ, Wit AL, ed., Cardiac electrophysiology: a textbook. Futura Publishing Company, Inc. 1990.

25. Hoffman BF, Rosen MR. Cellular mechanisms for cardiac arrhythmias. Circ Res. 1981;49:1-15.

26. Cranefield PF. Action potentials, afterpotentials, and arrhythmias. Circ Res. 1977;41:415-23.

27. Wit AL. Reentrant excitation in the ventricles. In: Rosen MR, Janse MJ, Wit AL, ed., Cardiac electrophysiology: a textbook. Futura Publishing Company, Inc. 1990.

28. Asano Y, Davidenko JM, Baxter WT, Gray RA, Jalife J. Optical mapping of drug-induced polymorphic arrhythmias and torsade de pointes in the isolated rabbit heart. J Am Coll Cardiol. 1997:29:831-42.

29. Murakawa Y, Sezaki K, Yamashita T, Kanese Y, Omata M. Three-dimensional activation sequence of cesium-induced ventricular arrhythmias. Am J Physiol. 1997:273:H1377-85. 
30. El-Sherif N, Caref EB, Yin H, Restivo M. The electrophysiological mechanism of ventricular arrhythmias in the long QT syndrome. Tridimensional mapping of activation and recovery patterns. Circ Res. 1996;79:474-92.

31. El-Sherif N, Chinushi M, Caref EB, Restivo M. Electrophysiological mechanism of the characteristic electrocardiographic morphology of torsade de pointes tachyarrhythmias in the long-QT syndrome: detailed analysis of ventricular tridimensional activation patterns. Circulation. 1997;96:4392-9.

32. Derakhchan K, Cardinal R, Brunet S, Klug D, Pharand C, Kus T, Sasyniuk BI. Polymorphic ventricular tachycardias induced by D-sotalol and phenylephrine in canine preparations of atrioventricular block: initiation in the conduction system followed by spatially unstable re- entry. Cardiovasc Res. 1998;38:617-30.

33. Antzelevitch C, Shimizu W, Yan GX, Sicouri S, Weissenburger J, Nesterenko VV, Burashnikov A. Di Diego J, Saffitz J, Thomas GP. The M cell: its contribution to the ECG and to normal and abnormal electrical function of the heart. J Cardiovasc Electrophysiol. 1999;10:1124-52.

34. Leenhardt A, Glaser E, Burguera M, Nurnberg M, Maison-Blanche P, Coumel P. Short-coupled variant of torsade de pointes. A new electrocardiographic entity in the spectrum of idiopathic ventricular tachyarrhythmias. Circulation. 1994;89:206-15.

35. El-Sherif N. Polymorphic ventricular tachycardia and torsades de pointes: beyond etymology. J Cardiovasc Electrophysiol. 2001;12:695-6.

36. Dessertenne F. Complexes électrique ventriculaire à phase lente prolongée. Semin Hop Paris. 1967;43:539-547.

37. El-Sherif N, Turitto G. The long QT syndrome and torsade de pointes. Pacing Clin Electrophysiol. 1999;22:91-110.

38. Camm AJ, Janse MJ, Roden DM, Rosen MR, Cinca J, Cobbe SM. Congenital and acquired long QT syndrome. Eur Heart J. 2000;21:1232-1237.

39. Cameron JS, Myerburg RJ, Wong SS, Gaide MS, Epstein K, Alvarez TR, Gelband H, Guse PA, Bassett AL. Electrophysiologic consequences of chronic experimentally induced left ventricular pressure overload. J Am Coll Cardiol. 1983;2:481-7.

40. Vermeulen JT, McGuire MA, Opthof T, Coronel R, de Bakker JM, Klopping C, Janse MJ. Triggered activity and automaticity in ventricular trabeculae of failing human and rabbit hearts. Cardiovasc Res. 1994;28:1547-54.

41. Pak PH, Nuss HB, Tunin RS, Kaab S, Tomaselli GF, Marban E, Kass DA. Repolarization abnormalities, arrhythmia and sudden death in canine tachycardia-induced cardiomyopathy. J Am Coll Cardiol. 1997;30:576-84.

42. Undrovinas AI, Maltsev VA, Sabbah HN. Repolarization abnormalities in cardiomyocytes of dogs with chronic heart failure: role of sustained inward current. Cell Mol Life Sci. 1999;55:494-505.

43. Ben-David J, Zipes DP, Ayers GM, Pride HP. Canine left ventricular hypertrophy predisposes to ventricular tachycardia induction by phase 2 early afterdepolarizations after administration of BAY K 8644. J Am Coll Cardiol. 1992;20:1576-84. 
44. Vos MA, de Groot SH, Verduyn SC, van der Zande J, Leunissen HD, Cleutjens JP, van Bilsen M, Daemen MJ, Schreuder JJ, Allessie MA, Wellens HJ. Enhanced susceptibility for acquired torsade de pointes arrhythmias in the dog with chronic, complete AV block is related to cardiac hypertrophy and electrical remodeling. Circulation. 1998;98:1125-35.

45. Volders PG, Sipido KR, Vos MA, Kulcsar A, Verduyn SC, Wellens HJ. Cellular basis of biventricular hypertrophy and arrhythmogenesis in dogs with chronic complete atrioventricular block and acquired torsade de pointes. Circulation. 1998;98:1136-47.

46. Keating M, Atkinson D, Dunn C, Timothy K, Vincent GM, Leppert M. Linkage of a cardiac arrhythmia, the long QT syndrome, and the Harvey ras-1 gene. Science. 1991;252:704-6.

47. Curran M, Atkinson D, Timothy K, Vincent GM, Moss AJ, Leppert M, Keating M. Locus heterogeneity of autosomal dominant long QT syndrome. J Clin Invest. 1993;92:799-803.

48. Wang Q, Shen J, Splawski I, Atkinson D, Li Z, Robinson JL, Moss AJ, Towbin JA, Keating MT. SCN5A mutations associated with an inherited cardiac arrhythmia, long QT syndrome. Cell. 1995;80:805-11.

49. Curran ME, Splawski I, Timothy KW, Vincent GM, Green ED, Keating MT. A molecular basis for cardiac arrhythmia: HERG mutations cause long QT syndrome. Cell. 1995;80:795-803.

50. Wang Q, Curran ME, Splawski I, Burn TC, Millholland JM, VanRaay TJ, Shen J, Timothy KW, Vincent GM, de Jager T, Schwartz PJ, Toubin JA, Moss AJ, Atkinson DL, Landes GM, Connors TD, Keating MT. Positional cloning of a novel potassium channel gene: KVLQT1 mutations cause cardiac arrhythmias. Nat Genet. 1996;12:17-23.

51. Splawski I, Tristani-Firouzi M, Lehmann MH, Sanguinetti MC, Keating MT. Mutations in the hminK gene cause long QT syndrome and suppress $I_{K s}$ function. Nat Genet. 1997;17:338-40.

52. Abbott GW, Sesti F, Splawski I, Buck ME, Lehmann MH, Timothy KW, Keating MT, Goldstein $\mathrm{SA}$. MiRPI forms $\mathrm{I}_{\mathrm{Kr}}$ potassium channels with HERG and is associated with cardiac arrhythmia. Cell. 1999;97:175-87.

53. Priori SG, Barhanin J, Hauer RN, Haverkamp W, Jongsma HJ, Kleber AG, McKenna WJ, Roden DM, Rudy Y, Schwartz K, Schwartz PJ, Towbin JA, Wilde AM. Genetic and molecular basis of cardiac arrhythmias: impact on clinical management parts I and II. Circulation. 1999;99:518-28.

54. Furukawa T, Myerburg RJ, Furukawa N, Kimura S, Bassett AL. Metabolic inhibition of $\mathrm{I}_{\mathrm{CaL}}$ and $I_{K}$ differs in feline left ventricular hypertrophy. Am J Physiol. 1994;266:H1121-31.

55. Kaab S, Nuss HB, Chiamvimonvat N, O'Rourke B, Pak PH, Kass DA, Marban E, Tomaselli GF. lonic mechanism of action potential prolongation in ventricular myocytes from dogs with pacing-induced heart failure. Circ Res. 1996:78:262-73.

56. Volders PG, Sipido KR, Vos MA, Spatjens RL, Leunissen JD, Carmeliet E, Wellens HJ. Downregulation of delayed rectifier $\mathrm{K}^{*}$ currents in dogs with chronic complete atrioventricular block and acquired torsades de pointes. Circulation. 1999;100:2455-61.

57. O'Rourke B, Kass DA. Tomaselli GF, Kaab S, Tunin R, Marban E. Mechanisms of altered excitation-contraction coupling in canine tachycardia-induced heart failure, I: experimental studies. Circ Res. 1999;84:562-70.

58. Pogwizd SM, Qi M, Yuan W, Samarel AM, Bers DM. Upregulation of $\mathrm{Na}^{+} / \mathrm{Ca}^{2+}$ exchanger expression and function in an arrhythmogenic rabbit model of heart failure. Circ Res. 1999;85:1009-19. 
59. Sipido KR, Volders PG, de Groot SH, Verdonck F, Van De Werf F, Wellens HJ, Vos MA. Enhanced $\mathrm{Ca}^{2+}$ release and $\mathrm{Na} / \mathrm{Ca}$ exchange activity in hypertrophied canine ventricular myocytes: potential link between contractile adaptation and arrhythmogenesis. Circulation. 2000;102: 2137-44.

60. Tsuji Y, Opthof T, Kamiya K, Yasui K, Liu W, Lu Z, Kodama I. Pacing-induced heart failure causes a reduction of delayed rectifier potassium currents along with decreases in calcium and transient outward currents in rabbit ventricle. Cardiovasc Res. 2000;48:300-9.

61. Pogwizd SM, Schlotthauer K, Li L, Yuan W, Bers DM. Arrhythmogenesis and contractile dysfunction in heart failure: Roles of sodium-calcium exchange, inward rectifier potassium current, and residual beta-adrenergic responsiveness. Circ Res. 2001:88:1159-67.

62. Xu X, Rials SJ, Wu Y, Salata JJ, Liu T, Bharucha DB, Marinchak RA, Kowey PR. Left ventricular hypertrophy decreases slowly but not rapidly activating delayed rectifier potassium currents of epicardial and endocardial myocytes in rabbits. Circulation. 2001;103:1585-90.

63. Roden DM. Taking the "idio" out of "idiosyncratic": predicting torsades de pointes. Pacing Clin Electrophysiol. 1998;21:1029-34.

64. Nattel S. Acquired delayed rectifier channelopathies: how heart disease and antiarrhythmic drugs mimic potentially-lethal congenital cardiac disorders. Cardiovasc Res. 2000;48:188-90.

65. Volders PG, Vos MA, Szabo B, Sipido KR, de Groot SH, Gorgels AP, Wellens HJ, Lazzara R. Progress in the understanding of cardiac early afterdepolarizations and torsades de pointes: time to revise current concepts. Cardiovasc Res. 2000;46:376-92.

66. Han J, Moe GK. Nonuniform recovery of excitability in ventricular muscle. Circ Res. 1964;14:44-60.

67. Kowey PR, Friechling TD, Sewter J, Wu Y, Sokil A, Paul J, Nocella J. Electrophysiological effects of left ventricular hypertrophy. Effect of calcium and potassium channel blockade. Circulation. 1991;83:2067-75.

68. Li HG, Jones DL, Yee R, Klein GJ. Electrophysiologic substrate associated with pacing-induced heart failure in dogs: potential value of programmed stimulation in predicting sudden death. J Am Coll Cardiol. 1992;19:444-9.

69. Sabbah HN, Goldberg AD, Schoels W, Kono T, Webb C, Brachmann J, Goldstein S. Spontaneous and inducible ventricular arrhythmias in a canine model of chronic heart failure: relation to haemodynamics and sympathoadrenergic activation. Eur Heart J. 1992;13:1562-72.

70. Barr CS, Naas A, Freeman M, Lang CC, Struthers AD. QT dispersion and sudden unexpected death in chronic heart failure. Lancet. 1994;343:327-9.

71. Berger RD, Kasper EK, Baughman KL, Marban E, Calkins H, Tomaselli GF. Beat-to-beat QT interval variability: novel evidence for repolarization lability in ischemic and nonischemic dilated cardiomyopathy. Circulation. 1997;96:1557-65.

72. Pogwizd SM. Nonreentrant mechanisms underlying spontaneous ventricular arrhythmias in a model of nonischemic heart failure in rabbits. Circulation. 1995;92:1034-48.

73. Rials SJ, Wu Y, Ford N, Pauletto FJ, Abramson SV, Rubin AM, Marinchak RA, Kowey PR. Effect of left ventricular hypertrophy and its regression on ventricular electrophysiology and vulnerability to inducible arrhythmia in the feline heart. Circulation. 1995;91:426-30. 
74. Vos M, Gorenek B, Verduyn S, van der Hulst F, Leunissen J, Dohmen L, Wellens H. Observations on the onset of Torsade de Pointes arrhythmias in the acquired long QT syndrome. Cardiovasc Res. 2000;48:421-29.

75. Yan GX, Wu Y, Liu T, Wang J, Marinchak RA, Kowey PR. Phase 2 early afterdepolarization as a trigger of polymorphic ventricular tachycardia in acquired long-QT syndrome : direct evidence from intracellular recordings in the intact left ventricular wall. Circulation. 2001;103:2851-6.

76. Schwartz PJ, Stramba-Badiale M, Segantini A, Austoni P, Bosi G, Giorgetti R, Grancini F, Marni ED, Perticone F, Rosti D, Salice P. Prolongation of the QT interval and the sudden infant death syndrome. N Engl J Med. 1998;338:1709-14.

77. Pinto JM, Boyden PA. Electrical remodeling in ischemia and infarction. Cardiovasc Res. 1999;42:284-97.

78. Schwartz PJ, Priori SG, Spazzolini C, Moss AJ, Vincent GM, Napolitano C, Denjoy I, Guicheney P, Breithardt G, Keating MT, Towbin JA, Beggs AH, Brink P, Wilde AA, Toivonen L, Zareba W, Robinson JL, Timothy KW, Corfield V, Wattanasirichaigoon D, Corbett C, Haverkamp W, Schulze-Bahr E, Lehmann MH, Schwartz K, Coumel P, Bloise R. Genotype-phenotype correlation in the long-QT syndrome: gene-specific triggers for life-threatening arrhythmias. Circulation. 2001:103:89-95.

79. Singh BN. Current antiarrhythmic drugs: an overview of mechanisms of action and potential clinical utility. J Cardiovasc Electrophysiol. 1999;10:283-301.

80. Singh BN, Sarma JS. Mechanisms of action of antiarrhythmic drugs relative to the origin and perpetuation of cardiac arrhythmias. J Cardiovasc Pharmacol Ther. 2001;6:69-87.

81. Preliminary report: effect of encainide and flecainide on mortality in a randomized trial of arrhythmia suppression after myocardial infarction. The Cardiac Arrhythmia Suppression Trial (CAST) Investigators. N Engl J Med. 1989;321:406-12.

82. Effect of the antiarrhythmic agent moricizine on survival after myocardial infarction. The Cardiac Arrhythmia Suppression Trial II Investigators. N Engl J Med. 1992;327:227-33.

83. Sanguinetti MC, Jurkiewicz NK. Two components of cardiac delayed rectifier $\mathrm{K}^{+}$current. Differential sensitivity to block by class III antiarrhythmic agents. J Gen Physiol. 1990;96:195-215.

84. Colatsky TJ, Follmer CH, Starmer CF. Channel specificity in antiarrhythmic drug action. Mechanism of potassium channel block and its role in suppressing and aggravating cardiac arrhythmias. Circulation. 1990;82:2235-42.

85. Waldo AL, Camm AJ, deRuyter H, Friedman PL, MacNeil DJ, Pauls JF, Pitt B, Pratt CM, Schwartz PJ, Veltri EP. Effect of d-sotalol on mortality in patients with left ventricular dysfunction after recent and remote myocardial infarction. The SWORD Investigators. Survival With Oral d-Sotalol. Lancet. 1996;348:7-12.

86. Torp-Pedersen C, Moller M, Bloch-Thomsen PE, Kober L, Sandoe E, Egstrup K, Agner E, Carlsen J, Videbaek J, Marchant B, Camm AJ. Dofetilide in patients with congestive heart failure and left ventricular dysfunction. Danish Investigations of Arrhythmia and Mortality on Dofetilide Study Group. N Engl J Med. 1999;341:857-65.

87. Roden DM, Spooner PM. Inherited long QT syndromes: a paradigm for understanding arrhythmogenesis. J Cardiovasc Electrophysiol. 1999;10:1664-83.

88. Roden DM. Pharmacogenetics and drug-induced arrhythmias. Cardiovasc Res. 2001;50:224-31. 
89. Sesti F, Abbott GW, Wei J, Murray KT, Saksena S, Schwartz PJ, Priori SG, Roden DM, George AL. Jr., Goldstein SA. A common polymorphism associated with antibiotic-induced cardiac arrhythmia. Proc Natl Acad Sci U S A. 2000;97:10613-8.

90. Donger C, Denjoy I, Berthet M, Neyroud N, Cruaud C, Bennaceur M, Chivoret G, Schwartz K, Coumel P, Guicheney P. KVLQT1 C-terminal missense mutation causes a forme fruste long-QT syndrome. Circulation. 1997;96:2778-81.

91. Napolitano C, Schwartz PJ, Brown AM, Ronchetti E. Bianchi L, Pinnavaia A. Acquaro G, Priori SG. Evidence for a cardiac ion channel mutation underlying drug-induced QT prolongation and life-threatening arrhythmias. J Cardiovasc Electrophysiol. 2000;11:691-6.

92. Vos MA, Verduyn SC, Gorgels AP, Lipcsei GC, Wellens HJ. Reproducible induction of early afterdepolarizations and torsade de pointes arrhythmias by d-sotalol and pacing in dogs with chronic atrioventricular block. Circulation. 1995;91:864-72.

93. Verduyn SC, Vos MA, van der Zande J, van der Hulst FF, Wellens HJ. Role of interventricular dispersion of repolarization in acquired torsade-de-pointes arrhythmias: reversal by magnesium. Cardiovasc Res. 1997;34:453-63.

94. Lehmann MH, Hardy S, Archibald D, Quart B, MacNeil DJ. Sex difference in risk of torsade de pointes with d,I-sotalol. Circulation. 1996;94:2535-41.

95. Hsieh MH, Chen Y], Lee SH, Ding YA, Chang MS, Chen SA. Proarrhythmic effects of ibutilide in a canine model of pacing induced cardiomyopathy. Pacing Clin Electrophysiol. 2000;23:149-56.

96. Levy D. The clinical toxicology of quinidin. JAMA. 1922;78:1919-1920.

97. Kerr J, Bender L. Paroxysmal ventricular fibrillation with cardiac recovery in a case of auricular fibrillation and complete heart-block while under quinidine sulphate therapy. Heart. 1929;9:269-281.

98. Haverkamp W, Breithardt G, Camm AJ, Janse MJ, Rosen MR, Antzelevitch C, Escande D, Franz M, Malik M, Moss A, Shah R. The potential for QT prolongation and pro-arrhythmia by non-anti- arrhythmic drugs: Clinical and regulatory implications. Report on a Policy Conference of the European Society of Cardiology. Cardiovasc Res. 2000;47:219-233.

99. Hondeghem LM, Snyders DJ. Class III antiarrhythmic agents have a lot of potential but a long way to go. Reduced effectiveness and dangers of reverse use dependence. Circulation. 1990;81:686-90.

100. Jurkiewicz NK, Sanguinetti MC. Rate-dependent prolongation of cardiac action potentials by a methanesulfonanilide class III antiarrhythmic agent. Specific block of rapidly activating delayed rectifier $\mathrm{K}^{+}$current by dofetilide. Circ Res. 1993;72:75-83.

101. Liu DW, Antzelevitch C. Characteristics of the delayed rectifier current $\left(I_{K r}\right.$ and $\left.I_{K s}\right)$ in canine ventricular epicardial, midmyocardial, and endocardial myocytes. A weaker IKs contributes to the longer action potential of the M cell. Circ Res. 1995;76:351-65.

102. Volders PG, Sipido KR, Carmeliet E, Spatjens RL, Wellens HJ, Vos MA. Repolarizing $\mathrm{K}^{+}$currents $\mathrm{I}_{\mathrm{TO}}$ and $\mathrm{I}_{\mathrm{Ks}}$ are larger in right than left canine ventricular midmyocardium. Circulation. 1999;99:206-10.

103. Yan GX, Antzelevitch C. Cellular basis for the normal T wave and the electrocardiographic manifestations of the long-QT syndrome. Circulation. 1998;98:1928-36. 
104. Shimizu W, Antzelevitch C. Cellular basis for the ECG features of the LQT1 form of the long-QT syndrome: effects of beta-adrenergic agonists and antagonists and sodium channel blockers on transmural dispersion of repolarization and torsade de pointes. Circulation. 1998;98:2314-22.

105. January CT, Riddle JM. Early afterdepolarizations: mechanism of induction and block. A role for L-type Ca ${ }^{2+}$ current. Circ Res. 1989;64:977-90.

106. Amos GJ, Abrahamsson C, Duker G, Hondeghem L, Palmer M, Carlsson L. Potassium and calcium current blocking properties of the novel antiarrhythmic agent $\mathrm{H} 345 / 52$ : implications for proarrhythmic potential. Cardiovasc Res. 2001;49:351-60.

107. Verduyn SC, Vos MA, Gorgels AP, van der Zande J, Leunissen JD, Wellens HJ. The effect of flunarizine and ryanodine on acquired torsades de pointes arrhythmias in the intact canine heart. J Cardiovasc Electrophysiol. 1995;6:189-200.

108. Carlsson L, Drews L, Duker G. Rhythm anomalies related to delayed repolarization in vivo: influence of sarcolemmal $\mathrm{Ca}^{2+}$ entry and intracellular $\mathrm{Ca}^{2+}$ overload. J Pharmacol Exp Ther. 1996;279:231-9.

109. Wu Y, Roden DM, Anderson ME. Calmodulin kinase inhibition prevents development of the arrhythmogenic transient inward current. Circ Res. 1999;84:906-12.

110. Kodama I, Kamiya K, Toyama J. Amiodarone: ionic and cellular mechanisms of action of the most promising class III agent. Am J Cardiol. 1999;84:20R-28R.

111. Sun W, Sarma JS, Singh BN. Electrophysiological effects of dronedarone (SR33589), a noniodinated benzofuran derivative, in the rabbit heart : comparison with amiodarone. Circulation. 1999;100:2276-81.

112. Carmeliet E. Use-dependent block and use-dependent unblock of the delayed rectifier $\mathrm{K}^{+}$current by almokalant in rabbit ventricular myocytes. Circ Res. 1993;73:857-68.

113. Houltz B, Darpo B, Edvardsson N, Blomstrom P, Brachmann J, Crijns HJ, Jensen SM, Svernhage E, Vallin H, Swedberg K. Electrocardiographic and clinical predictors of torsades de pointes induced by almokalant infusion in patients with chronic atrial fibrillation or flutter: a prospective study. Pacing Clin Electrophysiol. 1998;21:1044-57.

114. Fermini B, Jurkiewic NK, Jow B, Guinosso PJ, Jr., Baskin EP, Lynch JJ, Jr., Salata JJ. Use-dependent effects of the class III antiarrhythmic agent NE-10064 (azimilide) on cardiac repolarization: block of delayed rectifier potassium and L-type calcium currents. J Cardiovasc Pharmacol. 1995;26:259-71.

115. Yao JA, Tseng GN. Azimilide (NE-10064) can prolong or shorten the action potential duration in canine ventricular myocytes: dependence on blockade of $\mathrm{K}, \mathrm{Ca}$, and $\mathrm{Na}$ channels. J Cardiovasc Electrophysiol. 1997;8:184-98.

116. Gogelein H, Bruggemann A, Gerlach U, Brendel J, Busch AE. Inhibition of $\mathrm{I}_{\mathrm{Ks}}$ channels by HMR 1556. Naunyn Schmiedebergs Arch Pharmacol. 2000;362:480-8.

117. Kamiya K, Nishiyama A, Yasui K, Hojo M, Sanguinerti MC, Kodama I. Short- and long-term effects of amiodarone on the two components of cardiac delayed rectifier $\mathrm{K}^{+}$current. Circulation. 2001:103:1317-24.

118. Hohnloser SH. Singh BN. Proarrhythmia with class III antiarrhythmic drugs: definition, electrophysiologic mechanisms, incidence, predisposing factors, and dinical implications. J Cardiovasc Electrophysiol. 1995;6:920-36. 
119. Djandjighian L, Planchenault J, Finance O, Pastor G, Gautier P, Nisato D. Hemodynamic and antiadrenergic effects of dronedarone and amiodarone in animals with a healed myocardial infaretion. J Cardiovasc Pharmacol. 2000;36:376-83.

120. Points to consider: the assessment of the potential for QT interval prolongation by non-cardiovascular medicinal products: Committee for Proprietary Medicinal Products (CPMP) HMEU, publication NO. CPMP 986/96.

121. Roden DM. Acquired long QT syndromes and the risk of proarrhythmia. J Cardiovasc Electrophysiol. 2000;11:938-40.

122. Vos MA. Preclinical evaluation of antiarrhythmic drugs: new drugs should be safe to be successful. J Cardiovasc Electrophysiol. 2001;12:1034-6.

123. Verduyn SC, Ramakers C, Snoep G, Leunissen JD, Wellens HJ, Vos MA. Time course of structural adaptations in chronic AV block dogs: evidence for differential ventricular remodeling. Am J Physiol Heart Circ Physiol. 2001;280:H2882-90.

124. de Groot SH, Schoenmakers M, Molenschot MM, Leunissen JD, Wellens HJ, Vos MA. Contractile adaptations preserving cardiac output predispose the hypertrophied canine heart to delayed afterdepolarization-dependent ventricular arrhythmias. Circulation. 2000;102:2145-51.

125. Verduyn SC, Vos MA, van der Zande J, Kulcsar A, Wellens HJ. Further observations to elucidate the role of interventricular dispersion of repolarization and early afterdepolarizations in the genesis of acquired torsade de pointes arrhythmias: a comparison between almokalant and d-sotalol using the dog as its own control. J Am Coll Cardiol. 1997;30:1575-84.

126. Ramakers C, Dumaine R, Doevendans P, Antzelevitch C, Vos MA. Both KCNQ1 and KCNE1 expression is reduced in dogs with chronic AV block. Eur Heart J. 2000; 21:239 (abstract). 


\section{CHAPTER 2}

\section{Azimilide and Dofetilide Produce Similar Electrophysiological and Proarrhythmic Effects in a Canine Model of Torsade de Pointes Arrhythmias}

Jurren M. Van Opstal, Jet D.M. Leunissen, Hein J.J. Wellens, Marc A. Vos

Department of Cardiology, Cardiovascular Research Institute Maastricht, Maastricht, The Netherlands 


\section{ABSTRACT}

Background: Torsade de Pointes arrhythmias (TdP) are a feared proarrhythmic effect of (antiarrhythmic) drugs. In dogs with chronic complete AV block (CAVB), bradycardia-induced volume overload leads to electrical remodeling, which includes increased susceptibility to drug-induced Torsade de Pointes arrhythmias (TdP).

Methods and Results: The $\mathrm{I}_{\mathrm{Kr}}$ channel blocker, dofetilide (Tikosyn ${ }^{\mathrm{TM}}$, $0.025 \mathrm{mg} / \mathrm{kg} / 5$ minutes), and the less specific ion channel blocker, azimilide ( $5 \mathrm{mg} / \mathrm{kg} / 5$ minutes), were compared in 9 anesthetized dogs at 4 and 6 weeks of CAVB in a randomized crossover design. Dosages were based on our own dose-dependence studies and on antiarrhythmic dosages reported in the literature. Monophasic-action-potential (MAP) catheters were placed endocardially in both the left (LV) and right ventricle (RV) to measure MAP duration (MAPD), to visualize early afterdepolarizations (EADs), and to assess interventricular dispersion of repolarization ( $\triangle \mathrm{MAPD}$, i.e. LV MAPD (at 100\%) minus RV MAPD (at 100\%). Cycle length of idioventricular rhythm (CL-IVR), QT time and the occurrence of drug-induced TdP were determined using the surface ECG. Before drug administration the electrophysiological parameters were identical at 4 and 6 weeks. Both azimilide and dofetilide increased CL-IVR, LV and RV MAPD, and QT time. Dissimilar lengthening of LV and RV MAPD increased $\triangle$ MAPD significantly from $55 \mathrm{~ms}$ to $110 \mathrm{~ms}$ for both drugs. All dogs had EADs while, in the majority, ectopic ventricular beats developed (dofetilide 8 of 9 and azimilide 7 of 9 dogs). TdP incidence was comparable for doferilide ( 6 of 9 dogs) and azimilide ( 5 of 9 dogs).

Conclusions: Azimilide and dofetilide show similar electrophysiological and proarrhythmic effects in our canine model with a high incidence of TdP. 


\section{INTRODUCTION}

The introduction of newer antiarrhythmic agents has been disappointing. The clinical application of class III drugs, e.g. d-sotalol and doferilide, did not reduce mortality in patients after myocardial infarction. ${ }^{1,2}$ Proarrhythmic effects, such as Torsade de Pointes arrhythmias (TdP), probably contributed to these findings. ${ }^{2,3}$ Occurrence of $\mathrm{TdP}$ has been related to an increased heterogeneity of repolarization (dispersion), which can be located across the ventricular wall and/or between the ventricles. ${ }^{4-9}$ It has been proposed that these transmural or interventricular differences result, at least partly, from differences in relative densities of the $\mathrm{K}^{+}$outward currents. ${ }^{10-13}$ These intrinsic differences in action potential duration can become more pronounced during bradycardia, class- III drug administration and/or under pathological conditions such as hypertrophy and heart failure. ${ }^{4,9,13-15}$ The only drug which has been reported to decrease dispersion along with a low incidence of clinical $\mathrm{TdP}$ is amiodarone, a drug with multiple actions. ${ }^{16-20}$

Therefore, early screening for proarrhythmogenic properties of drugs in wellcharacterized animal models becomes mandatory. The dog with chronic complete AV block (CAVB) shows a high incidence of acquired TdP, caused by a number of adaptive processes including electrical remodeling, and has proven to be a suitable model to screen antiarrhythmic drugs. 4,5

Many new antiarrhythmic drugs, blocking specifically the fast component of the delayed rectifier channel, $\mathrm{I}_{\mathrm{Kr}}$, have been related to the occurrence of TdP., ${ }^{1,2,21}$ It has been speculated that drugs, which target multiple channels increase the action potential more homogeneously thereby reducing the risk of TdP (e.g. amiodarone). 16,22

Azimilide (Figure 1) is a channel blocker of $\mathrm{I}_{\mathrm{Kr}}, \mathrm{I}_{\mathrm{Ks}}, \mathrm{I}_{\mathrm{CaL}}$ and $\mathrm{I}_{\mathrm{Na}},{ }^{23,24}$ and as such could be expected to prolong action potential duration more homogeneously than selective $\mathrm{I}_{\mathrm{Kr}}$ channel blockers. Thus, we investigated whether azimilide had distinct (proarrhythmic) actions in the electrically remodeled CAVB heart in comparison to the specific $\mathrm{I}_{\mathrm{Kr}}$ channel blocker, dofetilide.

\section{METHODS}

Animal handling was in accordance with the 'Dutch Law on Animal Experimentation (WOD)' and the 'European Directive for the Protection of Vertebrate Animals used for Experimental and other Scientific Purposes (European Union Directive \#86/609/CEE)'. The experiments were approved by 'The Committee for Experiments on Animals (DEC)' of Maastricht University, The Netherlands. 


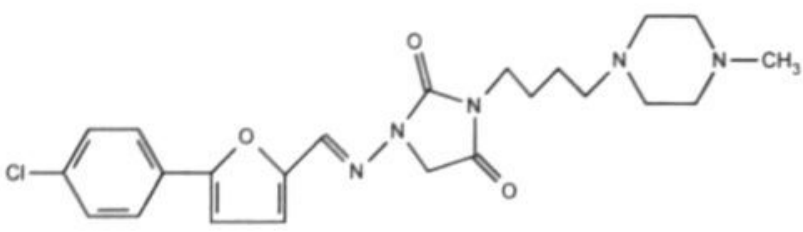

\section{Azimilide}

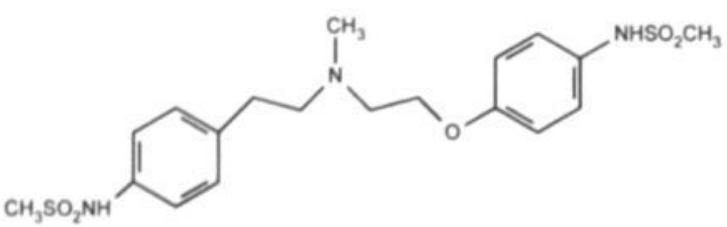

\section{Dofetilide}

Figure 1 - Structural formula of azimilide and of the specific $I_{k,}$ channel blocker, dofetilide.

\section{GENERAL}

A total of 47 experiments in 20 anesthetized mongrel dogs were performed under aseptic conditions. All animals were studied during sinus rhythm while a subset of 12 dogs was subjected to AV block as described below. After overnight fasting, anesthesia was induced by 1$)$ premedication i.m. $(1 \mathrm{ml} / 5 \mathrm{~kg}: 10 \mathrm{mg}$ oxycodon $\mathrm{HCl}, 1 \mathrm{mg}$ acepromazine, and $0.5 \mathrm{mg}$ atropine sulphate) and 2) sodium pentobarbital IV (20 $\mathrm{mg} / \mathrm{kg}$, Nembutal, Sanofi-Synthélabo). The dogs were artificially ventilated (Dräger, Lubeck, Germany) through a cuffed endotracheal tube at a respiratory rate of 12-14 per minute, using a mixture of oxygen, nitrous oxide $(40 / 60 \%)$ and halothane (vapor concentration $0.5 \%-1 \%)$. Tidal volume was adjusted $(10-15 \mathrm{ml} / \mathrm{kg}$ ) to maintain the end-expired carbon dioxide concentration between 3.5 and $4 \%$.

A thermal mattress was used to maintain body temperature. During the experiment, the dog received $0.5-1 \mathrm{~L} 0.9 \% \mathrm{NaCl}$ through the cephalic or saphenous vein to prevent volume depletion. This line was also used to administer drugs.

Proper care was taken before and after the experiments, including use of antibiotics ( $1000 \mathrm{mg}$ ampicillin) and analgesics $(0.015 \mathrm{mg} / \mathrm{kg}$ i.m. buprenorfine).

A 6-lead surface ECG and 2 endocardial monophasic action potentials (MAPs) were recorded simultaneously and stored on hard disk. Franz' MAP catheters (EP Technologies, Sunnyvale, CA, USA) were placed endocardially, under fluoroscopic guidance, in the left (LV) and right ventricular (RV) cavity. The signals were amplified with a customized isolated DC-coupled differential amplifier at a frequency range of $0-500 \mathrm{~Hz}$ with a $20 \mathrm{mV}$ calibration pulse. The offset of the amplifier is vari- 
able and can be adjusted to the recorded signal. MAP phases were defined according to the definitions used for transmembrane potentials, ${ }^{25}$ where amplitude has been defined as the voltage difference between phase 2 and 4 of the MAP signal. Besides minimal amplitude of $15 \mathrm{mV}$, the MAP has to have a stable configuration and a smooth shape to be acceptable for measurements.

The ventricular effective refractory period (VERP) was determined incrementally at twice the diastolic threshold by giving an extra stimulus in steps of $5 \mathrm{~ms}$ during steady state pacing from the RV MAP at a cycle length of $350 \mathrm{~ms}$.

\section{DRUG DOSAGES}

Azimilide and dofetilide were provided by Procter \& Gamble Pharmaceuticals, USA. Azimilide was dissolved in a phosphate buffer solution, while dofetilide was diluted in a $0.9 \% \mathrm{NaCl}$ water solution. All dosages were given in 5 minutes.

To select the appropriate drug dosage we searched initially for the reported antiarrhythmic efficacy, defined as $\pm 50 \%$ prevention or termination against atrial fibrillation or pacing-induced ventricular tachycardia after myocardial infarction in canine arrhythmia models. ${ }^{26-29}$ The dosages selected $(0.05 \mathrm{mg} / \mathrm{kg}$ dofetilide $(\mathrm{n}=8)$ and $10 \mathrm{mg} / \mathrm{kg}$ azimilide $(\mathrm{n}=8)$ increased the corrected QT time $\left(\mathrm{QT}_{\mathrm{c}}\right)$ by $24 \%$ and $27 \%$, respectively. This $\mathrm{QT}_{c}$ lengthening exceeds our desired range of $\mathrm{QT}_{c}$ increase of $15 \pm 5 \%$, which is based on the fact that most class III drugs have different sensitivities for atrial versus ventricular tissue, the atrial-effective antiarrhythmic dose being lower than the ventricular one. ${ }^{30}$ As atrial fibrillation will often be the clinical arrhythmia to treat, screening for TdP should be based primarily on atrial effectiveness. For that reason the dosages were adjusted to $0.025 \mathrm{mg} / \mathrm{kg}$ for dofetilide and to $5 \mathrm{mg} / \mathrm{kg}$ for azimilide and retested in two groups of $6 \mathrm{dogs}, 8$ of which also participated in the first determination (see Results). The latter dosages increased $\mathrm{QT}_{\mathrm{c}}$ by $13 \%$ for azimilide and $19 \%$ for dofetilide.

\section{TDP EXPERIMENTS IN CAVB DOGS}

Twelve of the above dogs were subjected to the creation of AV block by radio-frequency ablation. ${ }^{31}$ One dog died during the AV-block procedure and 1 during the first week after the procedure. An endocardial lead (StimTine 1SP 13B $8 \mathrm{~F}$; Vitatron Medical, Dieren, The Netherlands) was positioned in the apex of the right ventricle via the external jugular vein.

After the AV-block operation the animals temporarily received a pacemaker for $24 \mathrm{~h}$. The heart was paced from the right-ventricular lead at about 50-60 beats/ minute, and the pacemaker was placed externally in a purpose-designed jacket.

To confirm persistence of CAVB, ECGs were recorded every week. After 4 weeks of CAVB, the dogs reach a steady state in their different remodeling processes. ${ }^{32}$ Therefore, $\mathrm{TdP}$ screening was started after 4 weeks in the remaining $10 \mathrm{dogs}$, in a random 
crossover design in which the experiments were performed >one week apart. Five dogs received azimilide $(5 \mathrm{mg} / \mathrm{kg}$ ) in the first experiment. If TdP occurred during the drug administration, the infusion was stopped.

\section{DATA ANALYSIS}

Applying a custom-made computer program (ECG View), with a resolution of $2 \mathrm{~ms}$ and adjustable gain and time scale, we measured the following parameters off-line: RR interval length, QT time in lead II, and the duration of the LV and RV MAP (MAPD) at $100 \%$ of repolarization. From these measurements, the interventricular dispersion of repolarization ( $\triangle \mathrm{MAPD}$ ) was calculated, defined as LV MAPD minus RV MAPD. QT ${ }_{c}$ was calculated using the Bazett formula. ${ }^{33}$ All the electrophysiological measurements were performed at the "maximal" effect of the drug. To determine this moment of maximal effect, we tested the temporal electropharmacological behavior of 4 dogs in each group.

MAPs were also recorded to visualize early afterdepolarizations (EADs), which were defined as an interruption of the smooth contour of phase 2 and/or phase 3 of the action potential duration in either MAP. ${ }^{25}$ The occurrence of (triggered) ventricular ectopic beats and spontaneous $\mathrm{TdP}$ was monitored before and after drug administration. TdP was defined as a polymorphic ventricular tachycardia of at least 5 beats, characterized by an onset with abnormal QT prolongation and/or abnormal TU complexes, the electrocardiographic configuration of a progressively changing ventricular axis and spontaneous termination with the exception of rare degeneration into ventricular fibrillation. ${ }^{34} \mathrm{~A}$ dog was defined to be inducible for $\mathrm{TdP}$ when the arrhythmia occurred $\geq 3$ times spontaneously. In the case of ventricular fibrillation, cardioversion was applied through patches on the thorax, which had been placed in advance.

\section{STAIISTICS}

Pooled data are expressed as mean \pm standard deviation. Intergroup comparisons of the dosage determination were performed with unpaired Student's t-test, whereas serial comparisons in the CAVB experiments were performed with paired Student's t-test. The time-dependence study statistical analyses were done with a Friedman 2-way analysis of variance (ANOVA) with a post-hoc Bonferroni t-test. Values of $\mathrm{P}$ $<0.05$ were considered significant. 


\section{RESULTS}

\section{ELECTROPHYSIOLOGICAL EFFECTS OF AZIMILIDE AND DOFETILIDE IN ANESTHETIZED DOGS DURING NORMALLY CONDUCTED SINUS RHYTHM}

The baseline electrophysiological parameters were similar in the two sinus rhythm groups (control, left part of Table 1). The time-dependent effects of dofetilide and azimilide on QT time can be seen in Figure 2: the maximum QT time effect was reached 10 minutes after the start of the infusion. Therefore, we chose to report all the electrophysiological values for this moment $(t=10 \mathrm{~min}$, Table 1$)$.

Both dofetilide and azimilide caused a significant increase in RR interval, $Q T_{(c)}$ duration, LV MAPD, RV MAPD and VERP (Table 1). As a result of the more pronounced effect on the LV MAPD compared to the RV MAPD, the $\triangle M A P D$ doubled after both drugs, but became significant only for azimilide (from $15 \pm 5$ to $40 \pm 20 \mathrm{~ms}, \mathrm{P}<0.05$, Table 1). A representative example of the electrophysiological effects of azimilide is given in Figure 3, panels 1 and 2.

When the two drugs are compared, it appears that at the dosages used, dofetilide is more potent than azimilide: e.g. dofetilide increased $\mathrm{QT}_{\mathrm{c}}$ time by $19 \%$ while azimilide produced a $13 \%$ increase. During sinus rhythm no arrhythmogenic activity was seen during or after infusion of the drugs.

Table 1 - Comparison of dofetilide $(0.025 \mathrm{mg} / \mathrm{kg})$ and azimilide $(5 \mathrm{mg} / \mathrm{kg})$ in sinus rhythm dogs $(\mathrm{n}=6)$

\begin{tabular}{llll}
\hline & control & dofetilide & $\%$ \\
\hline RR & $525 \pm 130$ & $675 \pm 155^{\circ}$ & 29 \\
QT & $235 \pm 30$ & $315 \pm 45^{\circ}$ & 35 \\
QT $_{c}$ & $325 \pm 15$ & $385 \pm 30^{\circ}$ & 19 \\
LV MAPD & $205 \pm 15$ & $295 \pm 50^{\circ}$ & 43 \\
RV MAPD & $190 \pm 15$ & $260 \pm 35^{\circ}$ & 37 \\
$\Delta$ MAPD & $15 \pm 5$ & $35 \pm 20^{\circ}$ & 125 \\
VERP & $160 \pm 15$ & $200 \pm 25^{\circ}$ & 26 \\
\hline & control & azimilide & $\%$ \\
\hline RR & $505 \pm 75$ & $625 \pm 10^{\circ}$ & 24 \\
QT & $245 \pm 25$ & $310 \pm 35^{\circ}$ & 26 \\
QT & $345 \pm 20$ & $390 \pm 15^{\circ}$ & 13 \\
LV MAPD & $215 \pm 25$ & $275 \pm 50^{\circ}$ & 27 \\
RV MAPD & $200 \pm 25$ & $235 \pm 35^{\circ}$ & 19 \\
$\Delta M A P D$ & $15 \pm 5$ & $40 \pm 20^{\circ}$ & 140 \\
VERP & $180 \pm 20$ & $200 \pm 20^{\circ}$ & 11
\end{tabular}

Values in ms and mean $\pm \mathrm{SD} ;{ }^{*} \mathrm{P}<0.05$ drug es control 


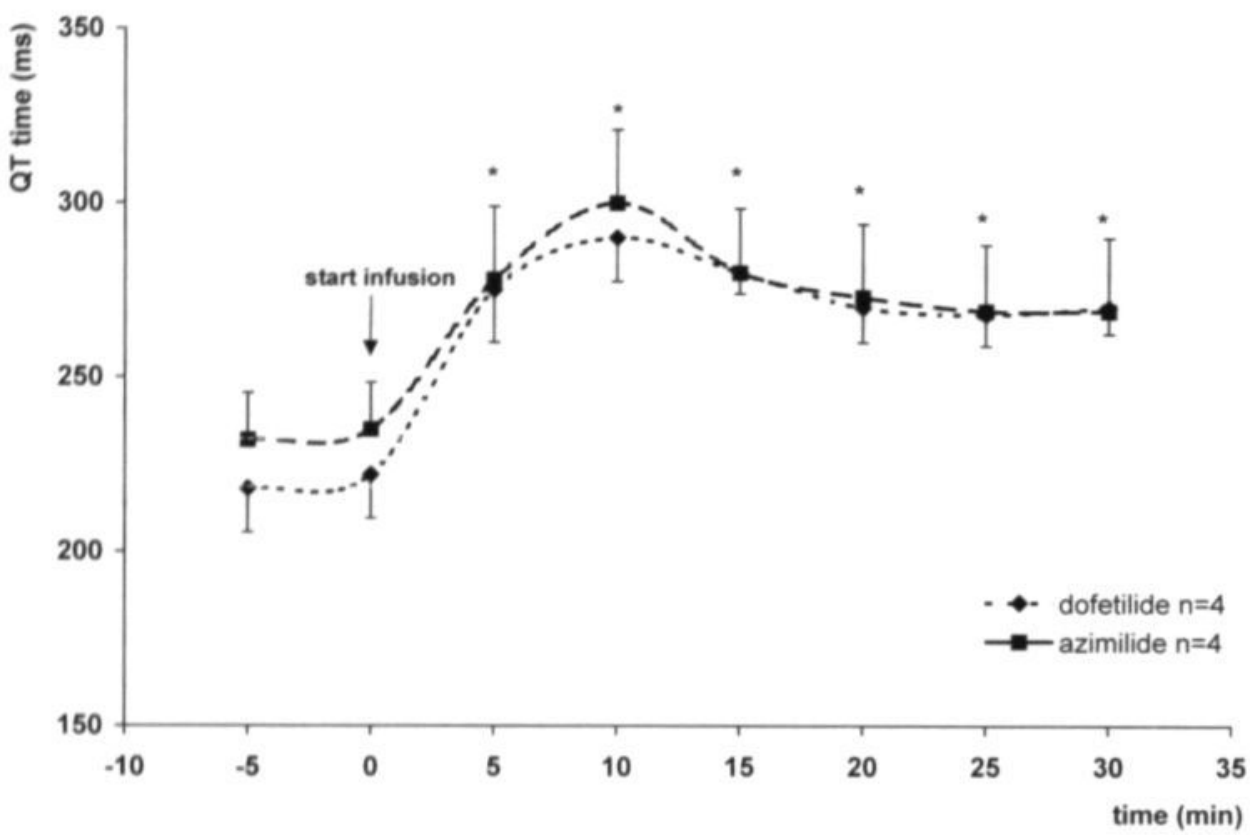

Figure 2 - Time-dependence of the QT time changes following azimilide $(5 \mathrm{mg} / \mathrm{kg} / 5 \mathrm{~min}$ ) and dofetilide $(0.025 \mathrm{mg} / \mathrm{kg} / 5 \mathrm{~min})$ during sinus rhythm. The drugs act very similarly to prolong repolarization time. The maximum QT effect was reached 10 minutes after the start of the infusion. After this time, there was a small decline to still significantly elevated values that remained stable over the observation period of $30 \mathrm{~min} .{ }^{*} \mathrm{P}<0.05$ vs $\mathrm{t}=0$ (ANOVA)

Table 2 - Comparison of dofetilide $(0.025 \mathrm{mg} / \mathrm{kg})$ and azimilide $(5 \mathrm{mg} / \mathrm{kg})$ in CAVB dogs $(\mathrm{n}=9)$

\begin{tabular}{|c|c|c|c|}
\hline & control & dofetilide & $\%$ \\
\hline RR & $1360 \pm 315$ & $1575 \pm 375^{\prime \prime}$ & 17 \\
\hline QT & $405 \pm 65$ & $505 \pm 95^{\prime \prime}$ & 25 \\
\hline $\mathrm{QT}_{\mathrm{c}}$ & $350 \pm 60$ & $405+70^{\prime}$ & 17 \\
\hline LV MAPD & $365 \pm 60$ & $490 \pm 90^{\prime \prime}$ & 34 \\
\hline RV MAPD & $310 \pm 45$ & $380 \pm 80^{\prime \prime}$ & 23 \\
\hline \multirow[t]{2}{*}{$\triangle \mathrm{MAPD}$} & $55 \pm 25$ & $110 \pm 25^{\prime \prime}$ & 100 \\
\hline & control & azimilide & 9 \\
\hline RR & $1420 \pm 225$ & $1575+290^{\prime \prime}$ & 11 \\
\hline QT & $400 \pm 65$ & $500 \pm 85^{\prime \prime}$ & 26 \\
\hline $\mathrm{QT}_{\mathrm{c}}$ & $335 \pm 50$ & $400 \pm 55^{\prime \prime}$ & 19 \\
\hline LV MAPD & $370 \pm 80$ & $500+110^{z}$ & 36 \\
\hline RV MAPD & $315 \pm 65$ & $390 \pm 85^{\prime \prime}$ & 22 \\
\hline$\triangle M A P D$ & $55 \pm 25$ & $110 \pm 50^{\prime}$ & 100 \\
\hline
\end{tabular}

Values in ms and mean $\pm S D ;=\mathrm{P}<0.05$ drug $v$ control 


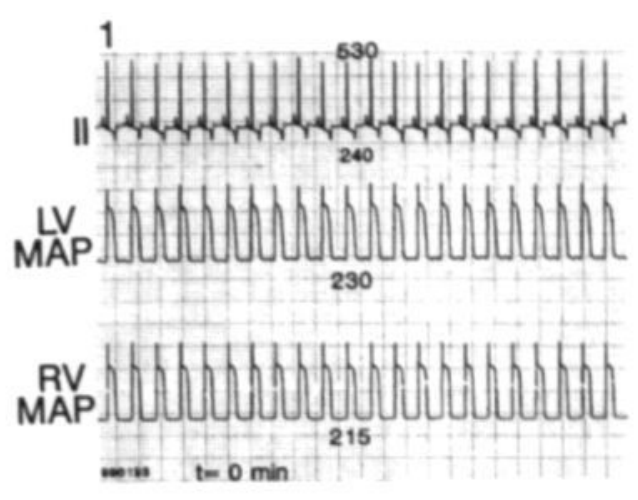

3

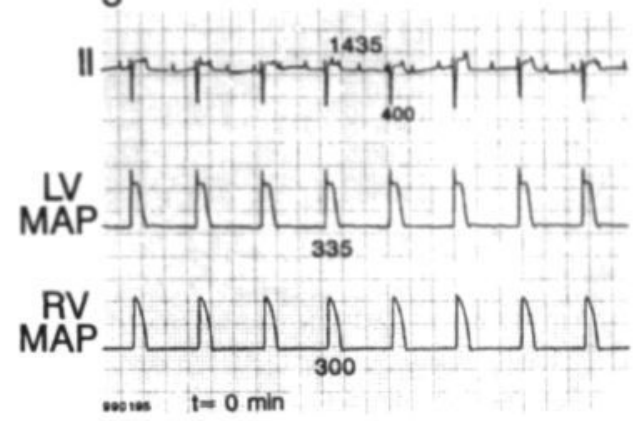

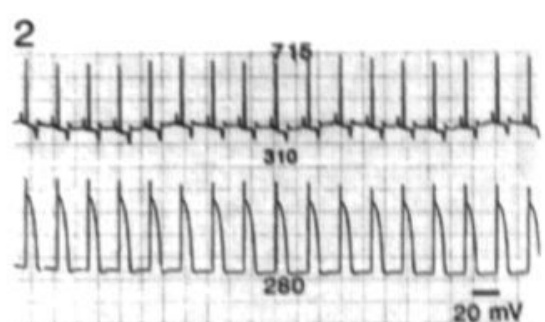

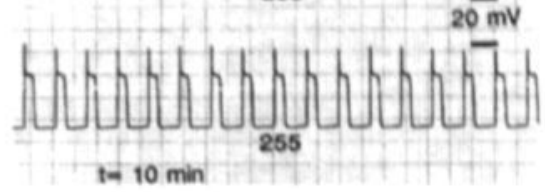

4

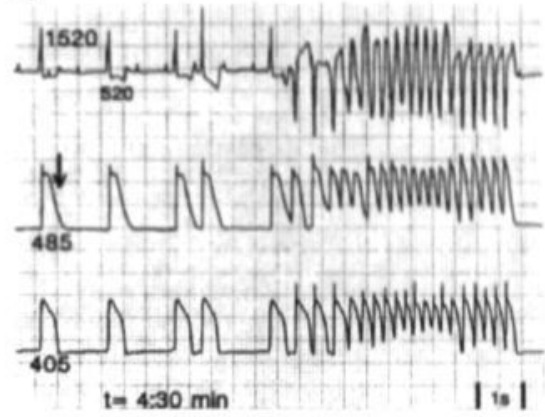

Figure 3 - Effect of azimilide ( $5 \mathrm{mg} / \mathrm{kg} / 5 \mathrm{~min}$ ) during sinus rhythm and chronic complete AV block (CAVB) in the same dog. In all panels, lead II of the surface ECG and 2 monophasic-action-potential catheters (MAP) in both the left ventricle (LV) and right ventricle (RV) are shown at a paper speed of 10 $\mathrm{mm} / \mathrm{s}$. In panel 1, the baseline situation during sinus rhythm (SR) is shown: the interventricular dispersion is minimal (15 ms). Ten minutes after azimilide administration, RR as well as QT time, LV MAP duration (LV MAPD), RV MAP duration (RV MAPD), and $\triangle M A P D$ (i.e. LV- minus RV MAAPD) have all increased (panel 2). At 4 weeks CAVB, bradycardia is clearly visible and accompanied by an increased QT time, LV- and RV MAPD. The $\triangle M A P D$ is $35 \mathrm{~ms}$ (panel 3). After azimilide, RR and QT time increase further, LV MAPD increases more than the RV MAPD leading to a considerable $\triangle M A P D$ of 80 ms. A short-long-short sequence of ventricular ectopic ventricular beats initiates a TdP arrhythmia which in this case terminated spontaneously.

\section{ELECTROPHYSIOLOGICAL AND PROARRHYTHMIC EFFECTS OF AZIMILIDE AND DOFETILIDE DURING CAVB}

Of the 10 anesthetized dogs tested initially after 4 weeks of CAVB, 1 animal showed arrhythmias prior to drug administration and was therefore excluded from this study.

In Figure 3, we show the electrophysiological adaptations (electrical remodeling) caused by CAVB (panel 1 sinus rhythm versus panel 3 CAVB at baseline). 


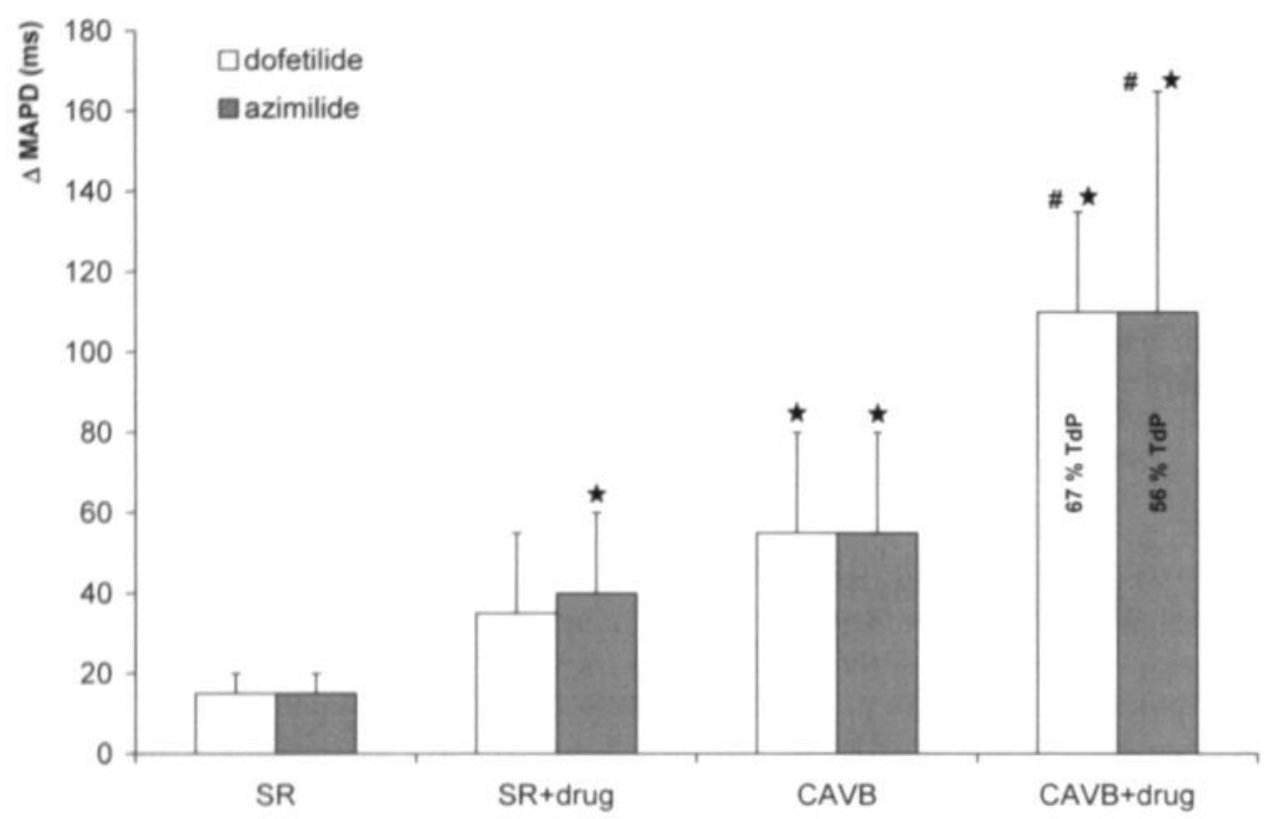

Figure 4 - Changes in interventricular dispersion ( $\triangle \mathrm{MAPD}$ on vertical axis) are illustrated under 4 different circumstances for doferilide and azimilide. During sinus rhythm (SR) the $\triangle M A P D$ was minimal and increased after drug administration. After chronic complete AV block (CAVB), the $\triangle M A P D$ increased to about $50 \mathrm{~ms}$ and showed a further marked increase after drug administration. A similar TdP incidence for both drugs was seen. ${ }^{\circ}, \mathrm{P}<0.05$ vs sinus rhythm and $\#, \mathrm{P}<0.05$ vs $\mathrm{CAVB}$.

As expected, the baseline values for the dogs tested, serially at CAVB, were similar (Table 2, left panel). Before drug administration, no arrhythmic activity (EADs or ventricular ectopic activity) was observed. Because TdP often occurred before the end of the dose regimen, we decided to determine all electrophysiological parameters immediately before the TdP arrhythmia (mean: $180 \pm 60 \mathrm{~s}$ ). For those dogs not showing $\mathrm{TdP}$, the measurements were taken at a similar time $(\mathrm{t}=3 \mathrm{~min}$, Table 2).

Dofetilide and azimilide prolonged all repolarization parameters equally, including $\triangle \mathrm{MAPD}$ (Figure 3, panels 3 and 4 and Table 2). After either drug, EADs developed in all experiments, while in the majority of dogs, single- and multiple ventricular ectopic beats occurred (Figure 3): 8 of 9 dogs for dofetilide and 7 of 9 dogs for azimilide (not significantly different). Interaction of this ectopic activity, often in the short-long-short sequence (Figure 3), along with the considerable $\triangle M A P D$ (e.g. $110 \pm 50 \mathrm{~ms}$ with azimilide, Table 2 and Figure 4) evoked TdP reproducibly (Figure 5). TdP incidence was not different for the two drugs and occurred in 6 of 9 dogs after dofetilide and in 5 of 9 dogs after azimilide (Figures 3-5). 
1

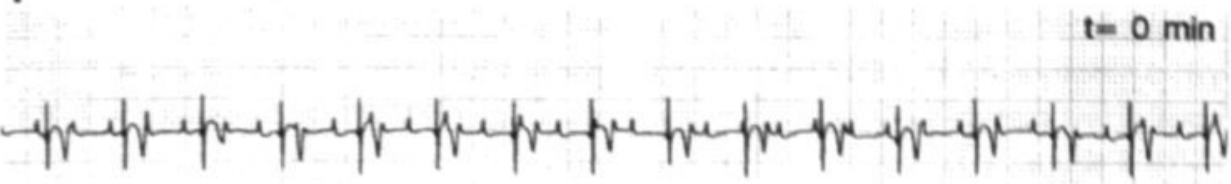

2

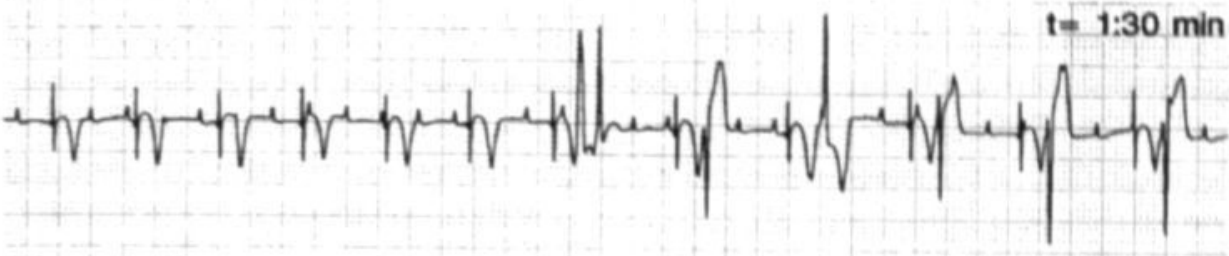

3

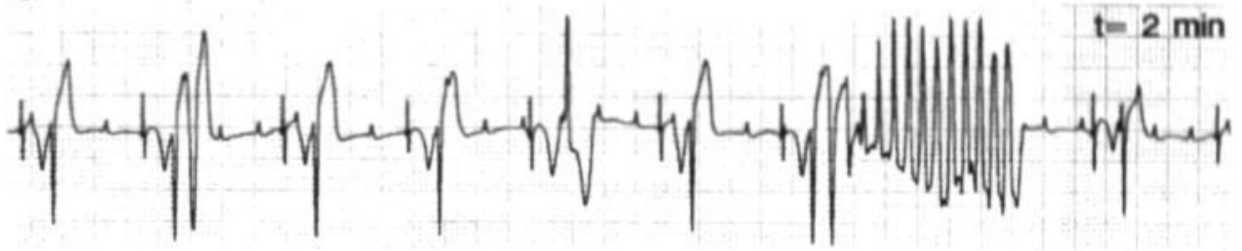

4

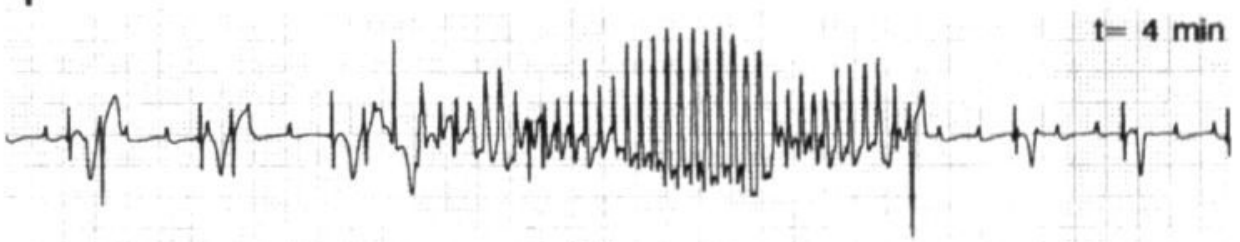

5

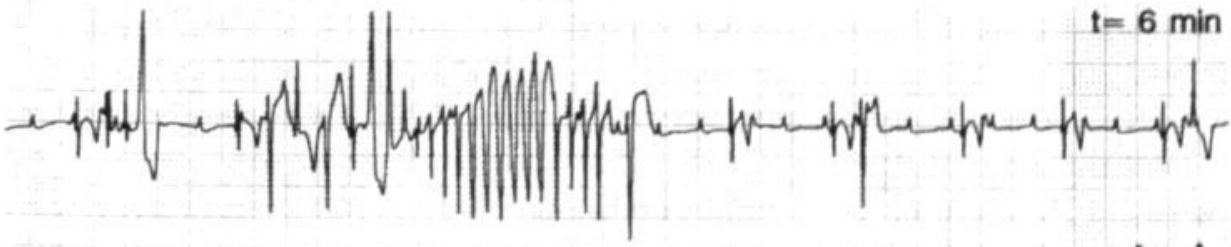

990245

Figure 5 - Reproducible TdP with azimilide $(5 \mathrm{mg} / \mathrm{kg} / 5 \mathrm{~min}$ ) during chronic complete AV block (CAVB). A 5-panel figure of lead II at a paper speed of $10 \mathrm{~mm} / \mathrm{s}$ demonstrates the events after administration (in minutes) of azimilide in the CAVB dog. Panel 1 shows the control situation. As early as $11 / 2$ min after the start of azimilide administration, ventricular ectopic activity developed (panel 2) which was followed by the reproducible initiation of life-threatening TdPs, all terminating spontaneously (panels 3 to 5). 
When we compare the electropharmacological response to azimilide at sinus rhythm versus CAVB, $\triangle \mathrm{MAPD}$ increased from $15 \pm 5 \mathrm{~ms}$ to $40 \pm 20 \mathrm{~ms}$ during normal sinus rhythm and from $55 \pm 25 \mathrm{~ms}$ to $110 \pm 50 \mathrm{~ms}$ when the drug was given at CAVB (Figure 4).

\section{DISCUSSION}

In the present study, we found that $0.025 \mathrm{mg} / \mathrm{kg}$ dofetilide and $5 \mathrm{mg} / \mathrm{kg}$ azimilide possessed similar ventricular electrophysiological and proarrhythmic effects in anesthetized CAVB dogs.

Dofetilide acts specifically on the $\mathrm{I}_{\mathrm{Kr}}$ channel while azimilide has multiple channel blocking properties ( $\mathrm{I}_{\mathrm{Kr}}, \mathrm{I}_{\mathrm{Ks}}, \mathrm{I}_{\mathrm{CaL}}$ and $\mathrm{I}_{\mathrm{Na}}$ channels). ${ }^{23,24}$ Dofetilide (Tikosyn ${ }^{\mathrm{TM}}$ ) is approved for clinical use in the USA for conversion of chronic atrial fibrillation and maintenance of normal sinus rhythm while azimilide is still under clinical investigation. ${ }^{35,36}$

The Survival With ORal D-sotalol (SWORD) and DAnish Investigations of Arrhythmia and Mortality On Doferilide (DIAMOND) trials, revealed that agents blocking specifically the $\mathrm{I}_{\mathrm{Kr}}$ channel do not reduce overall mortality. ${ }^{1,2}$ These disappointing results can probably be attributed to the increased risk of proarrhythmia, notably TdP. TdP arrhythmias are generally believed to be dependent on a substrate, dispersion in action potential duration, and a trigger, EAD-dependent triggered activity. ${ }^{5,6}$ Selective $\mathrm{I}_{\mathrm{Kr}}$ channel blockade is thought to aggravate the dispersion in action potential duration and facilitate the occurrence of EADs. ${ }^{5.11,13,14}$ These EADs can give rise to triggered ectopic activity, setting the stage for TdP. ${ }^{37}$

In contrast, a multiple channel blocker like amiodarone increases the action potential duration without causing dispersion of repolarization and is rarely associated with TdP. ${ }^{16-20}$ It is suggested that the low incidence of TdP with amiodarone is, at least partly, related to its $\mathrm{I}_{\mathrm{Cal}}$ channel blocking properties, which channel is considered to play a major role in EAD formation. ${ }^{37.38}$ In favor of this line of thinking is the fact that drugs which block simultaneously the $\mathrm{I}_{\mathrm{K}}$ channel and $\mathrm{I}_{\mathrm{Cal}}$ channel, prolong the action potential duration without the occurrence of TdP. ${ }^{39,40}$

Azimilide blocks, in addition to the $\mathrm{I}_{\mathrm{Cal}}$ channel, the $\mathrm{I}_{\mathrm{Ks}}$ channel. ${ }^{23,24} \mathrm{It}$ has been speculated that (additional) $\mathrm{I}_{\mathrm{K} s}$ channel blockade may have antiarrhythmic properties during faster heart rates and an enhanced sympathetic tone, when the $\mathrm{I}_{\mathrm{Ks}}$ channel is believed to play an important role in aggravating dispersion of repolarization. ${ }^{41-43}$

\section{THE CHRONIC COMPLETE-AV BLOCK DOG}

To test for the proarrhythmogenic potential of antiarrhythmic drugs, the adrenergically stimulated rabbit and various dog preparations have been used as animal 
models. ${ }^{9,14,44}$ The CAVB dog model has been well characterized for its specific structural, contractile and electrical adaptation processes. In short, compensated biventricular hypertrophy occurs in time, which is accompanied by nonhomogeneous increases in endocardial MAPD, leading to a higher $\triangle \mathrm{MAPD}$. Whereas the differences in ventricular MAPD are small during sinus rhythm, $\triangle \mathrm{MAPD}$ increases considerably after CAVB (Figure 4).

On the ion-channel level, the increase in action potential duration can be attributed, at least partly, to a downregulation of the $I_{K}$ in the model. ${ }^{10}$ An affected $I_{K}$ has been implicated in congenital long QT syndromes, ${ }^{45}$ and has been reported for patients with organic heart disease, such as congestive heart failure. ${ }^{15,46}$ The latter may explain the apparent increased risk for drug-induced TdP among these individuals. ${ }^{47,48}$ As such, the model is very suitable for demonstrating that a drug would produce an adequate lengthening of QT time without creating dispersion of repolarization.

Several antiarrhythmic agents have been tested in this model, 4.5 all showing an increase in $\triangle \mathrm{MAPD}$, which was associated with a TdP incidence ranging from $50-65 \%$. Because the electrical adaptations have been stabilized after 4 weeks of CAVB,${ }^{32}$ drug testing can be performed serially in the same dog, as we have done in this and a previous study. ${ }^{5}$

Both azimilide and dofetilide had pronounced effects on QT, LV MAPD, and RV MAPD (Table 2). $\triangle$ MAPD (Figure 4) increased by lengthening the LV MAPD more than the RV MAPD. Both drugs caused TdP, preceded by single- and multiple-ventricular ectopic beats, often in the short-long-short sequence. The short-long-short sequence is an important contributor in augmenting the dispersion and initiating TdP, as we recently described. ${ }^{5,49}$ The electrophysiological effects of the drugs described in Table 2 can be an underestimate because, in most animals, the infusion was stopped prematurely due to occurrence of TdP.

The results imply that the nonselective ion channel blockade provided by azimilide is not preferable to the use of the selective $\mathrm{I}_{\mathrm{Kr}}$ blocker dofetilide in the CAVB dog model. For this finding several explanations could be offered: 1) the fact that azimilide did not prevent EADs and related ventricular ectopic beats would suggest an insufficient $\mathrm{I}_{\mathrm{CaL}}$ channel blockade by the drug, 2) blocking the $\mathrm{I}_{\mathrm{K}}$ channel could be beneficial especially during the several episodes of rate switches, ventricular ectopic beats, which occurred after infusion of the drug. However, it is not clear to what extent azimilide can still favorably block this channel in the CAVB dog in which the $I_{K s}$ is significantly downregulated, ${ }^{10}$ and 3) azimilide blocks the multiple ion channels with different potencies (e.g. $\mathrm{IC}_{50} \mathrm{I}_{\mathrm{Kr}} 0.4 \mu \mathrm{mol} / \mathrm{L}$ and $\mathrm{I}_{\mathrm{Ks}} 3$ $\mu \mathrm{mol} / \mathrm{L}$ ) which could imply no, or less, effect on certain ion channels with the present dosage. ${ }^{23,24}$

To assess the possible beneficial role of less specific ion channel blockers versus specific $\mathrm{I}_{\mathrm{Kr}}$ channel blockers in the CAVB dog model, a proven antiarrhythmic agent 
with minimal proarrhythmic adverse effects, such as amiodarone, should be tested in order to examine the validity of the model.

\section{CONCLUSION}

Azimilide and dofetilide at doses, which provide similar electrophysiological effects cause a similar high incidence of $\mathrm{TdP}$ in dogs with atrioventricular block and remodeling.

\section{ACKNOWLEDGMENTS}

We would like to thank Dr. R.R. Brooks, Procter \& Gamble Pharmaceuticals, Cincinnati, USA for advice and comments. This study was financed in part by a grant from Procter \& Gamble Pharmaceuticals, Cincinnati, USA.

\section{REFERENCES}

1. Waldo AL, Camm AJ, deRuyter H, Friedman PL, MacNeil DJ, Pauls JF, Pitt B, Pratt CM, Schwartz PJ, Veltri EP. Effect of d-sotalol on mortality in patients with left ventricular dysfunction after recent and remote myocardial infarction. The SWORD Investigators. Survival With Oral d-Sotalol. Lancet. 1996;348:7-12.

2. Torp-Pedersen C, Moller M, Bloch-Thomsen PE, Kober L, Sandoe E, Egstrup K, Agner E, Carlsen J, Videbaek J, Marchant B, Camm AJ. Dofetilide in patients with congestive heart failure and left ventricular dysfunction. Danish Investigations of Arrhythmia and Mortality on Dofetilide Study Group. $N$ Engl J Med. 1999:341:857-65.

3. Pratt CM, Camm AJ, Cooper W, Friedman PL, MacNeil DJ, Moulton KM, Pitt B, Schwartz PJ, Veltri EP, Waldo AL. Mortality in the Survival With ORal D-sotalol (SWORD) trial: why did patients die? Am / Cardiol. 1998:81:869-76.

4. Vos MA, de Groot SH, Verduyn SC, van der Zande J, Leunissen HD, Cleutjens JP, van Bilsen M, Daemen MJ, Schreuder JJ. Allessie MA, Wellens HJ. Enhanced susceptibility for acquired torsade de pointes arrhythmias in the dog with chronic, complete AV block is related to cardiac hypertrophy and electrical remodeling. Circulation. 1998;98:1125-35.

5. Verduyn SC, Vos MA, van der Zande J, Kulcsar A. Wellens HJ. Further observations to elucidate the role of interventricular dispersion of repolarization and early afterdepolarizations in the genesis of acquired torsade de pointes arrhythmias: a comparison between almokalant and d-sotalol using the dog as its own control. I Am Coll Candiol. 1997:30:1575-84.

6. Surawicz B. Electrophysiologic substrate of torsade de pointes: dispersion of repolarization or early afterdepolarizations? I Am Coll Cardiol. 1989;14:172-84. 
7. Shimizu W, Antzelevitch C. Differential effects of beta-adrenergic agonists and antagonists in LQT1, LQT2 and LQT3 models of the long QT syndrome. J Am Coll Candiol. 2000:35:778-86.

8. El-Sherif N, Caref EB, Yin H, Restivo M. The electrophysiological mechanism of ventricular arrhythmias in the long QT syndrome. Tridimensional mapping of activation and recovery patterns. Cire Res. 1996;79:474-92.

9. Hsich MH, Chen YJ, Lee SH, Ding YA, Chang MS, Chen SA. Proarthythmic effects of ibutilide in a canine model of pacing induced cardiomyopathy. Pacing Clin Electrophysiol. 2000;23:149-56.

10. Volders PG, Sipido KR, Vos MA, Spatjens RL, Leunissen JD, Carmeliet E, Wellens HJ. Downregulation of delayed rectifier $\mathrm{K}^{*}$ currents in dogs with chronic complete atrioventricular block and acquired torsades de pointes. Cinculation. 1999;100:2455-61.

11. Viswanathan PC, Shaw RM, Rudy Y. Effects of $\mathrm{I}_{\mathrm{Kr}}$ and $\mathrm{I}_{\mathrm{K}}$, heterogeneity on action potential duration and its rate dependence: a simulation study. Circulation. 1999:99:2466-74.

12. Liu DW, Antzelevitch C. Characteristics of the delayed rectifier current $\left(\mathrm{I}_{K_{r}}\right.$ and $\left.\mathrm{I}_{\mathrm{Ks}}\right)$ in canine ventricular epicardial, midmyocardial, and endocardial myocytes. A weaker $\mathrm{I}_{\mathrm{K}}$ contributes to the longer action potential of the M cell. Circ Res. 1995:76:351-65.

13. Cheng J, Kamiya K, Liu W, Tsuji Y, Toyama J, Kodama I. Heterogeneous distribution of the two components of delayed rectifier $\mathrm{K}^{+}$current: a potential mechanism of the proarrhythmic effects of methanesulfonanilideclass III agents. Cardiovasc Res. 1999;43:135-47.

14. Antzelevitch C, Shimizu W, Yan GX, Sicouri S, Weissenburger J, Nesterenko VV, Burashnikov A, Di Diego J, Saffitz J, Thomas GP. The M cell: its contribution to the ECG and to normal and abnormal electrical function of the heart. J Cardiovase Electrophysiol. 1999;10:1124-52.

15. Beuckelmann DJ, Nabauer M, Erdmann E. Alterations of $\mathrm{K}^{+}$currents in isolated human ventricular myocytes from patients with terminal heart failure. Circ Res. 1993;73:379-85.

16. Connolly SJ. Evidence-based analysis of amiodarone efficacy and safety. Circulation. 1999;100:2025-34.

17. Kodama I, Kamiya K, Toyama J. Amiodarone: ionic and cellular mechanisms of action of the most promising class III agent. Am J Cardiol. 1999;84:20R-28R.

18. Merot J, Charpentier F, Poirier JM, Coutris G, Weissenburger J. Effects of chronic treatment by amiodarone on transmural heterogeneity of canine ventricular repolarization in vivo: interactions with acute sotalol. Cardiovasc Res. 1999;44:303-14.

19. Sicouri S, Moro S, Litovsky S, Elizari MV, Antzelevitch C. Chronic amiodarone reduces transmural dispersion of repolarization in the canine heart. J Cardiovasc Electrophysiol. 1997;8:1269-79.

20. Drouin E, Lande G, Charpentier F. Amiodarone reduces transmural heterogeneity of repolarization in the human heart. J Am Coll Cardiol. 1998;32:1063-7.

21. Wiesfeld AC, Crijns HJ, Tobe TJ, Almgren O, Bergstrand RH, Aberg J, Haaksma J, Lie KI. Electropharmacologic effects and pharmacokinetics of almokalant, a new class III antiarrhythmic, in patients with healed or healing myocardial infarcts and complex ventricular arrhythmias. Am J Cardiol. 1992;70:990-6.

22. Hondeghem LM. Classification of antiarrhythmic agents and the two laws of pharmacology. Cardiovasc Res. 2000;45:57-60. 
23. Yao JA, Tseng GN. Azimilide (NE-10064) can prolong or shorten the action potential duration in canine ventricular myocytes: dependence on blockade of $\mathrm{K}, \mathrm{Ca}$, and $\mathrm{Na}$ channels. J Cardiovase Electrophysiol. 1997;8:184-98.

24. Fermini B, Jurkiewicz NK, Jow B, Guinosso PJ, Jr., Baskin EP, Lynch JJ, Jr., Salata JJ. Use-dependent effects of the class III antiarrhythmic agent NE-10064 (azimilide) on cardiac repolarization: block of delayed rectifier potassium and L-type calcium currents. J Cardiovase Pharmacol. 1995;26:259-71.

25. Vos MA, Verduyn SC, Wellens HJJ. Early afterdepolarizations in the in situ canine heart. Mechanistic insights into acquired Torsade de Pointes arrhythmias. In: MR Franz, ed. Monophasic Action Potentials. Bridging Cell and Bedside. Armonk NY: Futura Publishing; 2000:553-569.

26. Black SC, Butterfield JL, Lucchesi BR. Protection against programmed electrical stimulation-induced ventricular tachycardia and sudden cardiac death by NE-10064, a class III antiarrhythmic drug. J Cardiovase Pharmacol. 1993;22:810-8.

27. Drexler AP, Micklas JM, Brooks RR. Suppression of inducible ventricular arrhythmias by intravenous azimilide in dogs with previous myocardial infarction. I Cardiovasc Pharmacol. 1996;28:848-55.

28. Nattel S, Liu L, St-Georges D. Effects of the novel antiarrhythmic agent azimilide on experimental atrial fibrillation and atrial electrophysiologic properties. Cardiovasc Res. 1998;37:627-35.

29. Zuanetti G, Corr PB. Antiarrhythmic efficacy of a new class III agent, UK-68,798, during chronic myocardial infarction: evaluation using three-dimensional mapping. J Pharmacol Exp Ther. 1991;256:325-34.

30. Baskin EP, Lynch JJ, Jr. Differential atrial versus ventricular activities of class III potassium channel blockers. J Pharmacol Exp Ther. 1998;285:135-42.

31. Rodriguez LM, Leunissen J, Hoekstra A, Korteling BJ, Smeets JL, Timmermans C, Vos M, Daemen $\mathrm{M}$, Wellens HJ. Transvenous cold mapping and cryoablation of the AV node in dogs: observations of chronic lesions and comparison to those obtained using radiofrequency ablation. $J$ Cardiovasc Electrophysiol. 1998;9:1055-61.

32. Verduyn SC, Ramakers C, Snoep G, Leunissen JD, Wellens HJ, Vos MA. Time course of structural adaptations in chronic AV block dogs: evidence for differential ventricular remodeling.

33. Bazett HC. An analysis of the time relations of electrocardiograms. Heart. 1920;7:353-368.

34. Eckardt L. Haverkamp W, Borggrefe M, Breithardt G. Experimental models of torsade de pointes. Cardiovase Res. 1998:39:178-93.

35. Grines CL. Safety and effectiveness of dofetilide for conversion of atrial fibrillation and nesiritide for acute decompensation of heart failure: a report from the cardiovascular and renal advisory panel of the Food and Drug Administration. Circulation. 2000;101:E200-1.

36. Camm AJ, Karam R, Pratt CM. The azimilide post-infarct survival evaluation (ALIVE) trial. Am J Candiol. 1998;81:35D-39D.

37. Volders PG, Vos MA, Szabo B, Sipido KR, de Groot SH, Gorgels AP, Wellens HJ, Lazzara R. Progress in the understanding of cardiac early afterdepolarizations and torsades de pointes: time to revise current concepts. Candiovasc Res. 2000;46:376-92. 
38. Starmer CF, Romashko DN, Reddy RS, Zilberter YI, Starobin J, Grant AO, Krinsky VI. Proarrhythmic response to potassium channel blockade. Numerical studies of polymorphic tachyarrhythmias. Circulation. 1995;92:595-605.

39. Bril A, Gout B, Bonhomme M, Landais L, Faivre JF, Linee P, Poyser RH, Ruffolo RR, Jr. Combined potassium and calcium channel blocking activities as a basis for antiarrhythmic efficacy with low proarrhythmic risk: experimental profile of BRL-32872. I Pharmacol Exp Ther. 1996;276:637-46.

40. Carlsson L, Drews L, Duker G. Rhythm anomalies related to delayed repolarization in vivo: influence of sarcolemmal $\mathrm{Ca}^{2+}$ entry and intracellular $\mathrm{Ca}^{2+}$ overload. I Pharmacol Exp Ther. 1996;279:231-9.

41. Lynch JJ, Jr., Houle MS, Stump GL, Wallace AA, Gilberto DB, Jahansouz H, Smith GR, Tebben AJ, Liverton NJ, Selnick HG, Claremon DA, Billman GE. Antiarrhythmic efficacy of selective blockade of the cardiac slowly activating delayed rectifier current, $\mathrm{I}_{\mathrm{K} s}$, in canine models of malignant ischemic ventricular arrhythmia. Circulation. 1999;100:1917-22.

42. Schreieck J, Wang Y, Gjini V, Korth M, Zrenner B, Schomig A, Schmitt C. Differential effect of beta-adrenergic stimulation on the frequency-dependent electrophysiologic actions of the new class III antiarrhythmics dofetilide, ambasilide, and chromanol 293B. J Cardiovasc Electrophysiol. 1997:8:1420-30.

43. Viswanathan PC, Rudy Y. Cellular arrhythmogenic effects of congenital and acquired long-QT syndrome in the heterogeneous myocardium. Circulation. 2000;101:1192-8.

44. Carlsson L, Abrahamsson C, Andersson B, Duker G, Schiller-Linhardt G. Proarrhythmic effects of the class III agent almokalant: importance of infusion rate, QT dispersion, and early afterdepolarisations. Cardiovasc Res. 1993;27:2186-93.

45. Priori SG, Barhanin J, Hauer RN, Haverkamp W, Jongsma HJ, Kleber AG, McKenna WJ, Roden DM, Rudy Y, Schwartz K, Schwartz PJ, Towbin JA, Wilde AM. Genetic and molecular basis of cardiac arrhythmias: impact on clinical management parts I and II. Circulation. 1999;99:518-28.

46. Marban E. Heart failure: the electrophysiologic connection. J Cardiovase Electrophysiol. 1999;10:1425-8.

47. Roden DM. Acquired long QT syndromes and the risk of proarrhythmia. J Cardiovase Electrophysiol. 2000;11:938-40.

48. Camm AJ, Janse MJ, Roden DM, Rosen MR, Cinca J, Cobbe SM. Congenital and acquired long QT syndrome. Eur Heart J. 2000;21:1232-1237.

49. Vos MA, Gorenek B, Verduyn SC, van der Hulst FF, Leunissen JD, Dohmen L, Wellens HJ. Observations on the onset of torsade de pointes arrhythmias in the acquired long QT syndrome. Cardiovasc Res. 2000 Dec;48(3):421-9. 


\section{CHAPTER 3}

\section{Probing the Contribution of $\mathrm{I}_{\mathrm{Ks}}$ to Canine Ventricular Repolarization}

Paul G.A. Volders, Jurren M. van Opstal, Milan Stengl, Uwe Gerlach, Roel L.H.M.G. Spätjens, Jet D.M. Leunissen-Beekman, Karin R. Sipido, Marc A. Vos

Department of Cardiology, Cardiovascular Research Institute Maastricht, Academic Hospital Maastricht, The Netherlands; Aventis Pharma Deutschland GmbH, Medicinal Chemistry (U.G.), Frankfurt / Main, Germany; and the Laboratory of Experimental Cardiology (K.R.S.), University of Leuven, Belgium 


\section{ABSTRACT}

Background: In large mammals and humans, the contribution of $\mathrm{I}_{\mathrm{Ks}}$ to ventricular repolarization is still incompletely understood.

Methods and Results: Cellular and in-vivo electrophysiological experiments were performed to study $\mathrm{I}_{\mathrm{K}}$ in canine ventricular repolarization. Activation of $\mathrm{I}_{\mathrm{Ks}}$ was restrained by the voltage and time domains of the action potential (AP), although at seconds-long depolarizations the current was substantial. Accordingly, $\mathrm{I}_{\mathrm{K}}$ block by chromanols 293B and HMR 1556 did not significantly prolong AP duration (APD) at fast or slow steady-state pacing rates. Sudden rate increases could promote $\mathrm{I}_{\mathrm{Ks}}$ accumulation due to incomplete deactivation, but only if coupling intervals were very short. $\mathrm{I}_{\mathrm{K} s}$ block did exaggerate repolarization instability by $\mathrm{I}_{\mathrm{Kr}}$ block, with further prolongation of APD. Isoproterenol increased and accelerated $\mathrm{I}_{\mathrm{Ks}}$ activation to promote AP shortening. This shortening was partially reversed by $293 \mathrm{~B}$ and HMR 1556. In-vivo administration of HMR 1556 caused substantial dosedependent QT prolongations $(65 \pm 15 \%$ at $30 \mathrm{mg} / \mathrm{kg} / \mathrm{PO} \mathrm{HMR}$ 1556) with broad-based $T$ waves in conscious dogs. Such repolarization effects (HMR 1556 and 293B) were significantly blunted during halothane and/or pentobarbital anesthesia.

Conclusions: We conclude that under baseline conditions in ventricular myocytes unstimulated $\mathrm{I}_{\mathrm{Ks}}$ does not contribute significantly to repolarization. However, $\mathrm{I}_{\mathrm{K}}$ becomes prominent during $\mathrm{I}_{\mathrm{Kr}}$ block when it limits repolarization prolongation and instability by timedependent activation, and during B-adrenergic receptor stimulation when it promotes AP shortening by increased activation. Our combined cellular and in-vivo data highlight the importance of $\mathrm{I}_{\mathrm{Ks}}$ function for ventricular repolarization and indicate the synergism between an intact basal $\mathrm{I}_{\mathrm{K} s}$ and a balanced sympathetic nervous function. 


\section{INTRODUCTION}

In large mammals and humans, the contribution of $\mathrm{I}_{\mathrm{Ks}}$ to the ventricular action potential (AP) is still unclear. In voltage-clamp studies $I_{K s}$ appears as a large outward current during seconds-long depolarizing pulses. $\mathrm{I}_{\mathrm{Ks}}$ deficiencies in the human congenital long-QT (LQT) syndromes $1^{1}$ and $5,{ }^{2}$ and in the Jervell and Lange-Nielsen syndrome are often associated with abnormally long QT intervals. Acquired QT prolongation (e.g., in cardiac hypertrophy or failure) is often attended by a downregulation of $\mathrm{I}_{\mathrm{Ks}} \cdot{ }^{3.9}$ Finally, some studies with the $\mathrm{I}_{\mathrm{Ks}}$-blocking drug chromanol 293B (293B) show AP prolongation in the rabbit, ${ }^{5} \operatorname{dog}^{6}$ and human. These data indicate that $\mathrm{I}_{\mathrm{K}}$ has a dominant role in repolarization.

On the other hand there is evidence that in rabbit, dog and human $I_{K s}$ functions predominately as a safery factor that enhances repolarization during AP prolongation (by other causes than $\mathrm{I}_{\mathrm{K}}$ block). Support for this comes from voltage-clamp studies in canine ventricular myocytes in which $\mathrm{I}_{\mathrm{Ks}}$ is little activated during AP commands of normal duration. Accordingly, the $\mathrm{I}_{\mathrm{Ks}}$-blocking drugs indapamide," $293 \mathrm{~B},{ }^{8,10,11}$ and $\mathrm{L}-735,821^{8,10}$ do not prolong canine and rabbit ventricular AP durations (APDs) at baseline. Discussions on these data and their implications are vivid. ${ }^{12,13}$ A safety-factor role emerges also from studies on $\mathrm{I}_{\mathrm{Ks}}$ in canine cardiac Purkinje cells. ${ }^{14}$ Without $B$-adrenergic receptor stimulation, $\mathrm{I}_{\mathrm{Ks}}$ contributes little to the repolarization of these cells. However, $B$-adrenergic enhancement of $I_{K s}$ provides an important braking function that limits AP prolongation by the action of other currents. $^{14}$

Given these paradoxes in the understanding of $\mathrm{I}_{\mathrm{Ks}}$ we performed cellular and in-vivo electrophysiological experiments in dogs to better determine the importance of this $\mathrm{K}^{+}$current for ventricular repolarization. $\mathrm{I}_{\mathrm{Ks}}$ was quantitatively assessed in conditions relevant for the AP, both at baseline and during specific pacing protocols, AP prolongation and $B$-adrenergic stimulation aimed at enhancing $I_{K s}$. Pharmacological $\mathrm{I}_{\mathrm{Ks}}$ block was applied in conscious and anesthetized dogs.

\section{MATERIALS AND METHODS}

Animal handling was in accordance with the 'Dutch Law on Animal Experimentation' and the 'European Directive for the Protection of Vertebrate Animals Used for Experimental and Other Scientific Purposes (86/609/EU)'. The experiments were approved by the Committee for Experiments on Animals of the Maastricht University. Fifty adult mongrel dogs of either sex weighing between 18 and $37 \mathrm{~kg}$ were used for the experiments. 


\section{CELLULAR EXPERIMENTS}

Anesthetized dogs received heparin IV upon thoracotomy. The hearts were quickly excised and washed in cold cardioplegic solution. The procedure for isolating ventricular midmyocardial cells, by coronary-artery cannulation and perfusion with collagenase, was the same as described earlier. ${ }^{15}$ Microelectrodes for transmembrane potential recordings had resistances of 30 to $60 \mathrm{M} \Omega$ when filled with $3.0 \mathrm{~mol} / \mathrm{L} \mathrm{KCl}$. Intracellular pacing was done at various cycle lengths (CLs). Whole-cell currents were measured using patch pipettes with resistances of 1.0 to $3.0 \mathrm{M} \Omega$ when filled with internal solution. Experiments were performed at $37 \pm 1^{\circ} \mathrm{C}$, in total on 83 cells from 31 dogs.

The standard-buffer solution used for the experiments was of the following composition (mmol/L): $\mathrm{NaCl} 145, \mathrm{KCl} 4.0, \mathrm{CaCl}_{2} 1.8, \mathrm{MgCl}_{2}$ 1.0, $\mathrm{NaH}_{2} \mathrm{PO}_{4} 1.0$, glucose 11, HEPES 10, pH 7.4 with $\mathrm{NaOH}$ at $37^{\circ} \mathrm{C}$. The patch-pipette solution contained (in mmol/L): potassium aspartate $125, \mathrm{KCl} 20, \mathrm{MgCl}_{2} 1.0, \mathrm{MgATP} 5$, HEPES 5, EGTA 10, pH 7.2 with $\mathrm{KOH}$. Almokalant (kindly provided by AstraZeneca, Inc, Mölndal, Sweden) was dissolved in the superfusate as needed. Isoproterenol was first dissolved in distilled water containing $30 \mu \mathrm{mol} / \mathrm{L}$ ascorbic acid, kept in the dark and at $5^{\circ} \mathrm{C}$ until use. 293B and HMR 1556 were dissolved in dimethyl sulfoxide (DMSO) as $100 \mathrm{mmol} / \mathrm{L}$ stock solutions and diluted in the superfusate to achieve a final concentration immediately before each application. The final concentrations of DMSO (maximally $0.1 \%$ ) in the superfusate had no measurable effects on ion currents and APs.

\section{IN-VIVO STUDIES}

For studies in conscious dogs aliquots of HMR 1556 were packed in gelatin capsules or suspended in $0.5 \%$ hydroxyethylcellulose, and fed to the animals in the morning after overnight fasting. ECG monitoring was done with 24-hour Holter recordings and/or standard-lead ECGs at regular intervals before and after oral drug administration.

For studies under anesthesia, dogs received premedication $(1 \mathrm{~mL} / 5 \mathrm{~kg}: 10 \mathrm{mg}$ oxycodone $\mathrm{HCl}, 1 \mathrm{mg}$ acepromazine, and $0.5 \mathrm{mg}$ atropine sulfate $\mathrm{IM}$ ) and sodium pentobarbital $(20 \mathrm{mg} / \mathrm{kg} \mathrm{IV})$ after overnight fasting. Animals were artificially ventilated with a mixture of oxygen, nitrous oxide $(40 \% / 60 \%)$ and halothane $(0.5 \%$ to $1 \%$ vapor concentration). A thermal mattress was used to maintain an adequate body temperature. To determine a possible influence of halothane on the repolarization during in-vivo $\mathrm{I}_{\mathrm{K}}$ inhibition, IV sodium pentobarbital was used as a substitute anestheric. Aliquots of HMR 1556 and 293B were dissolved in $0.25 \mathrm{~mL} \mathrm{DMSO}$ and then further diluted in $1.75 \mathrm{~mL}$ polyethylene glycol 400 immediately before IV administration. The vehicle solution did not exhibit electrophysiological effects. Standard 6-lead ECGs, and left (LV) and right-ventricular (RV) endocardial mono- 
phasic AP (MAP) recordings were obtained throughout these experiments. Dogs were studied during sinus rhythm or programmed electrical stimulation from the right atrium. Acute complete atrioventricular block was created by radiofrequency ablation of the region with His potentials.

\section{PLASMA ANALYSIS OF 293B AND HMR 1556}

Concentrations of 293B (MW 324.4) and its first metabolite S88-1690 (MW 310.4), and of HMR 1556 (MW 411.3) in venous plasma were determined after solid-liquid extraction using Extrelut ${ }^{\circledR}$ cartridges (Merck \& Co, Inc, Whitehouse Station, NJ) and dichloromethane. Following evaporation of the organic phase, the samples were redissolved using $20 \%$ methanol in water and analyzed by reversed phase-high performance liquid chromatography with UV detection.

\section{STATISTICS}

The data are expressed as mean \pm SEM. Intergroup comparisons were made with the Student's t-test for unpaired and paired data groups, after testing for the normality of distribution. Multiple groups were analyzed by 1 -way ANOVA. Differences were considered significant if $\mathrm{P}<0.05$.

\section{RESULTS}

IKS BLOCK BY 293B AND HMR 1556 FAILS TO PROLONG CL-DEPENDENT APD IN SINGLE CANINE VENTRICULAR MYOCYTES AT BASELINE

Figure $1 \mathrm{~A}$ shows that $100 \mu \mathrm{mol} / \mathrm{L} 293 \mathrm{~B}$ inhibited all time-dependent activating and tail currents in canine ventricular myocytes. Concentration-response studies on $\mathrm{I}_{\mathrm{Ks}}$ tails (Figure $1 \mathrm{~B}$ ) yielded that $\mathrm{IC}_{50}=8 \mu \mathrm{mol} / \mathrm{L}$ and $65 \mathrm{nmol} / \mathrm{L}$ for $293 \mathrm{~B}$ and HMR 1556, respectively, thus confirming that HMR 1556 is a more potent $\mathrm{I}_{\mathrm{K}}$ blocker than $293 \mathrm{~B}^{16}$

Increasing concentrations of 293B (3, 10,30 and $100 \mu \mathrm{mol} / \mathrm{L})$ or HMR 1556 $(100,300$ and $500 \mathrm{nmol} / \mathrm{L})$ were applied on single-cell APs at various pacing CLs. AP configurations remained unaltered at 3 and $10 \mu \mathrm{mol} / \mathrm{L} 293 \mathrm{~B}$, but a slight loss of the notch occurred at $30 \mu \mathrm{mol} / \mathrm{L}$, consistent with $\mathrm{I}_{\mathrm{TO}}$ inhibition. ${ }^{17}$ Complete loss of the notch, triangulation of the AP and aspecific APD responses were observed at 100 $\mu \mathrm{mol} / \mathrm{L}$. No AP changes were observed with HMR 1556. In Figure 1C, the APD at $95 \%$ of repolarization $\left(\mathrm{APD}_{95}\right)$ is plotted against $\mathrm{CLs}$ from 300 to $2000 \mathrm{~ms}$ during superfusion with $30 \mu \mathrm{mol} / \mathrm{L} 293 \mathrm{~B}$ (i.e. $>3 \times \mathrm{IC}_{50}$ for $\mathrm{I}_{\mathrm{Ks}}$ block) and $500 \mathrm{nmol} / \mathrm{L}$ HMR $1556\left(>7 \times \mathrm{IC}_{50}\right)$. Mean APDs remained unaltered at all CLs. Fast-pacingdependent shortening of the APD was maintained. 
$54 \mid$ Chapter 3

\section{$I_{\mathrm{Ks}}$ block by chromanols 293B and HMR 1556}

A

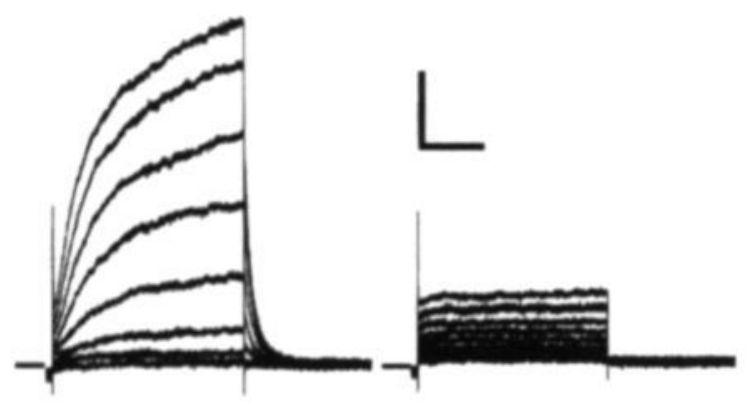

B
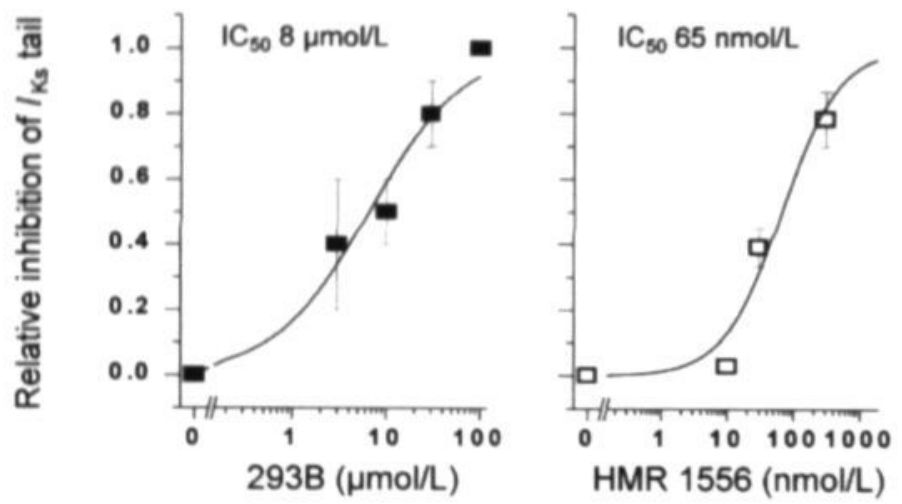

C
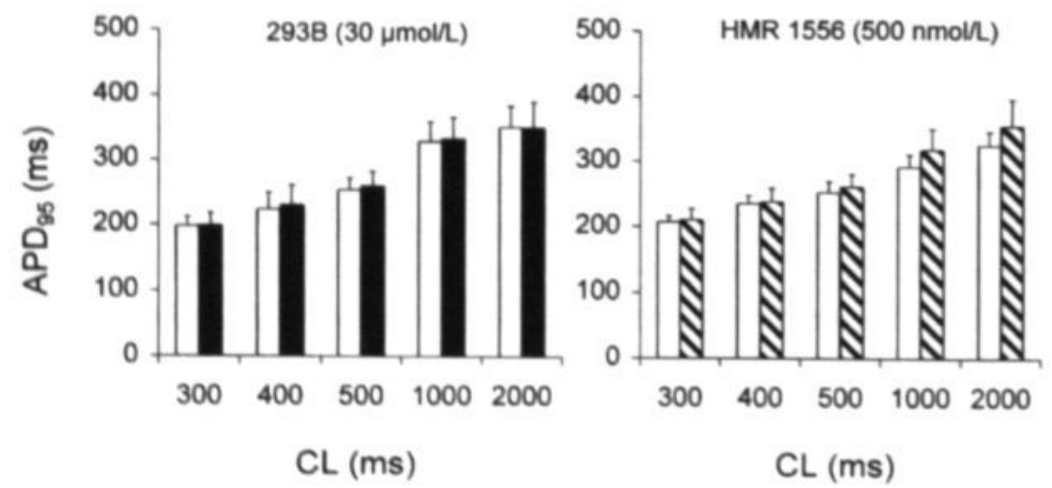

Figure $1-I_{\mathrm{n}}$, block by 293B and HMR 1556 fails to prolong APD in single canine ventricular midmyocytes. A, Left panel shows full block of time-dependent $I_{k}$ activation $(-20$ to $50 \mathrm{mV})$ and tail currents $(-25 \mathrm{mV})$ by $100 \mu \mathrm{mol} / \mathrm{L} .293 \mathrm{~B}$ in $0\left[\mathrm{~K}^{-}\right]$. Horizontal and vertical calibration bars indicate $1 \mathrm{~s}$ and $250 \mathrm{pA}$, respectively. Lower left horizontal bars, $0 \mathrm{pA}$. B. Concentration-response curves for the blocking effects of $293 \mathrm{~B}\left(\mathrm{IC}_{\omega}=8 \mu \mathrm{mol} / \mathrm{L}\right.$ ) and $\mathrm{HMR} 1556\left(\mathrm{IC}_{w}=65 \mathrm{nmol} / \mathrm{L}\right)$ on $\mathrm{I}_{\mathrm{n}}$ tails. C. $\mathrm{APD}_{n} / \mathrm{CL}$ relations at baseline and during $\mathrm{I}_{\mathrm{n}}$, block in normal superfusate (high-resistance microelectrodes containing $3 \mathrm{~mol} / \mathrm{L} \mathrm{KCl}$ ). Open bars indicate baseline. Values are means \pm SEM of 12 myocytes. 
Next, we evaluated the effects of $I_{K s}$ block after AP preprolongation with the $I_{K r}$ blocker almokalant $(1 \mu \mathrm{mol} / \mathrm{L}$; Figure 2 for CL $2000 \mathrm{~ms})$, assuming that during a longer AP more $I_{K s}$ is activated. ${ }^{8}$ Whereas 293B did not change the APD, almokalant increased it significantly from $293 \pm 2$ to $374 \pm 4 \mathrm{~ms}(+28 \%)$ at CL 500 $\mathrm{ms}$, and from $353 \pm 2$ to $813 \pm 21 \mathrm{~ms}(+130 \%)$ at CL $2000 \mathrm{~ms}$. The addition of 293B exaggerated the repolarization instability and further increased APD from 374 to $398 \pm 19 \mathrm{~ms}$, and from 813 to $1120 \pm 100 \mathrm{~ms}$ at the same CLs $(\mathrm{P}<0.05$ for both). Early afterdepolarizations were frequently seen under these circumstances. Similar observations were made at CL 1000 ms. Poincaré plots of APD 95 (beat n / n-1; Figure 2C) showed narrow clustering of the data points at baseline, increased deviations from the line $y=x$ during almokalant, and more complex polygons during almokalant plus 293B. These effects were reversible on washout.

To directly compare $\mathrm{I}_{\mathrm{Ks}}$ and $\mathrm{I}_{\mathrm{Kr}}$ in individual cells, 293B-sensitive and almokalan-tsensitive outward currents were examined during (APD-relevant) short depolarizations $\left(\mathrm{V}_{\text {test }}\right)$ of $300 \mathrm{~ms}$. Examples are shown in Figure 3A. At normal external $\mathrm{K}^{+}$concentration $\left(\left[\mathrm{K}^{*}\right]_{\mathrm{O}}\right), \mathrm{I}_{\mathrm{Kr}}$ activation reached maximal amplitudes of 93 , 114 and $131 \mathrm{pA}$ at $\mathrm{V}_{\text {test }} 0,20$ and $50 \mathrm{mV}$ within tens of ms. At these $\mathrm{V}_{\text {tess, }}, \mathrm{I}_{\mathrm{K}}$ reached maximal amplitudes of 23,132 and $488 \mathrm{pA}$, respectively, but only at the end of 300-ms depolarizations. IV relations at 50 and $100 \mathrm{~ms}$ are plotted in the right panels of Figure 3A. In Figure 3B voltage- and time-dependent activation of $\mathrm{I}_{\mathrm{Ks}}$ is shown for 31 cells in $0\left[\mathrm{~K}^{+}\right]_{\mathrm{O}}$. The arrow indicates that at 300 -ms duration no significant $\mathrm{I}_{\mathrm{Ks}}$ is generated at voltage steps $\left(\mathrm{V}_{\text {test }}\right) \leq 10 \mathrm{mV}$. However, at 3000 -ms duration it was $0.4 \pm 0.1 \mathrm{pA} / \mathrm{pF}$ in these same cells. The time course of full activation of $\mathrm{I}_{\mathrm{Ks}}$ could be measured during 5000 - $\mathrm{ms}_{\text {test }}$ to $20 \mathrm{mV}$. Half-maximal activation time was $702 \pm 59 \mathrm{~ms}$. Half-times for deactivation were voltage dependent and decreased from $333 \pm 27 \mathrm{~ms}$ upon repolarization to $-10 \mathrm{mV}$ to only $40 \pm 5 \mathrm{~ms}$ at $-80 \mathrm{mV}$, consistent with previous data.

\section{KS ACCUMULATION}

We examined whether a sudden increase of the pacing rate could promote $\mathrm{I}_{\mathrm{Ks}}$ accumulation on the basis of incomplete deactivation thus leading to APD shortening. Voltage-clamp conditions were designed to quantify the effects of depolarization duration and interpulse interval during pulses from -80 to $20 \mathrm{mV}$. Data in Figures $4 \mathrm{~A}$ and $4 \mathrm{~B}$ indicate that under baseline conditions, for 100-, 200- and 500-ms depolarizations, accumulation occurred only at interpulse intervals $<100 \mathrm{~ms}$. To examine the possibility of $\mathrm{I}_{\mathrm{Ks}}$ accumulation during sudden rate increases in AP recordings, we applied basic CLs that were interrupted by short-coupled extrastimulus pacing at CLs 300 and $350 \mathrm{~ms}$ for basic CL $500 \mathrm{~ms}$, and extrastimuli at CLs 300 and $500 \mathrm{~ms}$ for basic CLs 1000 and $2000 \mathrm{~ms}$. In none of these pacing combinations (with diastolic intervals often $<100 \mathrm{~ms}$ ) did 293B (10 and $30 \mu \mathrm{mol} / \mathrm{L})$ prolong 

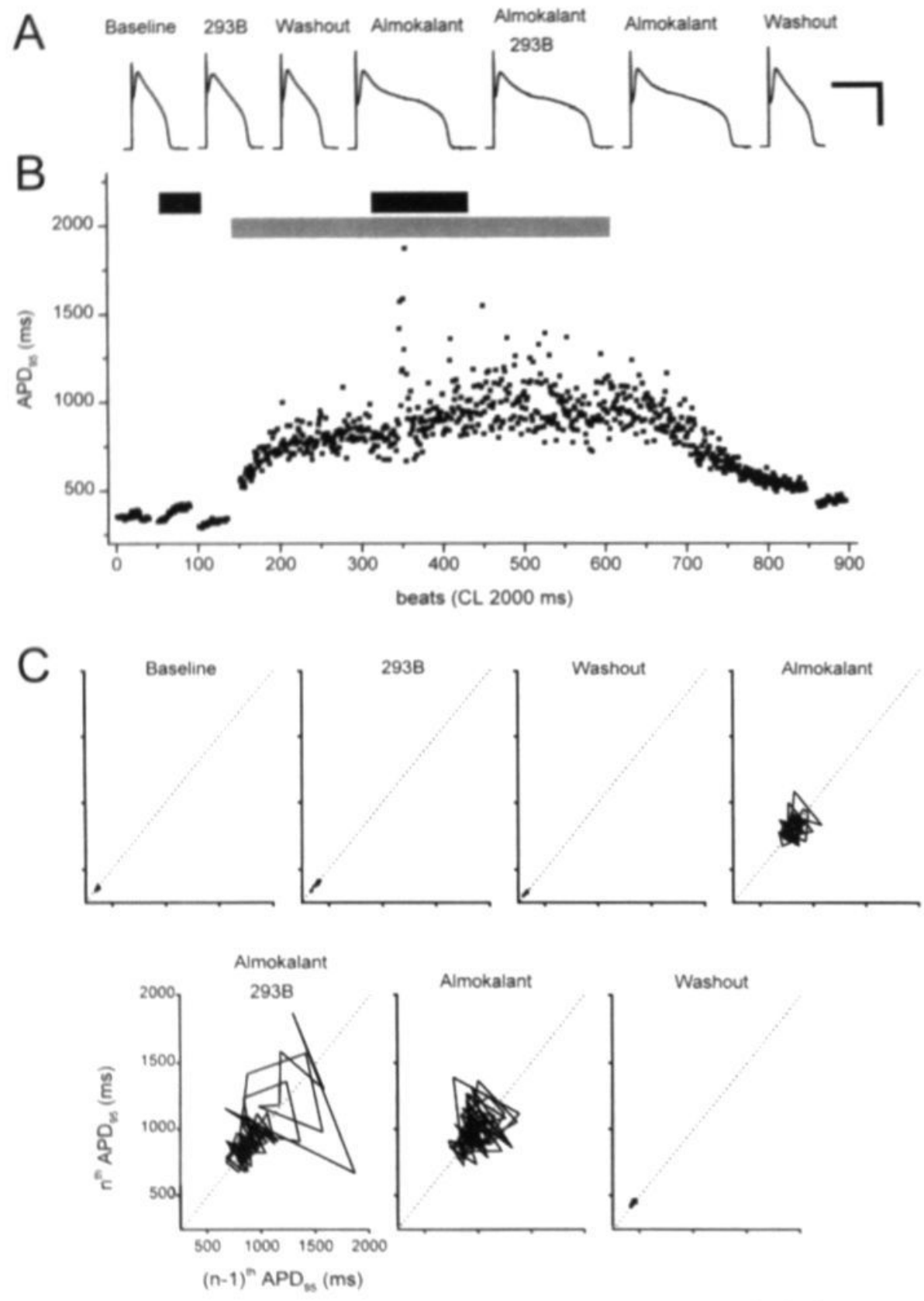

Figure 2 - Representative example of exaggerated repolarization instability by $\mathrm{I}_{\alpha}$, block after AP preprolongation with the $\mathrm{I}_{\mathrm{k}}$, blocker almokalant. A, APs at CL. $2000 \mathrm{~ms}$. Horizontal and vertical calibration bars indicate $500 \mathrm{~ms}$ and 0 to $-50 \mathrm{mV}$. B, Beat-to-beat analyses of the $\mathrm{APD}_{m}$ at baseline and during superfusion with 293B ( $30 \mu \mathrm{mol} / \mathrm{L}$; left upper black bar), almokalant ( $1 \mu \mathrm{mol} / \mathrm{L}$; upper gray bar), and almokalant plus 293B (right upper black bar), with washout periods to show reversibility of effects. C, Poincaré plots of $\mathrm{APD}_{n}$ data depicted in B. 

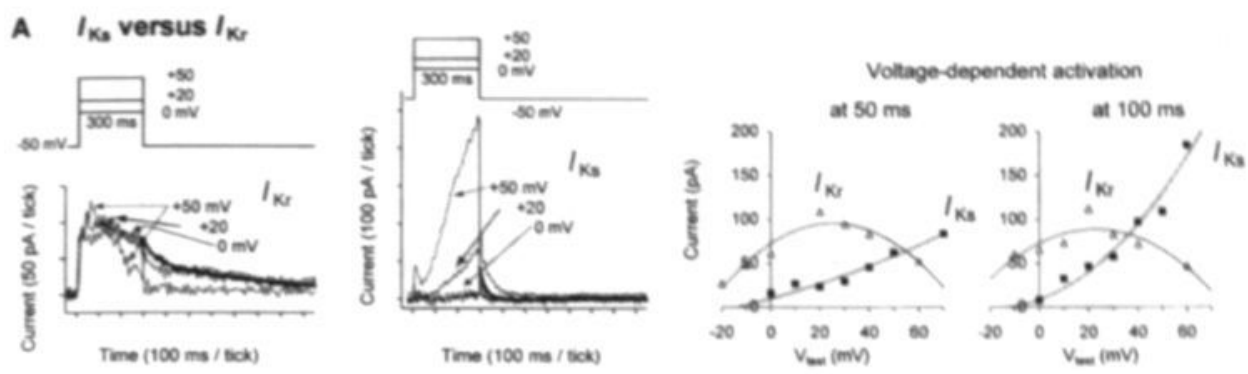

B Voltage- and time-dependent activation of $I_{\mathrm{K}}$.
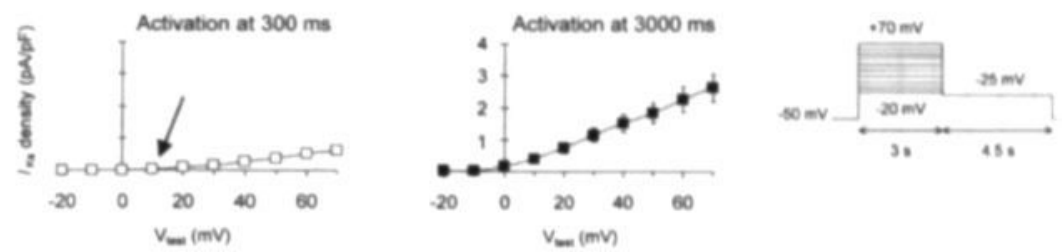

Figure 3 - Voltage- and time-dependent activation of $\mathrm{I}_{\mathrm{k}}$. A, Left panels show $\mathrm{I}_{\mathrm{k}}$ (almokalant-sensitive difference current; $1 \mu \mathrm{mol} / \mathrm{L}$ ) versus $\mathrm{I}_{\mathrm{k},}$ (293B-sensitive difference current; $30 \mu \mathrm{mol} / \mathrm{L}$ ) during 300-ms depolarizations in $4 \mathrm{mmol} / \mathrm{L}[\mathrm{K}]_{0}$. Thick solid lines are exponential fits for deactivation after $\mathrm{V}_{\text {te }}$ to 20 $\mathrm{mV}$. Right panels, IV relations of the same currents at 50 and $100 \mathrm{~ms}$. B, $\mathrm{I}_{\mathrm{k}-}$-density- $\mathrm{V}_{\mathrm{k}-\mathrm{t}}$ relations in 0 $\left[\mathrm{K}^{-}\right]_{\mathrm{o}}$. Time-dependent outward-current amplitudes were measured relative to their (close-to-)zero level at $100 \mathrm{~ms}$. The arrow indicates that, for clamp pulses of 300 -ms duration, no significant $I_{\mathrm{h}}$ was generated if $\mathrm{V}_{\mathrm{mat}} \leq 10 \mathrm{mV}$. Right inset, voltage-clamp protocol. Values are means \pm SEM of 31 cells.

the APD of the extrastimulus beats. Representative examples for basic CL $2000 \mathrm{~ms}$ are shown in Figure 4C.

\section{IKS ENHANCEMENT BY B-ADRENERGIC RECEPTOR STIMULATION}

$\mathrm{I}_{\mathrm{Ks}}$ was markedly enhanced by isoproterenol, as shown previously in ventricular myocytes of rabbit and guinea pig, ${ }^{19-21}$ and in canine cardiac Purkinje cells. ${ }^{14}$ Figure 5 shows time- and voltage-dependent activation during $100 \mathrm{nmol} / \mathrm{L}$. Compared to baseline, half-maximal activation time decreased to $510 \pm 67 \mathrm{~ms}(\mathrm{P}<0.05)$. Isoproterenol even enhanced $\mathrm{I}_{\mathrm{Ks}}$ during very short pulses of $100 \mathrm{~ms}$ when hardly any current had been measurable at baseline. In the example of Figure 5B the outwardcurrent amplitude at the end of the 100-ms depolarization increased from 535 to $710 \mathrm{pA}$, whereas the tail more than doubled from 40 to $100 \mathrm{pA}$. Enhancement and acceleration modified $\mathrm{I}_{\mathrm{Ks}}$ such that for 300 -ms pulses significant current amplitudes were reached at $V_{\text {test }}<0 \mathrm{mV}$ (Figure $5 \mathrm{C}$ ). Isoproterenol-enhanced $\mathrm{I}_{\mathrm{Ks}}$ could be completely inhibited by 293B, as shown in Figure 5D. Conversely, isoproterenol could enhance 293B-inhibited $\mathrm{I}_{\mathrm{K}}$, but only if there was residual current $>0$. 
A $I_{\mathrm{Ko}}$ accumulation
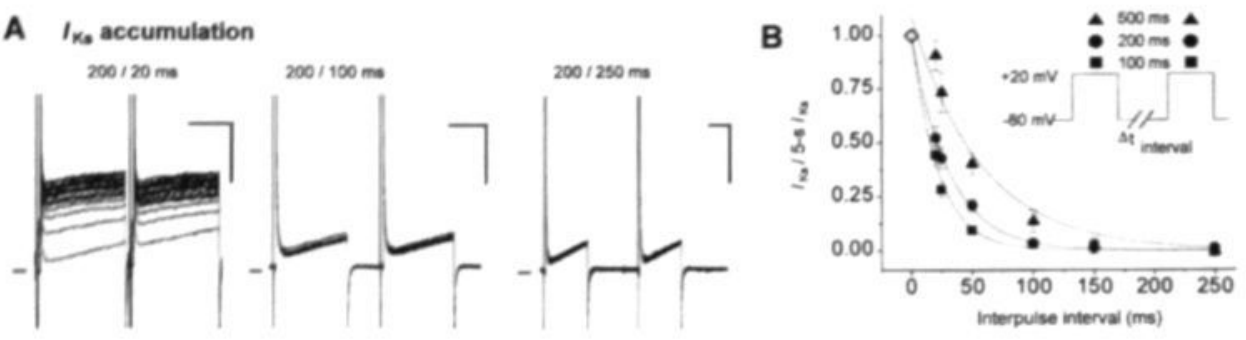

C Short-coupled extrastimulus pacing and APD
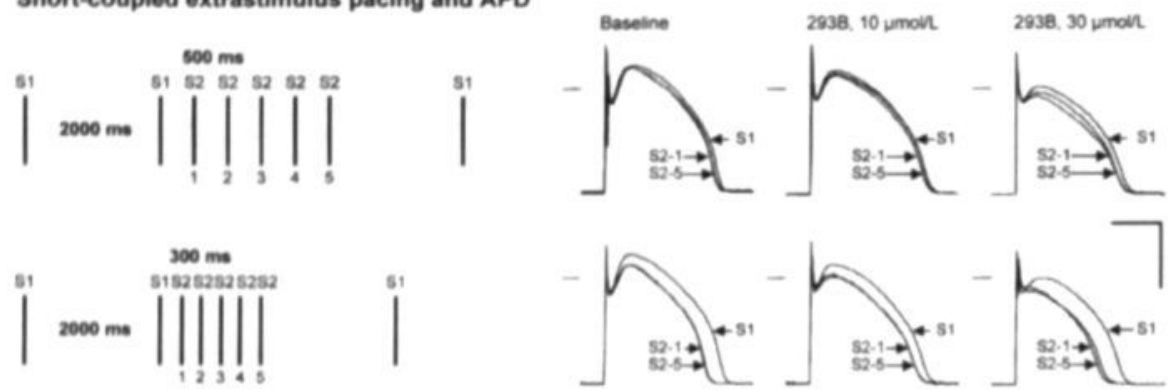

Figure $4-I_{k}$ accumulation. A, Accumulation occurs only at extreme depolarization duration / interpulse interval relations. Panels show original current traces during clamp pulses 1 to 40,99 and 100 after start of pacing. Depolarization durations / interpulse intervals are indicated above. Calibration bars, $100 \mathrm{~ms}$ and $500 \mathrm{pA}$. Lower left horizontal bars, $0 \mathrm{pA}$. B, Accumulated $\mathrm{I}_{\mathrm{k}}$ relative to the fully-activated $\mathrm{I}_{\mathrm{k},}$ (open diamond) measured during a 5000-ms depolarization to $20 \mathrm{mV}$. Accumulated $\mathrm{I}_{\mathrm{k}, \mathrm{s}}$ was measured as the current amplitude at the end of the $100^{\circ}$ depolarization minus that at the end of the $1^{\text {" }}$ depolarization to $20 \mathrm{mV}$. Interpulse intervals $(\Delta \mathrm{t})$ are $20,25,50,100,150$ and $250 \mathrm{~ms}$. The curves are monoexponential fits to the data. Values are means \pm SEM of 6 cells. No significant accumulation occurred at intervals $>100 \mathrm{~ms}$. Inset, voltage-clamp protocol. C, Short-coupled extrastimulus (S2) pacing (train of 5 beats at CL of 500 or $300 \mathrm{~ms}$ ) of APs at a basic CL (S1) of $2000 \mathrm{~ms}$ at baseline and during administration of 293B ( 10 and $30 \mu \mathrm{mol} / \mathrm{L}$ ). Examples in the right panels are the last AP at $\mathrm{S} 1$, and the first ( $\mathbf{2} 2-1)$ and fifth ( $22-5)$ extrastimulus AP. No significant extrastimulus AP prolongation is observed during 293B compared to baseline. Horizontal and vertical calibration bars, $500 \mathrm{~ms}$ and 50 $\mathrm{mV}$. Left horizontal bars, $0 \mathrm{mV}$.

In AP recordings isoproterenol ( 20 or $40 \mathrm{nmol} / \mathrm{L}$ ) increased plateau $V_{m}$, with no significant changes of the resting $\mathrm{V}_{\mathrm{m}}$. Plateau elevations were maximally $12 \mathrm{mV}$. Isoproterenol prolonged APD at $\mathrm{V}_{\mathrm{m}}>0 \mathrm{mV}$, whereas the $\mathrm{APD}_{95}$ was shortened at these concentrations. By the administration of $293 \mathrm{~B}(10$ and $30 \mu \mathrm{mol} / \mathrm{L})$ or $\mathrm{HMR}$ $1556(100$ and $500 \mathrm{nmol} / \mathrm{L})$ this shortening was partially reversed, most notably at the slow pacing rates (see Figures 6A and 6B). Invariably, the AP-prolonging effects of $\mathrm{I}_{\mathrm{Ks}}$ inhibition manifested at the end of the plateau, i.e. $>100 \mathrm{~ms}$ after the upstroke, and they were statistically significant for $\mathrm{APD}_{95}$ (Figure 6B). During isoproterenol plus $I_{K s}$ block fast-pacing-dependent shortening of the APD was main- 


\section{Voltage- and time-dependent activation of isoproterenol-enhanced $I_{\mathrm{Ks}}$}
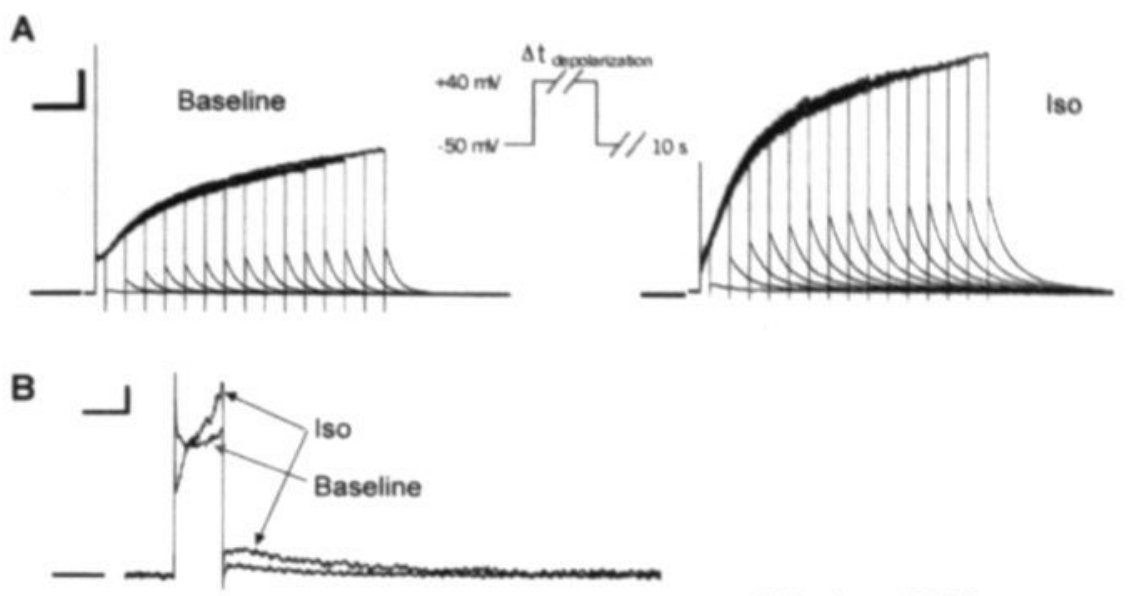

C

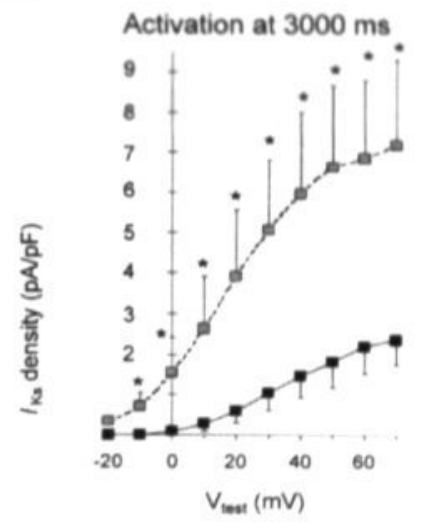

D
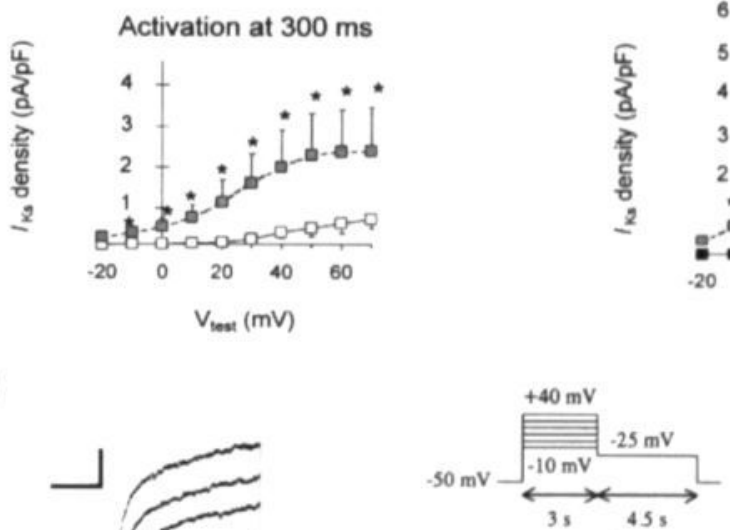

Iso

Iso +2938

Figure $5-I_{k}$ enhancement during isoproterenol. A, Time-dependent activation during depolarizations of 100 to $2900 \mathrm{~ms}$ with 200 -ms increments. Inset, voltage-clamp protocol. Calibration bars indicate 500 $\mathrm{ms}$ and $500 \mathrm{pA}$. B, $\mathrm{I}_{\mathrm{k}}$ is even enhanced during 100 -ms depolarizations. Calibration bars, $100 \mathrm{~ms}$ and 100 pA. C, Voltage-dependent activation in 11 cells. Protocol is the same as in Figure 3B. ${ }^{*}, \mathrm{P}<0.05$ vs baseline. D, Inhibition of isoproterenol-enhanced $\mathrm{I}_{\mathrm{k}}$, as evident from complete loss of tail currents, by $293 \mathrm{~B}$ $(100 \mu \mathrm{mol} / \mathrm{L}$ ). In the right panel, the increasing outward current at $40 \mathrm{mV}$ (in the absence of an inward or outward tail current upon repolarization) remained unidentified, but was not $\mathrm{I}_{\mathrm{k}}$. Calibration bars, $1000 \mathrm{~ms}$ and $250 \mathrm{pA}$. In panels $\mathrm{A}, \mathrm{B}$ and $\mathrm{D}$ the horizontal bars left to the traces indicate $0 \mathrm{pA}$. 
A
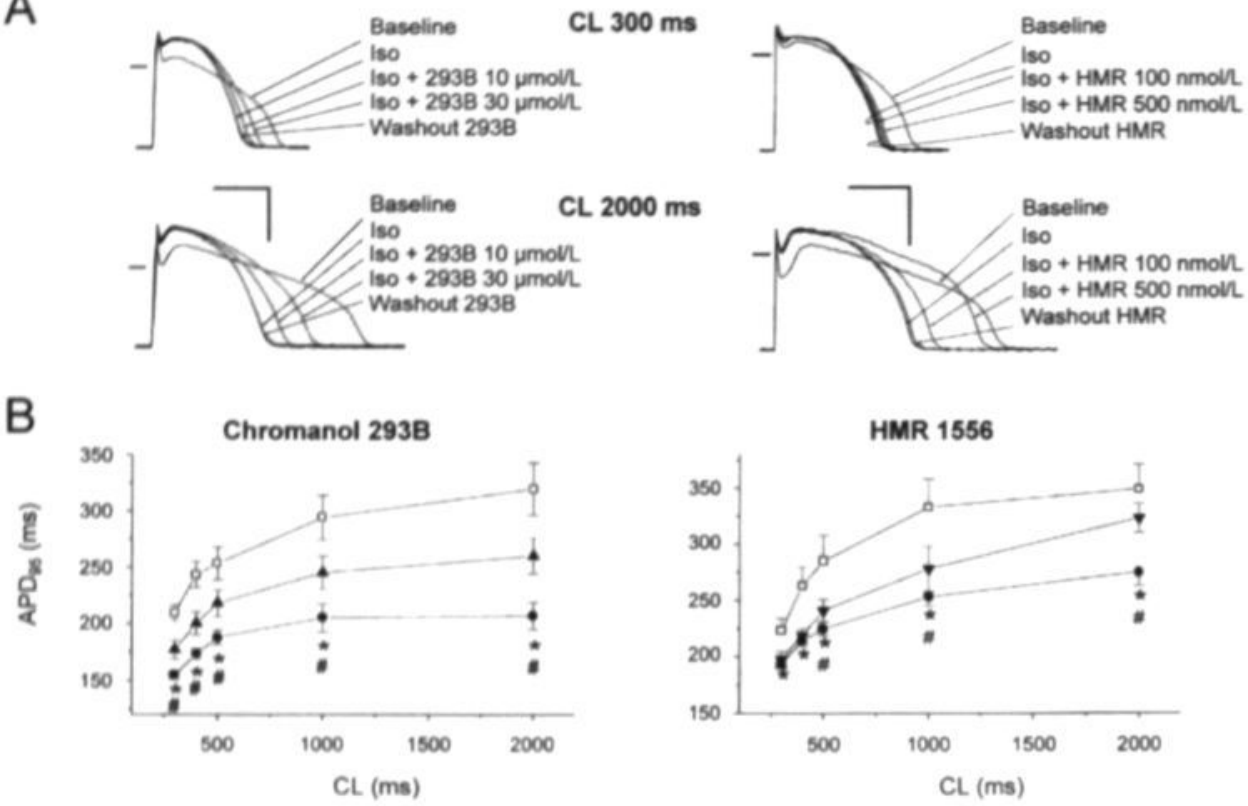

Figure 6 - B-Adrenergic shortening of the ventricular AP is partly reversed by $I_{n}$, block. A, Representative AP traces at CLs 300 and $2000 \mathrm{~ms}$ at baseline and during the subsequent administration of isoproterenol ( 20 or $40 \mathrm{nmol} / \mathrm{L}$ ), isoproterenol plus $\mathrm{I}_{\mathrm{k}}$ blocker 293B or HMR 1556 (concentration indicated), and washout. Calibration bars indicate $100 \mathrm{~ms}$ and $50 \mathrm{mV}$. Left horizontal bars to the APs, $0 \mathrm{mV} . \mathrm{B}, \mathrm{APD}_{9} /$ $\mathrm{CL}$ relations at baseline (open squares), during isoproterenol (filled circles) and during isoproterenol plus $I_{\mathrm{h}}$, blocker (solid triangles). Left panel 293B $(30 \mu \mathrm{mol} / \mathrm{L})$, right panel HMR $1556(500 \mathrm{nmol} / \mathrm{L})$. Symbols indicate $\mathrm{P}<0.05$ of isoproterenol vs baseline $\left(^{*}\right)$ and $v s$ isoproterenol plus $\mathrm{I}_{\mathrm{k}}$ blocker $(\#)$.

tained. These data indicated that $B$-adrenergic receptor stimulation enhanced $\mathrm{I}_{\mathrm{K}}$ directly and via favorable changes of the AP profile.

\section{QT PROLONGATION BY I KS BLOCK IN CONSCIOUS DOGS}

In-vivo experiments were performed in 10 conscious dogs to monitor ECG changes upon single oral administration of HMR 1556 at 3,10 or $30 \mathrm{mg} / \mathrm{kg}$. Regular standard-lead ECGs $(n=6$ dogs) and Holter recordings $(n=4$ dogs $)$ were made. As shown in Figures 7A and 7B, HMR 1556 caused a substantial dose-dependent prolongation of the $\mathrm{QT}_{c}$ interval (Fridericia's formula) within 3 hours of administration. From a baseline interval of $220 \pm 5 \mathrm{~ms}$, maximal QT ${ }_{\mathrm{c}}$ responses at the 3 drug doses were $+11 \pm 1 \%,+34 \pm 5 \%$, and $+65 \pm 15 \%$ relative to placebo values. T waves were broad-based and asymmetrical, and had an unaltered polarity under these conditions (Figure 7B). P-wave and QRS-complex morphology, and PQ and QRS intervals did not alter. Similar observations were made after IV administration. 
A

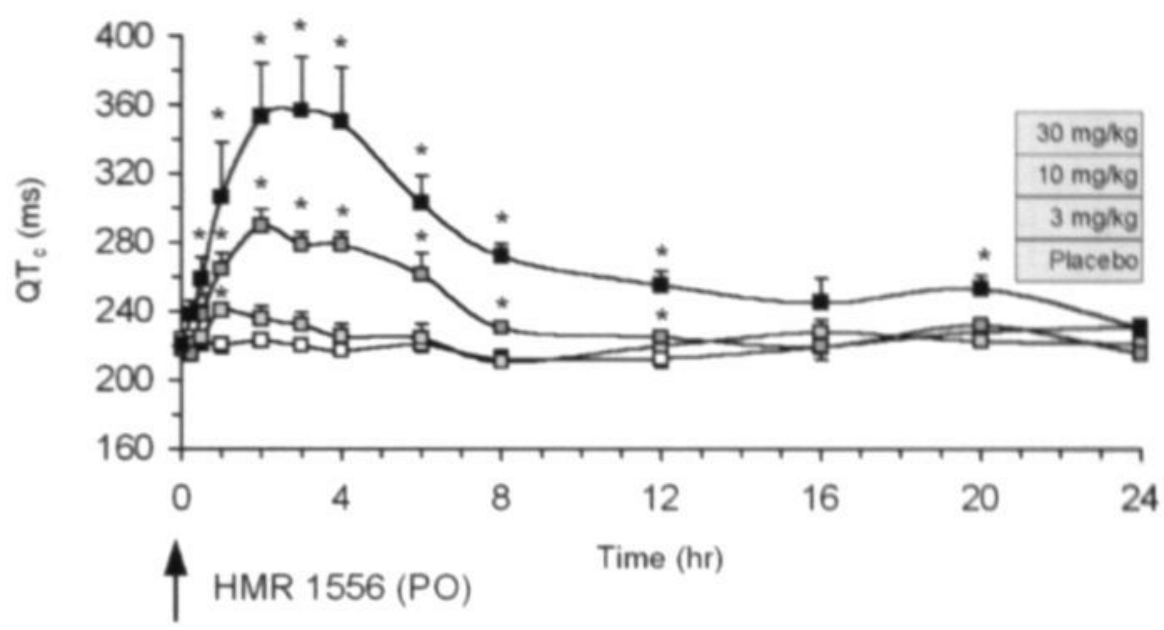

B

\section{Conscious dog, Holter recording}

baseline

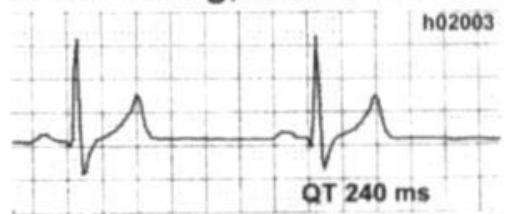

HMR 1556

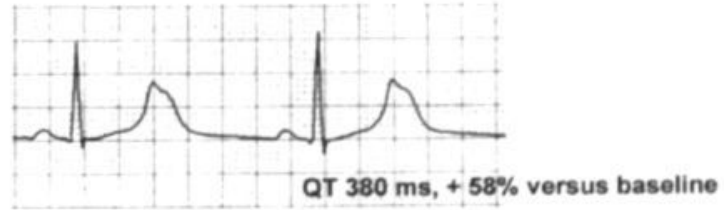

after 21 hours
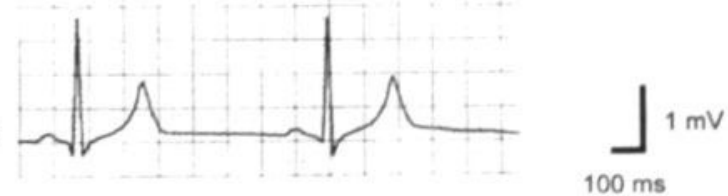

Figure 7 - Dose-dependent QT prolongation by $I_{k}$, block in conscious dogs. A, Mean QT, responses after oral doses of 3,10 and $30 \mathrm{mg} / \mathrm{kg}$ HMR 1556 versus placebo $(0.5 \%$ hydroxyethylcellulose $)$ in 6 animals. ${ }^{\circ}, \mathrm{P}<0.05$. Data obtained at Centre de Recherches Biologiques, Baugy, France. B, Holter recording showing typical changes of the QT interval and $\mathrm{T}$-wave morphology at peak response (middle panel) and 21 hours after $30 \mathrm{mg} / \mathrm{kg}$. In this dog, the highest measured plasma concentration of HMR 1556 was $3.25 \mu \mathrm{mol} / \mathrm{L}$. 


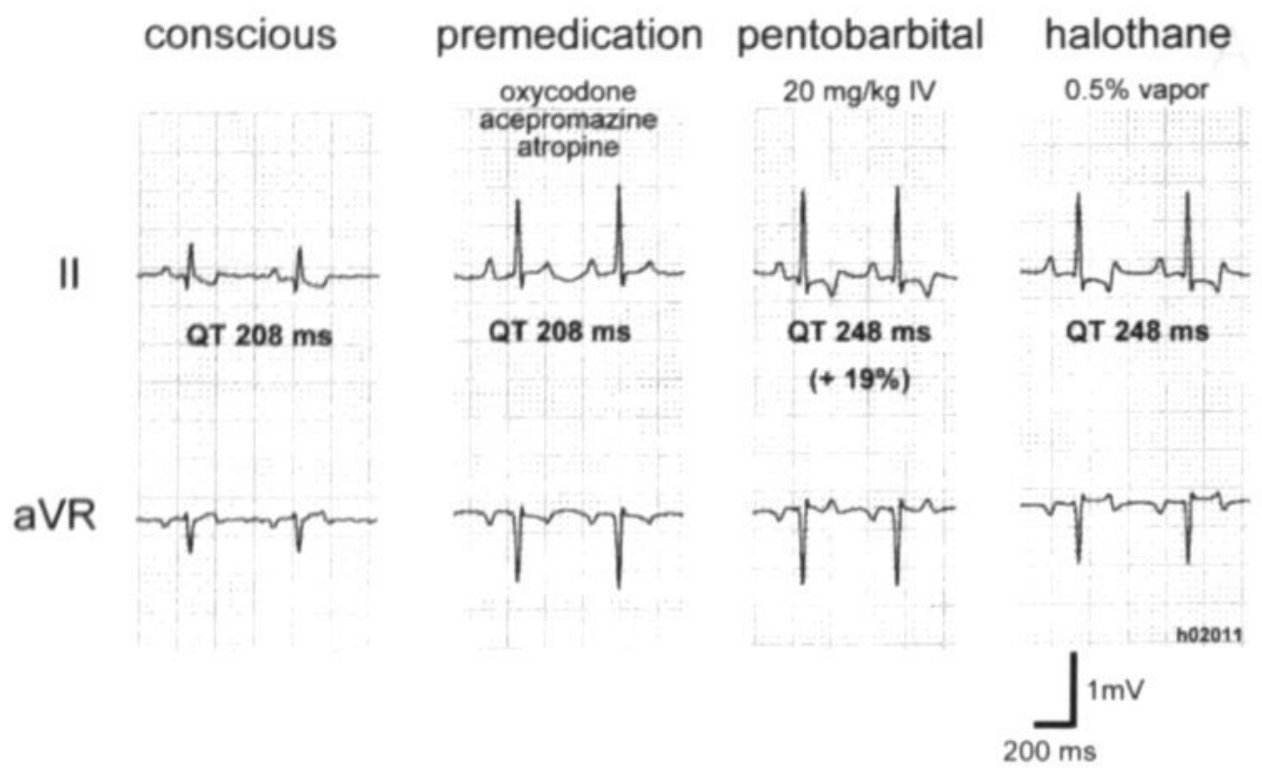

Figure 8 - QT prolongation during transition from conscious to anesthetized state in the dog. Left panel, ECG recording (leads II and aVR) in standing position at conscious state. Other panels, ECG in recumbent position after premedication with oxycodone, acepromazine and atropine, and during anesthesia with sodium pentobarbital and halothane, respectively. Pentobarbital $(20 \mathrm{mg} / \mathrm{kg}$ bolus) caused a $19 \%$ QT prolongation (208 to $248 \mathrm{~ms}$ ) and $\mathrm{T}$-wave inversion. This pattern was unchanged after the addition of halothane as the maintenance anesthetic.

Although most dogs tended to develop a slight drop in heart rate during HMR 1556, this effect was not statistically significant at any dose. After $30 \mathrm{mg} / \mathrm{kg}$ the maximal measured plasma-HMR-1556 concentration was $2.68 \pm 0.55 \mu \mathrm{mol} / \mathrm{L}$. Plasma concentrations returned to zero within 24 hours.

\section{ELECTROPHYSIOLOGICAL EFFECTS OF IV HMR 1556 AND 293 B IN ANESTHETIZED DOGS}

By itself, the transition from conscious to anesthetized state caused a significant QT response, which often exceeded 15\% prolongation (see Figure 8). In 16 anesthetized dogs HMR 1556 or $293 \mathrm{~B}$ caused much less effect on repolarization than under conscious conditions. HMR $1556(1.5 \mathrm{mg} / \mathrm{kg} / 5 \mathrm{~min} \mathrm{IV} ; \mathrm{n}=3 \mathrm{dogs})$ increased the $\mathrm{QT}_{\mathrm{c}}$ interval by only $9 \%$. Under these conditions, the sinus-rhythm CL increased from $605 \pm 70$ to $690 \pm 115 \mathrm{~ms}$, while the QT interval prolonged from $260 \pm 15$ to $300 \pm 20 \mathrm{~ms}$. Endocardial MAP durations (MAPDs) changed accordingly in the LV $(245 \pm 35$ to $280 \pm 40 \mathrm{~ms})$ and RV $(220 \pm 30$ to $245 \pm 30 \mathrm{~ms})$. Plasma analyses revealed a concentration of $2.35 \pm 0.24 \mu \mathrm{mol} / \mathrm{L}$ after $1.5 \mathrm{mg} / \mathrm{kg} \mathrm{HMR} 1556$. 
A
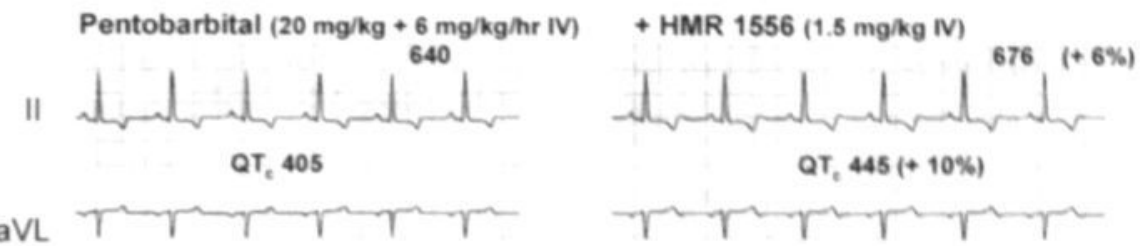

aVL
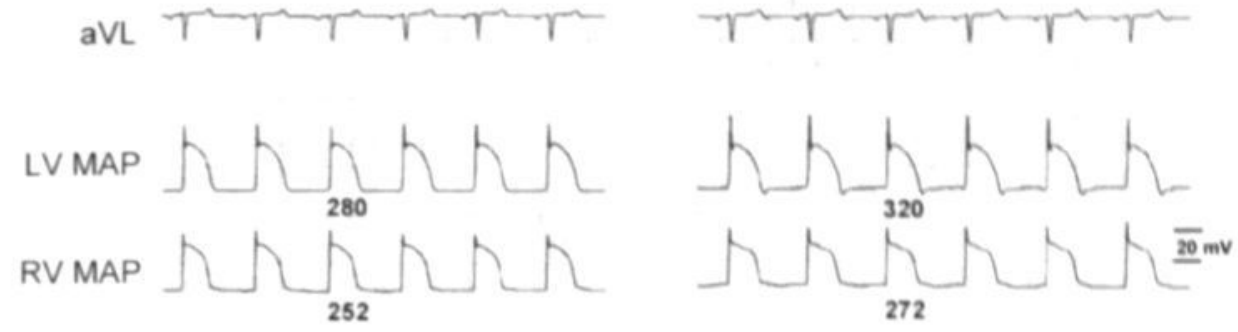

B
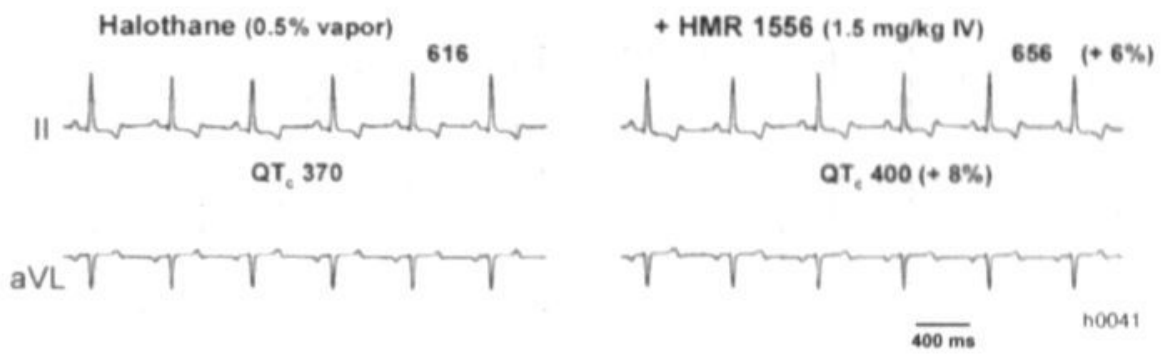

Figure 9- Limited QT response by $\mathrm{I}_{\mathrm{k},}$, block in the anesthetized dog and influence of specific anestherics. A, Effects of HMR $1556(1.5 \mathrm{mg} / \mathrm{kg} / 5 \mathrm{~min}$ IV) during sodium pentobarbital $(20 \mathrm{mg} / \mathrm{kg}$ bolus +6 $\mathrm{mg} / \mathrm{kg} /$ hour IV). Shown are the ECG leads II and aVL, and MAP recordings from the LV and RV. B, Same animal one week later, but now during anesthesia with halothane $(0.5 \%$ vapor after $20 \mathrm{mg} / \mathrm{kg}$ pentobarbital). A and B, HMR 1556 only moderately prolonged the QT interval by 13 and $12 \%$ in pentobarbital and halothane, respectively. When corrected for heart rate, the QT changed by $+10 \%$ and $+8 \%$, indicating much less response compared to conscious state and little difference between the 2 anesthesia regimens. Values in ms.

To determine the influence of specific anesthetics on the repolarization effects of $\mathrm{I}_{\mathrm{Ks}}$ block, HMR $1556(1.5 \mathrm{mg} / \mathrm{kg})$ was applied first during anesthesia with sodium pentobarbital $(20 \mathrm{mg} / \mathrm{kg}$ bolus $+6 \mathrm{mg} / \mathrm{kg} /$ hour IV; Figure $9 \mathrm{~A})$ and one week later with halothane $(0.5 \%$ vapor after $20 \mathrm{mg} / \mathrm{kg}$ sodium pentobarbital; Figure $9 \mathrm{~B})$. At sinus rhythm with CLs of 640 and $616 \mathrm{~ms}$, respectively, QT ${ }_{c}$ changed from 405 to $445 \mathrm{~ms}$ (+10\%; pentobarbital) and from 370 to $400 \mathrm{~ms}$ (+ $8 \%$; halothane), indicating little difference between the 2 anesthesia regimens, but confirming the blunted response to $\mathrm{I}_{\mathrm{Ks}}$ block. In 13 other anesthetized dogs $293 \mathrm{~B}$ was administered. Single or cumulative doses of 1,2 and $5 \mathrm{mg} / \mathrm{kg} / 5 \mathrm{~min}$ IV produced no significant QT or APD effects during sinus rhythm (see Figure 10) or at pacing CLs of 300, 400 and $500 \mathrm{~ms}$. At $10 \mathrm{mg} / \mathrm{kg}$ the QT interval prolonged by $8 \pm 1 \%$. During administration of $1+2+5 \mathrm{mg} / \mathrm{kg}$ (30 min apart), 293B-plasma concentrations rose to maximally $21 \pm 2 \mu \mathrm{mol} / \mathrm{L}$ ( $\mathrm{n}=5 \mathrm{dogs}$; Figure 10), which is $>2 \times \mathrm{IC}_{50}$ for in-vitro $\mathrm{I}_{\mathrm{Ks}}$ block. 


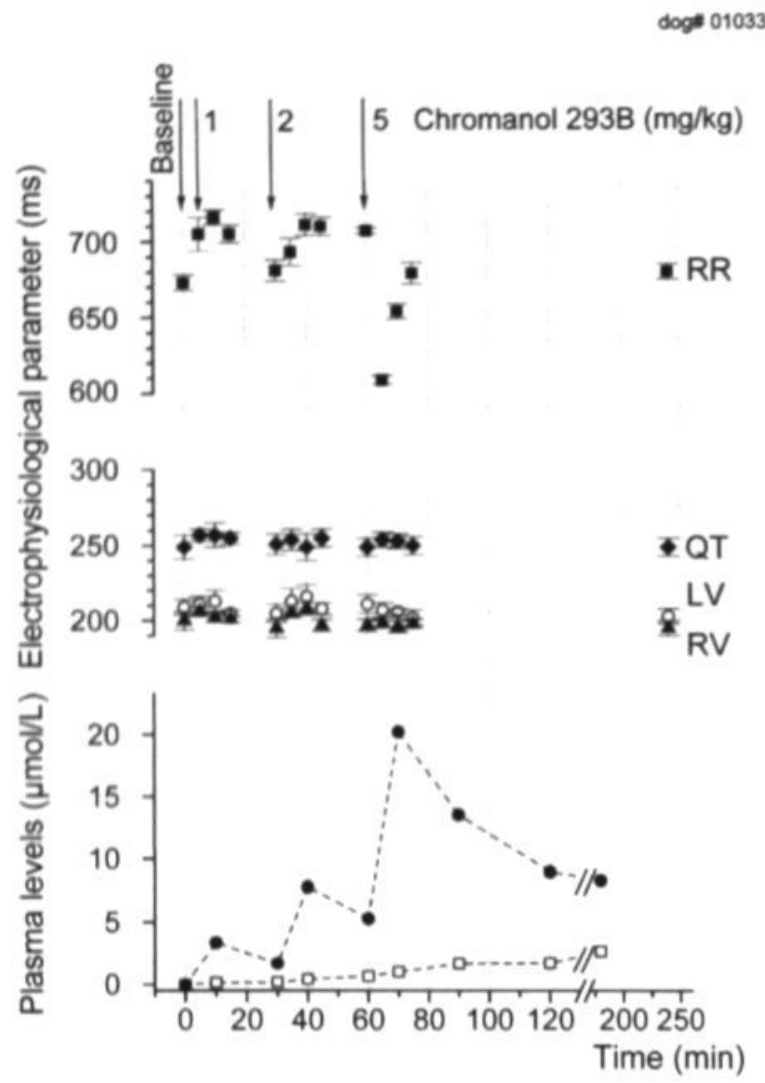

Figure 10 - Dose-response relations on 293B in an anesthetized dog with sinus rhythm. Upon IV infusions at cumulative doses of 1,2 and $5 \mathrm{mg} / \mathrm{kg} / 5 \mathrm{~min}$, venous-plasma concentrations of 293B (filled circles) and its metabolite S88-1690 (open squares) were monitored for 3 hours (lower part of figure). The maximal plasma concentration measured just after $1+2+5 \mathrm{mg} / \mathrm{kg} / 5 \mathrm{~min}$ was $20.3 \mu \mathrm{mol} / \mathrm{L}$. There was a relatively rapid decline of $293 \mathrm{~B}$ levels within $=30 \mathrm{~min}$ after infusion, followed by a phase with slow decrease. At the latest sample point of $180 \mathrm{~min}$ (110 min after last infusion) $293 \mathrm{~B}$ measured $9 \pm 2$ $\mu \mathrm{mol} / \mathrm{L}$, whereas its metabolite $S 88-1690$ had steadily increased to $5 \pm 1 \mu \mathrm{mol} / \mathrm{L}$ in plasma. In the upper part are depicted: sinus-rhythm CL. (RR; closed squares), QT time (filled diamonds), and LV (open circles) and RV (solid triangles) MAPDs. No significant changes in repolarization parameters were observed at increasing drug concentrations. S88-1690 has no effect on $\mathrm{I}_{\mathrm{h} .}\left(\mathrm{IC}_{\mathrm{x}}>100 \mu \mathrm{mol} / \mathrm{L}\right)$.

In an attempt to maximally enhance in-vivo $\mathrm{I}_{\mathrm{K} s}$ we combined bradycardia, repolarization preprolongation with $\mathrm{I}_{\mathrm{Kr}}$ block and $B$-adrenergic receptor stimulation in the same experiment (see Figure 11). During acute complete atrioventricular block with fixed-rate RV pacing at RR $1200 \mathrm{~ms}$ to maintain a steady-state heart rate, almokalant and isoproterenol ( $2 \mu \mathrm{g} / \mathrm{min}$ continuous infusion) were consecutively administered. Under these conditions, the addition of $293 \mathrm{~B}(5 \mathrm{mg} / \mathrm{kg})$ increased the QT time from $410 \pm 1$ to $470 \pm 2 \mathrm{~ms}(+15 \%)$, LV MAPD from $370 \pm 2$ to $415 \pm 2$ $\mathrm{ms}(+12 \%)$, and RV MAPD from $320 \pm 1$ to $370 \pm 1 \mathrm{~ms}(+16 \%)$. 


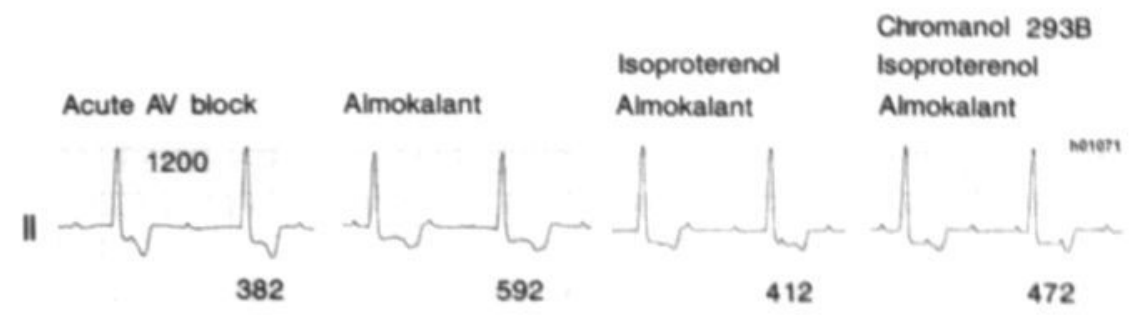

AVL
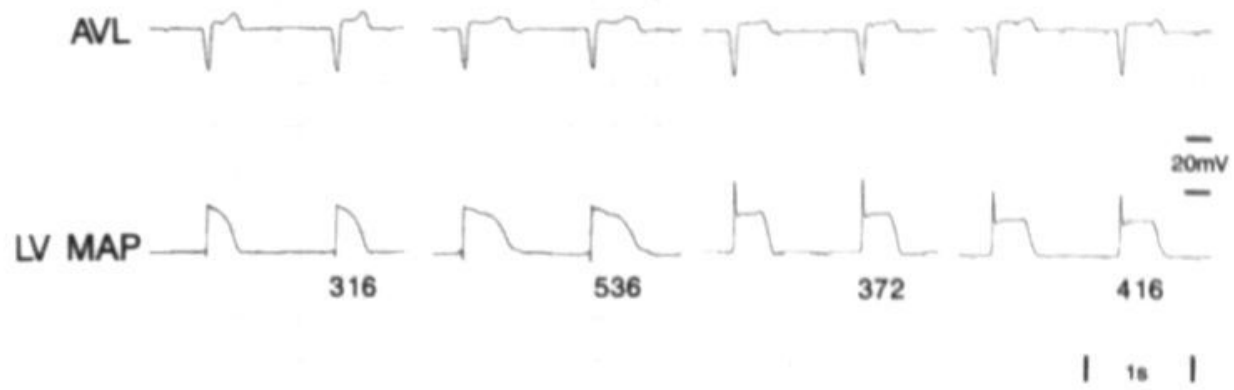

Figure 11 - Repolarization-delaying effect of 293B in an anesthetized dog subjected to interventions aimed at maximally enhancing $\mathrm{I}_{\mathrm{k}}$. First, acute complete atrioventricular (AV) block and RV pacing were applied to achieve fixed-rate bradycardia at a CL of $1200 \mathrm{~ms}$ throughout the experiment. Secondly, the $I_{\mathrm{k},}$ blocker almokalant $(0.12 \mathrm{mg} / \mathrm{kg} / 5 \mathrm{~min})$ was administered, which prolonged the QT time from 382 to $592 \mathrm{~ms}$ and the LV MAP from 316 to $536 \mathrm{~ms}$. Isoproterenol was then infused at $2 \mu \mathrm{g} / \mathrm{min}$, and this caused repolarization shortening at maintained CL of $1200 \mathrm{~ms}$ (no breakthrough chronotropic effect). Under these specific conditions IV 293B ( $5 \mathrm{mg} / \mathrm{kg} / 5 \mathrm{~min}$ ) caused a repolarization-delaying effect: the QT time increased from 412 to $472 \mathrm{~ms}$ (+15\%), whereas LV MAP increased from 372 to $416 \mathrm{~ms}(+12 \%)$.

\section{DISCUSSION}

The results of the present study indicate that: (1) under baseline conditions in ventricular myocytes adrenergically-unstimulated $\mathrm{I}_{\mathrm{Ks}}$ does not contribute significantly to repolarization, because its activation is restrained by the voltage and time domains of the AP. Accordingly, drug-induced $\mathrm{I}_{\mathrm{Ks}}$ inhibition does not prolong the cellular AP at baseline; (2) $\mathrm{I}_{\mathrm{Ks}}$ becomes prominent during $\mathrm{I}_{\mathrm{Kr}}$ block when it limits repolarization prolongation and instability by time-dependent activation, and during $B$-adrenergic receptor stimulation when it promotes AP shortening by increased and accelerated activation; (3) $\mathrm{I}_{\mathrm{Ks}}$ is a major contributor to ventricular repolarization in conscious dogs. 


\section{KINETICS OF IKS ACTIVATION PRECLUDE A SIGNIFICANT CONTRIBUTION TO CELLULAR REPOLARIZATION AT BASELINE}

Among the known sarcolemmal $\mathrm{K}^{+}$currents, the slowly-activating delayed rectifier $\mathrm{K}^{+}$current $\mathrm{I}_{\mathrm{K} s}$ has distinctively slow activation kinetics, and a unique pharmacological responsiveness, B-adrenergic sensitivity and regional myocardial distriburtion. ${ }^{15,19,22,23}$ In our recordings $\mathrm{I}_{\mathrm{Ks}}$ appeared as a robust outward current during seconds-long depolarizations. Slow activation and rapid deactivation kinetics typically characterized it. At pulses to $20 \mathrm{mV}$, half-maximal activation was reached at $\approx 700$ $\mathrm{ms}$ with little current generated in the first $100 \mathrm{~ms}$ of depolarization. Half-times for complete deactivation were as short as $40 \mathrm{~ms}$ at $-80 \mathrm{mV}$ (in line with ${ }^{18}$ ). Accumulation of $\mathrm{I}_{\mathrm{Ks}}$, on the basis of incomplete deactivation at the resting $\mathrm{V}_{\mathrm{m}}$, would thus be expected to occur only at very fast heart rates or short-coupled ES intervals. Indeed we found that for square-pulse clamps $(20 \mathrm{mV})$ of 100,200 , and $500 \mathrm{~ms} \mathrm{I}_{\mathrm{Ks}}$ accumulated only if the interpulse interval $<100 \mathrm{~ms}$, whereas little or no augmentation was seen at longer intervals. Short-coupled extrastimulus APs were not prolonged by 293B and neither were the APs at fast steady-state pacing rates. This can be explained by inferring that in APs, unlike square pulses, the time to repolarize from maximal plateau amplitudes to resting $\mathrm{V}_{\mathrm{m}}(>200 \mathrm{~ms}$ for CLs $\geq 400 \mathrm{~ms})$ is sufficient for complete deactivation of poorly-activated $\mathrm{I}_{\mathrm{K} s}$, as shown before. ${ }^{8} \mathrm{Lu}$ et al ${ }^{5}$ made related observations in a direct comparison of $\mathrm{I}_{\mathrm{K} s}$ accumulations in ventricular myocytes from rabbit and guinea pig. During $3-\mathrm{Hz}$ pacing of $200-\mathrm{ms}$ pulses little current augmentation was seen in the rabbit with relatively fast deactivation, whereas in guinea pig (the prototype of species with a large $\mathrm{I}_{\mathrm{Ks}}$ and slow deactivation) accumulation was marked. The finding that 293B left the APD / CL relation unaltered indicates that ion currents other than $\mathrm{I}_{\mathrm{Ks}}$ play a role in reverse-rate dependence in canine ventricular myocardium. ${ }^{18}$ The recent demonstration of fast deactivation kinetics in human ventricular myocytes ${ }^{23}$ underscores the clinical relevance of our data.

Previous studies showed that $293 \mathrm{~B}$ prolonged the APD of isolated rabbit ${ }^{5}$ and human ventricular myocytes. ${ }^{7}$ In both studies repolarization was already affected during phase 1 of the AP. Given the slow activation of $I_{K}$, we believe that this early AP effect expressed 293B's inhibition of other ion current(s), although we cannot exclude that block of $\mathrm{I}_{\mathrm{Ks}}$ later during repolarization contributed to the prolongation. Other groups reported minimal or no AP prolongation in rabbit ventricular tissue during administration of $\mathrm{L}-735,821$ or $293 \mathrm{~B} .{ }^{10,11}$

\section{IKS BECOMES PROMINENT DURING IKR BLOCK AND B-ADRENERGIC RECEPTOR STIMULATION}

In Poincaré plots of prolonged APDs during $\mathrm{I}_{\mathrm{K}_{\mathrm{r}}}$ block with almokalant we noted an exaggeration of repolarization instability when $293 \mathrm{~B}$ was also added. This strongly suggested that time-dependent activation of $\mathrm{I}_{\mathrm{K}}$ is recruited when other influences 
cause excessive AP prolongation. ${ }^{8,24}$ Such protective role would be enhanced during naturally-stimulated or drug-induced $\mathrm{I}_{\mathrm{Ks}}$ increases. ${ }^{25}$ B-Adrenergic receptor stimulation increased and accelerated $\mathrm{I}_{\mathrm{K}}$ activation, so that it became relevant for AP shortening. Even during very short clamp pulses of $100 \mathrm{~ms}$, which were generally not sufficient to activate basal $\mathrm{I}_{\mathrm{K}}$, isoproterenol brought the current to significant amplitude. Inferentially, the isoproterenol-induced AP plateau elevation and AP prolongation at $\mathrm{V}_{\mathrm{m}}>0 \mathrm{mV}$ also increased $\mathrm{I}_{\mathrm{Ks}}$. Consequent shortening of $\mathrm{APD}_{95}$ was partly reversed by HMR 1556 and 293B, whereas no AP prolongation had been demonstrable in the same cells at baseline.

Antzelevitch et al provided the important insight that $\mathrm{I}_{\mathrm{Ks}}$ block combined with B-adrenergic receptor stimulation in canine left ventricular wedge preparations increases transmural dispersion of repolarization and can induce polymorphic tachyarrhythmias. ${ }^{6}$ These investigators reported homogeneous prolongations of transmural APDs by 293B at baseline, ${ }^{6,26}$ which appears to be in contrast with our present finding that cellular APs were not prolonged (Figure 1). We assume that in ventricular wedge preparations residual adrenergic activity remains present for considerable time after excision of the tissue. For example, norepinephrine is progressively released after $\geq 5$ to $10 \mathrm{~min}$ of no-flow ischemia and reperfusion in excised cardiac tissue of various species, ${ }^{27}$ including human ${ }^{28}$ and dog. ${ }^{25}$ This could mean that adrenergically-stimulated, not basal, $\mathrm{I}_{\mathrm{Ks}}$ is inhibited in wedge preparations.

\section{SELECTIVITY AND POTENCY OF IKS BLOCKERS 293B AND HMR 1556}

Selective $\mathrm{I}_{\mathrm{Ks}}$-blocking agents have only become available since 1995 (modified chromanols), 1996 (modified benzodiazepines), and 2000 (modified benzamides). ${ }^{30}$ In 2 studies, the chromanol $293 \mathrm{~B}$ inhibited $\mathrm{I}_{\mathrm{K}_{s}}$ of guinea-pig ventricular myocytes at $\mathrm{IC}_{50}$ values of $2.1 \mu \mathrm{mol} / \mathrm{L}^{31}$ and $1.02 \mu \mathrm{mol} / \mathrm{L}$. $\mathrm{I}_{\mathrm{TO}}$ of human ventricular myocytes was half-maximally inhibited at $24 \mu \mathrm{mol} / \mathrm{L}$, whereas guinea-pig $\mathrm{I}_{\mathrm{Kr}}, \mathrm{I}_{\mathrm{Kl}}, \mathrm{I}_{\mathrm{Na}}$ and $\mathrm{I}_{\mathrm{CaL}}$ were unaffected even at $50 \mu \mathrm{mol} / \mathrm{L}$. ${ }^{5}$ Sun et al ${ }^{17}$ reported similar values in canine left ventricular myocytes: $293 \mathrm{~B}$ blocked $\mathrm{I}_{\mathrm{Ks}}$ with an $\mathrm{IC}_{50}$ of $1.8 \mu \mathrm{mol} / \mathrm{L}$ and $\mathrm{I}_{\mathrm{TO}}$ with an $\mathrm{IC}_{50}$ of $38 \mu \mathrm{mol} / \mathrm{L}$, indicating a 20 -fold selectivity for $\mathrm{I}_{\mathrm{Ks}}$. Concentrations of 30 $\mu \mathrm{mol} / \mathrm{L}$ did not affect $\mathrm{I}_{\mathrm{Kr}}, \mathrm{I}_{\mathrm{K} 1}$ and $\mathrm{I}_{\mathrm{CaL}}$. Our present data show a somewhat higher $\mathrm{IC}_{50}$ of $8 \mu \mathrm{mol} / \mathrm{L}$ for $\mathrm{I}_{\mathrm{Ks}}$ inhibition by 293B. The more potent chromanol HMR 1556 blocked $\mathrm{I}_{\mathrm{Ks}}$ of guinea-pig ventricular myocytes half-maximally at $34 \mathrm{nmol} / \mathrm{L}$, whereas $\mathrm{I}_{\mathrm{Kr}}$ and $\mathrm{I}_{\mathrm{K} 1}$ were not decreased at $1 \mu \mathrm{mol} / \mathrm{L}$ and only slightly $\left(\mathrm{I}_{\mathrm{Kr}}\right.$ by $\left.15 \%\right)$ at $10 \mu \mathrm{mol} / \mathrm{L}$. ${ }^{16}$ The same accounted for rat $\mathrm{I}_{\mathrm{TO}}$ : no decrease at $1 \mu \mathrm{mol} / \mathrm{L}$ and $25 \%$ inhibition at $10 \mu \mathrm{mol} / \mathrm{L}$. ${ }^{16}$ These results indicated that HMR 1556 was much more selective for $\mathrm{I}_{\mathrm{Ks}}$ than 293B. In canine ventricular myocytes we found an $\mathrm{IC}_{50}$ of 65 $\mathrm{nmol} / \mathrm{L}$ (this study). 


\section{IKS IS A MAJOR CONTRIBUTOR TO VENTRICULAR REPOLARIZATION IN CONSCIOUS DOGS}

Our in-vivo results with HMR 1556 in conscious dogs indicate that the QT interval can prolong quite dramatically by $\mathrm{I}_{\mathrm{Ks}}$ inhibition. QT responses were dose-dependent at 3,10 and $30 \mathrm{mg} / \mathrm{kg}$. After oral administration of $30 \mathrm{mg} / \mathrm{kg}$, maximal QT prolongations ranged from 32 to $129 \%$ in different animals (mean $65 \pm 15 \%$; Figure 7 ). According to earlier data, ${ }^{16}$ HMR 1556 would still be highly selective for $\mathrm{I}_{\mathrm{Ks}}$ at the measured plasma concentration of $2.68 \pm 0.55 \mu \mathrm{mol} / \mathrm{L}$ (after $30 \mathrm{mg} / \mathrm{kg}$ ), and thus we believe that the observed repolarization effects are in major part due to an inhibition of $\mathrm{I}_{\mathrm{Ks}}$. Other investigators administered the benzodiazepine-derived $\mathrm{I}_{\mathrm{Ks}}$ blocker $\mathrm{L}-768,673\left(\mathrm{IC}_{50}=6 \mathrm{nmol} / \mathrm{L}^{32}\right.$ ) to conscious dogs and found a dose-dependent QT prolongation of 5 to $15 \%$ at 0.03 to $1.0 \mathrm{mg} / \mathrm{kg}$. ${ }^{32}$ The oral bioavailibility of L-768, 673 in methocell suspension was only $27 \%$ and plasma concentrations were not reported. Therefore, we cannot compare these QT responses with our own findings. Subsequent experiments with $\mathrm{L}-768,673(0.03 \mathrm{mg} / \mathrm{kg})$ in exercising dogs with healed anterior-wall myocardial infarction and superimposed ischemia (transient occlusion of left circumflex coronary artery) demonstrated the drug's efficacy against ventricular fibrillation, even at a modest $7 \%$ increase in $\mathrm{QT}_{\mathrm{c}}$ at baseline. ${ }^{33}$ It is tempting to speculate that cardiac sympathetic activity was intense but dispersed during exercise and regional ischemia, and that L-768,673 prevented arrhythmogenic dispersion of repolarization by attenuating adrenergically-sensitive $\mathrm{I}_{\mathrm{Ks}}$.

In anesthetized dogs the $\mathrm{QT}_{\mathrm{c}}$ interval and local MAPDs prolonged by only $\approx$ $10 \%$ at IV doses of $1.5 \mathrm{mg} / \mathrm{kg}$ HMR 1556 and $10 \mathrm{mg} / \mathrm{kg} \mathrm{293B}$. Plasma analyses of HMR 1556 ruled out that drug concentrations were lower in anesthetized than conscious dogs. Rather, the repolarization data indicated that $\mathrm{I}_{\mathrm{Ks}}$ was depressed or less responsive during anesthesia. We considered 2 possible causes: (1) the anesthetic drugs pentobarbital and/or halothane had a direct blocking effect on $I_{K s} ;(2)$ anesthesia-induced attenuation of cardiac sympathetic tone decreased adrenergic stimulation of $\mathrm{I}_{\mathrm{K}_{s}}$. Sun et al ${ }^{34}$ found significant reductions of $\mathrm{I}_{\mathrm{Ks}_{s}}(-50 \%), \mathrm{I}_{\mathrm{Kr}}(-20 \%), \mathrm{I}_{\mathrm{K} 1}$ $(-40 \%)$, and late $\mathrm{I}_{\mathrm{Na}}(-50 \%)$ in canine ventricular myocytes superfused with 20 $\mu \mathrm{g} / \mathrm{mL}$ pentobarbital. Likewise, Bachmann et $\mathrm{al}^{35}$ recently showed that pentobarbital suppressed both cloned $\mathrm{I}_{\mathrm{K}}$ and $\mathrm{I}_{\mathrm{Kir} 2.2}$, and native $\mathrm{I}_{\mathrm{K}}$ and $\mathrm{I}_{\mathrm{K} 1}$ in guinea pig ventricular myocytes, with the highest affinity for $\mathrm{I}_{\mathrm{Ks}}$. Other studies (although none in canine ventricular myocytes) showed that halothane depressed $\mathrm{I}_{\mathrm{K}}$ (and other ion currents) in guinea-pig cardiac cells, ${ }^{36}$ and $\mathrm{I}_{\operatorname{minK}}$ in Xenopus oocytes. ${ }^{37}$ Thus, a direct blocking effect on $\mathrm{I}_{\mathrm{Ks}}$ could well be present. In addition, we found that despite the possible inhibition of $\mathrm{I}_{\mathrm{K}}$ by anesthetics (Figure 8), its contribution to ventricular repolarization could still be increased by appropriate (including B-adrenergic) stimuli (see Figure 11). This, together with the much more pronounced contribution of $\mathrm{I}_{\mathrm{K}}$ under conscious conditions when cardiac sympathetic tone is normal, strongly 
suggested that $B$-adrenergic stimulation is a major determinant of $I_{K s}$ function, in line with the cellular data.

Finally, Bauer and coworkers ${ }^{38}$ reported on the effects of $10 \mathrm{mg} / \mathrm{kg} 293$ B in anesthetized dogs with acute complete atrioventricular block, demonstrating that ventricular effective refractory periods were more prolonged at fast (CL. $300 \mathrm{~ms}$ ) than at slow (CL $850 \mathrm{~ms}$ ) pacing rates. In dogs with subacute myocardial infarction, 293B prolonged local effective refractory periods more in the infarct zone than in normal areas. ${ }^{39}$ Unfortunately, no QT-interval or MAPD data were provided. These results appear to contrast with our finding that QT times, and transmembrane and monophasic APDs were not prolonged by $I_{K s}$ block at fast pacing rates. However, we have to consider the possibility that the experimental situation of thoracotomy, acute heart block and 36 transmurally-inserted needle electrodes caused high catecholamine levels that facilitated $\mathrm{I}_{\mathrm{Ks}}$ accumulation during fast pacing rates, explaining the observations by Bauer et al.

In conclusion, both our cellular and in-vivo data highlight the prominent role of $\mathrm{I}_{\mathrm{Ks}}$ in canine ventricular repolarization. $\mathrm{I}_{\mathrm{Ks}}$ limits excessive AP prolongation by time-dependent activation during $\mathrm{I}_{\mathrm{Kr}}$ block and under other circumstances when repolarization is delayed. $\mathrm{I}_{\mathrm{K}}$ shortens the APD by increase and acceleration of activation during $B$-adrenergic receptor stimulation. The synergism between an intact basal $\mathrm{I}_{\mathrm{Ks}}$ and a balanced sympathetic nervous function promotes a short and homogeneous repolarization of the ventricles.

\section{ACKNOWLEDGMENTS}

P.G.A.V. is supported by The Netherlands Organization for Health Research and Development (ZonMw 906-02-068). The authors express their gratitude to Dr. Wolfgang Ulmer and Dr. Dietmar Schmidt (Aventis Pharma, Frankfurt / Main, Germany) for performing the HMR-1556- and 293B-plasma analyses. The authors wish to thank Dr. Alexander Bauer and Professors Edward Carmeliet, André Kleber and Michael Rosen for helpful discussions.

\section{REFERENCES}

1. Wang Q, Curran ME, Splawski I, Burn TC, Millholland JM, VanRaay TJ, Shen J, Timothy KW, Vincent GM, de Jager T, Schwartz PJ, Towbin JA, Moss AJ, Atkinson DL, Landes GM, Connors TD, Keating MT. Positional cloning of a novel potassium channel gene: KVLQTI mutations cause cardiac arrhythmias. Nat Genet. 1996;12:17-23.

2. Splawski I, Tristani-Firouzi M, Lehmann MH, Sanguinetti MC, Keating MT. Mutations in the hminK gene cause long QT syndrome and suppress I Ks function. Nat Genet. 1997;17:338-340. 
3. Volders PGA, Sipido KR, Vos MA, Spärjens RLHMG, Leunissen JDM, Carmeliet E, Wellens HJJ. Downregulation of delayed rectifier $\mathrm{K}^{+}$currents in dogs with chronic complete atrioventricular block and acquired torsades de pointes. Circulation. 1999;100:2455-2461.

4. Tsuji Y, Opthof T, Kamiya K, Yasui K, Liu W, Lu Z, Kodama I. Pacing-induced heart failure causes a reduction of delayed rectifier potassium currents along with decreases in calcium and transient outward currents in rabbit ventricle. Cardiovasc Res. 2000;48:300-309.

5. Lu Z, Kamiya K, Opthof T, Yasui K, Kodama I. Density and kinetics of $\mathrm{I}_{\mathrm{Kr}}$ and $\mathrm{I}_{\mathrm{Ks}}$ in guinea pig and rabbit ventricular myocytes explain different efficacy of $\mathrm{I}_{\mathrm{Ks}_{s}}$ blockade at high heart rate in guinea pig and rabbit: implications for arrhythmogenesis in humans. Circulation. 2001;104:951-956.

6. Shimizu W, Antzelevitch C. Cellular basis for the ECG features of the LQT1 form of the long-QT syndrome: effects of B-adrenergic agonists and antagonists and sodium channel blockers on transmural dispersion of repolarization and torsade de pointes. Circulation. 1998;98:2314-2322.

7. Bosch RF, Gaspo R, Busch AE, Lang HJ, Li GR, Nattel S. Effects of the chromanol 293B, a selective blocker of the slow, component of the delayed rectifier $\mathrm{K}^{+}$current, on repolarization in human and guinea pig ventricular myocytes. Cardiovase Res. 1998;38:441-450.

8. Varró A, Baláti B, lost N, Takács J, Virág L, Lathrop DA, Csaba L, Tálosi L, Papp JG. The role of the delayed rectifier component $\mathrm{I}_{\mathrm{Ks}}$ in dog ventricular muscle and Purkinje fibre repolarization. $J$ Physiol. 2000;523:67-81.

9. Fiset C, Drolet B, Hamelin BA, Turgeon J. Block of $\mathrm{I}_{\mathrm{Ks}}$ by the diuretic agent indapamide modulates cardiac electrophysiological effects of the class III antiarrhythmic drug dl-sotalol. J Pharmacol Exp Ther. 1997;283:148-156.

10. Lengyel C, lost N, Virág L, Varró A, Lathrop DA, Papp JG. Pharmacological block of the slow component of the outward delayed rectifier current $\left(\mathrm{I}_{\mathrm{Ks}}\right)$ fails to lengthen rabbit ventricular muscle QT ${ }_{c}$ and action potential duration. Br J Pharmacol. 2001;132:101-110.

11. Pham TV, Sosunov EA, Gainullin RZ, Danilo P, Jr, Rosen MR. Impact of sex and gonadal steroids on prolongation of ventricular repolarization and arrhythmias induced by $\mathrm{I}_{\mathrm{K}}$-blocking drugs. Circulation. 2001;103:2207-2212.

12. Varró A, Lathrop DA, Papp JG. Role of the delayed rectifier component $\mathrm{I}_{\mathrm{Ks}}$ in cardiac repolarization. / Cardiovasc Electrophysiol. 2001;12:1204-1205.

13. Sun ZQ. Thomas G. Antzelevitch C. Role of the delayed rectifier component $I_{K s}$ in cardiac repolarization [reply]. J Cardiovasc Electrophysiol. 2001;12:1205-6.

14. Han W, Wang Z, Nattel S. Slow delayed rectifier current and repolarization in canine cardiac Purkinje cells. Am J Physiol. 2001;280:H1075-H1080.

15. Volders PGA, Sipido KR, Carmeliet E, Spätjens RLHMG, Wellens HJJ, Vos MA. Repolarizing $\mathrm{K}^{*}$ currents $\mathrm{I}_{\mathrm{TO}}$ and $\mathrm{I}_{\mathrm{Ks}}$ are larger in right than left canine ventricular midmyocardium. Circulation. 1999:99:206-210.

16. Gögelein H, Brüggemann A, Gerlach U, Brendel J, Busch AE. Inhibition of $\mathrm{I}_{\mathrm{Ks}}$ channels by HMR 1556. Naunyn-Schmiedeberg's Anch Pharmacol. 2000;362:480-488.

17. Sun ZQ, Thomas GP, Antzelevitch C. Chromanol 293B inhibits slowly activating delayed rectifier and transient outward currents in canine left ventricular myocytes. / Cardionass Electrophysiol. 2001:12:472-478. 
18. Gintant GA. Two components of delayed rectifier current in canine atrium and ventricle: does $\mathrm{I}_{\mathrm{Ks}}$ play a role in the reverse rate dependence of class III agents? Cin Res. 1996;78:26-37.

19. Salata JJ, Jurkiewicz NK, Jow B, Folander K, Guinosso PJ, Jr, Raynor B, Swanson R. Fermini B. $\mathrm{I}_{\mathrm{K}}$ of rabbit ventricle is composed of two currents: evidence for $\mathrm{I}_{\mathrm{Ks}}$. Am J Physiol. 1996;271:H2477-H2489.

20. Walsh KB, Begenisich TB, Kass RS. Beta-adrenergic modulation of cardiac ion channels: differential temperature sensitivity of potassium and calcium currents. J Gen Plysiol. 1989;93:841-854.

21. Sanguinetti MC, Jurkiewicz NK, Scott A, Siegl PKS. Isoproterenol antagonizes prolongation of refractory period by the class $\mathrm{III}$ antiarrhythmic agent $\mathrm{E}-4031$ in guinea pig myocytes: mechanism of action. Circ Res. 1991;68:77-84.

22. Liu DW, Antzelevitch C. Characteristics of the delayed rectifier current $\left(\mathrm{I}_{K_{r}}\right.$ and $\left.\mathrm{I}_{\mathrm{Ks}}\right)$ in canine ventricular epicardial, midmyocardial, and endocardial myocytes: a weaker $\mathrm{I}_{\mathrm{Ks}}$ contributes to the longer action potential of the M cell. Circ Res. 1995:76:351-365.

23. Virág L, Iost N, Opincariu M, Szolnoky J, Szécsi J, Bogáts G, Szenohradszky P, Varró A, Papp JG. The slow component of the delayed rectifier potassium current in undiseased human ventricular myocytes. Cardiovasc Res. 2001:49:790-797.

24. Burashnikov A, Antzelevitch C. Prominent $\mathrm{I}_{\mathrm{Ks}}$ in epicardium and endocardium contributes to development of transmural dispersion of repolarization but protects against development of early afterdepolarizations. J Cardiovasc Electrophysiol. 2002;13:172-177.

25. Salata JJ, Jurkiewicz NK, Wang J, Evans BE, Orme HT, Sanguinetri MC. A novel benzodiazepine that activates cardiac slow delayed rectifier $\mathrm{K}^{+}$currents. Mol Pharmacol. 1998;54:220-230.

26. Burashnikov A, Antzelevitch C. Block of $\mathrm{I}_{\mathrm{Ks}}$ does not induce early afterdepolarization activity but promotes B-adrenergic agonist-induced delayed afterdepolarization activity. I Cardiovasc Electrophysiol. 2000;11:458-465.

27. Schömig A. Catecholamines in myocardial ischemia: systemic and cardiac release. Circulation. 1990;82(suppl II):II-13-II-22.

28. Kurz T, Richardt G, Seyfarth M, Schömig A. Nonexocytotic noradrenaline release induced by pharmacological agents or anoxia in human cardiac tissue. Naunyn-Schmiedeberg's Arch Pharmacol. 1996;354:7-16.

29. Seya K, Daitoku K, Motomura S. Norepinephrine measurement in the isolated, blood-perfused papillary muscle of the dog by using ex vivo microdialysis. J Pharmacol Toxicol. 1999:42:149-155.

30. Gerlach U. $\mathrm{I}_{\mathrm{Ks}}$ channel blockers: potential antiarrhythmic agents. Drugs Fut. 2001;26:473-484.

31. Busch AE, Suessbrich H, Waldegger S, Sailer E, Greger R, Lang HJ, Lang F, Gibson KJ, Maylie JG. Inhibition of $\mathrm{I}_{\mathrm{Ks}}$ in guinea pig cardiac myocytes and guinea pig $\mathrm{I}_{\mathrm{sK}}$ channels by the chromanol 293B. Pfligers Arch. 1996;432:1094-1096.

32. Selnick HG, Liverton NJ, Baldwin JJ, Butcher JW, Claremon DA, Elliott JM, Freidinger RM, King SA, Libby BE, McIntyre CJ, Pribush DA, Remy DC, Smith GR, Tebben AJ, Jurkiewicz NK, Lynch JJ, Salata JJ, Sanguinetti MC, Siegl PKS, Slaughter DE, Vyas K. Class III antiarrhythmic activity in vivo by selective blockade of the slowly activating cardiac delayed rectifier potassium current $I_{\mathrm{Ks}}$ by $(R)$-2-(2,4-trifluoromethyl)- $N$-[2-oxo-5-phenyl-1-(2,2,2-trifluoroethyl)- 2,3dihydro-1 $H$-benzo[e][1,4]diazepin-3-yl]acetamide. J Med Chem. 1997;40:3865-3868. 
33. Lynch JJ, Jr, Houle MS, Stump GL, Wallace AA, Gilberto DB, Jahansouz H, Smith GR, Tebben AJ, Liverton NJ, Selnick HG, Claremon DA, Billman GE. Antiarrhythmic efficacy of selective blockade of the cardiac slowly activating delayed rectifier current, $\mathrm{I}_{\mathrm{Ks}}$, in canine models of malignant ischemic ventricular arrhythmia. Circulation. 1999;100:1917-1922.

34. Sun ZQ, Eddlestone GT, Antzelevitch C. Ionic mechanisms underlying the effects of sodium pentobarbital to diminish transmural dispersion of repolarization. Pacing Clin Electrophysiol. 1997;20 (pe II):1116. Abstract.

35. Bachmann A, Mueller S, Kopp K, Brueggemann A, Suessbrich H, Gerlach U, Busch AE. Inhibition of cardiac potassium currents by pentobarbital. Naunyn-Schmiedeberg's Arch Pharmacol. 2002;365:29-37.

36. Hirota K, Ito Y, Masuda A, Momose Y. Effects of halothane on membrane ionic currents in guinea pig atrial and ventricular myocytes. Acta Anaesthesiol Scand. 1989;33:239-244.

37. Zorn L, Kulkarni R, Anantharam V, Bayley H, Treistman SN. Halothane acts on many potassium channels, including a minimal potassium channel. Neurosci Lett. 1993:161:81-84.

38. Bauer A, Becker R, Freigang KD, Senges JC, Voss F, Hansen A, Müller M, Lang HJ, Gerlach U, Busch A, Kraft P, Kübler W, Schöls W. Rate- and site-dependent effects of propafenone, dofetilide, and the new $I_{\mathrm{Ks}}$-blocking agent chromanol 293b on individual muscle layers of the intact canine heart. Circulation. 1999;100:2184-2190.

39. Bauer A, Becker R, Freigang KD, Senges JC, Voss F, Kraft P, Kuebler W, Schoels W. Electrophysiologic effects of the new $\mathrm{I}_{\mathrm{Ks}}$-blocking agent chromanol $293 \mathrm{~b}$ in the postinfarction canine heart: preserved positive use-dependence and preferential prolongation of refractoriness in the infarct zone. Basic Res Cardiol. 2000;95:324-332. 


\section{CHAPTER 4}

\section{Chronic Amiodarone Evokes No Torsade de Pointes Arrhythmias Despite QT Lengthening in an Animal Model of Acquired Long-QT Syndrome}

Jurren M. van Opstal, Marieke Schoenmakers, S. Cora Verduyn, S.H. Marieke de Groot, Jet D.M. Leunissen, Ferenc F. van der Hulst, Mirella M.C. Molenschot, Hein J.J. Wellens, Marc A. Vos

Department of Cardiology, Cardiovascular Research Institute Maastricht, Maastricht, The Netherlands 


\section{ABSTRACT}

Background: Amiodarone is an effective antiarrhythmic drug rarely associated with Torsade de Pointes arrhythmias (TdP). The non-iodinated compound dronedarone could resemble amiodarone and be devoid of the adverse effects. In the dog with chronic complete atrioventricular (AV) block (CAVB) and acquired long-QT syndrome, the electrophysiological and proarrhythmic properties of the drugs were compared after 4 weeks of oral treatment.

Methods and Results: Amiodarone ( $\mathrm{n}=7,40 \mathrm{mg} / \mathrm{kg} / \mathrm{day})$ and dronedarone $(\mathrm{n}=8,20 \mathrm{mg} / \mathrm{kg} / \mathrm{BID})$ were started at $6 \mathrm{wks}$ CAVB (baseline). Six dogs served as control. Surface ECGs and endocardially-placed MAP catheters in the left (LV) and right (RV) ventricles were recorded to assess: $\mathrm{QT}_{(\mathrm{c})}$ time, monophasic action potential duration (MAPD), interventricular dispersion ( $\triangle \mathrm{MAPD}=\mathrm{LV}$ MAPD minus RV MAPD), early afterdepolarizations (EADs), ectopic beats and TdP. Results: Both amiodarone $(+21 \%)$ and dronedarone $(+31 \%)$ increased QT time. Amiodarone showed no increase in $\triangle \mathrm{MAPD}$ in 4 of 7 dogs, whereas dronedarone augmented $\triangle \mathrm{MAPD}$ in 7 of 8 animals. After dronedarone, TdP occurred in 4 of 8 dogs with the highest $\triangle M A P D$ $(105 \pm 20 \mathrm{~ms})$. TdP was never seen with amiodarone, not even in the dogs that had $\triangle \mathrm{MAPD}$ values comparable to those with dronedarone. Furthermore, a difference existed in EADs and ectopic activity incidence (dronedarone 3 of 8 ; amiodarone 0 of 7 ), which was also seen during an epinephrine challenge.

Conclusions: In the CAVB dog model, both amiodarone and dronedarone prolong QT time (class III effect). The absence of TdP with amiodarone seems to be related to homogeneous APD lengthening in the majority of dogs and the lack of EADs and/or ventricular ectopic beats in all. 


\section{INTRODUCTION}

Amiodarone is the most potent antiarrhythmic drug in the prevention of life- threatening ventricular arrhythmias and demonstrates a very low incidence of Torsade de Pointes arrhythmias (TdP). ${ }^{1-4}$ The non-cardiac adverse effects of amiodarone, however, attributed to the iodinated nature of the molecule, limit its clinical applicability. 5,6 The non-iodinated benzofuran derivative dronedarone, which is structurally related to amiodarone, could possess similar antiarrhythmic efficacy as well as the low proarrhythmic potential of amiodarone and be devoid of the unwanted side effects. ${ }^{7-9}$

The anesthetized dog with chronic complete AV block (CAVB) and acquired long-QT syndrome is a suitable model to assess the proarrhythmic potential of intravenously administered antiarrhythmic drugs and to study factors involved in acquired TdP. ${ }^{10-15} \mathrm{TdP}$ in this model depends on: 1) bradycardia, 2) long repolarization times, 3) large regional dispersion of repolarization and/or 4) afterdepolarizations and triggered ectopic activity. ${ }^{10,15}$ The aim of the present study was to determine and compare the electrophysiological changes and possible proarrhythmic consequences of chronic oral administration of amiodarone and dronedarone in this animal model.

\section{METHODS}

\section{GENERAL}

Twenty-seven mongrel dogs (weight $26 \pm 5 \mathrm{~kg}, 18 \mathrm{female}$ ) were subjected to an initial experiment for creation of complete AV block and implantation of an epicardial pacing electrode. The procedure, anesthesia, ventilation, pre- and postoperative care has been described in previous articles from our group. ${ }^{10,11,15}$ The actual study started at 6 weeks of CAVB, as the heart has then reached a stable state in the different ventricular remodeling processes. ${ }^{14}$

Animal handling was in accordance with the European Directive for the Protection of Vertebrate Animals used for Experimental and other Scientific Purposes (European Union Directive \#86/609/CEE)'.

\section{STUDIES IN ANESTHETIZED DOGS AT 6 AND 10 WEEKS OF CAVB}

Figure 1 provides a flow chart of the experiment performed at 6 and 10 weeks of $\mathrm{CAVB}$, consisting of electrophysiologic and hemodynamic recordings at baseline and during proarrhythmic challenges.

A 6-lead surface ECG, 2 endocardial monophasic action potentials (MAPs, EP Technologies Inc, CA, USA) in the left (LV) and right (RV) ventricle and an LV 


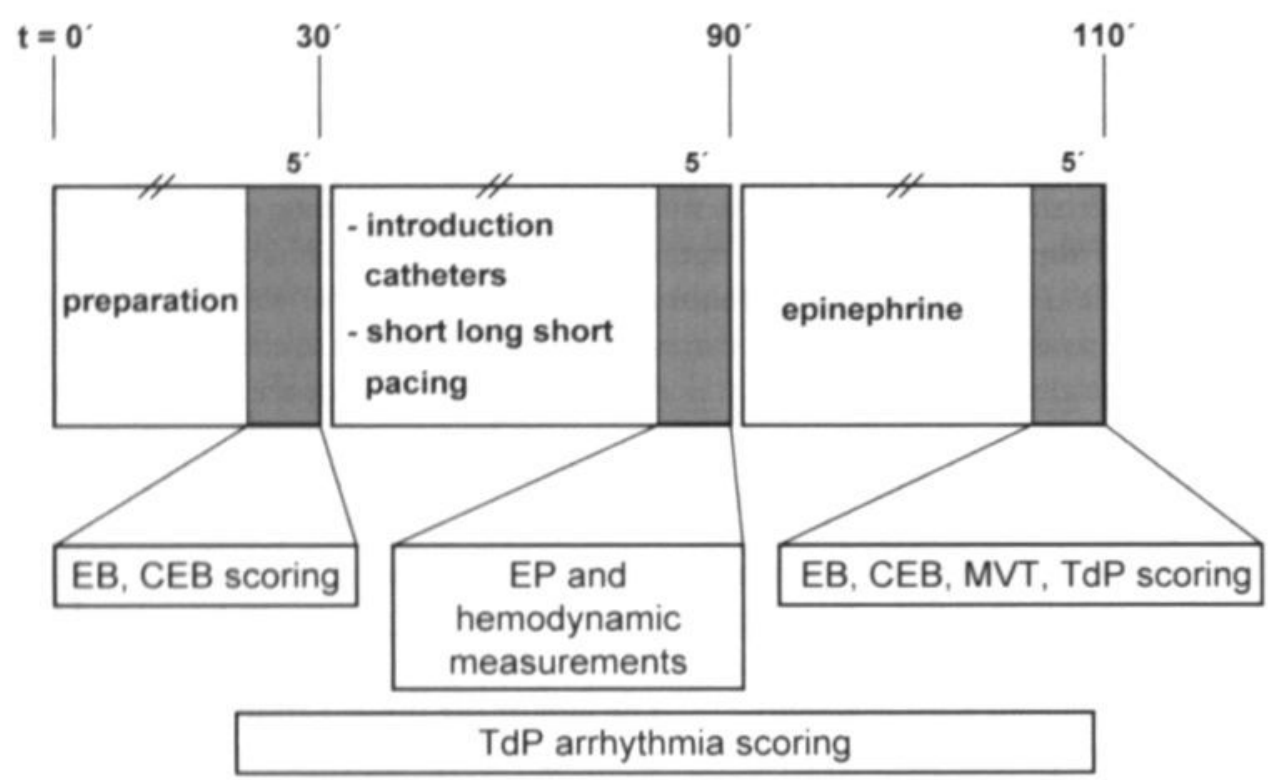

Figure I - Flow chart of experiment at 6 and 10 weeks of CAVB. $t=0$ indicates start of anesthesia; EB: ectopic beats; CEB: consecutive EB; and EP: electrophysiology.

pressure signal (Sentron Europe Inc, Roden, The Netherlands) were simultaneously registered and stored. For definitions, amplifications and filter settings we refer to previous publications. ${ }^{10,11,15}$

Two intervention protocols were performed to evoke arrhythmias: 1) shortlong-short pacing from the RV MAP catheter $\left(4.600 \mathrm{~ms}+1200 \mathrm{~ms}+\right.$ extrastimulus $\left.^{10}\right)$ and 2) IV administration of epinephrine ( $1 \mu \mathrm{g} / \mathrm{kg} / \mathrm{min}$ ) for 20 minutes (Figure 1). Six dogs were excluded from the study before the start of amiodarone or dronedarone because of clinical signs of heart failure in 1 animal and inducible TdP by pacing in 5 animals. The latter is associated with sudden cardiac death in this model, disallowing screening for proarrhythmic potential of class III drugs. ${ }^{16}$

The 21 remaining animals were randomized to 1) control group $(n=6), 2)$ amiodarone $(\mathrm{n}=7,40 \mathrm{mg} / \mathrm{kg} / \mathrm{d})$ group, and 3) dronedarone $(\mathrm{n}=8,20 \mathrm{mg} / \mathrm{kg} / \mathrm{BID})$ group. Drugs were provided by Sanofi-Synthélabo, Montpellier, France and administered at fixed times. Dosages were chosen on the basis of previous publications. ${ }^{8,9,12,17}$ After four weeks of oral administration the studies were repeated (CAVB 10 weeks) and the dogs sacrificed. Heart, lungs and liver were excised to determine the ratios of organ weight to body weight (BW). 


\section{STUDIES IN CONSCIOUS DOGS BETWEEN 6-10 WEEKS OF CAVB}

Both during idioventricular rhythm (IVR) and at a paced cycle length (CL) of 1000 $\mathrm{ms}$ (pacing from the LV epicardial electrode), the QT time and ventricular effective refractory period (VERP) were assessed every week. VERP was determined at twice diastolic threshold by delivering an extrastimulus using incremental steps of $5 \mathrm{~ms}$.

\section{DATA ANALYSIS AND DEFINITIONS}

Figure 1 shows the time periods of the electrophysiological and functional measurements and arrhythmia scoring.

The following parameters were measured off-line: LV end-systolic pressure, LV end-diastolic pressure, $\mathrm{LV}$ peak rate of pressure rise $\left(+\mathrm{dP} / \mathrm{dt}_{\max }\right), \mathrm{CL}-\mathrm{IVR}, \mathrm{QT}$ time and duration of the LV and RV MAP (MAPD) at $100 \%$ of repolarization. $\mathrm{QT}_{c}$ time was calculated using the Van de Water formula. ${ }^{18}$ Furthermore, the planimetric area of the JT wave ( $\left.\int{ }^{\mathrm{T}}, \mathrm{mV} \cdot \mathrm{ms}\right)$ in lead II of the surface ECG was assessed as a noninvasive parameter of dispersion of repolarization.

All data presented are the mean of 5 consecutive beats during stable CL-IVR after at least 1 hour of anesthesia. Interventricular dispersion ( $\triangle M A P D)$ was calculated as LV MAPD minus RV MAPD. Early afterdepolarizations (EADs) were assessed on the MAP signals. Spontaneous occurring ventricular ectopic beats were counted: 1) prior to catheter introduction during a 5-minute time interval, and 2) during the last 5 minutes of the 20-minute epinephrine infusion period. An ectopic beat was defined as a ventricular complex having a coupling interval of $<50 \%$ CL-IVR. Arrhythmic activity was scored on the basis of: 1) single ectopic beats, 2) consecutive ectopic beats, 3) monomorphic non sustained ventricular tachycardia (MVT, $>5$ consecutive ectopic beats) or 4) TdP.

\section{DETERMINATION OF DRUG LEVELS}

Venous blood samples were taken weekly. Myocardial tissue samples $\left(\approx 1 \mathrm{~cm}^{3}\right)$ were obtained from the free wall of both ventricles at sacrifice. Analyses of drug plasma and tissue levels including metabolites (n-monodebutyldronedarone and n-desethylamiodarone) were performed by the Department of Pharmacokinetics, SanofiSynthélabo, Montpellier, France. For details concerning analyses see Reference ?.

\section{STATISTICS}

Pooled data are expressed as mean \pm standard deviation (SD) except for the arrhythmia scoring data during epinephrine administration which are expressed as mean \pm SEM. Serial comparisons were performed by paired Student's t-test and single parameters between independent groups by 2-way analysis of variance (ANOVA) 
test with a post-hoc Bonferroni t-test. Statistical analysis of the time-dependency studies was done by ANOVA for repeated measures. Incidence was compared by Chi-square testing. Values of $\mathrm{P}<0.05$ were considered significant.

\section{RESULTS}

ELECTROPHYSIOLOGICAL STUDIES IN CONSCIOUS DOGS BETWEEN 6 AND 10 WEEKS OF CAVB

All 21 animals survived the 4 weeks of drug administration. In 1 dog of the amiodarone and 2 dogs of the dronedarone-treated group, the VERP determinations could not be completed due to electrode dysfunction.

In the control group, the CL-IVR and QT time remained similar (CL-IVR $1245 \pm 150 \mathrm{~ms}$ and QT time $315 \pm 15 \mathrm{~ms}$ at 6 weeks CAVB versus $1270 \pm 185 \mathrm{~ms}$ and $320 \pm 25 \mathrm{~ms}$ at 10 weeks CAVB).

Both amiodarone $(1230 \pm 185 \mathrm{~ms}$ to $1675 \pm 435 \mathrm{~ms})$ and dronedarone $(1145 \pm$ $165 \mathrm{~ms}$ to $1360 \pm 190 \mathrm{~ms}$ ) had a significant bradycardic effect. QT time prolonged significantly for both drugs at IVR (amiodarone $290 \pm 15 \mathrm{~ms}$ to $355 \pm 25 \mathrm{~ms}$ and dronedarone from $295 \pm 25 \mathrm{~ms}$ to $365 \pm 30 \mathrm{~ms}$ ). Also at 1000 -ms paced CL, QT time (amiodarone $+12 \%$ and dronedarone $+13 \%$ ) as well as VERP (amiodarone $191 \pm 13 \mathrm{~ms}$ to $223 \pm 18 \mathrm{~ms}$ and dronedarone $204 \pm 30 \mathrm{~ms}$ to $243 \pm 33 \mathrm{~ms}$ ) increased (Figure 2).

\section{STUDIES IN ANESTHETIZED DOGS AT 6 AND 10 WEEKS OF CAVB}

The baseline electrophysiological values were comparable between the 3 groups (Table 1, left). EADs, ectopic activity and TdPs were absent. The hemodynamic parameters were also similar, although the amiodarone group had a relatively low LV end-diastolic pressure value. These electrophysiological and hemodynamic data are in agreement with data published previously in the CAVB dog. ${ }^{10,11,15}$ Epinephrine administration decreased CL-IVR and all repolarization parameters including $\triangle \mathrm{MAPD}$ (data not shown). The average number of epinephrine-evoked ectopic beats and MVTs at 6 weeks of CAVB is depicted in Figure 3 ( $n=21$, control 6 weeks).

The right side of Table 1 presents the electrophysiological and hemodynamic results after 4 weeks of treatment. The QT time and LV- and RV MAPD were longer for both drugs compared with the control group. Dronedarone had a stronger "class III effect": e.g. dronedarone increased QT ${ }_{c}$ time from $350 \pm 50 \mathrm{~ms}$ to $460 \pm 30$ $\mathrm{ms}(31 \%)$, whereas amiodarone increased $\mathrm{QT}_{\mathrm{c}}$ time from $330 \pm 35 \mathrm{~ms}$ to $400 \pm 60$ $\mathrm{ms}(21 \%, \mathrm{P}<0.05$ for both). Remarkably, for the amiodarone group the prolonged QT time was accompanied by an augmented $\triangle M A P D$ in only 3 dogs (Figure 4). As a consequence, $\triangle \mathrm{MAPD}$ did not increase significantly (Table 1). In contrast, 
amiodarone
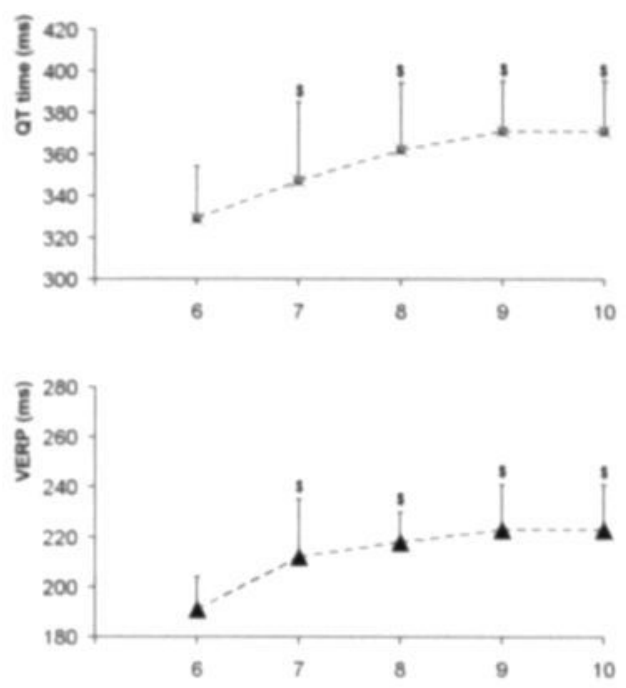

\section{dronedarone}
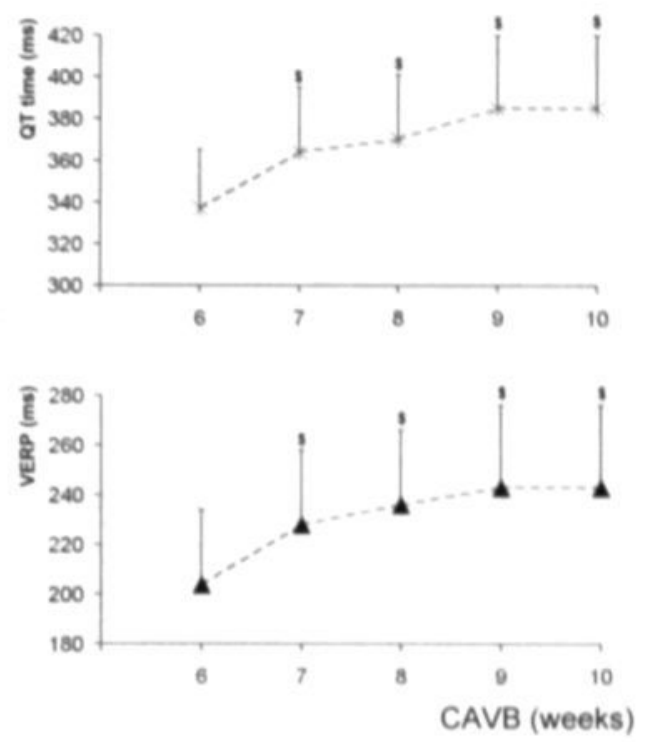

Figure 2 - Temporal behavior of QT time (top) and VERP (bottom) during amiodarone (left) and dronedarone (right) treatment in conscious dogs at paced CL of $1000 \mathrm{~ms}$. On the horizontal axis the time in weeks after CAVB. Start of treatment at 6 weeks CAVB. Both drugs increased QT time and VERP similarly (\$, P<0.05 vs 6 weeks CAVB).

\section{epinephrine (1 $\mu \mathrm{g} / \mathrm{kg} / \mathrm{min})$ challenge}

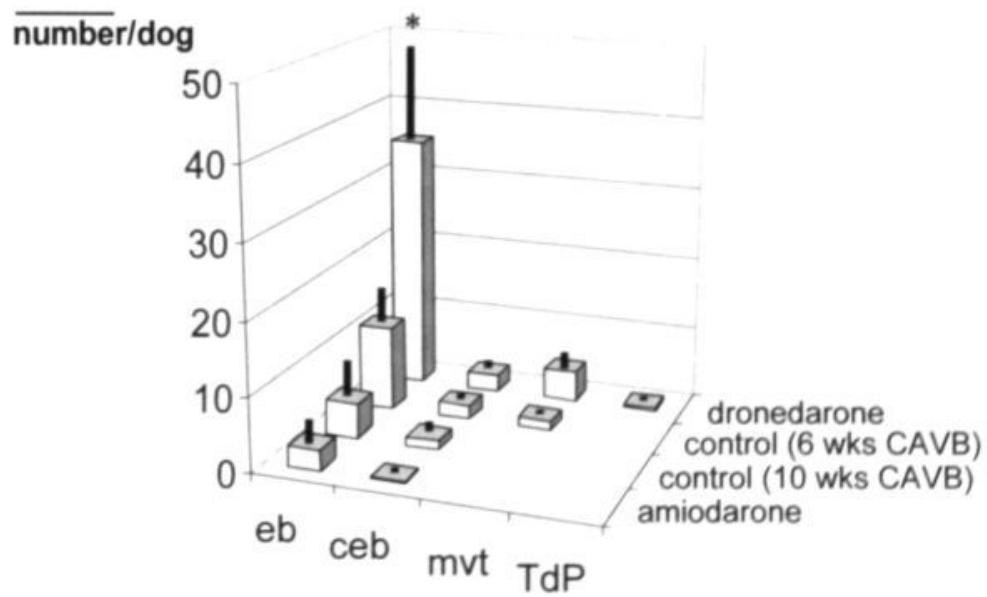

Figure 3 - Arrhythmia scoring for a 5-minute period during epinephrine infusion for two control (6 and 10 weeks CAVB), amiodarone-, and dronedarone-treated groups. On the horizontal axis, the division between single ectopic beats (EB), consecutive EB (CEB), monomorphic VT (MVT), and TdP. On the vertical axis the mean number of the different arrhythmias per dog. The dronedarone group demonstrated significantly $(*, \mathrm{P}<0.05)$ more ectopic activity. 
$80 \mid$ Chapter 4
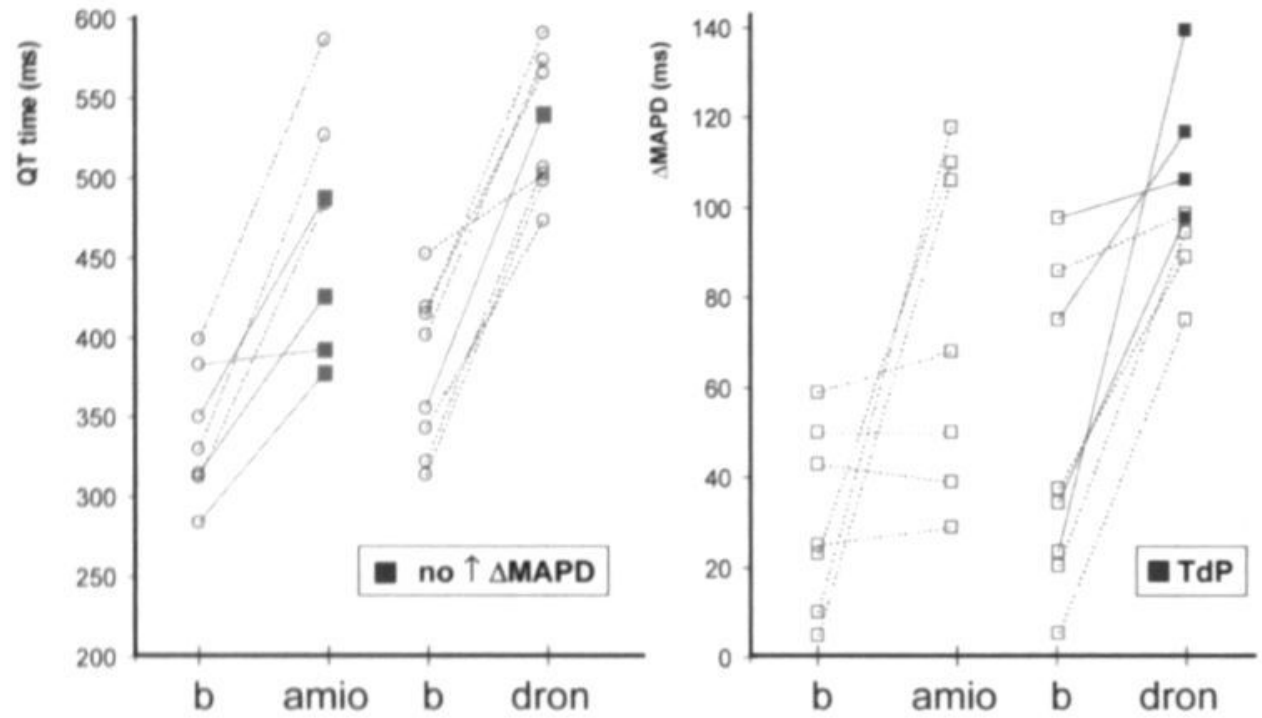

Figure 4 - Individual data of QT time (left) and interventricular dispersion ( $\triangle \mathrm{MAPD}$, right) are shown before (b) and after amiodarone (amio) or dronedarone (dron) treatment. Left, amiodarone prolonged QT time in 6 of 7 dogs, but was associated with an increase in $\triangle \mathrm{MAPD}$ (right) in only 3 of 7 ( , left). Dronedarone increased QT time in all, and $\triangle \mathrm{MAPD}$ in 7 of $8 \mathrm{dogs}$ (right), being associated with TdP for those dogs having highest $\triangle \mathrm{MAPD}$ ( $\mathbf{\mathbf { m }}$, right).

Table 1 - Electrophysiological and hemodynamic results before and after 4 weeks of amiodarone or dronedarone treatment compared with the control group

\begin{tabular}{|c|c|c|c|c|c|c|}
\hline & $\begin{array}{l}\text { control } \\
6 \text { wks } \\
C A V B \\
(n=6)\end{array}$ & $\begin{array}{l}\text { before } \\
\text { amiodarone } \\
(n=7)\end{array}$ & $\begin{array}{l}\text { before } \\
\text { dronedarone } \\
(n=8)\end{array}$ & $\begin{array}{l}\text { control } \\
10 \text { wks } \\
C A V B \\
(n=6)\end{array}$ & amiodarone & dronedarone \\
\hline CL-IVR(ms) & $1145 \pm 115$ & $1110 \pm 140$ & $1210 \pm 160$ & $1215 \pm 75$ & $1805 \pm 360^{\prime}$ & $1630 \pm 475$ \\
\hline QRS time(ms) & $76 \pm 11$ & $82 \pm 9$ & $85 \pm 9$ & $73 \pm 13$ & $89 \pm 9$ & $94 \pm 15^{*}$ \\
\hline QT time(ms) & $360 \pm 55$ & $340 \pm 40$ & $370 \pm 50$ & $380 \pm 50$ & $470 \pm 75^{\prime \prime}$ & $515 \pm 40^{*}$ \\
\hline $\mathrm{QT}_{\mathrm{c}}$ time (ms) & $345 \pm 40$ & $330 \pm 35$ & $350 \pm 50$ & $360 \pm 45$ & $400 \pm 60$ & $460 \pm 30^{\prime \prime}$ \\
\hline $\mathrm{JT}$ area $(\mathrm{mV} \cdot \mathrm{ms})$ & $167 \pm 61$ & $145 \pm 50$ & $157 \pm 89$ & $161 \pm 55$ & $128 \pm 39$ & $200 \pm 104$ \\
\hline LV MAPD(ms) & $335 \pm 35$ & $310 \pm 25$ & $355 \pm 55$ & $350 \pm 35$ & $435 \pm 70=$ & $505 \pm 45^{\prime \prime}$ \\
\hline RV MAPD(ms) & $285 \pm 55$ & $270 \pm 20$ & $305 \pm 30$ & $300 \pm 40$ & $360 \pm 45^{z}$ & $410 \pm 40^{\prime \prime}$ \\
\hline$\triangle M A P D(m s)$ & $50 \pm 30$ & $40 \pm 20$ & $45 \pm 30$ & $50 \pm 30$ & $75 \pm 35$ & $95 \pm 20^{\prime}$ \\
\hline LV ESP $(\mathrm{mm} \mathrm{Hg})$ & $115+14$ & $120 \pm 15$ & $115 \pm 14$ & $100 \pm 12$ & $100 \pm 8$ & $100 \pm 14$ \\
\hline LV EDP $(\mathrm{mm} \mathrm{Hg})$ & $12 \pm 5$ & $5 \pm 4^{\circ}$ & $15 \pm 7$ & $11 \pm 5$ & $9 \pm 3$ & $14 \pm 9$ \\
\hline $\begin{array}{l}\mathrm{LV}+\mathrm{dP} / \mathrm{dt}_{\max } \\
(\mathrm{mm} \mathrm{Hg} / \mathrm{s})\end{array}$ & $2740 \pm 115$ & $3205 \pm 990$ & $2790 \pm 620$ & $1940 \pm 400$ & $2250 \pm 610$ & $2035 \pm 225$ \\
\hline
\end{tabular}

ESP indicates end-systolic pressure; EDP, end-diastolic pressure. ${ }^{\circ}, \mathrm{P}<0.05$ amiodarone $t s$ dronedarone $\#$, $\mathrm{P}<0.05$ vs control, ANOVA 
dronedarone affected LV MAPD far more than RV MAPD in 7 of 8 dogs, augmenting $\triangle \mathrm{MAPD}$ significantly (Figure 4). Also JT area increased in the dronedarone group (from $157 \pm 89 \mathrm{mV} \cdot \mathrm{ms}$ to $200 \pm 104 \mathrm{mV} \cdot \mathrm{ms}$ ), whereas the control and the amiodarone-treated groups remained similar (Table 1).

\section{ARRHYTHMIAS WITH AMIODARONE AND DRONEDARONE}

At 10 weeks of CAVB, none of the animals in the control or amiodarone group showed EADs or spontaneous ectopic activity in the 5 -minute period before catheter introduction. In contrast, 6 of 8 dronedarone animals showed EADs $(P<0.01$ versus amiodarone) on the LV MAP, of which 3 also developed considerable ventricular ectopic activity.

In the control group, spontaneous $\mathrm{TdP}$ was never seen, but it could be induced by pacing in 1 of 6 animals. In the amiodarone group no spontaneous or pacing-induced TdP occurred. Multiple episodes of spontaneous TdP (Figure 5) were seen in 3 dogs with dronedarone treatment. Furthermore, TdP was inducible by pacing in 1 animal in which EADs but no ectopic beats were observed, resulting in a total TdP incidence of 4 of 8 dronedarone-treated dogs. Subgroup analysis looking at LV MAPD resulted in an absence of ectopic beats and spontaneous or inducible TdP for those dogs having an LV MAPD $<500 \mathrm{~ms}$.

In the dronedarone-treated group only, epinephrine administration resulted in an increased number of ectopic beats ( Figure 3).

\section{MYOCARDIAL TISSUE AND PLASMA CONCENTRATIONS}

The plasma levels of dronedarone $(1.3 \pm 0.3 \mathrm{mg} / \mathrm{L})$, amiodarone $(3.5 \pm 0.6 \mathrm{mg} / \mathrm{L})$, and their metabolites were in agreement with data published recently. ${ }^{9}$ The myocardial tissue data of amiodarone (LV 17.9 \pm 3.8 , RV $13.3 \pm 3.8 \mathrm{mg} / \mathrm{kg})$, n-desethylamiodarone $(\mathrm{LV} 12.7 \pm 2.9, \mathrm{RV} 8.0 \pm 2.3 \mathrm{mg} / \mathrm{kg})$, dronedarone $(\mathrm{LV} 13.5 \pm 3.8, \mathrm{RV}$ $13.2 \pm 3.9 \mathrm{mg} / \mathrm{kg}$ ) and n-monodebutyldronedarone (LV $2.8 \pm 0.7, \mathrm{RV} 3.4 \pm 0.9$ $\mathrm{mg} / \mathrm{kg}$ ) were comparable to data published by Latini et al ${ }^{19}$ and Merot et al. ${ }^{20}$ The 3 animals showing an increased $\triangle \mathrm{MAPD}$ on amiodarone also tended to have higher tissue levels of the compound (LV $25.7 \pm 11.6 \mathrm{mg} / \mathrm{kg}$ versus $12.0 \pm 2.6 \mathrm{mg} / \mathrm{kg}$ ) and its metabolite ( $\mathrm{LV} 16.7 \pm 10.6 \mathrm{mg} / \mathrm{kg}$ versus $9.8 \pm 3.4 \mathrm{mg} / \mathrm{kg}$ ) compared with the other 4 animals.

\section{AUTOPSY DATA}

At autopsy, the heart weight $/ \mathrm{BW}(12.4 \pm 1.2 \mathrm{~g} / \mathrm{kg}$ in the control, $13.0 \pm 0.9 \mathrm{~g} / \mathrm{kg}$ in the dronedarone, and $11.6 \pm 2.1 \mathrm{~g} / \mathrm{kg}$ in the amiodarone groups), liver weight $/ \mathrm{BW}$ ( $26.7 \pm 3.2,28.1 \pm 4.4$, and $30.4 \pm 2.3 \mathrm{~g} / \mathrm{kg}$, respectively), and lung weight $/ \mathrm{BW}$ (12.6 $\pm 2.9,14.5 \pm 4.3$ and $10.8 \pm 2.4 \mathrm{~g} / \mathrm{kg}$ ) ratios were similar in the 3 groups. 
$\mathbf{8 2} \mid$ Chapter 4

1

$09: 19$

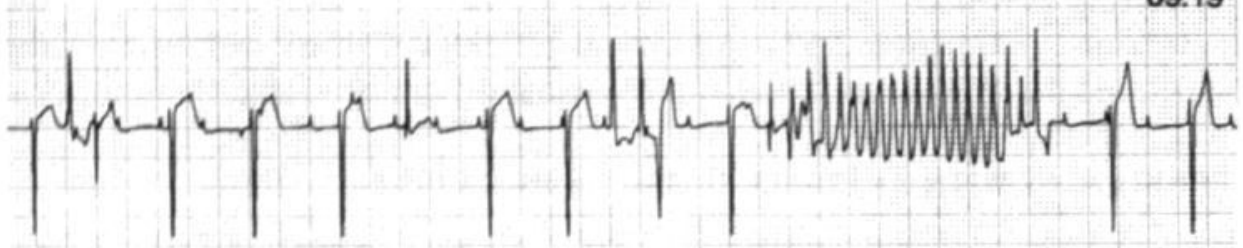

2

$09 \cdot 20$

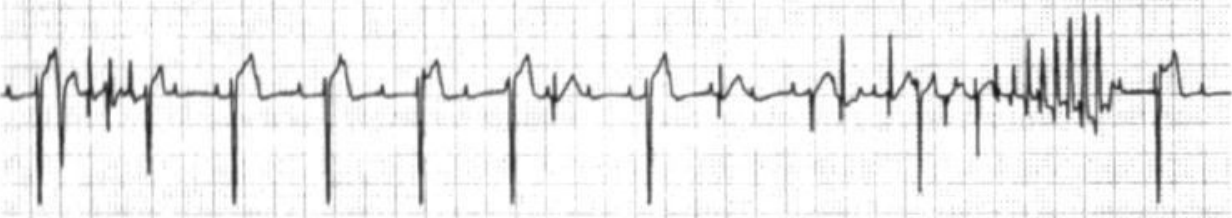

3

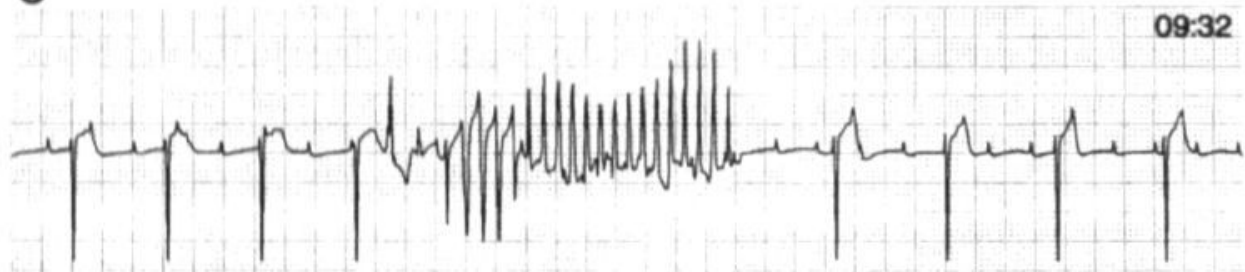

4

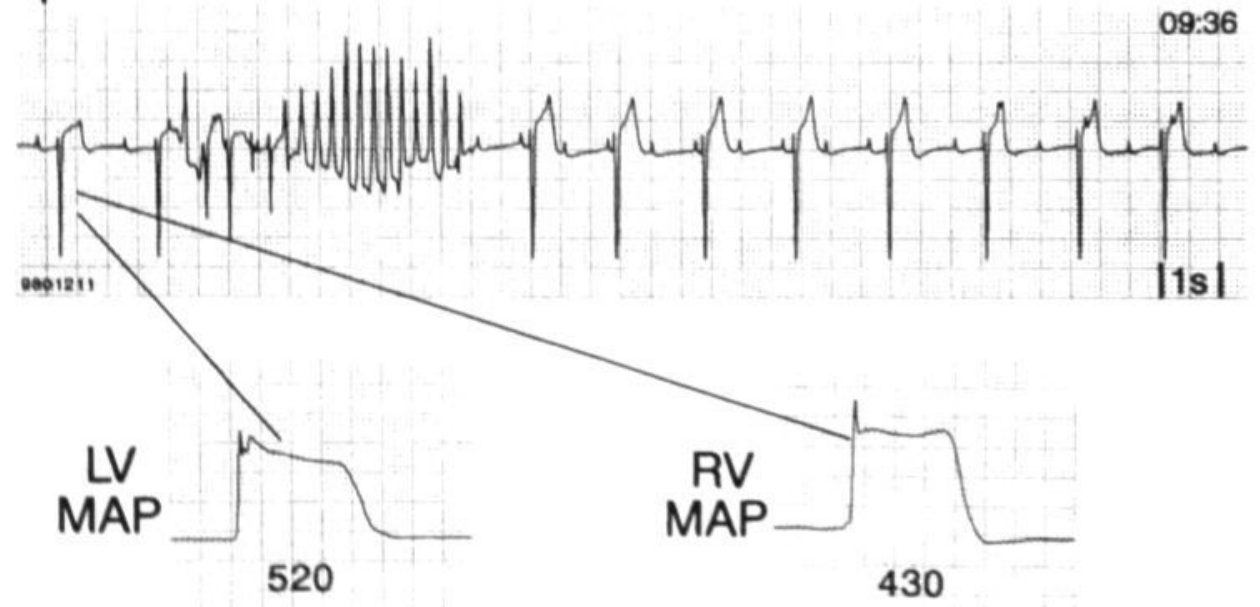

Figure 5 - Spontaneously occurring TdP during chronic dronedarone treatment in an anesthetized CAVB dog. Four panels with lead II of the surface ECG at $10 \mathrm{~mm} / \mathrm{s}$ demonstrate several episodes of TdP during a 17 -minute period. Single LV and RV MAPs are shown to exemplify $\triangle M A P D$ ( $520 \mathrm{~ms}$ minus $430 \mathrm{~ms})$. 


\section{DISCUSSION}

In the CAVB dog, both amiodarone and dronedarone prolonged QT time and VERP significantly (Figure 2). These increases in QT time and VERP for amiodarone under conscious conditions are comparable to human data. ${ }^{21}$ Amiodarone, unlike dronedarone, evoked no EADs, ectopic beats, or TdP and did not increase dispersion of repolarization significantly. In contrast, other antiarrhythmic drugs administered intravenously in the CAVB dog, like dofetilide or almokalant, augmented dispersion of repolarization and elicited EADs, ectopic beats and TdPs. ${ }^{10,15}$

Amiodarone does not fit well into conventional antiarrhythmic classification schemes. Used long-term, amiodarone prolongs the ventricular APD and therefore is classified generally as a class III agent. However, the drug also possesses class I (sodium channel blockade), class II (antiadrenergic), and class IV (calcium channel blockade) effects. ${ }^{5,8,22}$ The multiple ion channel interaction by amiodarone has been speculated to contribute to its minimal reverse use dependency and low incidence of clinical TdP arrhythmias, even in patients who develop TdP on other antiarrhythmics. ${ }^{5,22-24}$ Dronedarone, given either long-term or short-term, has been suggested to possess a similar electrophysiological profile, but the effects of chronic dronedarone on specific cardiac ion channels are still unknown. ${ }^{7-9}$

\section{ARRHYTHMIC PARAMETERS: DISPERSION}

$\mathrm{TdP}$ is generally thought to be dependent on two interrelated mechanisms: the trigger (ectopic beat) and the substrate (dispersion). ${ }^{10,25}$ The length of the LV MAP plays an important role in both, either by creating regional dispersion of repolarization between the ventricles or by generating EAD-dependent triggered arrhythmias. ${ }^{26}$ Furthermore EADs will contribute to dispersion when their presence in the ventricles is not homogeneous. Second, when EADs give rise to ectopic beats, electrical heterogeneity will be further augmented (e.g. $\triangle \mathrm{MAPD}),{ }^{27}$ a concept that has been referred to as modulated dispersion of repolarization. ${ }^{27-29}$

Dronedarone increased $\triangle \mathrm{MAPD}$ in 7 of 8 dogs (Figure 4), based on a more pronounced lengthening of the MAPD in the LV versus the RV. Despite QT lengthening and bradycardia, amiodarone prolonged the ventricular APDs homogeneously in 4 of 7 dogs, resulting in a nonsignificant overall increase of $\triangle \mathrm{MAPD}$. Similar results on equal or reduced transmural dispersion during chronic amiodarone treatment have been described by others, both in vivo as in vitro, ${ }^{17,20,30}$ although QT time lengthening was not convincingly present in these studies. The divergent response of $\triangle \mathrm{MAPD}$ in 3 dogs of the amiodarone group could be based upon a different distribution or clearance of the drug. 
In the CAVB dog, drug-induced TdP has been associated with ventricular ectopic activity and a pronounced $\triangle \mathrm{MAPD} .{ }^{10,15}$ Dronedarone resulted in a $50 \% \mathrm{TdP}$ incidence and was observed in: 1) the 3 dogs with multiple ectopic beats (Figure 5) and 2) the 4 dogs with the highest $\triangle \mathrm{MAPD}$ (Figure 4 ). Amiodarone did not induce TdP in any of the dogs, not even in those with a similar magnitude of $\triangle$ MAPD.

Therefore, the lack of TdP with amiodarone appears to be linked to the prevention of EADs and/or ectopic activity, even during proarrhythmic challenges with pacing protocols and epinephrine administration. Absence of EADs after amiodarone treatment was observed earlier in canine $\mathrm{M} \mathrm{cells}{ }^{17}$ and in isolated rabbit right ventricular tissue. ${ }^{31}$

Why dronedarone-treated animals respond differently is unclear, but this could be related to: 1) unfortunate randomization, 2) the selected dosage, or 3) dissimilar electrophysiological effects. With respect to point 1 , the 3 dogs showing TdP after dronedarone had a relatively high LV MAPD at baseline (6 weeks CAVB) (mean $405 \pm 25 \mathrm{~ms})$ compared with amiodarone $(310 \pm 25 \mathrm{~ms})$. The length of LV MAPD at baseline was recently described as a predisposing factor for (drug-induced) arrhythmias. ${ }^{16}$ Point 2, although the selected dosages showed similar increases in QT time under conscious conditions, differences in repolarization parameters were seen under anesthesia, which could have proarrhythmic consequences. Indeed, subgroup analysis confirmed that LV MAPD values $>500 \mathrm{~ms}$ in the dronedarone group were consistently associated with ectopic beats and TdP. Point 3 , the different electrophysiological and arrhythmic outcomes of the drugs in the present study could suggest that chronic amiodarone exerts its beneficial effect by: 1) modulating the ion channels differently, 2) inhibiting thyroid hormone activation in cardiac muscle or 3) a combination of both. . $^{52}$

\section{CLINICAL IMPLICATIONS}

The CHF-STAT, CAMIAT and EMIAT trials showed that amiodarone lacked proarrhythmia and reduced the incidence of arrhythmias and arrhythmic death in high-risk patients. ${ }^{1,3,4}$ The present study demonstrates that the preventive effect of amiodarone on EAD formation and/or related ventricular ectopic activity could account for the clinical safety and efficacy of the drug. The possible proarrhythmic effects of dronedarone should be carefully evaluated in future clinical trials. 


\section{LIMITATIONS}

The selection of only one dosage in relatively small groups as well as possible predisposing factors prevent us from drawing definite conclusions about the proarrhythmic outcome of dronedarone.

\section{CONCLUSIONS}

Amiodarone is the first drug having pronounced class III effects, which do not result in TdP in this model. This is in agreement with the clinical safery of the drug and supports the validity of the model for screening arrhythmic potential of (antiarrhythmic) drugs. The absence of $\mathrm{TdP}$ with amiodarone can be explained by 1) the absence of EADs and/or ventricular ectopic activity in all animals, and 2) a homogeneous increase in LV- and RV MAPD in the majority of dogs.

\section{ACKNOWLEDGMENTS}

The authors would like to thank Dr. Paul Volders for critical reading of the manuscript. The helpful discussions with Drs. Dino Nisato and Patrick Gautier, Sanofi-Synthélabo, Montpellier, France, are greatly appreciated. Financial support by "the Netherlands Heart Foundation" (\#98.042), "the Netherlands Society for Scientific Research” (\#902-16-214) and Sanofi-Synthélabo, Paris, France, is gratefully acknowledged.

\section{REFERENCES}

1. Singh SN, Fletcher RD, Fisher SG, Singh BN, Lewis HD, Deedwania PC, Massie BM, Colling C, Lazzeri D. Amiodarone in patients with congestive heart failure and asymptomatic ventricular arrhythmia. Survival Trial of Antiarrhythmic Therapy in Congestive Heart Failure. N Engl J Med. 1995;333:77-82.

2. Hohnloser SH, Singh BN. Proarrhythmia with class III antiarrhythmic drugs: definition, electrophysiologic mechanisms, incidence, predisposing factors, and clinical implications. J Cardiovasc Electrophysiol. 1995;6:920-36.

3. Cairns JA, Connolly SJ, Roberts R, Gent M. Randomised trial of outcome after myocardial infarction in patients with frequent or repetitive ventricular premature depolarisations: CAMIAT. Canadian Amiodarone Myocardial Infarction Arrhythmia Trial Investigators. Lancet. 1997:349:675-82. 
4. Julian DG, Camm AJ, Frangin G, Janse MJ, Munoz A, Schwartz PJ, Simon P. Randomised trial of effect of amiodarone on mortality in patients with left-ventricular dysfunction after recent myocardial infarction: EMIAT. European Myocardial Infarct Amiodarone Trial Investigators. Lancet. 1997:349:667-74.

5. Singh BN, Venkatesh N, Nademanee K, Josephson MA, Kannan R. The historical development, cellular electrophysiology and pharmacology of amiodarone. Prog Cardiovase Dis. 1989;31:249-80.

6. Vorperian VR, Havighurst TC, Miller S, January CT. Adverse effects of low dose amiodarone: a meta-analysis. J Am Coll Cardiol. 1997;30:791-8.

7. Manning A, Thisse V, Hodeige D, Richard J, Heyndrickx JP, Chatelain P. SR 33589, a new amiodarone-like antiarrhythmic agent: electrophysiological effects in anesthetized dogs. J Cardiovasc Pharmacol. 1995;25:252-61.

8. Sun W, Sarma JS, Singh BN. Electrophysiological effects of dronedarone (SR33589), a noniodinated benzofuran derivative, in the rabbit heart : comparison with amiodarone. Circulation. 1999:100:2276-81.

9. Djandjighian L. Planchenault J, Finance O, Pastor G, Gautier P, Nisato D. Hemodynamic and antiadrenergic effects of dronedarone and amiodarone in animals with a healed myocardial infarction. J Cardiovasc Pharmacol. 2000;36:376-83.

10. Verduyn SC, Vos MA, van der Zande J, Kulcsar A, Wellens HJ. Further observations to elucidate the role of interventricular dispersion of repolarization and early afterdepolarizations in the genesis of acquired torsade de pointes arrhythmias: a comparison between almokalant and d-sotalol using the dog as its own control. J Am Coll Cardiol. 1997:30:1575-84.

11. Vos MA, de Groot SH, Verduyn SC, van der Zande J, Leunissen HD, Cleutjens JP, van Bilsen M, Daemen MJ, Schreuder JJ, Allessie MA, Wellens HJ. Enhanced susceptibility for acquired torsade de pointes arrhythmias in the dog with chronic, complete AV block is related to cardiac hypertrophy and electrical remodeling. Circulation. 1998;98:1125-35.

12. Verduyn SC, Vos MA, Leunissen HD, van Opstal JM, Wellens HJ. Evaluation of the acute electrophysiologic effects of intravenous dronedarone, an amiodarone-like agent, with special emphasis on ventricular repolarization and acquired torsade de pointes arrhythmias. $J$ Cardiovasc Pharmacol. 1999:33:212-22.

13. Vos MA, Verduyn SC, Wellens HJJ. Early afterdepolarizations in the in situ canine heart. Mechanistic insights into acquired Torsade de Pointes arrhythmias. In: MR Franz, ed. Monophasic Action Potentials. Bridging Cell and Bedside. Armonk NY: Futura Publishing;2000:553-569.

14. Verduyn SC, Ramakers C. Snoep G, Leunissen JD, Wellens HJ, Vos MA. Time course of structural adaptations in chronic AV block dogs: evidence for differential ventricular remodeling. $\mathrm{Am}$ J Plysiol Heart Circ Physiol, 2001;280:H2882-90.

15. Van Opstal JM, Leunissen JD, Wellens HJ, Vos MA. Azimilide and dofetilide produce similar electrophysiological and proarrhythmic effects in a canine model of Torsade de Pointes arrhythmias. Eur J Pharmacol. 2001:412:67-76.

16. Van Opstal JM, Verduyn SC, Leunissen HD, de Groot SH, Wellens HJ, Vos MA. Electrophysiological parameters indicative of sudden cardiac death in the dog with chronic complete AV-block. Candiousese Res. 2001:50:354-61. 
17. Sicouri S, Moro S, Litovsky S, Elizari MV, Antzelevitch C. Chronic amiodarone reduces transmural dispersion of repolarization in the canine heart. J Candionase Electrophysiol. 1997;8:1269-79.

18. Van de Water A, Verheyen J, Xhonneux R, Reneman RS. An improved method to correct the QT interval of the electrocardiogram for changes in heart rate. J Pharmacol Methods. 1989;22:207-17.

19. Latini R, Connolly SJ, Kates RE. Myocardial disposition of amiodarone in the dog. J Pharmacol Exp Ther. 1983;224:603-8.

20. Merot J, Charpentier F, Poirier JM, Coutris G, Weissenburger J. Effects of chronic treatment by amiodarone on transmural heterogeneity of canine ventricular repolarization in vivo: interactions with acute sotalol. Cardiovase Res. 1999;44:303-14.

21. Mitchell LB, Wyse DG, Gillis AM, Duff HJ. Electropharmacology of amiodarone therapy initiation. Time courses of onset of electrophysiologic and antiarrhythmic effects. Cinculation. 1989;80:34-42.

22. Kodama I, Kamiya K, Toyama J. Cellular electropharmacology of amiodarone. Cardiovasc Res. 1997;35:13-29.

23. Martioni TA, Zheutlin TA, Sarmiento JJ, Parker M, Lesch M, Kehoe RF. Amiodarone in patients with previous drug-mediated torsade de pointes. Long-term safety and efficacy. Ann Intern Med. 1989;111:574-80.

24. Sager PT, Uppal P, Follmer C, Antimisiaris M, Pruitt C, Singh BN. Frequency- dependent electrophysiologic effects of amiodarone in humans. Circulation. 1993;88:1063- 71.

25. Surawicz B. Electrophysiologic substrate of torsade de pointes: dispersion of repolarization or early afterdepolarizations? J Am Coll Cardiol. 1989;14:172-84.

26. Volders PG, Vos MA, Szabo B, Sipido KR, de Groot SH, Gorgels AP, Wellens HJ, Lazzara R. Progress in the understanding of cardiac early afterdepolarizations and torsades de pointes: time to revise current concepts. Cardiovasc Res. 2000;46:376-92.

27. Vos MA, Gorenek B, Verduyn SC, van der Hulst FF, Leunissen JD, Dohmen L, Wellens HJ. Observations on the onset of torsade de pointes arrhythmias in the acquired long QT syndrome. Cardiovasc Res. 2000;48:421-9.

28. Laurita KR, Girouard SD, Akar FG, Rosenbaum DS. Modulated dispersion explains changes in arrhythmia vulnerability during premature stimulation of the heart. Circulation. 1998;98:2774-80.

29. El-Sherif N, Turitto G. The long QT syndrome and torsade de pointes. Pacing Clin Electrophysiol. 1999;22:91-110.

30. Drouin E, Lande G, Charpentier F. Amiodarone reduces transmural heterogeneity of repolarization in the human heart. J Am Coll Cardiol. 1998;32:1063-7.

31. Ohta M, Karagueuzian HS, Mandel WJ, Peter T. Acute and chronic effects of amiodarone on delayed afterdepolarization and triggered automaticity in rabbit ventricular myocardium. Am Heart J. 1987;113:289-96. 



\section{CHAPTER 5}

\section{The JT area Indicates Dispersion of Repolarization in Dogs with Atrioventricular Block}

Jurren M. van Opstal, S. Cora Verduyn, Stephan K. Winckels, Hendrik M.

Leerssen, Jet D.M. Leunissen, Hein J.J. Wellens, Marc A. Vos

Department of Cardiology, Cardiovascular Research Institute Maastricht, Maastricht, The Netherlands 


\section{ABSTRACT}

Background: Heterogeneity in cardiac repolarization $(\triangle \mathrm{APD})$ is known to be arrhythmic. In the dog model of chronic complete AV block and acquired long QT syndrome, an increase in $\triangle \mathrm{MAPD}$ (defined as left ventricular monophasic action potential duration (MAPD) minus right ventricular MAPD) is often associated with changes in T wave morphology. The purpose of this study was to correlate known changes in $\triangle M A P D$ with the planimetric total area of the $T$ wave on the surface ECG (f $\mathrm{T}$, $\mathrm{mV} \cdot \mathrm{ms})$.

Methods and Results: The relationship between $\triangle \mathrm{MAPD}$ and total area of the T wave (i.e. JT area) was assessed in four different protocols with different types of dispersion after: 1) class III drugs followed by levcromakalim $(n=7), 2)$ LAD coronary artery occlusion and reperfusion $(n=6), 3)$ dronedarone i.v, an amiodarone like agent $(n=5)$ and 4) steady state pacing at cycle lengths of $1000 \mathrm{~ms}$ and $500 \mathrm{~ms}(\mathrm{n}=5)$. Class III drugs increased $\triangle \mathrm{MAPD}(55 \pm 40 \mathrm{~ms}$ to $120 \pm 50 \mathrm{~ms}, \mathrm{P}<0.05)$, which was correlated $(r=0.74, \mathrm{P}<0.001)$ with an increased $\mathrm{JT}$ area $(50$ $\pm 40 \mathrm{mV} \cdot \mathrm{ms}$ to $95 \pm 35 \mathrm{mV} \cdot \mathrm{ms}, \mathrm{P}<0.05)$. Ischemia increased both $\triangle \mathrm{MAPD}(30 \pm 25 \mathrm{~ms}$ to $90 \pm 40 \mathrm{~ms}, \mathrm{P}<0.05)$ and $\mathrm{JT}$ area $(60 \pm 55$ $\mathrm{mV} \cdot \mathrm{ms}$ to $75 \pm 50 \mathrm{mV} \cdot \mathrm{ms}, \mathrm{P}<0.05)$. Both levcromakalim and reperfusion reversed these conditions. Dronedarone had no effect on $\triangle \mathrm{MAPD}$ or on JT area while a faster frequency reduced both $\triangle \mathrm{MAPD}$ and $\mathrm{JT}$ area.

Conclusions: Changes in dispersion of ventricular repolarization are reflected by alterations in JT area. This non-invasive parameter may therefore be used to recognize changes in heterogeneity in ventricular repolarization. 


\section{INTRODUCTION}

Dispersion of ventricular repolarization is a widely used term to describe spatial inhomogeneities in cardiac action potential durations (APDs) throughout the heart. Both clinically and experimentally, ${ }^{1-18}$ inhomogeneity of repolarization has been shown to play an important role in the genesis and maintenance of ventricular arrhythmias, such as Torsade de Pointes arrhythmias (TdP). Unfortunately, dispersion can only be assessed invasively by catheter (endo and/or epicardially) or (multiple) needle techniques (transmurally). ${ }^{1-18}$

Whether dispersion can be visualized non-invasively, on the surface ECG, remains uncertain. For over a decade, QT dispersion was considered to represent spatial repolarization dispersion in the heart. However, recent studies challenged the concept, and also the clinical usefulness of QT dispersion was questioned. ${ }^{19-23}$ Consequently, emphasis shifted to the T-wave morphology as the better representative of repolarization dispersion. . $^{3,10,24-34}$

In the dog model with chronic AV block and acquired long QT syndrome we and others have demonstrated, by needle and catheter mapping, the relevance of regional dispersion of repolarization for drug induced TdP and sudden cardiac death. ${ }^{6-9,11,15-18}$ In the model, an increased dispersion after class III drugs is often associated with changes in $\mathrm{T}$-wave morphology and/or occurrence of $\mathrm{U}$ waves. Two recent studies proposed the area of the total $\mathrm{T}$ wave (i.e., JT area), including both amplitude and time components of repolarization, ${ }^{29,32}$ to reflect spatial dispersion in the heart. Therefore, we investigated whether known changes in interventricular dispersion of repolarization could be visualized in the ECG by measuring JT area. The protocols that we used to alter repolarization parameters included: 1) the administration of class III antiarrhythmic drugs, which increase dispersion by inhomogeneous lengthening of the APD, and 2) acute ischemia, which increases dispersion by inhomogeneous shortening of the APD.

\section{METHODS}

\section{GENERAL}

A total of 28 experiments in anesthetized complete-AV block dogs were performed. ${ }^{6,8}$ A detailed description of the procedure, anesthesia, ventilation, pre and postoperative care has been described in previous articles from our group.

Animal handling was in accordance with the 'European Directive for the Protection of Vertebrate Animals used for Experimental and other Scientific Purposes (European Union Directive \#86/609/CEE)'.

Six-surface ECG leads and 2 endocardial monophasic action potential signals (MAP) were recorded simultaneously and stored on hard disk. MAP catheters (EP 
Technologies Inc, Sunnyvale, CA, USA) were placed endocardially in the left (LV) and right ventricular (RV) cavity under fluoroscopic guidance. The signals were amplified with a customized isolated DC-coupled differential amplifier with a frequency range of $0-500 \mathrm{~Hz}$ and a $20-\mathrm{mV}$ calibration pulse. The offset of the amplifier is variable and can be adjusted to the recorded signal. MAP phases were defined according to the definitions used for transmembrane potentials, ${ }^{35}$ where amplitude has been defined as the voltage difference between phase 2 and 4 of the MAP signal. Besides a minimal amplitude of $15 \mathrm{mV}$, the MAP has to have a stable configuration and a smooth shape to be acceptable for measurements. MAP catheters were maintained in the same position except in the class III drug and levcromakalim protocol (see further), in which the catheters were readjusted to improve contact with the endocardium. The readjustment, however, did not influence MAP duration.

\section{STUDY DESIGN}

Interventricular dispersion in relation to the JT area was assessed in four protocols in which interventricular dispersion was differently modulated: 1) inhomogeneous lengthening of the APD by IV administration of ibutilide or almokalant $(n=10)$, followed by the $\mathrm{I}_{\mathrm{K}-\mathrm{ATP}}$ channel opener levcromakalim to revert the class III-induced electrophysiological changes, 2) inhomogeneous shortening of the APD by 6 minutes of temporary occlusion of the left anterior descending coronary artery (LAD) ( $n=6$ ) followed by reperfusion, 3) homogeneous shortening of the APD by intravenous administration of the amiodarone like agent dronedarone $(n=7)$, and 4) rate dependent shortening of the APD by steady state paced cycle lengths of $1000 \mathrm{~ms}$ and $500 \mathrm{~ms}(\mathrm{n}=5)$.

The dronedarone and ischemia/reperfusion experiments were analyzed retrospectively using data from previous publications, ${ }^{6,36,37}$ while the class III/ levcromakalim and APD-rate dependency experiments were done prospectively. In the ischemia and rate dependency experiments, continuous pacing was performed using a fixed pacing electrode. In the class III and dronedarone studies, idioventricular rhythm was present. Only experiments were accepted which showed no changes in QRS configuration and/or QRS voltage during the study.

\section{Class III drugs and Levcromakalim}

The dose of almokalant $(0.12 \mathrm{mg} / \mathrm{kg} / 10 \mathrm{~min}, \mathrm{n}=3)$ was based on previous animal studies, ${ }^{6}$ while the dosage of ibutilide $(0.025 \mathrm{mg} / \mathrm{kg} / 5 \mathrm{~min}, \mathrm{n}=4)$ was determined using clinical data. ${ }^{38}$ All dogs received $0.01 \mathrm{mg} / \mathrm{kg} / 3 \mathrm{~min}$ of levcromakalim $35-55$ minutes after the start of the class III agent to revert the electrophysiological effects and, if present, to suppress TdP. The time of levcromakalim administration was dependent on the frequency of TdP occurrence. Electrophysiological measurements were performed just before and 10 minutes after the start of the infusion of the class III drugs respectively levcromakalim. 


\section{LAD Occlusion and Reperfusion}

The LV MAP was placed in the area supplied by the LAD coronary artery. A left sided thoracotomy was performed to ligate the LAD just below the first or second diagonal branch $(n=6)$. After six minutes of occlusion, the coronary artery was reopened. During the experiment the heart was paced continuously at a cycle length of $800 \mathrm{~ms}$ from a right ventricular endocardial electrode to maintain the same QRS configuration. ${ }^{37}$

Electrophysiological measurements with intervals of 30 seconds were performed from one minute before the start of the occlusion till 4 minutes after the end of the occlusion.

\section{Dronedarone}

For details about the dronedarone protocol $(2.5 \mathrm{mg} / \mathrm{kg} / 10 \mathrm{~min}, \mathrm{n}=5)$, we refer to a previous publication. ${ }^{36}$ Dronedarone given intravenously, in contrast to chronic administration, ${ }^{18,39}$ results in APD shortening. The electrophysiological effects were measured at baseline and 10 minutes after the start of drug infusion.

\section{Rate Changes}

As dispersion of repolarization is known to increase with bradycardia, ${ }^{7}$ the behavior of $\mathrm{JT}$ area in relation to dispersion of repolarization was assessed in another 5 dogs during paced frequencies of $1000 \mathrm{~ms}$ and $500 \mathrm{~ms}$. Pacing was performed from an LV epicardial electrode which had been placed during the creation of AV block. Electrophysiological parameters were measured after two minutes of pacing when a steady state was reached.

\section{DATA ANALYSIS}

Measurements were performed independently by two researchers (JVO and SW). Applying a custom made-computer program (ECG View), with a resolution of $2 \mathrm{~ms}$ and adjustable gain and time scale, we measured the following parameters off line: the cycle length of idioventricular rhythm (CL-IVR), QT time, the duration of the LV- and RV MAP at $100 \%$ of repolarization. From these measurements, the interventricular dispersion of repolarization $(\triangle M A P D)$ was calculated, defined as LV MAP duration (LV MAPD) minus RV MAP duration (RV MAPD).

The JT area was measured in all 6-surface ECG leads and was defined as the total planimetric area from J point to the $T$ end point (the area of the ECG voltage minus its baseline, integrated over the JT interval, i.e. ${ }_{\mathrm{J}} \mathrm{T}, \mathrm{mV} \cdot \mathrm{ms}$ ) as already described by Wilson et al in the 30 's of the last century. ${ }^{40}$ The baseline was defined as the isoelectric segment just preceding the QRS complex. The first delimiter was set at the first deflection of the T wave if an isoelectric ST segment was present; otherwise it was set just following the J point of the QRS. The second delimiter was 


\section{control class III}
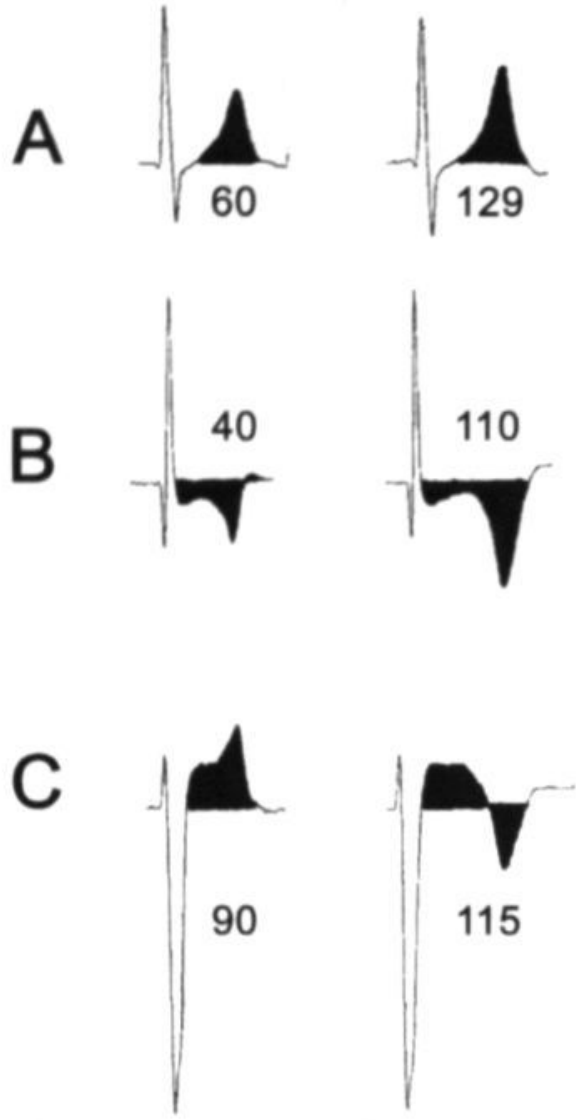

Figure 1 - Three representative examples $(\operatorname{dogs} A, B, C)$ with different JT morphologies to illustrate the assessment of the JT area $(\mathrm{mV} \cdot \mathrm{ms})$ in lead II before and after class III drug administration.

set just following the end of the $T$ or, if present, $U$ wave (Figure 1). In case a $P$ wave affected the JT interval, this interval was excluded from analysis.

\section{STATISIICS}

Pooled data are expressed as mean \pm standard deviation (SD). Comparisons were made using a paired Student t-test, except for the ischemia-reperfusion study were statistical analysis was performed using ANOVA for repeated measures. P-values < 0.05 were considered significant. 


\section{RESULTS}

\section{INTERLEAD DIFFERENCES OF JT AREA}

JT area measurements of the surface ECG leads showed considerable variation with the largest values seen in lead II (range $8-95 \mathrm{mV} \cdot \mathrm{ms}$ ). The mean JT area amounted $10 \pm 5,50 \pm 40,45 \pm 40,30 \pm 20,20 \pm 20$, and $45 \pm 35 \mathrm{mV} \cdot \mathrm{ms}$ for respectively leads I, II, III, aVR, aVL, and aVF.

Because no interlead differences in the behavior of the JT area to challenges were present and the absolute values were highest in lead II, we chose to present the JT area data from lead II.

\section{CLASS III AGENTS AND LEVCROMAKALIM}

Administration of class III drugs resulted in a significant increase in the CL-IVR and the repolarization parameters, QT time, LV MAPD and RV MAPD (Table 1). As LV MAPD increased more than RV MAPD, $\triangle$ MAPD augmented. Spontaneous TdP occurred in four out of seven animals that had also the highest JT area values $(116 \pm 14 \mathrm{mV} \cdot \mathrm{ms})$.

Figure 1 shows representative examples of different JT morphologies before and after class III drug administration. Both in this figure and in Table 1, a clear increase in JT area can be seen after drug treatment (Table 1). Figure 2 shows a representative example of the electrophysiological changes occurring after class III drugs (same dog as panel B in Figure 1). During control (left panel) both the LV-and RV MAP show a smooth contour and no interventricular dispersion. Ibutilide (central panel) increased LV MAPD and $\triangle$ MAPD markedly while the T wave broadened and deepened, leading to a JT area of $110 \mathrm{mV} \cdot \mathrm{ms}$.

The electrophysiological values prior to levcromakalim ( $t=0$ ' lem in Table 1) were comparable in 5 of 7 dogs to the values measured 10 minutes after class III drug administration, whereas 2 of 7 dogs showed a reduction in QT time. Levcromakalim

Table 1 - Electrophysiological effect of class III drugs and levcromakalim ( $\mathbf{n = 7})$

\begin{tabular}{lllll}
\hline & control & $t=10^{\prime}$ class III & $t=0^{\prime} \mathrm{lem}$ & $t=10^{\prime} \mathrm{lem}$ \\
\hline CL-IVR & $1585 \pm 450$ & $2045 \pm 340^{\circ}$ & $2030 \pm 655$ & $2025 \pm 960$ \\
QT time & $395 \pm 25$ & $530 \pm 80^{\circ}$ & $500 \pm 65$ & $405 \pm 55^{*} \cdot$ \\
LV MAPD & $370 \pm 70$ & $515 \pm 85^{\circ}$ & $515 \pm 75$ & $360 \pm 45^{*}$ \\
RV MAPD & $315 \pm 40$ & $400 \pm 40^{\circ}$ & $395 \pm 25$ & $325 \pm 30^{*}$ \\
$\Delta$ MAPD & $55 \pm 40$ & $120 \pm 50^{\circ}$ & $115 \pm 50$ & $30 \pm 30^{* *}$ \\
JT area & $50 \pm 40$ & $95 \pm 35^{\circ}$ & $100 \pm 40$ & $50 \pm 30^{* *}$ \\
\hline
\end{tabular}

Values in $\mathrm{ms}$ or or $\mathrm{mV} \cdot \mathrm{ms}$ (JT area) and mean $\pm \mathrm{SD}$; class III: ibutulide / almokalant; lem: levcromakalim; ' $\mathrm{p}<0.05 \mathrm{t}=10$ ' class III $v$ s control; ${ }^{\cdots} \mathrm{p}<0.05 \mathrm{t}=10^{\prime}$ lem $v$ t $\mathrm{t}=0$ lem 
1 control

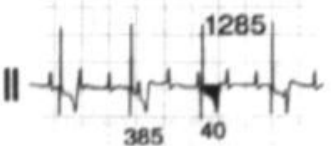

avr
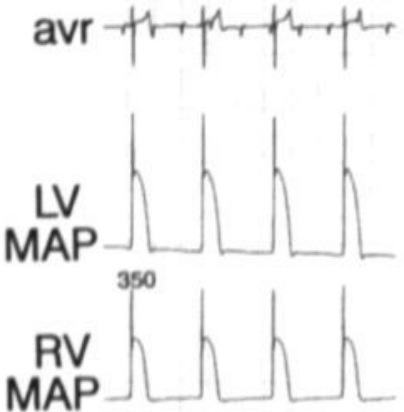

360
2 ibutilide
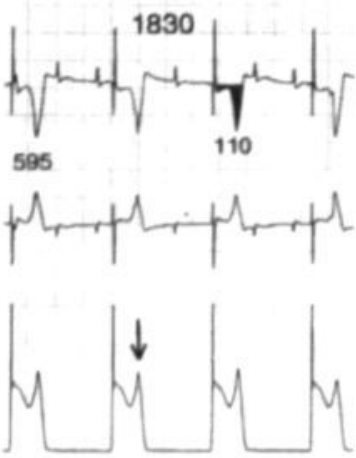

650

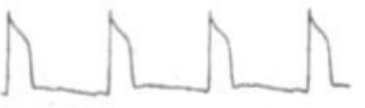

460

\section{3 levcromakalim}
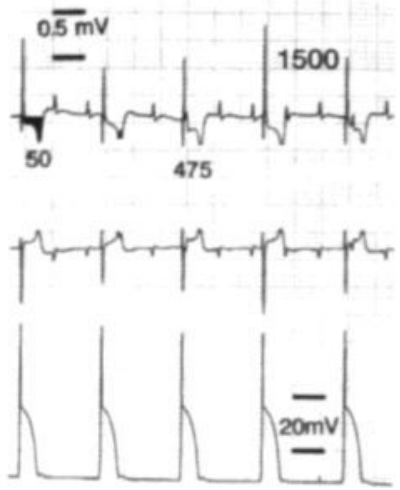

360

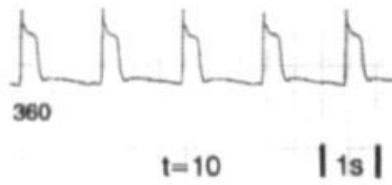

Figure 2 - Concomitant behavior of JT area and $\triangle \mathrm{MAPD}$ after ibutilide and levcromakalim administration. Panel 1: Under control circumstances the LV and RV MAP show a smooth contour and no $\triangle M A P D$. The JT area measures $40 \mathrm{mV}$. $\mathrm{ms}$. Panel 2: Ibutilide $(0.025 \mathrm{mg} / \mathrm{kg} / 5 \mathrm{~min})$ increases $\triangle M A P D$ to $190 \mathrm{~ms}$ and EADs develop in the LV MAP (indicated by arrow). On the surface ECG the JT area has increased threefold compared to the control situation. $t=55$ min indicates the time in minutes after the start of the ibutilide infusion which is just before starting levcromakalim. Panel 3: Ten minutes later levcromakalim $(0.01 \mathrm{mg} / \mathrm{kg} / 3 \mathrm{~min})$ returned both $\triangle \mathrm{MAPD}$ and $\mathrm{JT}$ area to control values.

decreased the repolarization parameters considerably (QT time, LV MAPD, RV MAPD, $\triangle M A P D$ and JT area) in all dogs (right panel in Figure 2 and Table 1) and prevented recurrences of TdP arrhythmias, while CL-IVR remained similar.

Figure 3 shows the correlation, $r=0.74, p<0.001$, between the JT area and $\triangle M A P D$ when combining baseline and class III drugs values $(n=7)$.

\section{LAD OCCLUSION}

Ischemia of the LAD area for six minutes did not affect QT time, but decreased LV MAPD dramatically without affecting RV MAPD (Table 2). This resulted in an inverted (negative) $\triangle M A P D$ exceeding the positive $\triangle M A P D$ during control circumstances (Table 2). Also JT area increased significantly. Reperfusion reverted LV MAPD, $\triangle \mathrm{MAPD}$ and JT area to baseline values. The close relation between $\triangle \mathrm{MAPD}$ and JT area can be appreciated in Figure 4, where the increase and decrease in $\triangle \mathrm{MAPD}$ is mirrored by the JT area response. 


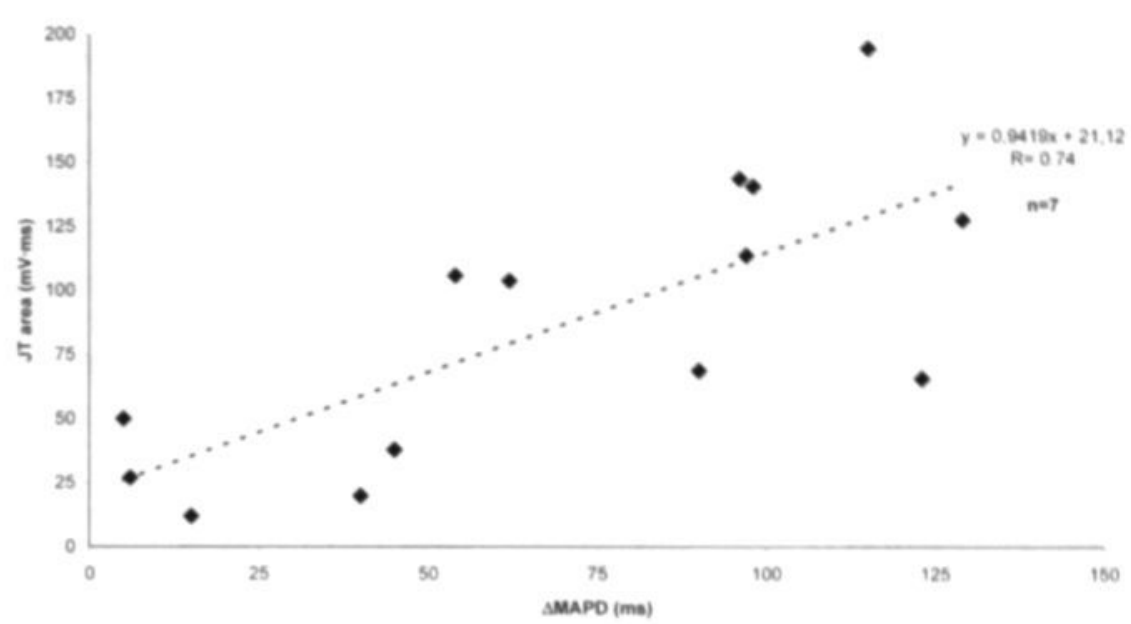

Figure 3 - Correlation of JT area and $\triangle \mathrm{MAPD}$ values before and after administration of class III drugs ( $r=0.74, p<0.001)$

Table 2 - Electrophysiological effects of ischemia and reperfusion $(n=6)$

\begin{tabular}{llll}
\hline & control & ischemia & reperfusion \\
\hline CL-IVR & 800 paced & 800 paced & 800 paced \\
QT time & $380 \pm 50$ & $370 \pm 50$ & $380 \pm 55$ \\
LV MAPD & $310 \pm 40$ & $195 \pm 25^{\circ}$ & $310 \pm 30^{*}$ \\
RV MAPD & $280 \pm 35$ & $280 \pm 35$ & $285 \pm 40$ \\
DMAPD & $30 \pm 25$ & $-90 \pm 40^{\circ}$ & $25 \pm 15^{\circ} \cdot$ \\
JT area & $60 \pm 55$ & $75 \pm 50^{\circ}$ & $60 \pm 55^{*}$ \\
\hline
\end{tabular}

Values in $\mathrm{ms}$ or $\mathrm{mV} \cdot \mathrm{ms}\left(\mathrm{JT}\right.$ area) and mean $\pm \mathrm{SD}^{*} \mathrm{p}<0.05$ ischemia $v$ s control; ${ }^{*} \mathrm{p}<0.05$ reperfusion $v s$ ischemia

\section{DRONEDARONE}

Dronedarone did not affect CL-IVR, but decreased QT time $(410 \pm 45 \mathrm{~ms}$ to $370 \pm$ $45 \mathrm{~ms})$, LV MAPD $(375 \pm 60 \mathrm{~ms}$ to $340 \pm 55 \mathrm{~ms})$ and RV MAPD $(335 \pm 20 \mathrm{~ms}$ to $300 \pm 40 \mathrm{~ms})$ significantly. Because both MAPDs did reduce equally, $\triangle \mathrm{MAPD}(50 \pm$ $40 \mathrm{~ms}$ to $55 \pm 35 \mathrm{~ms})$ did not change. Also the JT area $(65 \pm 40 \mathrm{mV} \cdot \mathrm{ms}$ to $65 \pm 40$ $\mathrm{mV} \cdot \mathrm{ms})$ remained the same.

\section{RATE CHANGES}

At a paced frequency of $1000 \mathrm{~ms}$, QT time measured $390 \pm 35 \mathrm{~ms}$ with a $\triangle \mathrm{MAPD}$ of $70 \pm 25 \mathrm{~ms}$ and a JT area of $190 \pm 125 \mathrm{mV} \cdot \mathrm{ms}$. The faster cycle length of $500 \mathrm{~ms}$ decreased QT time to $320 \pm 15 \mathrm{~ms}, \triangle \mathrm{MAPD}$ to $35 \pm 20 \mathrm{~ms}$ and JT area to $140 \pm 90$ $\mathrm{mV} \cdot \mathrm{ms}($ all $\mathrm{P}<0.05)$. 
Table 3 - Overview of the electrophysiological effects in the different protocols

\begin{tabular}{llll}
\hline & $\triangle M A P D$ & $J T$ area & $Q T$ time \\
\hline Class III & $\uparrow$ & $\uparrow$ & $\uparrow$ \\
Ischemia & $\uparrow$ & $\uparrow$ & $=$ \\
Dronedarone & $=$ & $=$ & $\downarrow$ \\
Rate Increase & $\downarrow$ & $\downarrow$ & $\downarrow$ \\
\hline
\end{tabular}

$\uparrow \downarrow$ : increase respectively decrease in values with intervention

* : no change in values with intervention

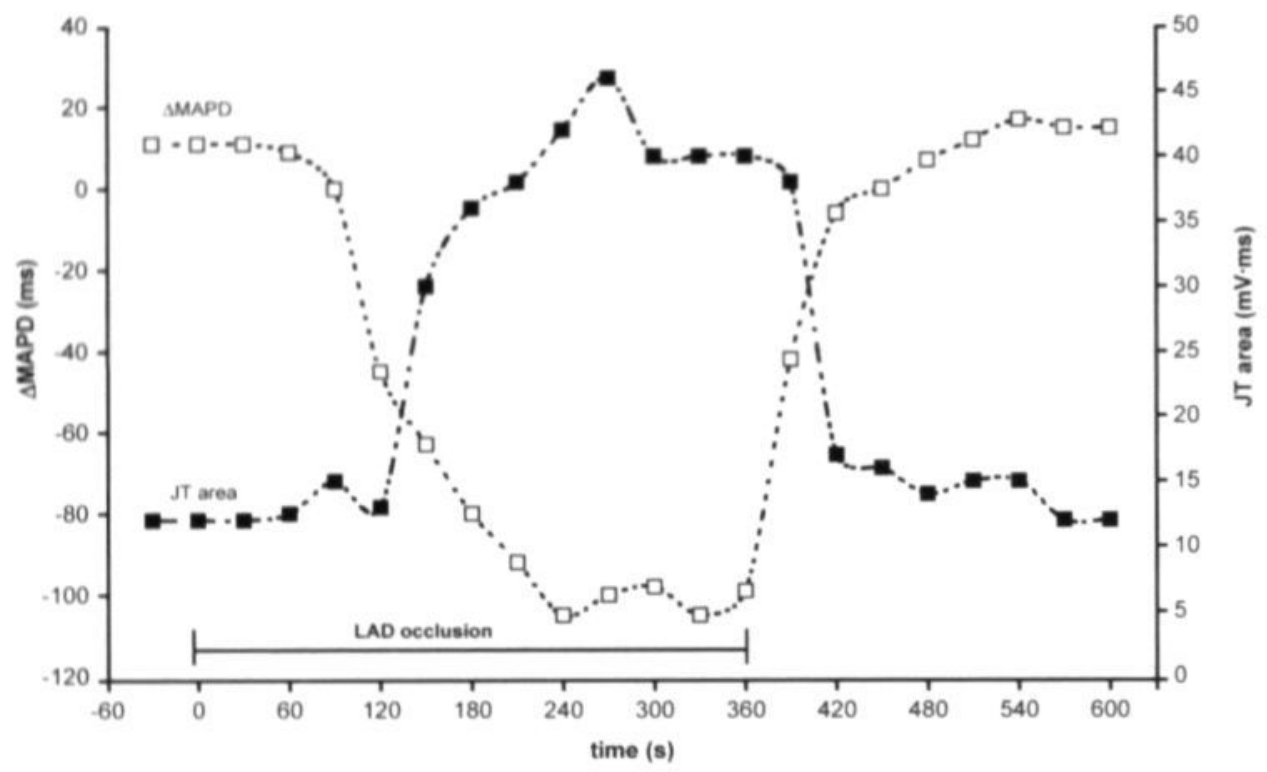

Figure 4 - Relation between JT area (closed squares) and $\triangle \mathrm{MAPD}$ (open squares) during ischemia and reperfusion in an individual dog. On the horizontal axis the time in seconds is indicated with the period of LAD occlusion (0-360 s). On the left vertical axis $\triangle M A P D$ is depicted in ms, while on the right vertical axis JT area in $\mathrm{mV} \cdot \mathrm{ms}$ is shown. As a result of the shortening of LV MAPD by ischemia, the difference with the non-ischemic RV MAPD increases, resulting in negative $\triangle M A P D$ values. JT area follows the increase in heterogeneity closely, thereby showing the mirror image of $\triangle M A P D$. Reperfusion returns both $\triangle \mathrm{MAPD}$ and JT area to control values.

\section{OVERVIEW}

In Table 3 the results are summarized for the four different interventions and their effect on $\triangle \mathrm{MAPD}, \mathrm{JT}$ area and QT time. JT area follows $\triangle \mathrm{MAPD}$ during all different conditions, while this is not the case for the QT time, i.e. during ischemia and dronedarone treatment. 


\section{DISCUSSION}

The present study demonstrates that changes in interventricular dispersion of repolarization measured by MAPs in the AV-block dog are reflected by alterations in $\mathrm{JT}$ area (Table 3 ). The highest $\mathrm{JT}$ area values in the class III drug experiments were associated with $\mathrm{TdP}$ occurrence.

\section{RELATION OF JT AREA WITH INTERVENTRICULAR DISPERSION OF REPOLARIZATION}

Dispersion of APD has been demonstrated to exist over the left ventricular (LV) wall, between the ventricles (interventricular dispersion: $\triangle M A P D$ ) and between LV apex to base. Accurate assessment of dispersion requires an invasive procedure, either using catheters (endo- or epicardially) or needles with multiple recording sites through the ventricular wall. ${ }^{1-8,10-18}$ In the present study, an increase or decrease in $\triangle \mathrm{MAPD}$ was compared with different ECG parameters. A relation between $\triangle \mathrm{MAPD}$ and JT area was found, both during inhomogeneous lengthening of the APD (class III drugs, Table 1) or regional shortening of the APD (ischemia, Table 2). A linear correlation $(r=0.74, p<0.001)$ was present between $J T$ area and MAP dispersion during class III drugs but not during ischemia. A possible explanation could be that during ischemia most of the LV repolarization does not shorten as evident from the constant QT time. Only the APD of the ischemic area shortens, bringing the peak of the $T$ wave forward explaining ST elevation. Therefore $\triangle A P D$ does not represent JT area. Furthermore, JT area and MAP dispersion were associated when we 1) reversed the class III effects by the $\mathrm{I}_{\mathrm{K}-\mathrm{ATP}}$ opener levcromakalim (Table 1), 2) reperfused the ischemic area (Table 2), 3) administered dronedarone, and 4) during fixed rate pacing, using two pacing rates.

Several experimental and clinical studies pointed to changes in the $\mathrm{T}$ wave in relation to invasively assessed (transmural) heterogeneity of repolarization. $3,10,24,29,31,32$ Also analyses of $\mathrm{T}$ wave morphology proved to be useful for recognizing patients with disordered repolarization. ${ }^{22,26,28,30,33,34}$ In the isolated rabbit and canine heart it was demonstrated that the area of the $T$ wave correlated well with the actual dispersion of repolarization. ${ }^{29,32} \mathrm{Zabel}$ et al. found a correlation of $\mathrm{r}=0.79$ between MAP dispersion and TU area, a value which corresponds well with the relationship in our study $(r=0.74)$, while Punske et al. found a relationship of $r=0.98$ between recovery times and STT area. However, in humans a correlation between MAP dispersion at baseline, i.e. without intervention, and $\mathrm{T}$ area was not found. ${ }^{31}$ Also in a prospective study to identify post myocardial infarct patients at risk for arrhythmic events, the $\mathrm{T}$ area at baseline appeared not to be predictive. ${ }^{20}$ These and our results suggest that the absolute JT area at baseline is not useful to assess the amount of heterogeneity of repolarization or to identify subjects at risk for arrhythmias, probably because of large interindividual variations in JT area. 
However, as the present study demonstrates, JT area can be used to assess susceptibility to arrhythmias after a challenge (e.g. class III drugs) in a serial comparison.

\section{JT TIME OR JTU TIME?}

As the exact origin of the $U$ wave is not known yet, ${ }^{41}$ the correct nomenclature of the repolarization phase, JT time or JTU time, is a controversial subject. We considered the entire repolarization phase as a $T$ wave and as such included biphasic $T$ waves or $\mathrm{U}$ waves as part of the duration and area measurements. ${ }^{10,22}$

\section{NO RELATION BETWEEN QT TIME AND $\triangle M A P D$}

QT time appeared to behave independently from $\triangle \mathrm{MAPD}$ or from JT area, as shown during ischemia/reperfusion and dronedarone (Table 3). A decrease in QT time by dronedarone did not result in a diminished $\triangle \mathrm{MAPD}$ or JT area while ischemia increased both $\triangle \mathrm{MAPD}$ and JT area, but not QT time.

\section{LIMITATIONS}

An important limitation of the present study is the abnormal ventricular activation pattern in our dogs because of the ventricular escape rhythm during complete AV block or ventricular pacing. The pattern of ventricular activation (and rate) may be an important contributor the amount of dispersion between different animals, which could account for the large inter individual variations in JT area under control circumstances. As a consequence the behavior of the JT area in response to a challenge should be assessed intraindividually than interindividually.

$\triangle M A P D$ was chosen as the reference. We are well aware of the fact that dispersion measured at only two sites in the heart ( $\mathrm{LV}$ and RV) ignores possible transmural and intraventricular differences. Recent studies have shown that dispersion in the CAVB dog heart is located in many regions, including transmurally and transeptally. ${ }^{9}$ Thus, to what extent increased transmural differences in APD will affect T wave morphology has to be investigated.

\section{CONCLUSIONS}

An increase in heterogeneity of ventricular repolarization after a challenge in the chronic complete-AV block dog can be visualized on the ECG by measuring area changes in the total phase of repolarization, i.e., the JT area. Interventricular dispersion was not reflected by QT time. The JT area is relatively easy to assess and should 
be evaluated in risk-stratifying the individual patient for the development of TdP arrhythmias after class III drug administration.

\section{ACKNOWLEDGMENTS}

The authors would like to express their gratitude to Dr. Joep Smeets for helpful comments on the manuscript.

Dr. Verduyn was supported by a research grant of the Janssen Research Foundation. Financial support by the Netherlands Heart Foundation (\#98.042) is gratefully acknowledged. Dr. Dino Nisato, Sanofi-Synthélabo, Montpellier, France, provided dronedarone.

\section{REFERENCES}

1. Han J, Moe GK. Nonuniform recovery of excitability in ventricular muscle. Cine Res. 1964; 14:44-60.

2. Kuo CS, Munakata K, Reddy CP, Surawicz B. Characteristics and possible mechanism of ventricular arrhythmia dependent on the dispersion of action potential durations. Circulation. 1983;67:1356-67.

3. El-Sherif N, Zeiler RH, Craelius W, Gough WB, Henkin R. QTU prolongation and polymorphic ventricular tachyarrhythmias due to bradycardia-dependent early afterdepolarizations. Afterdepolarizations and ventricular arrhythmias. Circ Res. 1988;63:286-305.

4. Vassallo JA, Cassidy DM, Kindwall KE, Marchlinski FE, Josephson ME. Nonuniform recovery of excitability in the left ventricle. Circulation. 1988;78:1365-72.

5. Habbab MA, El-Sherif N. Drug-induced torsades de pointes: role of early afterdepolarizations and dispersion of repolarization. Am J Med. 1990;89:241-6.

6. Verduyn SC, Vos MA, van der Zande J, Kulcsar A, Wellens HJ. Further observations to elucidate the role of interventricular dispersion of repolarization and early afterdepolarizations in the genesis of acquired torsade de pointes arrhythmias: a comparison between almokalant and d-sotalol using the dog as its own control. J Am Coll Cardiol. 1997;30:1575-84.

7. Verduyn SC, Vos MA, van der Zande J, van der Hulst FF, Wellens HJ. Role of interventricular dispersion of repolarization in acquired torsade-de-pointes arrhythmias: reversal by magnesium. Cardiovase Res. 1997;34:453-63.

8. Vos MA, de Groot SH, Verduyn SC, van der Zande J, Leunissen HD, Cleutjens JP, van Bilsen M, Daemen MJ, Schreuder JJ, Allessie MA, Wellens HJ. Enhanced susceptibility for acquired torsade de pointes arrhythmias in the dog with chronic, complete AV block is related to cardiac hypertrophy and electrical remodeling. Circulation. 1998;98:1125-35.

9. Jungschleger JJ, van der Hulst FF, Verduyn SC, Leunissen JD, Anyukhovsky EP, de Bakker JMT, Vos MA. Enhancement of dispersion in repolarization after atrio-ventricular block in the canine heart. PACE 2001;24:624. 
10. Yan GX, Antzelevitch C. Cellular basis for the normal $T$ wave and the electrocardiographic manifestations of the long-QT syndrome. Circulation. 1998;98:1928-36.

11. Chen YJ, Hsich MH, Chiou CW, Chen SA. Electropharmacologic characteristics of ventricular proarrhythmia induced by iburilide. J Cardiovasc Pharmacol. 1999;34:237-47.

12. Shimizu H, Inoue T, Miwa S, Yoshida A, Itagaki T, Ohnishi Y, Yokoyama M. Dispersion of the monophasic action potential duration in patients with polymorphic ventricular tachycardia. $J$ Electrocardiol. 1999;32:217-24.

13. Cheng J, Kamiya K, Liu W, Tsuji Y, Toyama J, Kodama I. Heterogeneous distribution of the two components of delayed rectifier $\mathrm{K}^{+}$current: a potential mechanism of the proarrhythmic effects of methanesulfonanilideclass III agents. Cardiovase Res. 1999;43:135-47.

14. Weissenburger J, Nesterenko VV, Antzelevitch C. Transmural heterogeneity of ventricular repolarization under baseline and long QT conditions in the canine heart in vivo: torsades de pointes develops with halothane but not pentobarbital anesthesia. J Cardiovasc Electrophysiol. 2000;11:290-304.

15. Yamamoto K, Kozhevnikov DO, Robotis D, Restivo M, El-Sherif N. Mechanism of enhanced susceptibility of hypertrophied heart to acquired Torsade de Pointes arrhythmias. J Am Coll Cardiol. 2001;37:92 A.

16. van Opstal JM, Leunissen JD, Wellens HJ, Vos MA. Azimilide and dofetilide produce similar electrophysiological and proarrhythmic effects in a canine model of Torsade de Pointes arrhythmias. Eur J Pharmacol. 2001;412:67-76.

17. van Opstal JM, Verduyn SC, Leunissen HD, de Groot SH, Wellens HJ, Vos MA. Electrophysiological parameters indicative of sudden cardiac death in the dog with chronic complete AV-block. Cardiovasc Res. 2001;50:354-61.

18. van Opstal JM, Schoenmakers M, Verduyn SC, de Groot SH, Leunissen JD, van Der Hulst FF, Molenschot MM, Wellens HJ, Vos MA. Chronic Amiodarone Evokes No Torsade de Pointes Arrhythmias Despite QT Lengthening in an Animal Model of Acquired Long-QT Syndrome. Circulation. 2001;104:2722-7.

19. Coumel P, Maison-Blanche P, Badilini F. Dispersion of ventricular repolarization: reality? Illusion? Significance? Circulation. 1998;97:2491-3.

20. Zabel M, Klingenheben T, Franz MR, Hohnloser SH. Assessment of QT dispersion for prediction of mortality or arrhythmic events after myocardial infarction: results of a prospective, long-term follow-up study. Cinculation. 1998;97:2543-50.

21. Malik M, Batchvarov VN. Measurement, interpretation and clinical potential of QT dispersion. J Am Coll Cardiol. 2000;36:1749-66.

22. Malik M, Acar B, Gang Y, Yap YG, Hnatkova K, Camm AJ. QT dispersion does not represent electrocardiographic interlead heterogeneity of ventricular repolarization. I Cardiovase Electrophysiol. 2000;11:835-43.

23. Brendorp B, Elming H, Jun L, Kober L, Malik M, Jensen GB, Torp-Pedersen C. QT Dispersion Has No Prognostic Information for Patients With Advanced Congestive Heart Failure and Reduced Left Ventricular Systolic Function. Circulation. 2001:103:831-835. 
24. Franz MR, Bargheer K, Rafflenbeul W, Haverich A, Lichtlen PR. Monophasic action potential mapping in human subjects with normal electrocardiograms: direct evidence for the genesis of the T wave. Cinculation. 1987;75:379-86.

25. Merri M, Benhorin J, Alberti M, Locati E, Moss AJ. Electrocardiographic quantitation of ventricular repolarization. Circulation. 1989;80:1301-8.

26. Benhorin J, Merri M, Alberti M, Locati E, Moss AJ, Hall WJ, Cui L. Long QT syndrome. New electrocardiographic characteristics. Circulation. 1990;82:521-7.

27. Habbab MA, El-Sherif N. TU alternans, long QTU, and torsade de pointes: clinical and experimental observations. Pacing Clin Electrophysiol. 1992;15:916-31.

28. Malfatto G, Beria G, Sala S, Bonazzi O, Schwartz PJ. Quantitative analysis of T wave abnormalities and their prognostic implications in the idiopathic long QT syndrome. J Am Coll Cardiol. 1994;23:296-301.

29. Zabel M, Portnoy S, Franz MR. Electrocardiographic indexes of dispersion of ventricular repolarization: an isolated heart validation study. J Am Coll Cardiol. 1995;25:746-52.

30. Priori SG, Mortara DW, Napolitano C, Diehl L, Paganini V, Cantu F, Cantu G, Schwartz PJ. Evaluation of the spatial aspects of $\mathrm{T}$ wave complexity in the long-QT syndrome. Circulation. 1997;96:3006-12.

31. Zabel M, Lichtlen PR, Haverich A, Franz MR. Comparison of ECG variables of dispersion of ventricular repolarization with direct myocardial repolarization measurements in the human heart. J Cardiovasc Electrophysiol. 1998;9:1279-84.

32. Punske BB, Lux RL, MacLeod RS, Fuller MS, Ershler PR, Dustman TJ, Vyhmeister Y, Taccardi B. Mechanisms of the spatial distribution of QT intervals on the epicardial and body surfaces. J Cardiovasc Electrophysiol. 1999;10:1605-18.

33. Zabel M, Acar B, Klingenheben T, Franz MR, Hohnloser SH, Malik M. Analysis of 12-lead T wave morphology for risk stratification after myocardial infarction. Circulation. 2000;102:1252-7.

34. Lupoglazoff JM, Denjoy II, Berthet M, Neyroud N, Demay L, Richard P, Hainque B, Vaksmann G, Klug D, Leenhardt A, Maillard G, Coumel P, Guicheney P. Notched T Waves on Holter Recordings Enhance Detection of Patients With LQT2 (HERG) Mutations. Circulation. 2001;103:1095-1101.

35. Vos MA, Verduyn SC, Wellens HJJ. Early afterdepolarizations in the in situ canine heart. Mechanistic insights into acquired Torsade de Pointes arrhythmias. In: MR Franz, ed. Monophasic Action Potentials. Bridging Cell and Bedside. Armonk NY: Futura Publishing; 2000:553-569.

36. Verduyn SC, Vos MA, Leunissen HD, van Opstal JM, Wellens HJ. Evaluation of the acute electrophysiologic effects of intravenous dronedarone, an amiodarone-like agent, with special emphasis on ventricular repolarization and acquired torsade de pointes arrhythmias. J Cardiovasc Pharmacol. 1999;33:212-22.

37. Leerssen HM, Vos MA, Houben R, den Dulk K, Wellens HJ. High uniformity of left and right ventricular repolarization dynamics induced by an abrupt decrease in pacing cycle length in a dog is not affected by left ventricular ischemia. J Cardiovasc Electrophysiol. 2000;11:421-9. 
38. Vos MA, Golitsyn SR, Stangl K, Ruda MY, Van Wijk LV, Harry JD, Perry KT, Touboul P, Steinbeck G, Wellens HJ. Superiority of ibutilide (a new class III agent) over DL-sotalol in converting atrial flutter and atrial fibrillation. The Ibutilide/Sotalol Comparator Study Group. Heart. 1998;79:568-75.

39. Sun W, Sarma JS, Singh BN. Electrophysiological effects of dronedarone (SR33589), a noniodinated benzofuran derivative, in the rabbit heart : comparison with amiodarone. Circulation. 1999;100:2276-81.

40. Wilson FN, MacLeod AG, Barker PS, Johnston FD. The determination and the significance of the areas of the ventricular deflections of the electrocardiogram. Am Heart Journal. 1931;10:46-61.

41. Surawicz B. U wave: facts, hypotheses, misconceptions, and misnomers. J Cardiovasc Electrophysiol. 1998:9:1117-28. 


\section{CHAPTER 6}

\section{Electrophysiological Parameters Indicative of Sudden Cardiac Death in the Dog with Chronic Complete AV block}

Jurren M. van Opstal, S. Cora Verduyn, Jet D.M. Leunissen, S.H. Marieke de Groot, Hein J.J. Wellens, Marc A. Vos

Department of Cardiology, Cardiovascular Research Institute Maastricht, Maastricht, The Netherlands 
$106 \mid$ Chapter 6

\section{ABSTRACT}

Background: The dog model with chronic complete AV block (CAVB) demonstrates a considerable incidence of (witnessed) sudden death (16 of a total of $117 \mathrm{dogs})$. In this study we tried to: 1) elucidate the mechanisms of sudden death using an ECG telemetry device and 2) identify retrospectively the risk parameters indicative of this arrhythmogenic death.

Methods and Results: Between 1994-1998, 78 anesthetized dogs underwent an extensive electrophysiological study including: 1) left (LV) and right ventricular (RV) monophasic action potential (MAP) recordings to assess $\triangle$ MAPD (LV MAP duration minus RV MAP duration) and 2) pacing protocols (PES) to induce Torsade de Pointes arrhythmias (TdP) at 4-6 weeks CAVB. Eight animals experienced sudden cardiac death (SCD) during the follow up period (mean $7 \pm 3$ weeks). Since the response of the CAVB dog to class III drugs is not uniform we also made comparisons among the SCD group, animals demonstrating TdP with drugs (drug responders), and non-responders. For this purpose we selected all animals which 1) received almokalant $(n=15$, $0.12 \mathrm{mg} / \mathrm{kg} / 5 \mathrm{~min}$ ) or ibutilide $(\mathrm{n}=9,0.025 \mathrm{mg} / \mathrm{kg} / 5 \mathrm{~min}$ ) as an additional challenge to induce TdP and 2) had a follow up period of at least 4 weeks. Results: 6 of 8 SCD dogs showed inducible TdP at baseline. Two of 8 dogs had telemetric ECG surveillance and both revealed polymorphic VT as the cause of SCD. Baseline $\triangle \mathrm{MAPD}$ of the SCD $(90 \pm 15$ ms) was significantly higher than the non-SCD group $(n=70$, $60 \pm 30 \mathrm{~ms}$ ). Of the 24 dogs which received class III drugs, 12 belonged to the drug-responder group. $\triangle \mathrm{MAPD}$ of the drug-responder group $(80 \pm 15 \mathrm{~ms})$ was similar to the SCD group and significantly higher compared to the non-responder group ( $\mathrm{n}=12,40 \pm 25 \mathrm{~ms}$ ). QT time and cycle length of idioventricular rhythm were not different. Conclusions: In the CAVB dog model, SCD is 1) most probably related to $\mathrm{TdP}$ while 2) inducible $\mathrm{TdP}$ and the measure of $\triangle \mathrm{MAPD}$ at baseline indicate susceptibility to SCD. 


\section{INTRODUCTION}

In Maastricht, the chronic complete-AV block (CAVB) dog has been studied extensively to understand its enhanced susceptibility to ventricular arrhythmias. ${ }^{1-5}$ The bradycardia-induced volume overload by acute AV block initiates rapidly a number of adaptation processes to compensate for the decreased cardiac output and the increased end-diastolic pressure. ${ }^{5}$ These remodeling processes are completed within four weeks of CAVB and include 1) development of biventricular eccentric hypertrophy, 2) compensated cardiac hemodynamics and 3) heterogeneous prolongation of the ventricular repolarization time, resulting in an increased dispersion of repolarization (i.e. electrical remodeling). ${ }^{1,2.5}$ These adaptations, alone or synergistically, increase the risk for early afterdepolarizations (EAD) - respectively delayed afterdepolarization-dependent triggered arrhythmias and drug-induced Torsade de Pointes arrhythmias (TdP). 1,2,4-10 Moreover, a number of (witnessed) sudden deaths occur in the cages after four weeks of CAVB.

To assess if sudden death could be attributed to ventricular arrhythmias, a 2-lead electrocardiagram (ECG) telemetric device was implanted prospectively. As telemetry revealed sudden death to be arrhythmogenic, our large canine database at baseline CAVB was used to identify retrospectively the electrophysiological parameters which could predict susceptibility to sudden cardiac death (SCD).

\section{METHODS}

Between 1994-1998, the CAVB dog (in total, $\mathrm{n}=117$ ) was investigated to determine 1) the different remodeling processes in relation to ventricular arrhythmias and 2) to compare the ability of different antiarrhythmic drugs to induce TdP. During this period 16 of 117 dogs experienced sudden death.

Before discussing the employment of the telemetry device, the definition of $\mathrm{SCD}$, and the use of our electrophysiological database, the general methodology will be described briefly.

\section{GENERAL}

Animal handling was in accordance with the 'Dutch Law on Animal Experimentation (WOD)' and the 'European Directive for the Protection of Vertebrae Animals used for Experimental and other Scientific Purposes (European Union Directive \#86/609/CEE)'. The experiments were approved by 'The Committee for Experiments on Animals (DEC)' of Maastricht University, The Netherlands.

The methods used for induction of anesthesia, creation of AV block, and the electrophysiological studies performed at 4-6 weeks of AV block are described previously. ${ }^{1,5,6,8,9}$ In short, anesthesia was induced by premedication and sodium 
pentobarbital (20-25 mg/kg) and the dogs were ventilated artificially using a mixture of oxygen, nitrous oxide and $0.5 \%$ halothane. Complete AV block was created by injection of formaldehyde in the AV groove after a right-sided thoracotomy. Proper care was taken before and after the experiments including antibiotics and analgesics. During the time period between the AV block operation and the actual experiments at 4-6 weeks of AV block, the dogs were checked daily to assess their physical condition, and a weekly surface ECG was made to verify persistence of CAVB.

During the electrophysiological studies at 4-6 weeks of AV block six surface ECGs and two endocardial monophasic action potential signals (MAPs) were simultaneously registered and stored on hard disk. MAP catheters (EP Technologies Inc, CA, USA ) were placed endocardially, under fluoroscopic guidance, in the left- (LV) and right ventricular (RV) cavity. MAPs were positioned where a qualitatively good, stable and reproducible signal could be obtained.

Two different pacing modes (PES) were used to induce TdP at baseline circumstances: 1) a short-long-short sequence $(400,800+$ extrastimulus, or $4.600,1200+$ extrastimulus, 2) eight basic stimuli with a cycle length of $600 \mathrm{~ms}$ followed by an extrastimulus. Pacing was performed from a left epicardial electrode which was implanted during the AV block operation. A number of dogs received class III drugs to provoke TdP. TdP was considered significant if the arrhythmia occurred $\geq 3$ times.

After completion of the follow up period, or SCD, the heart was excised to determine the heart weight to body weight $(\mathrm{BW})$ ratio.

\section{SUDDEN CARDIAC DEATH}

SCD was defined as unexpected death occurring in the cage. To exclude all other non-cardiac causes of death an autopsy was performed. To record the circumstances of SCD, a custom made 24-hours telemetry device was developed in collaboration with M. Janssen, Wageningen, Netherlands and L. Dohmen, Maastricht University. In the same session as the electrophysiological study, the telemetry device, $8.5 .2 \mathrm{~cm}$, was placed in a total of 5 dogs in a subcutaneous pocket at the left side of the thorax. Three electrodes (each $10 \mathrm{~cm}$ long) were positioned in an Y-shape configuration under the skin to record a 2-lead ECG, one lead to inferior, one to the sternum and one to the left scapula. We made sure that one of these leads was similar to lead II of the surface ECG. The transmitter unit contained a radio-frequency transmitter and a battery. The cage had a receiver and both output signals (lead 1 and 2) were connected to an analog- to digital converter interface of a PC-based data acquisition system to process signals. Multiple cages could be connected simultaneously to the computer. Signals were displayed in real-time on a PC monitor and stored continuously ( 24 hours / day) and processed off line. 
Of the total of 117 CAVB dogs, 78 underwent an extensive electrophysiological study at 4-6 weeks of CAVB consisting of: 1) recordings of two qualitatively good MAP signals ${ }^{7}$ to assess interventricular dispersion, and 2) completion of a PES protocol to provoke $\mathrm{TdP}$ at baseline.

Eight of these 78 animals experienced SCD during the follow up period (SCD group) and were compared to the 70 non-SCD dogs. Since the response of the CAVB dog to class III drugs is not uniform, we also made electrophysiological comparisons at baseline between the SCD group, dogs demonstrating TdP with drugs (drug responders), and non-responders. For this purpose we selected all dogs which 1) showed no (inducible) $\mathrm{TdP}$ at baseline, 2) received almokalant $(0.12$ $\mathrm{mg} / \mathrm{kg} / 5 \mathrm{~min}$ ) or ibutilide (Corvert ${ }^{\mathrm{TM}}, 0.025 \mathrm{mg} / \mathrm{kg} / 5 \mathrm{~min}$ ) as an additional challenge to induce TdP, and 3) had a follow up period of at least 4 weeks after the electrophysiological study performed at 4-6 weeks of CAVB. Part of the almokalant-treated dogs have been published previously, ${ }^{9}$ although the results are now used for a different purpose.

\section{DATA ANALYSIS AT CAVB BASELINE}

Applying a custom made computer program (ECG View, Maastricht University), with a resolution of $2 \mathrm{~ms}$ and adjustable gain and time scale, the following parameters were measured off line: cycle length of idioventricular rhythm (CL-IVR), QT time, the duration of the monophasic action potential (MAPD) of the LV and RV at $100 \%$ of repolarization. From these measurements, the interventricular dispersion ( $\triangle \mathrm{MAPD}$ ) was calculated, defined as LV MAPD minus RV MAPD.

Electrophysiological data were measured during a stable CL-IVR after at least 1 hour of anesthesia and are the mean of 5 consecutive beats. Both at baseline and during class III drugs the electrophysiological measurements were done beat to beat to determine maximum values.

\section{STATISTICS}

Pooled data are expressed as mean \pm standard deviation (SD). Two group comparisons between the SCD and the non-SCD group were analyzed by unpaired Student's t-test. Multiple comparisons between the SCD -, drug-responder - and non-responder groups were performed by one-way analysis of variance (ANOVA) test with a post-hoc Bonferroni t-test. Chi-square test was used when the data were presented as a proportion. 


\section{RESULTS}

\section{SCD GROUP: ELECTROPHYSIOLOGICAL AND ARRHYTHMIC PARAMETERS}

Mean time of SCD was $7 \pm 3$ weeks after CAVB. Gender, age and the amount of cardiac hypertrophy in the SCD dogs (heart weight $/ \mathrm{BW} 12.6 \pm 1.5 \mathrm{~g} / \mathrm{kg}$ ) was not different from the non-SCD dogs (heart weight $/ \mathrm{BW} 11.5 \pm 2.4 \mathrm{~g} / \mathrm{kg}$ ). Two of the eight SCD dogs had a telemetric device implanted and revealed a polymorphic ventricular tachycardia as cause of death. As can be seen in Figure 1, the tachycardia was preceded by an acceleration in heart rate and the occurrence of ventricular ectopic activity. This particular animal also showed a substantial amount of ectopic activity and a self terminating polymorphic ventricular tachycardia in the hours preceding its death. In the other $6 \mathrm{SCD}$ animals, having no telemetric device, other causes of death could be excluded. Two of these 6 animals were witnessed to have SCD while excited, dying in front of the animal technician. Resuscitation equipment was not available in the stables.

The left part of Table 1 shows that CL-IVR, QT time and RV MAPD did not differ between the SCD dogs and the non-SCD dogs $(n=70)$. LV MAPD and $\triangle M A P D$ were however significantly different between the two groups.

When looking at the arrhythmia incidence in the SCD group, 6 of 8 animals (75\%) already demonstrated TdP at baseline: in four dogs multiple episodes of spontaneous TdP were seen during the (preparation of the) electrophysiological study (Figure 2), while in 5 dogs TdP could be induced by PES. In the non-SCD group the incidence of $\mathrm{TdP}$ at baseline was 11 of $70(16 \%, \mathrm{P}<0.001 \mathrm{SCD}-$ versus non-SCD group).

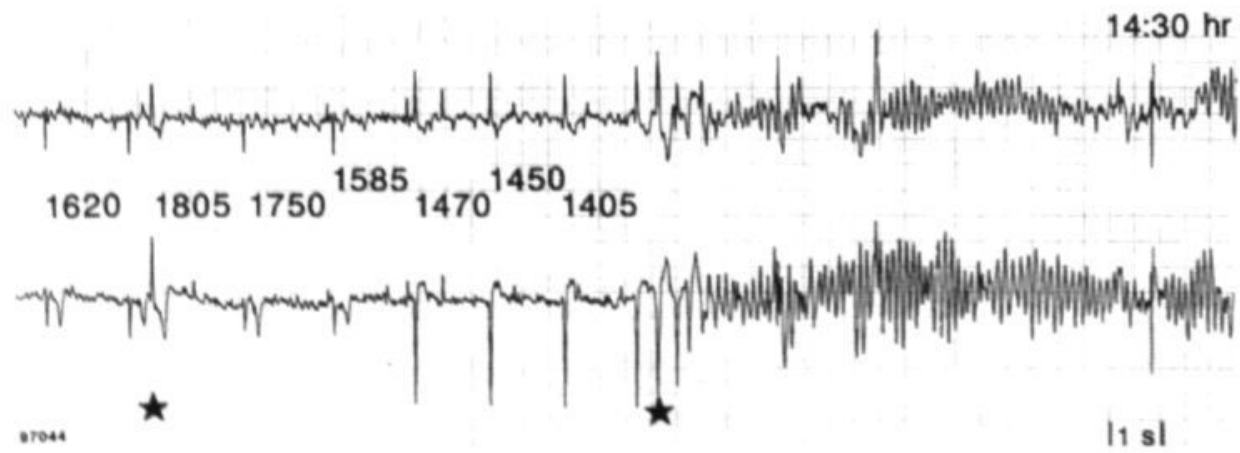

Figure 1 - Example of sudden cardiac death in the cage recorded by telemetry. A 2-lead ECG is shown at a paper speed of $10 \mathrm{~mm} / \mathrm{s}$. An acceleration of the rhythm with frequent ectopic activity (asterisk) is followed by a polymorphic ventricular tachycardia which degenerated in ventricular fibrillation resulting in sudden cardiac death. The numbers refer to the cycle length of the different beats. 
Table 1 - Electrophysiological parameters of the non-SCD and SCD
non-responders

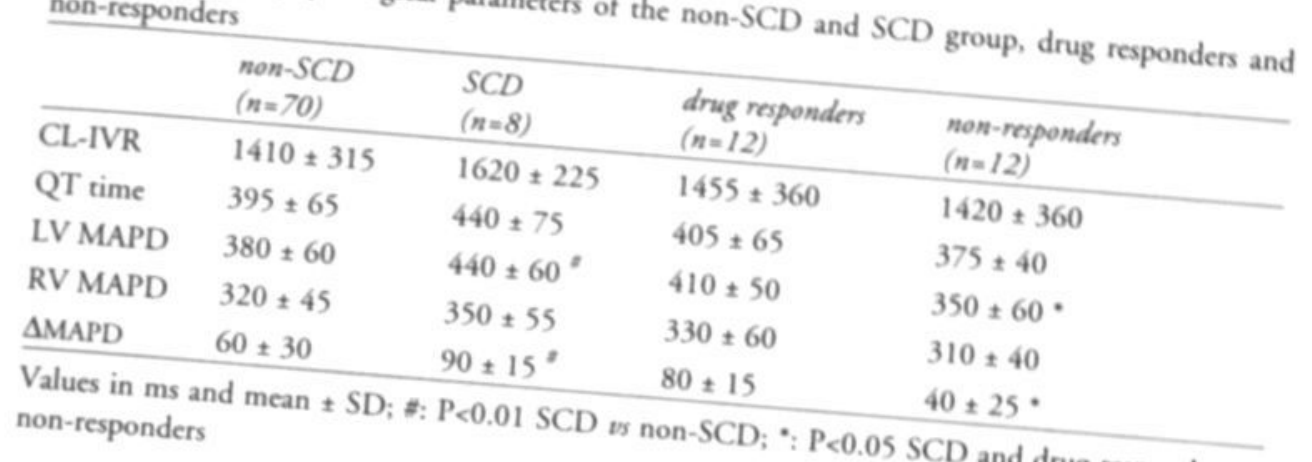
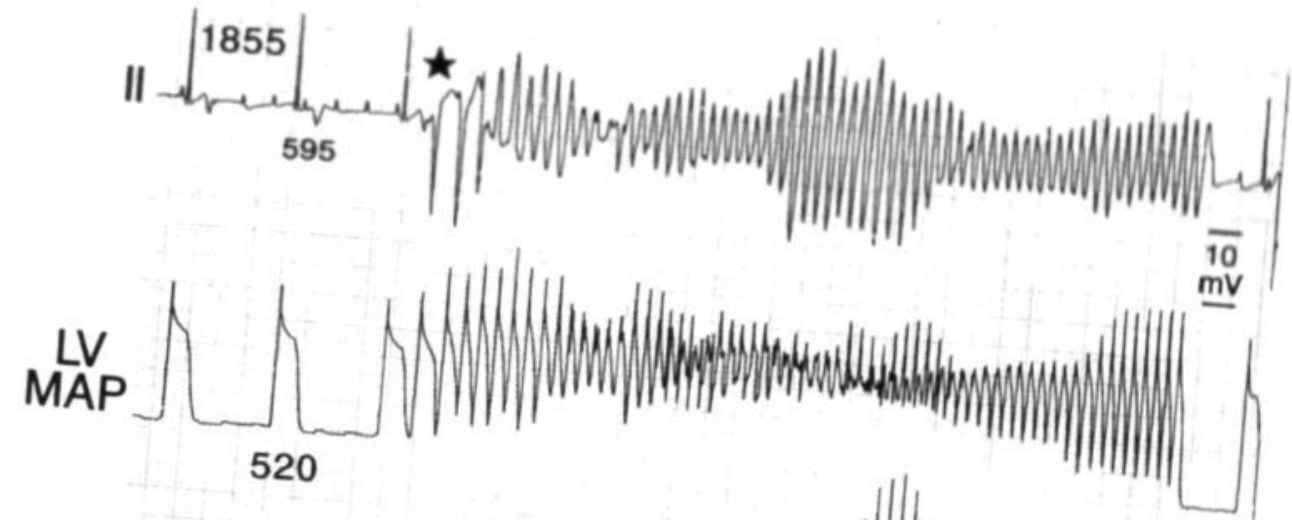

520

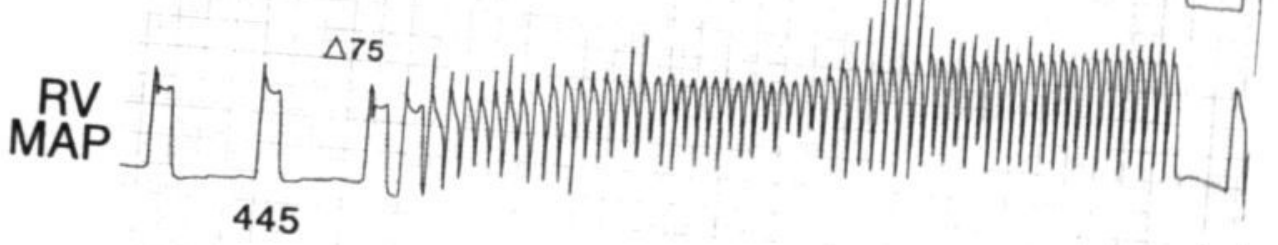

97044

Figure $2-R$

the surface ECG $\quad$ It sl recorded simultaneously at (LV)- and right (RV) ventricular monophasic aseline conditions. Lead II of MAPD $(520 \mathrm{~ms})$ and 4 at a paper speed of $10 \mathrm{~mm} / \mathrm{s}$. Under bapelic action potential (MAP) were neous ectopic beat (asterisk) (LV minus RV MAPD $=75 \mathrm{~ms}$ ) were al conditions the values of LV terminated spontaneously. 
1 control

I
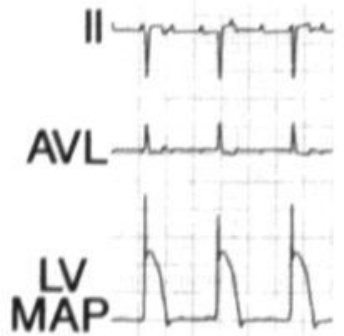

435

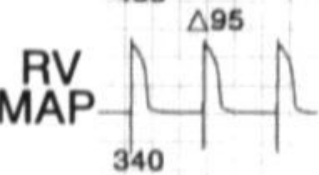

\section{2 ibutilide $t=5: 30 \mathrm{~min}$}
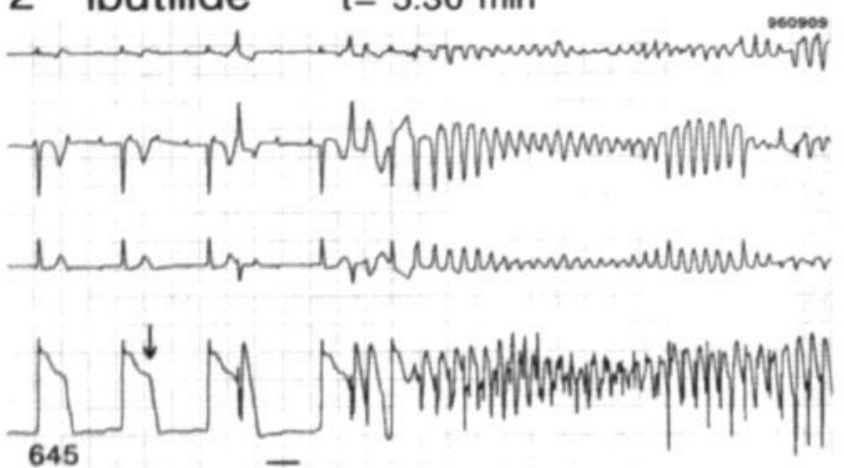

645

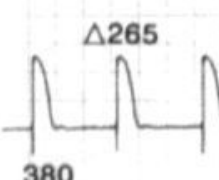

\section{$\overline{20}$}

380

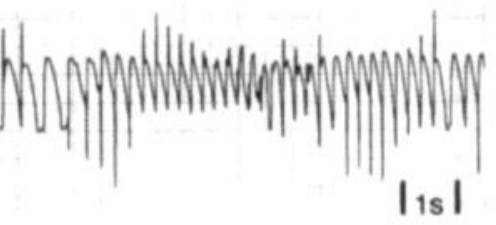

Figure 3 - Representative example of drug-induced Torsade de Pointes arrhythmia. In the two panels (1. control and 2. after ibutilide infusion) three leads of the surface ECG and a left (LV)- and right ventricular (RV) monophasic action potential (MAP) at a paper speed of $10 \mathrm{~mm} / \mathrm{s}$ are shown. The dispersion ( $\triangle \mathrm{MAPD}$ ) at baseline was considerable $(95 \mathrm{~ms})$. After ibutilide administration $\triangle \mathrm{MAPD}$ increased more than twofold. Also QT time increased, TU wave morphology changed and EADs can be appreciated in the LV MAP (arrow). A spontaneous short-long-short sequence of (triggered) ventricular extra beats induced a Torsade de Pointes arrhythmia.

\section{DRUG-RESPONDER VERSUS NON-RESPONDER GROUP}

Twenty four dogs met the inclusion criteria of which 15 received almokalant and 9 ibutilide. Half of them ( $n=6$ ibutilide, $n=6$ almokalant) responded with TdP to the drug challenge (i.e. drug responders) while the other half did not (i.e. non-responders).

As previously described ${ }^{8,9}$ and visualized in Figure 3, class III drugs increased significantly 1) CL-IVR, 2) QT time, and 3) all MAP derived durations, including $\triangle M A P D$ (data not shown).

\section{ARRHYTHMIC AND ELECTROPHYSIOLOGICAL PARAMETERS OF THE SUBGROUPS} AT BASELINE: SCD, DRUG RESPONDERS AND NON-RESPONDERS

In Table 1 (right part) the electrophysiological parameters of the SCD group, drug responders and non-responders at baseline are compared. No significant differences existed between the three subgroups in CL-IVR, QT time and RV MAPD. LV MAPD and $\triangle M A P D$ were however significantly different between the SCD and drug responders versus non-responders. Although LV MAPD and $\triangle M A P D$ 


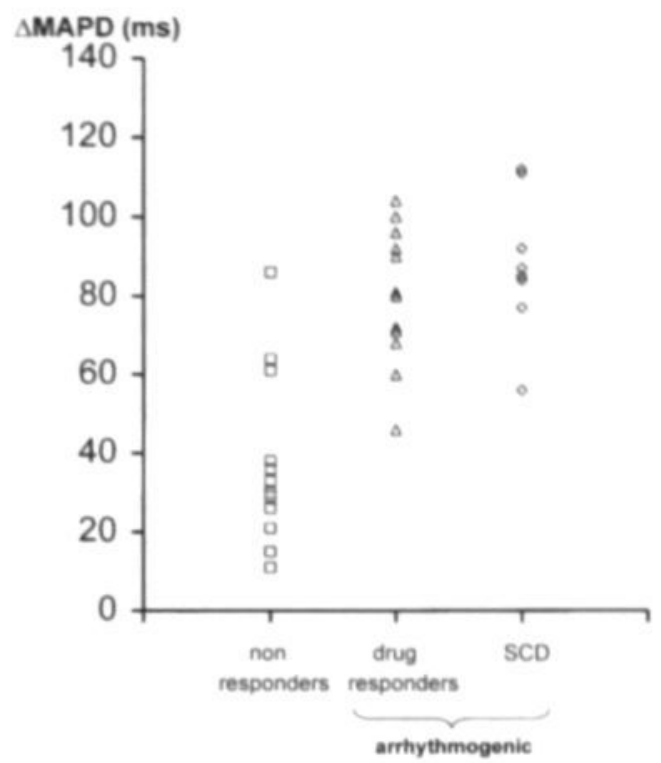

Figure 4 - Individual $\triangle \mathrm{MAPD}$ (vertical axis) data of the three subgroups: sudden cardiac death (SCD), drug-responder and non-responder groups. A clear distinction in $\triangle \mathrm{MAPD}$ can be seen between the SCD- and the drug-responder group on the one hand versus the non-responder group on the other. This is indicated by the term arrhythmogenic which combines the SCD- and the drug-responder group.

Table 2 - Risk stratification of arrhythmia occurrence $(\mathrm{n}=32)$

\begin{tabular}{llcl}
\hline$\triangle M A P D(m s)$ & sensitivity (\%) & specificity (\%) & likelihood ratio \\
\hline$\geq 40$ & 100 & 75 & 4.0 \\
$\geq 65$ & 85 & 92 & 10.2 \\
$\geq 90$ & 40 & 100 & infinitive \\
\hline
\end{tabular}

appeared somewhat larger in the SCD than the drug-responder group, these differences did not reach significance. Figure 4 shows the individual data points of the $\triangle \mathrm{MAPD}$ in the three groups, which reveals clearly the distinction between the SCDand drug-responder groups on the one hand versus the non-responder group on the other.

Thus, in fact we can distinguish two groups: arrhythmogenic and non-arrhythmogenic, on the basis of LV MAPD and $\triangle$ MAPD during baseline. In Table 2, the different specificity and sensitivity values for cut-off points of $\triangle M A P D 40,65$, and $90 \mathrm{~ms}$ can be seen in relation to the occurrence of ventricular arrhythmias. 


\section{DISCUSSION}

This study demonstrates that in the dog with CAVB, SCD can most probably be attributed to (polymorphic) ventricular tachycardias. The ability to induce TdP at baseline and the measure of LV MAPD and $\triangle M A P D$ indicate susceptibility to SCD.

\section{TELEMETRY DEVICE}

The observation period started after the electrophysiological study, which was performed after at least 4 weeks of CAVB. After this time, we assume that the electrical remodeling processes are completed and stable in time. ${ }^{11,12}$

To record the mode of death, we developed a telemetry system which provides a 2-lead ECG recording for 24 hours a day for a maximum of 2 months in a dog which can move freely in his cage. The first analysis of these telemetry recordings in the two dogs dying suddenly, revealed in both cases that the arrhythmia was preceded by an acceleration in idioventricular rhythm, being accompanied by ventricular ectopic activity (Figure 1). The latter pattern shows similarities with the initiation sequence of drug-induced TdP (Figure 3) in which EADs trigger ectopic beats, setting the stage for a TdP arrhythmia. The observed acceleration in rate and the fact that the two witnessed deaths occurred when the dogs were excited suggest an adrenergic contribution to the initiation of the arrhythmia.

\section{PREDICTIVE PARAMETERS OF SCD}

In our retrospective study we looked at 78 CAVB dogs, including 8 SCD dogs. The group of 24 dogs that received almokalant or ibutilide, showed a drug responder versus non-responder ratio comparable to other antiarrhythmic drugs used in the model. ${ }^{10}$

An arrhythmogenic parameter indicative of SCD was the ability to evoke TdP already under baseline circumstances. In some anesthetized dogs TdP arose spontaneously (Figure 2), while in others our short-long-short mimicking pacing protocols were necessary to initiate TdP.

One of the other electrophysiological parameters we focused on was $\triangle M A P D$, as we recently demonstrated that the amount of $\triangle M A P D$ is strongly associated with drug-induced TdP. ${ }^{1,8-10}$ Also in other models of hypertrophy and heart failure inter-and intraventricular inhomogeneity in action potential duration has been described, ${ }^{13.14}$ while Antzelevitch et al demonstrated transmural dispersion of repolarization. ${ }^{15}$ In Table 1 it can be seen that the $\triangle \mathrm{MAPD}$ of the SCD group is significantly larger compared to the non-SCD group.

Interestingly the SCD group and the drug-responder group show many similarities. The $\triangle M A P D$ at baseline of these two groups was significantly different from the non-responder group (Table 1 and Figure 4). A $\triangle M A P D$ of $\geq 65 \mathrm{~ms}$ had a sensi- 
tivity of $85 \%$ and a specificity of $92 \%$ for the occurrence of ventricular arrhythmias (Table 2). Besides $\triangle \mathrm{MAPD}$, the only other electrophysiological parameter which showed a significant difference was LV MAPD.

This suggests that the length of the LV MAPD plays an important role, either in creating dispersion between the ventricles ( $\triangle \mathrm{MAPD})$, or in generating early afterdepolarizations triggering arrhythmias. ${ }^{16,17}$ It was surprising to find that QT time did not discriminate sufficiently to become predictive. Also CL-IVR was similar in the different group comparisons excluding bradycardia as an arrhythmogenic factor.

\section{BASIS OF THE ENHANCED SENSITIVITY TO SCD IN THE CAVB DOG}

QT prolongation or repolarization lability are regarded as risk factors for ventricular arrhythmias and SCD in patients with cardiac hypertrophy or failure. ${ }^{18}$ Recently the concept of a decreased repolarization reserve was introduced. ${ }^{19,20}$ Arrhythmias would then occur when the reduced repolarization is challenged, e.g. by drugs or adrenergic stimulation. ${ }^{19-21}$

We have described that the prolonged repolarization in the CAVB dog can be attributed to a decrease in $\mathrm{I}_{\mathrm{K}}$ and an upregulation of the $\mathrm{Na}^{+}-\mathrm{Ca}^{2+}$ exchanger in both ventricles. ${ }^{3,4}$ All other currents which we have measured so far (e.g. $\mathrm{I}_{\mathrm{Cal}}, \mathrm{I}_{\mathrm{TO}}, \mathrm{I}_{\mathrm{K} 1}$ ) did not show any change. These electrical adaptations result in a more pronounced interventricular dispersion and a higher susceptibility to TdP. ${ }^{1,8,9}$ The electrical remodeling is accompanied by an eccentric biventricular hypertrophy and by a maintained cardiac output (compensated function). ${ }^{1,4,5}$

To some degree the above mentioned characteristics in cardiac hypertrophy and/or failure may be regarded as a form of acquired long-QT syndrome. 3.19,21 The fact that the CAVB population can now be divided further in an arrhythmogenic and a non-arrhythmogenic group is new, and it is tempting to suggest that arrhythmogenic dogs would have the least repolarization reserve. To test this hypothesis, ion channel expression levels of arrhythmogenic versus non-arrhythmogenic dogs will be part of future investigations.

Besides possessing a substrate ( $\triangle \mathrm{MAPD})$, the arrhythmogenic group needed an additional trigger to start the arrhythmia. This trigger, which is likely to be related to triggered activity or abnormal automaticity, can be provided by the addition of a challenging factor. So far these include: an increased adrenergic state (excitement), anesthesia, pacing, and / or class III drugs. Whether other factors are involved will be part of ongoing investigations.

\section{RELEVANCE OF THE MODEL}

Only few studies have been able to demonstrate arrhythmogenic consequences of the mentioned repolarization abnormalities in hypertrophy and heart failure. 13,14,22-26 
The presumed adrenergically-induced TdP in the conscious CAVB dog, in which the $\mathrm{I}_{\mathrm{K}}$ is decreased shows similarities with some forms of the congenital long QT syndrome (LQT1 and LQT2) in which SCD is related to $\mathrm{I}_{\mathrm{Kr}_{r}}$ or $\mathrm{I}_{\mathrm{Ks}}$ downregulation and adrenergic stimulation. ${ }^{27}$ Also patients with "forme fruste" congenital LQT syndrome show an increased TdP susceptibility to class III drugs. ${ }^{28}$

\section{LIMITATIONS}

SCD is a complex phenomenon, whose appearance is unpredictable. In this respect our follow-up period of $\geq 4$ weeks could have been too short. The scope of the study prevents us from drawing conclusions about the cause of the increased susceptibility to SCD in a subgroup of CAVB dogs. Cellular electrophysiological studies on sudden death could not be performed because cells can only be obtained from freshly arrested hearts. Placement of MAP catheters at only two sites (LV and RV) ignores possible transmural and intraventricular differences. However we have shown with multisite transmural needle electrodes that $\triangle A P D$ is present within the CAVB dog heart. ${ }^{29}$

\section{CONCLUSION}

In the CAVB dog model, SCD is 1) most probably related to TdP while 2) inducible TdP and the measure of LV MAPD and $\triangle \mathrm{MAPD}$ at baseline indicate susceptibility to SCD.

\section{ACKNOWLEDGMENTS}

The authors would like to express their gratitude to Dr. Stengl for helpful comments and advice on the manuscript and to Leon Dohmen, BSc for developing and maintaining the telemetry equipment. Financial support by "The Netherlands Heart Foundation (\#98.042)" and "Netherlands Organization for Scientific Research $(\# 950.10 .647) ”$ is gratefully acknowledged.

\section{REFERENCES}

1. Vos MA, de Groot SH, Verduyn SC, van der Zande J, Leunissen HD, Cleutjens JP, van Bilsen M, Daemen MJ. Schreuder JJ, Allessie MA, Wellens HJ. Enhanced susceptibility for acquired torsade de pointes arrhythmias in the dog with chronic, complete AV block is related to cardiac hypertrophy and electrical remodeling. Circulation. 1998;98:1125-35. 
2. Volders PG, Sipido KR, Vos MA, Kulcsar A, Verduyn SC, Wellens HJ. Cellular basis of biventricular hypertrophy and arrhythmogenesis in dogs with chronic complete atrioventricular block and acquired torsade de pointes. Circulation. 1998;98:1136-47.

3. Volders PG, Sipido KR, Vos MA, Spätjens RL, Leunissen JD, Carmeliet E, Wellens HJ. Downregulation of delayed rectifier $\mathrm{K}^{+}$currents in dogs with chronic complete atrioventricular block and acquired torsades de pointes. Cinculation. 1999;100:2455-61.

4. Sipido KR, Volders PGA, de Groot SHM, Verdonck F, Van de Werf F, Wellens HJJ, Vos MA. Enhanced $\mathrm{Ca}^{2+}$ release and $\mathrm{Na} / \mathrm{Ca}$ exchange activity in hypertrophied canine ventricular myocytes. Circulation. 2000;102:2137-44.

5. de Groot SH, Schoenmakers M, Molenschot MMC, Leunissen HDM, Wellens HJJ, Vos MA. Contractile adaptations preserving cardiac output predispose the hypertrophied canine heart to delayed afterdepolarization dependent ventricular arrhythmias. Circulation. 2000;102:2145-5.

6. Vos MA, Verduyn SC, Gorgels AP, Lipesei GC, Wellens HJ. Reproducible induction of early afterdepolarizations and torsade de pointes arrhythmias by $\mathrm{d}$-sotalol and pacing in dogs with chronic atrioventricular block. Circulation. 1995;91:864-72.

7. Vos MA, Verduyn SC, Wellens HJJ. Early afterdepolarizations in the in situ canine heart. Mechanistic insights into acquired Torsade de Pointes arrhythmias. In: MR Franz, ed. Monophasic Action Potentials. Bridging Cell and Bedside. Armonk NY: Futura Publishing: 2000:553-569.

8. Verduyn SC, Vos MA, van der Zande J, van der Hulst FF, Wellens HJ. Role of interventricular dispersion of repolarization in acquired torsade-de-pointes arrhythmias: reversal by magnesium. Cardiovasc Res. 1997;34:453-63.

9. Verduyn SC, Vos MA, van der Zande J, Kulcsar A, Wellens HJ. Further observations to elucidate the role of interventricular dispersion of repolarization and early afterdepolarizations in the genesis of acquired torsade de pointes arrhythmias: a comparison between almokalant and d-sotalol using the dog as its own control. J Am Coll Cardiol. 1997;30:1575-84.

10. van Opstal JM, Leunissen HDM, Wellens HJJ, Vos MA. Azimilide and dofetilide produce similar electrophysiological and proarrhythmic effects in a canine model of Torsade de Pointes arrhythmias. Eur J Pharmacol. 2001;412:69-78.

11. Verduyn SC, Vos MA, Snoep G, Leunissen HDM, Wellens HJJ. Bradycardia induced volume overload leads to rapid structural and electrophysiological changes in the AV block dog. abstract: Pacing Clin Electrophysiol. 1999;22:726, 109.

12. Peschar M, Vanagt WYR, Vos MA, Prinzen FW. Lack of reverse electrical remodeling during regression of volume overload hypertrophy. abstract: Pacing Clin Electrophysiol. 1999;22:881.

13. Kowey PR, Friechling TD, Sewter J, Wu Y, Sokil A, Paul J, Nocella J. Electrophysiological effects of left ventricular hypertrophy. Effect of calcium and potassium channel blockade. Circulation. 1991;83:2067-75.

14. Pak PH, Nuss HB, Tunin RS, Kaab S, Tomaselli GF, Marban E, Kass DA. Repolarization abnormalities, arrhythmia and sudden death in canine tachycardia-induced cardiomyopathy. J Am Coll Cardiol. 1997:30:576-84.

15. Antzelevitch C, Shimizu W, Yan GX, Sicouri S, Weissenburger J, Nesterenko VV, Burashnikov A, Di Diego J, Saffitz J, Thomas GP. The M cell: its contribution to the ECG and to normal and abnormal electrical function of the heart. J Cardiovasc Electrophysiol. 1999;10:1124-52. 
16. January CT, Riddle JM. Early afterdepolarizations: mechanism of induction and block. A role for L-type Ca ${ }^{2+}$ current. Circ Res. 1989;64:977-90.

17. Volders PG, Vos MA, Szabo B, Sipido KR, de Groot SH, Gorgels AP, Wellens HJ, Lazzara R. Progress in the understanding of cardiac early afterdepolarizations and Torsade de Pointes: time to revise current concepts. Cardiovase Res. 2000;46:376-392.

18. Zipes DP, Wellens HJ. Sudden cardiac death. Circulation. 1998;98:2334-51.

19. Marban E. Heart failure: the electrophysiologic connection. J Cardiovase Electrophysiol. 1999;10:1425-8.

20. Roden DM. Taking the "idio" out of "idiosyncratic": predicting torsades de pointes. Pacing Clin Electrophysiol. 1998:21:1029-34.

21. Nabauer M, Kaab S. Potassium channel down-regulation in heart failure. Cardiovase Res. 1998:37:324-34.

22. Hsich MH, Chen YJ, Lee SH, Ding YA, Chang MS, Chen SA. Proarrhythmic effects of ibutilide in a canine model of pacing induced cardiomyopathy. Pacing Clin Electrophysiol. 2000:23:149-56.

23. Sabbah HN, Goldberg AD, Schoels W, Kono T, Webb C, Brachmann J, Goldstein S. Spontaneous and inducible ventricular arrhythmias in a canine model of chronic heart failure: relation to haemodynamics and sympathoadrenergic activation. Eur Heart J. 1992;13:1562-72.

24. Sabbah HN, Stein PD, Kono T, Gheorghiade M, Levine TB, Jafri S, Hawkins ET, Goldstein S. A canine model of chronic heart failure produced by multiple sequential coronary microembolizations. Am J Physiol. 1991;260:H1379-84.

25. Pogwizd SM. Nonreentrant mechanisms underlying spontaneous ventricular arrhythmias in a model of nonischemic heart failure in rabbits. Circulation. 1995;92:1034-48.

26. Rials SJ, Wu Y, Ford N, Pauletto FJ, Abramson SV, Rubin AM, Marinchak RA, Kowey PR. Effect of left ventricular hypertrophy and its regression on ventricular electrophysiology and vulnerability to inducible arrhythmia in the feline heart. Circulation. 1995;91:426-30.

27. Priori SG, Barhanin J, Hauer RN, Haverkamp W, Jongsma HJ, Kleber AG, McKenna WJ, Roden DM, Rudy Y, Schwartz K, Schwartz PJ, Towbin JA, Wilde AM. Genetic and molecular basis of cardiac arrhythmias: impact on clinical management parts I and II. Circulation. 1999;99:518-28.

28. Napolitano C, Schwartz PJ, Brown AM, Ronchetti E, Bianchi L, Pinnavaia A, Acquaro G, Priori SG. Evidence for a cardiac ion channel mutation underlying drug-induced QT prolongation and life-threatening arrhythmias. J Cardiovasc Electrophysiol. 2000;11:691-696.

29. Vos MA, Bakker JMT de, Jungschleger JJ, Hulst FF vd, Winckels S, Anyukhovsky E, Opthof T, Wellens HJJ. The importance of the septum for ventricular dispersion in the dog with chronic AV block. abstract: Circulation. 1999;100:51. 


\section{General Discussion}

\section{Content}

7.1 Introduction

7.2 Electrical Remodeling and Drug-Induced TdP Arrhythmias in the CAVB Dog

7.3 Different Phenotypes in the CAVB Dog

7.4 Drug-Induced Torsade de Pointes Arrhythmias and Sudden Cardiac Death in the Remodeled Canine Heart: Investigations in the Conscious CAVB Dog

7.5 Where to Go from Here 


\subsection{INTRODUCTION}

The first publications of our group related to drug-induced TdP in the chronic complete-atrioventicular block (CAVB) dog appeared in $1994,{ }^{1}$ and $1995 .{ }^{2}$ In the latter paper it was noted that "to reproducibly induce TdP arrhythmias (by d-sotalol), the cycle length of the idioventricular rhythm (bradycardia) and QT time have to be sufficiently long at the start of the experiment whereas spontaneous and pacing-dependent TdP rely for their induction on the presence of early afterdepolarizations (EADs)". Two years later the parameter interventricular dispersion of repolarization was introduced, ${ }^{3}$ and two antiarrhythmic drugs (almokalant and $\mathrm{d}$-sotalol) were compared in a random crossover design using the dog as its own control. ${ }^{4}$ The increased occurrence of TdP after almokalant was shown to be preceded by 1) a further inhomogeneous increase in the left (LV) and right ventricular (RV) action potential duration (APD), 2) the more frequent occurrence of (subthreshold) EADs, 3) and single ectopic beats followed by multiple ectopic beats, and 4) a further increase in dispersion of repolarization resulting from the dynamic response of the LV APD because of frequency changes.

In 1998 the background of the enhanced susceptibility to drug-induced TdP was partially demonstrated: long-lasting bradycardia with AV asynchrony as a result of CAVB leads to biventricular hypertrophy and to an increase in LV APD of $32 \%$ while the increase in RV APD is less pronounced $(+21 \%)$, resulting in an increased dispersion of repolarization. The prolonged repolarization times can facilitate the development of EADs. ${ }^{5}$ The changes in ion currents, likely to be expected to form the basis for the altered repolarization parameters were at that time not known. Subsequently it was shown that downregulation of $\mathrm{I}_{\mathrm{K}}{ }^{6}$, and an upregulation of the $\mathrm{Na}^{+}-\mathrm{Ca}^{2+}$ exchanger, ${ }^{7}$ contributed to the electrical remodeling and the increased propensity to triggered activity.

\subsection{ELECTRICAL REMODELING AND DRUG-INDUCED TDP ARRHYTHMIAS IN THE CAVB DOG}

Figure 1 shows the absolute and relative increase in repolarization parameters after administration of the $\mathrm{I}_{\mathrm{K}_{\mathrm{r}}}$ blocker dofetilide during sinus rhythm, acute AV block and chronic AV block. Dofetilide prolongs the QT time with $40 \%$ during sinus rhythm and $32 \%$ during acute AV block. Despite these large relative increases, the absolute values of the QT time, LV APD, RV APD and $\triangle A P D$, do not reach a critical level and TdP does not occur. In the remodeled CAVB heart with the acquired long-QT syndrome, ${ }^{5-8}$ the administration of dofetilide prolongs the QT time with only $25 \%$. However, as a result of the baseline absolute higher values, the QT time reaches higher levels after a drug challenge in the CAVB situation than during sinus rhythm and acute AV block (Figure 1). The longer-QT respectively LV-APD values can make 

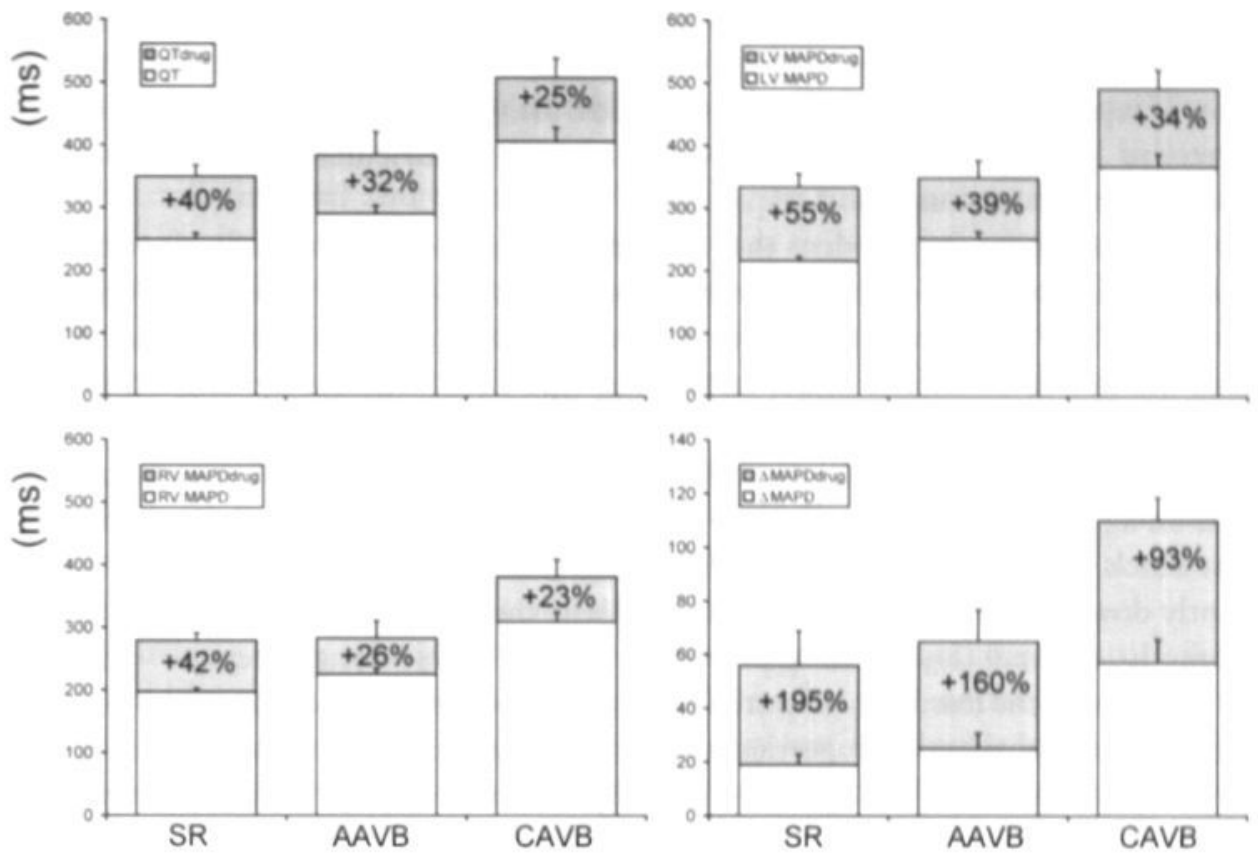

Figure 1 - Four panel figure showing the effect of $0.025 \mathrm{mg} / \mathrm{kg}$ dofetilide administration on QT time, LV MAPD, RV MAPD and $\triangle$ MAPD during sinus rhythm (SR), bradycardia (acute atrioventricular block, AAVB), and after electrical remodeling because of chronic complete AV block (CAVB). On the vertical axis, the values in ms are shown. On the horizontal axis, the SR, AAVB and CAVB situation is shown, with (filled part) and without (open part) the administration of dofetilide. The percentages indicate the relative increase of the different repolarization parameters after administration of the drug. During SR and AAVB the electrophysiological values after dofetilide administration increase relatively seen more than during CAVB, but absolutely higher values are reached during CAVB because of the increased repolarization parameters at baseline. This is associated with a 6 of $9 \mathrm{TdP}$ incidence. Values in mean \pm SEM.

the heart more sensitive to EAD-related ventricular ectopic beats, thereby providing the trigger for an arrhythmia. Secondly, as the LV APD increases absolutely as well as relatively more than the RV APD, a large dispersion of repolarization is reached during CAVB after a drug challenge. The increase in dispersion and the occurrence of EADs, respectively ectopic beats, after dofetilide administration is associated with a two-third TdP incidence in the CAVB dog. The drug thereby unmasks those dogs that have a reduced repolarization reserve.

The hypothesis that the new antiarrhythmic agent azimilide, which has combined $\mathrm{I}_{\mathrm{Kr}}$ and $\mathrm{I}_{\mathrm{Ks}}$ channel blockade, would show less proarrhythmia by lengthening the APD more homogeneously than the selective $I_{K r}$ channel blocker dofetilide was shown to be incorrect in Chapter 2. To achieve a comparable QT time prolongation for both drugs, drug dosages in this study were selected by dose-dependency testing 
in dogs with normally conducted sinus rhythm. In a random crossover design in the CAVB dog, azimilide and dofetilide increased QT time, and simultaneously dispersion of repolarization. Both drugs caused TdP arrhythmias in two-third of the dogs, preceded by EAD associated single- and multiple ventricular ectopic beats, often coupled in a short-long-short sequence.

These results imply that the additional $\mathrm{I}_{\mathrm{Ks}}$ channel blockade provided by azimilide is not superior to the use of the selective $\mathrm{I}_{\mathrm{Kr}_{r}}$ blocker dofetilide in the dog with CAVB. For this finding several explanations can be offered: 1) blocking the $\mathrm{I}_{\mathrm{K}}$ channel can be beneficial under non-adrenergic circumstances by lengthening the APD homogeneously. However, when an adrenergic drive is present, which is the normal physiological condition in the intact animal and human, triggered activity and an aggravation of dispersion of repolarization can occur ${ }^{10,11}$ 2) azimilide does not block the $\mathrm{I}_{\mathrm{Ks}}$ channel in the CAVB dog because the current is already significantly downregulated, ${ }^{6}$ and 3 ) azimilide blocks the $\mathrm{I}_{\mathrm{K} s}$ channel weakly as compared to the $\mathrm{I}_{\mathrm{K}_{r}}$ channel $\left(\mathrm{I}_{\mathrm{K}_{r}}\right.$ blocking potency 8 times $>\mathrm{I}_{\mathrm{K}_{s}}$ blocking potency $\left.{ }^{12,13}\right)$.

To study the feasibility of pure $\mathrm{I}_{\mathrm{Ks}}$ channel blockade as an antiarrhythmic target without proarrhythmic properties, specific $I_{K s}$ channel blockers were used. Unexpectedly, already in the dog with normally conducted sinus rhythm under anesthesia, high dosages of $\mathrm{I}_{\mathrm{Ks}}$ channel blockers caused less QT prolongation than the $\mathrm{I}_{\mathrm{Kr}}$ channel blockers. This precluded assessing the proarrhythmic potential of the $\mathrm{I}_{\mathrm{Ks}}$ channel blockers in the CAVB dog, which is based on the fact that the increase in repolarization parameters should be equal between drugs to compare their proarrhythmic properties.

To unravel the unclear contribution of the $\mathrm{I}_{\mathrm{Ks}}$ channel to ventricular repolarization, both cellular and in-vivo electrophysiological experiments were performed in sinus rhythm dogs (Chapter 3). We demonstrated that under baseline conditions adrenergically-unstimulated $\mathrm{I}_{\mathrm{Ks}}$ does not contribute significantly to repolarization in ventricular myocytes, because its activation is restrained by the voltage and time domains of the action potential. Therefore, drug-induced $I_{K s}$ inhibition does not prolong the cellular action potential at baseline. However, $\mathrm{I}_{\mathrm{Ks}}$ becomes more prominent during $\mathrm{I}_{\mathrm{Kr}}$ block by time-dependent activation, and during $\beta$-adrenergic receptor stimulation when it promotes action potential shortening by increased and accelerated activation.

In the intact sinus rhythm dog, under anesthesia, $\mathrm{I}_{\mathrm{Ks}}$ blockade led maximally to $\mathrm{QT}_{\mathrm{c}}$ prolongations of $10 \%$. Even in the presence of intravenously administered isoproterenol, when the channel, according to the cellular findings, should be maximally activated, the $\mathrm{QT}_{\mathrm{c}}$ did not prolong further. These results seemed to be in conflict with 1) our cellular investigations in which a significant role for $I_{K s}$ in adrenergically-stimulated ventricular myocytes was found, 2) other studies, ${ }^{14-17}$ and 3) data from patients with the congenital long QT 1 syndrome ${ }^{18-20}$. Therefore, the $\mathrm{I}_{\mathrm{Ks}}$ blocker was orally administered in the awake dog. Surprisingly, under conscious circumstances, (complete) $\mathrm{I}_{\mathrm{Ks}}$ channel blockade resulted in QT time prolongations 
of more than $50 \%$. One dog even died during excitement, and the Holter recordings revealed that death could be attributed to a tachyarrhythmia. Detailed analysis of the Holter recording showed that the animal probably died because of the inability to shorten the QT time sufficiently during an increased heart rate, leading to a very short diastolic interval and ultimately R-on $\mathrm{T}$ wave initiation of the arrhythmia. Thus, the study shows that the adrenergic system is an essential component to have the $\mathrm{I}_{\mathrm{K} s}$ channel function, ${ }^{21}$ and that the channel seems to be (especially) important for the shortening of the QT time during an increased heart rate and/or an enhanced adrenergic tone. In other words, the $\mathrm{I}_{\mathrm{Ks}}$ channel seems indispensable to maintain the, life saving, rate dependent duration of the QT time. For the discrepancy between the anesthetized and conscious in vivo-data, two possible causes can be offered: 1) the anesthetic drugs pentobarbital and/or halothane have a direct blocking effect on $I_{K s}$ and/or 2) anesthesia-induced attenuation of cardiac sympathetic tone decreases adrenergic stimulation of $\mathrm{I}_{\mathrm{Ks}}$.

In Chapter 4 the multiple channel blockers amiodarone and dronedarone were compared. In the clinical setting, amiodarone is the only antiarrhythmic drug achieving prolongation of repolarization with a very low TdP incidence. ${ }^{22}$ However, serious non-cardiac side effects, being attributed to the iodinated nature of the molecule, limit its widespread clinical use. ${ }^{23.24}$ Dronedarone was introduced as similarly effective as amiodarone, but devoid of iodine. ${ }^{25-27}$ In the CAVB dog, both amiodarone and dronedarone prolonged $\mathrm{QT}_{\mathrm{c}}$ time more than $20 \%$ when administered orally chronically. Amiodarone, similar to the clinical situation, evoked no $\mathrm{TdP}$ thereby proving that the model possesses, next to a high sensitivity, also a high specificity for assessing proarrhythmic properties of drugs. Moreover, amiodarone shows that the absolute $Q T_{(c)}$ time reached with a drug is not the golden standard to predict the proarrhythmic properties of an (antiarrhythmic) drug. The absence of TdP during amiodarone, despite $\mathrm{QT}_{(\mathrm{c})}$ time lengthening, was related to a homogeneous APD lengthening in the majority and the lack of EADs and ventricular ectopic beats in all of the dogs.

Dronedarone demonstrated TdP in $50 \%$ of the animals. The different arrhythmic outcome of dronedarone compared to amiodarone can be related to: 1) unfortunate randomization because of the group comparison, in which the dronedarone animals had higher baseline electrophysiological parameters, ${ }^{28}$ 2) the selected dosage, or 3) different electrophysiological effects of the drugs which could suggest that chronic amiodarone exerts its beneficial effect by modulating the ion channels differently and/or inhibiting thyroid hormone activation in cardiac muscle. ${ }^{23,29}$

The Table summarizes the arrhythmic results of the first 3 chapters of the thesis. All the different ion-channel blockers, which were studied, increased QT time. However, only amiodarone did not have proarrhythmic potential. From the Table it is clear that for TdP to occur both 1) dispersion of repolarization, 2) EADs and 3) ectopic beats are necessary. Thus, a significant finding of this thesis infers that QT 
time lengthening does not have to be proarrhythmic, as long as dispersion of repolarization, EADs and/or ectopic beats are absent. The exact contribution of each factor and their mutual interaction in relation to TdP occurrence needs further investigation.

Chapter 5 assesses the non-invasive measurement of dispersion of repolarization on the surface ECG. We demonstrated that during different protocols, including APD lengthening and shortening, the JT area on the surface ECG reflected alterations in interventricular dispersion. Administration of class III drugs increased both QT time and JT area, which was associated with TdP occurrence for the highest JT area values reached. In contrast, chronic amiodarone increased QT time but did not augment $\mathrm{JT}$ area, which was associated with the absence of TdP (Chapter 4). Therefore, the JT area should be evaluated to risk-stratify the individual patient for the development of TdP arrhythmias after the administration of class III drugs.

Finally, to assess if sudden cardiac death (SCD) in the CAVB dog was indeed related to an arrhythmia, a telemetric ECG device was developed and implanted in a number of dogs, which were at risk for SCD (Chapter 6). The telemetry recordings provided the evidence that SCD was related to (polymorphic) ventricular tachycardias. In addition, it was possible to risk-stratify those dogs that were susceptible to SCD by the measure of their LV APD and dispersion of repolarization at baseline (see below).

\subsection{DIFFERENT PHENOTYPES IN THE CAVB DOG}

The fact that the CAVB dog has 3 different phenotypes is an important finding of this thesis (see also Chapter 6): 1) 10\% of the dogs show spontaneous or pacing-induced TdP at baseline and have a high risk of arrhythmic SCD during follow-up, 2) $60 \%$ of the dogs respond with TdP when they are challenged with a repolarization prolonging drug (i.e. drug responders) 3) 30\% of the dogs do not respond with $\mathrm{TdP}$, even after a drug challenge (i.e. non-responders). The first and the second group can be characterized electrophysiologically by a higher degree of the LV APD, and dispersion of repolarization at baseline compared to the non-responder group (Figure 2). The electrophysiological differences between the $S C D$, responder and non-responder group, however, cannot be attributed to differences in the degree of ventricular hypertrophy (heart weight / BW: SCD group 12.6 $\pm 1.5 \mathrm{~g} / \mathrm{kg}$; TdP responder group: $11.2 \pm 1.4 \mathrm{~g} / \mathrm{kg}$ and non-responder group $11.1 \pm$ $1.6 \mathrm{~g} / \mathrm{kg}$ ). The longer QT time, LV APD and dispersion of repolarization at baseline of the drug-responder group (i.e. predisposition) compared to the non-responder group, result in longer repolarization values and TdP after the administration of dofetilide (Figure 2). This suggests that the drug-responder group, and the SCD group, possess a lower repolarization reserve, than the non-responder group. These findings stress the importance of performing drug comparisons in the same subset of 


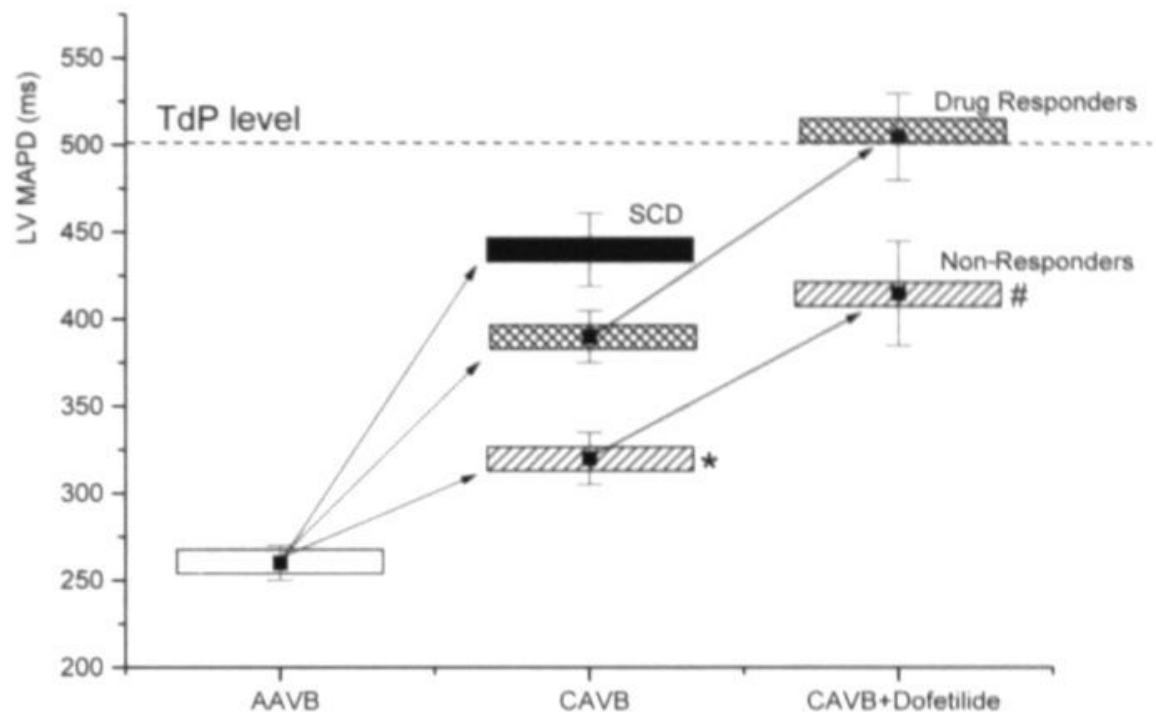

mean $\mathrm{x}$ sem

Figure 2 - For abbreviations see Figure 1: After AAVB ( $n=7)$, electrical remodeling takes place, leading to an increased LV MAPD at CAVB. Three groups can be distinguished: 1) dogs having spontaneous TdP and SCD at baseline without receiving dofetilide $(n=8) 2)$ dogs showing TdP after dofetilide (drug responders, $n=12$ ), and 3 ) dogs not developing TdP after dofetilide (non-responders, $n=6$ ). During CAVB, the baseline LV MAPD values of the SCD and drug-responder group are significantly higher ( $\left(^{*}\right.$, $\mathrm{P}<0.05)$. Administration of dofetilide results in a further increase of LV MAPD, which reaches a critical level leading to $\mathrm{TdP}$ in the responder group (\#, $\mathrm{P}<0.05$ vs non-responders). Values in mean \pm SEM.

Table 1 - The effects of different drugs on electrophysiological parameters and arrhythmias

\begin{tabular}{llllll}
\hline & $\uparrow Q T_{c}$ & $\triangle A P D$ & $E A D s$ & $E B s$ & $T d P$ \\
\hline Dofetilide IV & + & + & + & + & + \\
Azimilide IV & + & + & + & + & + \\
Amiodarone PO & + & $+/-$ & - & - & - \\
Dronedarone PO & + & + & + & + & + \\
HMR 1556 & + & $?$ & $?$ & $?$ & + \\
\hline
\end{tabular}

+/- : effect present / absent; $\triangle \mathrm{APD}$ : dispersion of repolarization; EADs: early afterdepolarizations; EBs: ventricular ectopic beats; IV: intravenously administered; PO: orally administered

dogs to ensure the same phenotype. The lower repolarization reserve in the drug-responder and SCD group might be due to, among others, a larger downregulation (or less expression) of outward currents, notably $\mathrm{I}_{\mathrm{K}}$.

The fact that, despite an apparently similar stressor (CAVB), different electrophysiological and arrhythmic phenotypes exist is intriguing. Complete AV block 
induces, among others, neurohumoral activation, e.g. catecholamines, angiotensinconverting enzyme, angiotensin II, and mechanical wall stress. These modulators can activate numerous intracellular signal pathways thereby altering the function and/or density of e.g. ion channels by changing the transcription, translation and/or post-translation processes of the gene(s) involved. Knowledge of higher or lower expression levels of gene products related to the remodeling processes and the different electrophysiological and arrhythmic phenotypes in the CAVB dog can eventually lead to the identification of entirely new targets for effective intervention to prevent and treat potentially lethal arrhythmias.

\subsection{DRUG INDUCED TORSADE DE POINTES ARRHYTHMIAS AND SUDDEN CARDIAC DEATH IN THE REMODELED CANINE HEART: INVESTIGATIONS IN THE CONSCIOUS CAVB DOG}

In Chapter 6 it was documented that a subset of CAVB dogs are prone to TdP and SCD under anesthesia without any drug challenge. Subsequently, the question arose whether dogs, which show drug-induced TdP under anesthesia, would also demonstrate drug-induced TdP and SCD during awake conditions. This became important after the finding that dronedarone caused $\mathrm{TdP}$ in $50 \%$ of the dogs under anesthesia, but did not lead to SCD in the cages, although the occurrence of non-lethal arrhythmias cannot be completely excluded. In view of these findings, a comparison with a selective $\mathrm{I}_{\mathrm{Kr}}$ blocker under conscious conditions in relation to $\mathrm{SCD}$ occurrence was needed. Obviously, when the drugs would be administered orally under awake circumstances, the model would mimic the clinical situation more closely. These two considerations were the starting point of a pilot study in the awake animal.

An integral part of the study were recordings of the cardiac rhythm with a 2-channel Holter during a 10-hour period, together with a video camera surveillance system to provide a link between the arrhythmias and the behavior of the dog. First, seven animals in sinus rhythm received single oral dosages of 0.025 and $0.05 \mathrm{mg} / \mathrm{kg}$ doferilide under conscious conditions. None of these animals demonstrated arrhythmias. Second, five CAVB dogs, which showed drug-induced TdP under anesthesia after IV administration of the $\mathrm{I}_{\mathrm{Kr}}$ blocker dofetilide, were also studied under awake circumstances. These dogs received a single oral dose of 0.025 - or 0.05 $\mathrm{mg} / \mathrm{kg}$ dofetilide after 12-hours of fasting. All the five animals developed arrhythmic activity under conscious conditions as well. The arrhythmias started $2 \frac{1}{2} 2$ to 4 hours after drug administration and the arrhythmic activity lasted for 30 minutes to 3 hours. This time period, in which the arrhythmias occurred, corresponds well with the reported peak plasma concentrations following oral dofetilide administration in humans. ${ }^{30}$ Three animals showed non-sustained episodes of polymorphic ventricular tachycardias, which were initiated by oscillatory short-long-short cycle length 


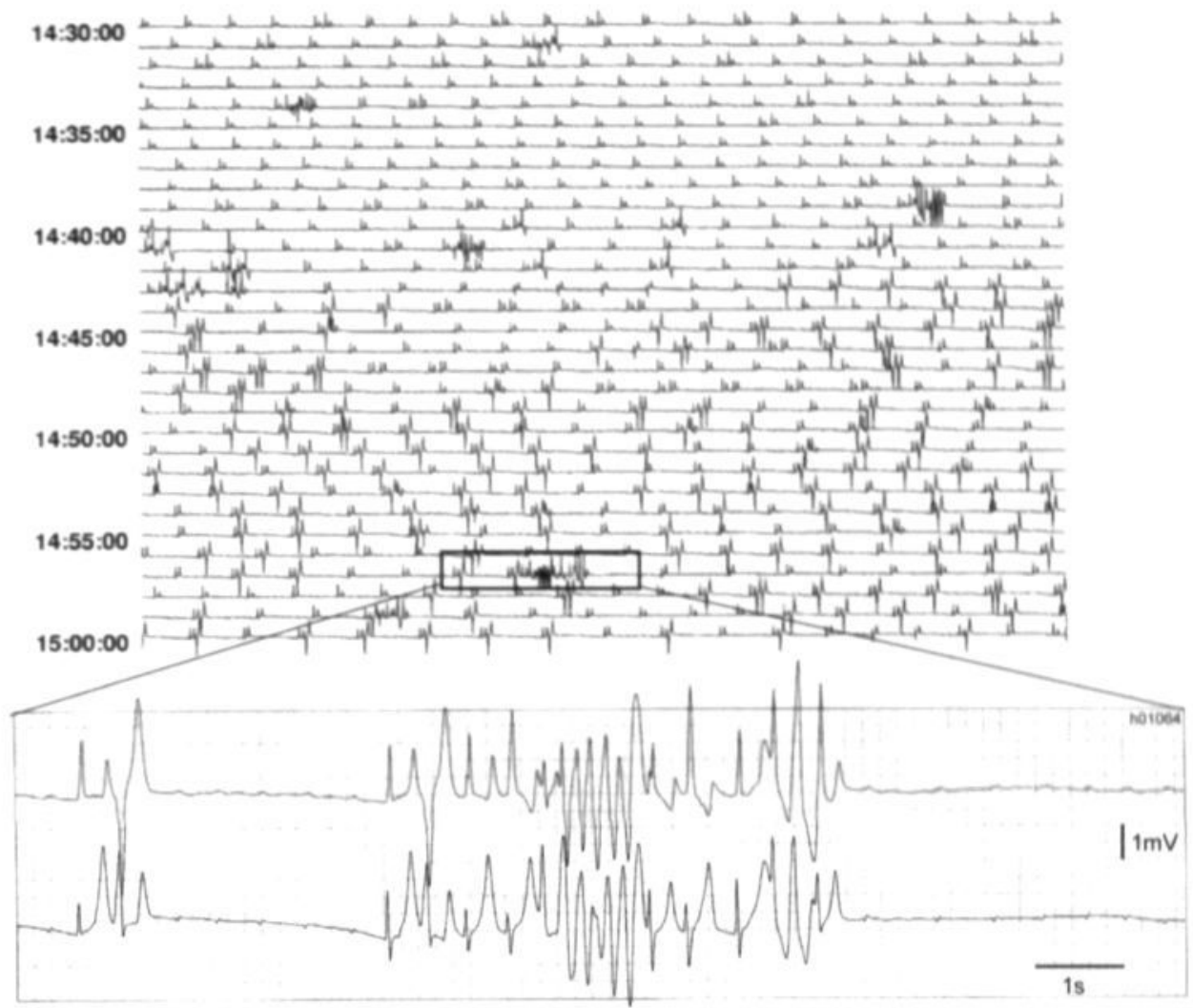

Figure 3 - Ventricular ectopic beats and TdP arrhythmias registered on Holter after $0.025 \mathrm{mg} / \mathrm{kg}$ dofetilide orally in a conscious dog. The upper panel shows a 30 -minute continuous recording in which single- and consecutive ectopic beats preceding the TdPs can be seen. The lower panel is a magnification of the arrhythmia in the upper panel. The arrhythmia is initiated by a short-long-short sequence and terminates spontaneously.

patterns (Figure 3). The initiation of the arrhythmias under conscious conditions after oral administration of dofetilide showed remarkable similarities with TdP after IV application in the same anesthetized animal, as can be seen in Figure 4.

One dog demonstrated a ventricular tachyarrhythmia, initiated by an extremely short coupling interval of $220 \mathrm{~ms}$, which did not terminate spontaneously and eventually degenerated into ventricular fibrillation leading to SCD (Figure 5). To cardiovert the arrhythmias and prevent SCD in the stable, 3 dogs were equipped with an implantable cardioverter defibrillator (GEM, Medtronic Inc). As can be seen in Figure 6, the implantable cardioverter defibrillator was capable to record and treat dofetilide induced tachyarrhythmias. Interestingly, the video camera recordings revealed that all the arrhythmic events occurred under resting conditions. In one dog the arrhythmia even disappeared when it became active. These findings suggest that the prolonged QT time by $\mathrm{I}_{\mathrm{Kr}}$ block could be shortened during exercise 
$t=0$
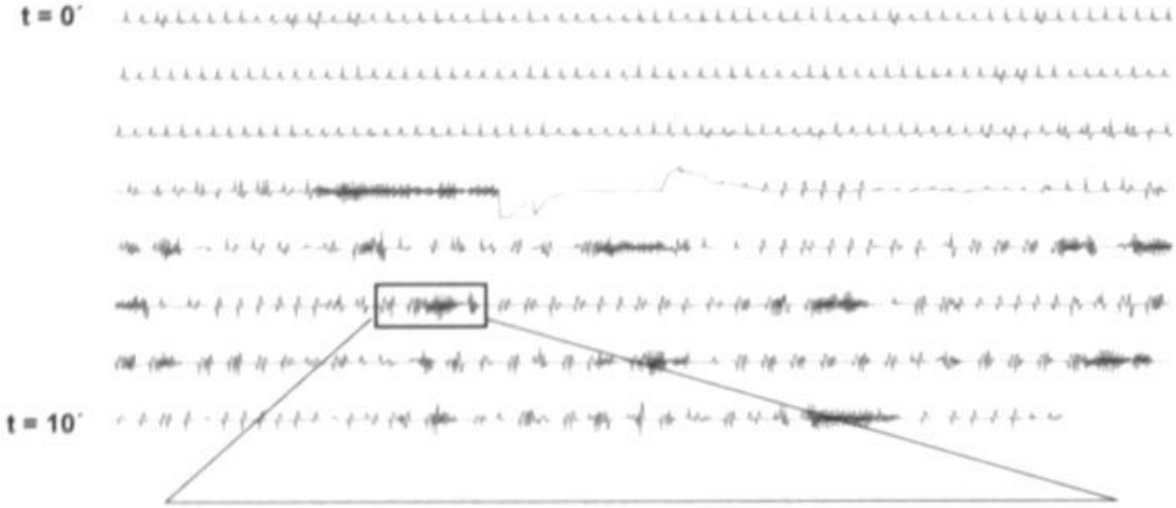

II
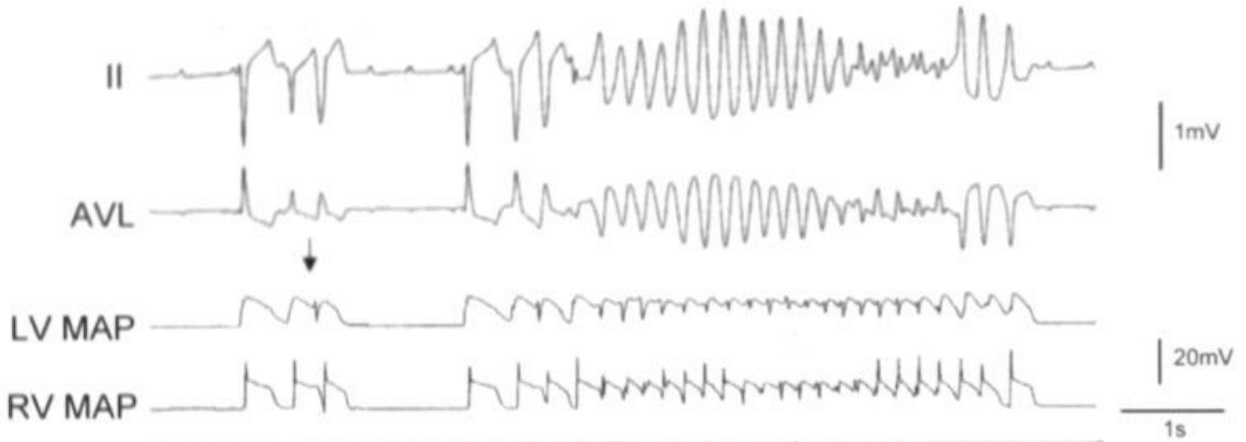

Figure 4 - Spontaneous ventricular ectopic beats and TdP after $0.025 \mathrm{mg} / \mathrm{kg}$ dofetilide IV under anesthesia. Same dog as in Figure 3, showing in a 10 minutes period multiple TdPs of which 1 had to be cardioverted. The incidence and duration of arrhythmias is more severe than after oral dofetilide administration. The lower panel shows leads II, aVL of the surface ECG and the LV and RV MAPD at a paper speed of $25 \mathrm{~mm} / \mathrm{s}$. The TdP is initiated by a short-long-short sequence of ventricular ectopic beats, which seem to be triggered by early afterdepolarizations (arrow).

because of an increased $\mathrm{I}_{\mathrm{Ks}}$ during adrenergic circumstances (Chapter 3 ). This mechanism would prevent repolarization dependent tachyarrhythmias during exercise. However, under resting conditions the $\mathrm{I}_{\mathrm{K} s}$ would be less activated, making the repolarization more dependent on the (drug-blocked) $\mathrm{I}_{\mathrm{Kr}}$ channel, thereby reducing the net repolarization current and rendering the heart susceptible to arrhythmias.

Looking at the TdP characteristics, the cycle length of the arrhythmias was similar under anesthesia $(200 \pm 18 \mathrm{~ms})$ compared to conscious conditions $(217 \pm 32$ $\mathrm{ms})$, but the incidence of arrhythmias $(10 \pm 6 \mathrm{vs} 6 \pm 5)$ and the duration $(6.1 \pm 3.5 \mathrm{~s}$ vs $2.6 \pm 0.4 \mathrm{~s}$ ) was markedly lower during conscious circumstances.

In conclusion, orally administered, clinically relevant dosages of the antiarrhythmic drug dofetilide can evoke TdP in the conscious CAVB dog. The possibility of testing (antiarrhythmic) drugs in the awake dog significantly increases the clinical value of the model. 


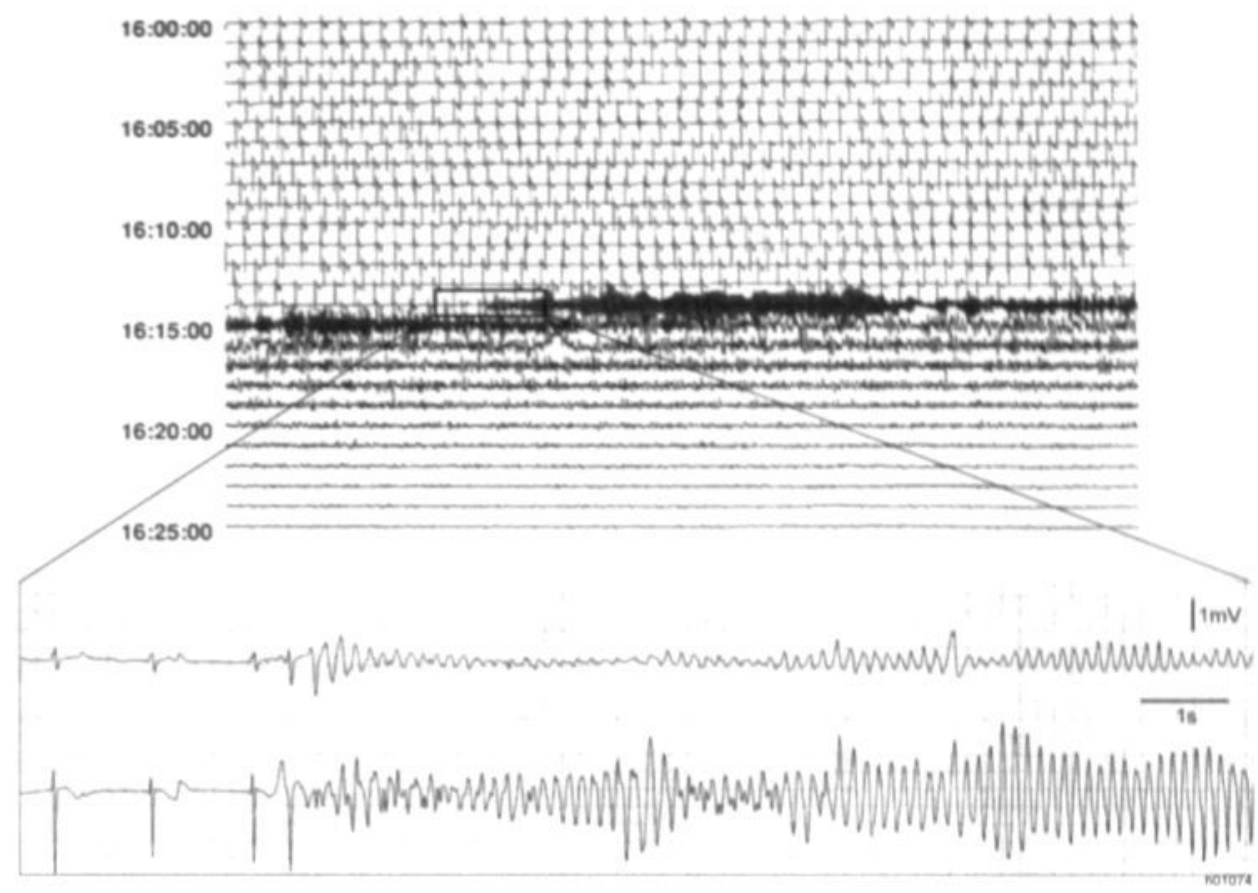

Figure 5 - Sudden cardiac death registered on a Holter recording in a conscious dog after oral administration of $0.050 \mathrm{mg} / \mathrm{kg}$ dofetilide. The upper panel shows a 25 - minute continuous recording in which long pauses and T-wave changes can be appreciated. A very short-coupled ectopic beat $(220 \mathrm{~ms}$, see lower panel) initiates the arrhythmia that deteriorates into ventricular fibrillation.

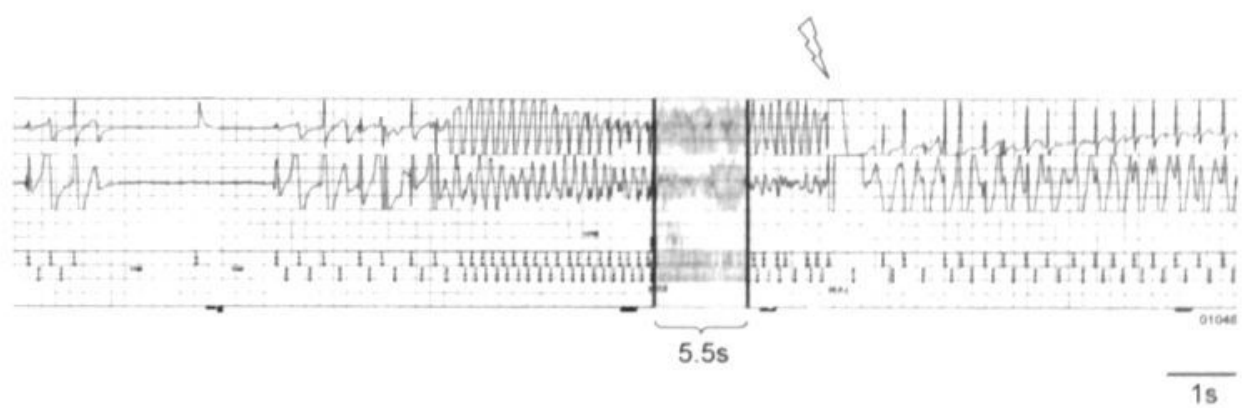

Figure 6 - Ventricular electrogram recorded by an ICD (GEM, Medtronic Inc) in a conscious dog. The ICD successfully cardioverted (indicated by the arrow) the arrhythmia degenerating into ventricular fibrillation, which occurred after oral administration of dofetilide. 

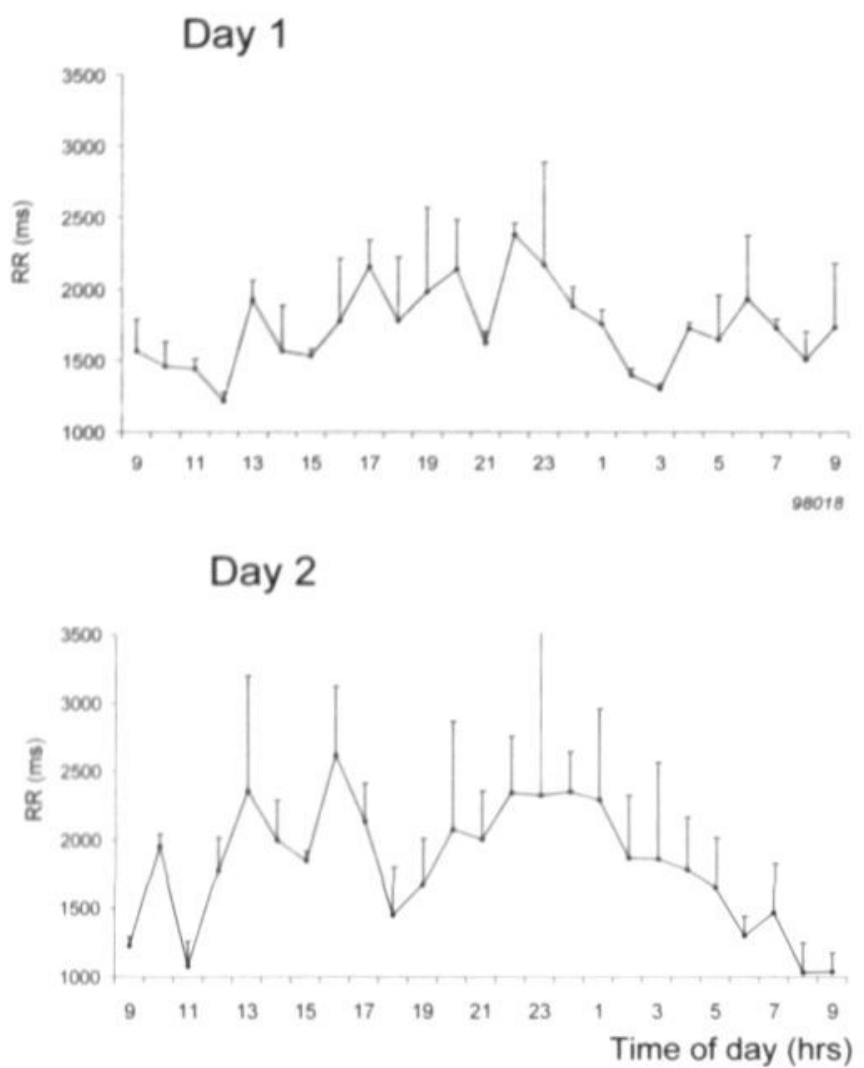

Figure 7 - Fluctuations in heart rate during two 24-hour periods (day 1 and 2) in a conscious CAVB dog, demonstrating that a clear influence of the autonomic nervous system is still present in the CAVB heart. The horizontal axis shows the time of day in hours and the vertical axis the RR interval in ms.

The measurement of QT times and RR changes in relation to drug induced $\mathrm{TdP}$ in the awake CAVB dog, could give further insights into the mechanisms of drug induced arrhythmias and SCD in patients.

However, a number of technical problems concerning the assessment and interpretation of RR and QT times on Holter has to be overcome. In the CAVB dog, as in the sinus rhythm dog, the heart rate fluctuates from hour to hour and from day to day (Figure 7). In general, the most used formula for adjusting QT interval to the heart rate is Bazetts formula. ${ }^{31}$ This formula, though, applies only to the ECG during steady state circumstances. ${ }^{32,33}$ To circumvent this problem, selective averaging procedures have been proposed in order to better control for the heart rate and autonomic nervous system activity in which a given event occurs. Selective averaging procedures average only those beats meeting specific criteria, for example a similar heart rate, regardless of the time of occurrence during the recording. ${ }^{33.34}$ 
In contrast, to explore the fluctuations of QT duration as the function of the cycle length changes, a beat-to-beat analysis has to be performed. The rate dependency of the QT time interval can be evaluated from ECG Holter recordings by computing the linear regression between QT intervals and correspondent RR intervals. The QT-RR relation can be derived by selective averaging procedures, e.g. 30-seconds or hourly templates, or by beat-to-beat analysis for short term high-quality ECG recordings obtained in controlled conditions. ${ }^{34}$

The evaluation of the circadian modulation of QT variability may have clinical relevance, as abnormal circadian patterns of prolonged QT interval have been associated with an increased incidence of malignant arrhythmias. ${ }^{35,36}$ Also class III drugs, ${ }^{37}$ or inherited cardiac ion channel abnormalities may modify the circadian pattern of QT variability. ${ }^{38-40}$ Likewise, the occurrence of arrhythmias during $\mathrm{I}_{\mathrm{K}}$ channel blockade in the conscious dog seems to be related to a failure of QT time shortening during shorter cycle lengths, i.e. a flat slope of the QT-RR relation.

Therefore, the combined analysis of ventricular repolarization dynamics and mechanisms of onset of arrhythmias by Holter monitoring can provide more insights in the interaction between the autonomic nervous system and the myocardial substrate.

\subsection{WHERE TO GO FROM HERE}

The CAVB dog has been established as a model in which different phenotypes are present: those who are arrhythmia susceptible and those who are not. Molecular studies on differences in gene expression between these phenotypes might provide insight into the genes, and signaling pathways involved in remodeling and proarrhythmia. Eventually, this may lead to the identification of entirely new targets for effective prevention and treatment of lethal arrhythmias.

\section{REFERENCES}

1. Vos MA, Gorgels AP, Lipcsei GC, De Groot SH, Leunissen JD, Wellens HJ. Mechanism-specific antiarrhythmic effects of the potassium channel activator levcromakalim against repolarization-dependent tachycardias. J Cardiovasc Electrophysiol. 1994;5:731-42.

2. Vos MA, Verduyn SC, Gorgels AP, Lipcsei GC, Wellens HJ. Reproducible induction of early afterdepolarizations and torsade de pointes arrhythmias by $\mathrm{d}$-sotalol and pacing in dogs with chronic atrioventricular block. Circulation. 1995;91:864-72.

3. Verduyn SC, Vos MA, van der Zande J, van der Hulst FF, Wellens HJ. Role of interventricular dispersion of repolarization in acquired torsade-de-pointes arrhythmias: reversal by magnesium. Cardiovasc Res. 1997;34:453-63. 
4. Verduyn SC, Vos MA, van der Zande J, Kulcsar A, Wellens HJ. Further observations to elucidate the role of interventricular dispersion of repolarization and early afterdepolarizations in the genesis of acquired torsade de pointes arrhythmias: a comparison between almokalant and d-sotalol using the dog as its own control. J Am Coll Cardiol. 1997;30:1575-84.

5. Vos MA, de Groot SH, Verduyn SC, van der Zande J, Leunissen HD, Cleutjens JP, van Bilsen M, Daemen MJ, Schreuder JJ, Allessie MA, Wellens HJ. Enhanced susceptibility for acquired torsade de pointes arrhythmias in the dog with chronic, complete AV block is related to cardiac hypertrophy and electrical remodeling. Circulation. 1998;98:1125-35.

6. Volders PG, Sipido KR, Vos MA, Spatjens RL, Leunissen JD, Carmeliet E, Wellens HJ. Downregulation of delayed rectifier $\mathrm{K}^{+}$currents in dogs with chronic complete atrioventricular block and acquired torsades de pointes. Circulation. 1999;100:2455-61.

7. Sipido KR, Volders PG, de Groot SH, Verdonck F, Van De Werf F, Wellens HJ, Vos MA. Enhanced $\mathrm{Ca}^{2+}$ release and $\mathrm{Na} / \mathrm{Ca}$ exchange activity in hypertrophied canine ventricular myocytes: potential link between contractile adaptation and arrhythmogenesis. Cinculation. 2000;102:2137-44.

8. Volders PG, Sipido KR, Vos MA, Kulcsar A, Verduyn SC, Wellens HJ. Cellular basis of biventricular hypertrophy and arrhythmogenesis in dogs with chronic complete atrioventricular block and acquired torsade de pointes. Circulation. 1998;98:1136-47.

9. Roden DM. Taking the "idio" out of "idiosyncratic": predicting torsades de pointes. Pacing Clin Electrophysiol. 1998;21:1029-34.

10. Burashnikov A, Antzelevitch C. Prominent $\mathrm{I}_{\mathrm{Ks}}$ in epicardium and endocardium contributes to development of transmural dispersion of repolarization but protects against development of early afterdepolarizations. J Cardiovase Electrophysiol. 2002;13:172-7.

11. Burashnikov A, Antzelevitch C. Block of $\mathrm{I}_{\mathrm{Ks}}$ does not induce early afterdepolarization activity but promotes beta-adrenergic agonist-induced delayed afterdepolarization activity. J Cardiovasc Electrophysiol. 2000;11:458-65.

12. Yao JA, Tseng GN. Azimilide (NE-10064) can prolong or shorten the action potential duration in canine ventricular myocytes: dependence on blockade of $\mathrm{K}, \mathrm{Ca}$, and $\mathrm{Na}$ channels. J Cardiovase Electrophysiol. 1997;8:184-98.

13. Fermini B, Jurkiewic NK, Jow B, Guinosso PJ, Jr., Baskin EP, Lynch JJ, Jr., Salata JJ. Use-dependent effects of the class III antiarrhythmic agent NE-10064 (azimilide) on cardiac repolarization: block of delayed rectifier potassium and L-type calcium currents. J Cardiovase Pharmacol. 1995;26:259-71.

14. Shimizu W, Antzelevitch C. Cellular basis for the ECG features of the LQT1 form of the long-QT syndrome: effects of beta-adrenergic agonists and antagonists and sodium channel blockers on transmural dispersion of repolarization and torsade de pointes. Circulation. 1998;98:2314-22.

15. Bosch RF, Gaspo R, Busch AE, Lang HJ, Li GR, Nattel S. Effects of the chromanol 293B, a selective blocker of the slow, component of the delayed rectifier $\mathrm{K}^{+}$current, on repolarization in human and guinca pig ventricular myocytes. Cardiovase Res. 1998;38:441-50.

16. Shimizu W, Antzelevitch $C$. Differential effects of beta-adrenergic agonists and antagonists in LQT1, LQT2 and LQT3 models of the long QT syndrome. J Am Coll Cardiol. 2000;35:778-86. 
17. Lu Z, Kamiya K, Opthof T, Yasui K, Kodama I. Density and kinetics of $\mathrm{I}_{\mathrm{Kr}}$ and $\mathrm{I}_{\mathrm{Ks}}$ in guinea pig and rabbit ventricular myocytes explain different efficacy of $\mathrm{I}_{\mathrm{Ks}}$ blockade at high heart rate in guinea pig and rabbit: implications for arrhythmogenesis in humans. Cinculation. 2001;104:951-6.

18. Wang Q, Curran ME, Splawski I, Burn TC, Millholland JM, VanRaay TJ, Shen J, Timothy KW, Vincent GM, de Jager T, Schwartz PJ, Toubin JA, Moss AJ, Atkinson DL, Landes GM, Connors TD, Keating MT. Positional cloning of a novel potassium channel gene: KVLQT1 mutations cause cardiac arrhythmias. Nat Genet. 1996;12:17-23.

19. Swan H, Saarinen K, Kontula K, Toivonen L, Viitasalo M. Evaluation of QT interval duration and dispersion and proposed clinical criteria in diagnosis of long QT syndrome in patients with a genetically uniform type of LQT1. J Am Coll Cardiol. 1998;32:486-91.

20. Zareba W, Moss AJ, Schwartz PJ, Vincent GM, Robinson JL, Priori SG, Benhorin J, Locati EH, Towbin JA, Keating MT, Lehmann MH, Hall WJ. Influence of genotype on the clinical course of the long-QT syndrome. International Long-QT Syndrome Registry Research Group. N Engl J Med. 1998;339:960-5.

21. Marx SO, Kurokawa J, Reiken S, Motoike H, D'Armiento J, Marks AR, Kass RS. Requirement of a macromolecular signaling complex for beta adrenergic receptor modulation of the KCNQ1-KCNE1 potassium channel. Science. 2002;295:496-9.

22. Hohnloser SH, Singh BN. Proarrhythmia with class III antiarrhythmic drugs: definition, electrophysiologic mechanisms, incidence, predisposing factors, and clinical implications. J Cardiovasc Electrophysiol. 1995;6:920-36.

23. Singh BN, Venkatesh N, Nademanee K, Josephson MA, Kannan R. The historical development, cellular electrophysiology and pharmacology of amiodarone. Prog Cardiovasc Dis. 1989;31:249-80.

24. Vorperian VR, Havighurst TC, Miller S, January CT. Adverse effects of low dose amiodarone: a meta-analysis. J Am Coll Cardiol. 1997;30:791-8.

25. Manning A, Thisse V, Hodeige D, Richard J, Heyndrickx JP, Chatelain P. SR 33589, a new amiodarone-like antiarrhythmic agent: electrophysiological effects in anesthetized dogs. J Cardiovasc Pharmacol. 1995;25:252-61.

26. Sun W, Sarma JS, Singh BN. Electrophysiological effects of dronedarone (SR33589), a noniodinated benzofuran derivative, in the rabbit heart : comparison with amiodarone. Circulation. 1999;100:2276-81.

27. Djandjighian L, Planchenault J, Finance O, Pastor G, Gautier P, Nisato D. Hemodynamic and antiadrenergic effects of dronedarone and amiodarone in animals with a healed myocardial infaretion. J Cardiovasc Pharmacol. 2000;36:376-83.

28. van Opstal JM, Verduyn SC, Leunissen HD, de Groot SH, Wellens HJ, Vos MA. Electrophysiological parameters indicative of sudden cardiac death in the dog with chronic complete AV-block. Cardiovasc Res. 2001;50:354-61.

29. Kodama I, Kamiya K, Toyama J. Cellular electropharmacology of amiodarone. Cardiovase Res. 1997:35:13-29.

30. Le Coz F, Funck-Brentano C, Morell T, Ghadanfar MM, Jaillon P. Pharmacokinetic and pharmacodynamic modeling of the effects of oral and intravenous administrations of dofetilide on ventricular repolarization. Clin Pharmacol Ther. 1995;57:533-42. 
31. Bazett HC. An analysis of the time relations of electrocardiograms. Heart. 1920;7:353-368.

32. Sarma JS, Sarma RJ, Bilitch M, Karz D, Song SL. An exponental formula for heart rate dependence of QT interval during exercise and cardiac pacing in humans: reevaluation of Bazett's formula. Am J Cardiol. 1984;54:103-8.

33. Lande G, Funck-Brentano C, Ghadanfar M, Escande D. Steady-state versus non-steady-state QT-RR relationships in 24-hour Holter recordings. Pacing Clin Electrophysial. 2000;23:293-302

34. Locati E. QT interval duration and adaptation to heart rate. In: Zareba W, Maison-Blanche P, Locati, E (eds). Noninvasive electrocardiology in clinical practice. Futura Publishing Company, Inc. 2001: 71-93.

35. Homs E, Marti V, Guindo J, Laguna P, Vinolas X, Caminal P, Elosua R, Bayes de Luna A. Automatic measurement of corrected QT interval in Holter recordings: comparison of its dynamic behavior in patients after myocardial infarction with and without life-threatening arrhythmias. Am Heart J. 1997;134:181-7.

36. Molnar J, Zhang F, Weiss J, Ehlert FA, Rosenthal JE. Diurnal pattern of QT ${ }_{c}$ interval: how long is prolonged? Possible relation to circadian triggers of cardiovascular events. $J$ Am Coll Cardiol. 1996;27:76-83.

37. Okada Y, Ogawa S, Sadanaga T, Mitamura H. Assessment of reverse use-dependent blocking actions of class III antiarrhythmic drugs by 24-hour Holter electrocardiography. J Am Coll Cardiol. 1996;27:84-9.

38. Merri M, Moss AJ, Benhorin J, Locati EH, Alberti M, Badilini F. Relation between ventricular repolarization duration and cardiac cycle length during 24-hour Holter recordings. Findings in normal patients and patients with long QT syndrome. Circulation. 1992;85:1816-21.

39. Neyroud N, Maison-Blanche P, Denjoy I, Chevret S, Donger C, Dausse E, Fayn J, Badilini F, Menhabi N, Schwartz K, Guicheney P, Coumel P. Diagnostic performance of QT interval variables from 24-h electrocardiography in the long QT syndrome. Eur Heart J. 1998;19:158-65.

40. Lande G, Kyndt F, Baro I, Chabannes D, Boisseau P, Pony JC, Escande D, Le Marec H. Dynamic analysis of the QT interval in long QT1 syndrome patients with a normal phenotype. Eur Heart J. 2001:22:410-22. 
Summary 
The heart continuously pumps blood throughout the body, roughly three billion times in an average lifetime. Every heartbeat is initiated by a pulse of electrical activation, which is generated in specialized pacemaker cells and subsequently spreads to the atria and ventricles of the heart. The electrical impulse leads to excitation of each individual cell in the heart, thereby activating the contractile machinery. Thereafter, the heart returns (i.e. repolarizes) to the resting phase, where after the cell can be excited again.

If the ventricles beat too slow, bradycardias, or too fast, tachycardias, then this can lead to no or insufficient blood supply to the body. This may, in the extreme case, lead to sudden cardiac death. Class III antiarrhythmic drugs are given to treat both atrial and ventricular tachycardias. These drugs exert their action by prolonging the repolarization of the heart, via ion-channel blockade, which can be seen on the ECG as a prolongation of the QT time. However, prolongation of the repolarization by these drugs can, paradoxically, lead to ventricular tachycardias (Torsade de Pointes) and sudden cardiac death in 3-8\% of patients.

The risk of Torsade de Pointes increases significantly if the patient is predisposed. Hypertrophy, heart failure and other pathophysiological conditions of the heart are associated with electrical remodeling processes. These electrical remodeling processes result in a reduced repolarization capacity, and an increased susceptibility to repolarization prolonging drugs, such as class III antiarrhythmic drugs. Therefore, it is imperative to have an (animal) model with a high sensitivity and specificity to preclinically screen and study these drugs for their propensity to induce Torsade de Pointes.

In this thesis an animal model is used in which operatively induced chronic complete atrioventricular block leads to ventricular hypertrophy and electrical remodeling.

Chapter 1 contains the introduction to the thesis. The background of the electrical remodeling processes in hypertrophy and heart failure resulting in an enhanced susceptibility to (drug-induced) Torsade de Pointes and sudden cardiac death are discussed. The dog model with chronic complete atrioventricular block is introduced and the goals of the thesis are formulated.

Chapter 2 demonstrates the high sensitivity to Torsade de Pointes with class III drugs in the electrically-remodeled canine heart. The increased sensitivity is associated with an increased duration of ventricular repolarization, and increased differences in repolarization duration between areas of the ventricles (i.e. dispersion of repolarization). The new class III antiarrhythmic drug azimilide, which blocks an additional ion channel $\left(\mathrm{I}_{\mathrm{K} s}\right)$ next to the "classic" $\mathrm{I}_{\mathrm{Kr}}$ channel, was thought to evoke less Torsade de Pointes. However, in the remodeled heart no difference in Torsade de Pointes incidence existed between azimilide and the clinically used selective $\mathrm{I}_{\mathrm{Kr}_{r}}$-channel blocker dofetilide. The occurrence of Torsade de Pointes was for both drugs associated with the development of early afterdepolarizations, ventricular ectopic activity and an increased dispersion of repolarization.

Because additional $\mathrm{I}_{\mathrm{K} s}$ channel blockade was not favorable to selective $\mathrm{I}_{\mathrm{K}_{\mathrm{r}}}$ channel blockade, the $\mathrm{I}_{\mathrm{K} s}$ channel was extensively studied in the normal canine heart, both on the 
cellular and in-vivo level. The function of the $\mathrm{I}_{\mathrm{Ks}}$ channel appeared to be importantly dependent on the adrenergic drive, and was shown to be a major contributor to ventricular repolarization in conscious dogs. Blockade of the channel, especially under strong adrenergic circumstances, probably results in the inability to shorten the repolarization sufficiently and leads to Torsade de Pointes. These findings provide more insights in congenital and acquired diseases in which the $\mathrm{I}_{\mathrm{K} s}$ channel is involved (Chapter 3).

The antiarrhythmic drug amiodarone was studied in Chapter 4 . Amiodarone is the only antiarrhythmic drug having a very low incidence of Torsade de Pointes in the clinical situation. Unfortunately, its many non-cardiac adverse effects limit the widespread clinical use. Amiodarone did not evoke Torsade de Pointes in the model, similar to the clinical situation, thereby demonstrating that the model possesses, next to a high sensitivity, also a high specificity for testing proarrhythmic properties of (antiarrhythmic) drugs. Secondly, the study showed that prolongation of the repolarization is feasible in the remodeled heart without the occurrence of Torsade de Pointes. Torsade de Pointes does not occur as long as early afterdepolarizations, ventricular ectopic activity and an increase in dispersion of ventricular repolarization are absent. Thus, although the amount of QT time prolongation is used by regulatory drug administrations for risk-assessment of drug-induced Torsade de Pointes, this seems not to be the golden standard.

Unfortunately, the assessment of electrical properties of the heart, which are important for the occurrence of arrhythmias, can only be assessed invasively by catheters. Therefore, we related these invasively assessed parameters with the non-invasive ECG, and showed that the area of the T wave on the surface ECG reflects the invasivelyassessed dispersion of repolarization (Chapter 5). This parameter can possibly be used to identify patients who are at risk for drug-induced Torsade de Pointes.

Normally, antiarrhythmic-drug studies in the model are performed under anesthesia, which condition is however not comparable to the patient situation. As a result the model was extended, and made more clinically relevant by studying the antiarrhythmic drugs under conscious circumstances. It was demonstrated, by ECG telemetry, Holter and implantable-cardioverter-defibrillator recordings, that the model possesses also a high sensitivity to antiarrhythmic drug-induced Torsade de Pointes and sudden cardiac death under conscious circumstances (Chapter 7).

Furthermore, we could assess in advance which animals are at risk for class III druginduced Torsade de Pointes and sudden cardiac death and those who are not. This on the basis of the left ventricular repolarization duration and dispersion of repolarization duration at baseline (Chapters 6 and 7).

The latter findings make it possible to identify, and possibly treat, underlying genes or gene products, which determine drug-induced Torsade de Pointes and sudden cardiac death in the remodeled heart. 



\section{Samenvatting}


Het hart is een holle spier die gemiddeld 3 miljard maal in een mensenleven samentrekt en daarmee bloed door het lichaam pompt. Elke hartslag wordt geïnitieerd door een elektrische prikkel, die ontstaat in gespecialiseerde pacemakercellen en vervolgens wordt voortgeleid over de boezems en kamers van het hart. Deze elektrische prikkel leidt tot excitatie van elke individuele hartcel waarna de kontraktiele machinerie wordt geactiveerd en de cel samentrekt. Hierna keert de cel terug (repolariseert) naar de rustfase, waarna hij weer geëxciteerd kan worden.

Als de kamers van het hart te langzaam (bradycardieën) of te snel kloppen (tachycardieën) kan dit leiden dit tot geen- of onvoldoende bloedtoevoer naar het lichaam. In het meest extreme geval kan dit resulteren in overlijden (plotse hartdood).

Voor de behandeling van zowel boezem- als kamertachycardieën worden klasseIII-anti-arrhythmica gegeven. Deze medicamenten kunnen tachycardieën verhinderen of beëindigen door de duur van de repolarisatie in het hart, via blokkade van bepaalde ionkanalen, te verlengen. Dit is op het hartfilmpje (ECG) te zien als een verlenging van de zogenaamde QT-tijd. Echter, het verlengen van de repolarisatieduur door medicamenten kan, paradoxaal, bij 3-8\% van de patiënten juist bepaalde kamertachycardieën (Torsade de Pointes) en plotse hartdood opwekken.

Het risico op Torsade de Pointes wordt aanzienlijk verhoogd wanneer de patiënt gepredisponeerd is. Hypertrofie, verdikking van de hartspier, hartfalen en ander pathofysiologische condities zijn geassocieerd met veranderingsprocessen (remodelering) van de elektrische eigenschappen van het hart. Deze elektrische remodeleringsprocessen resulteren in een verminderde repolarisatiecapaciteit van het hart, leidend tot een verhoogde gevoeligheid voor Torsade de Pointes wanneer medicamenten worden toegediend die de repolarisatieduur verlengen, zoals klasseIII-anti-arrhythmica. Het is daarom van groot belang dat klasse-III-anti-arrhythmica pre-klinisch gescreend en bestudeerd kunnen worden op de bijwerking Torsade de Pointes. Daarvoor is een (dier) model nodig met een hoge sensitiviteit en specificiteit voor medicament-gerelateerde Torsade de Pointes .

In dit proefschrift werd gekozen voor een diermodel waarbij operatief chronisch compleet atrioventriculair blok wordt gemaakt, leidend tot kamerhypertrofie en elektrische remodelering.

Hoofdstuk 1 bevat de algemene introduktie van het proefschrift. De achtergrond van de elektrische remodeleringprocessen in hypertrofie en hartfalen die leiden tot een verhoogde gevoeligheid voor (medicament-gerelateerde) Torsade de Pointes en plotse hartdood worden besproken. Het hondenmodel met chronisch compleet atrioventriculair blok wordt geïntroduceerd en de doelstellingen van het proefschrift geformuleerd.

Hoofdstuk 2 laat zien dat het elektrisch geremodeleerde hondenhart zeer sensitief is voor klasse-III-anti-arrhythmica gerelateerde Torsade de Pointes. Dit op basis van een toename in de repolarisatieduur van de kamers - en verschillen in repolarisatieduur (repolarisatiedispersie) tussen gebieden in de kamers. Het nieuwe klasse-III-anti-arrhythmicum azimilide, welke een bepaald ionkanaal ( $\mathrm{I}_{\mathrm{Ks}}$ ) extra 
naast het "klassieke" $I_{K r}$ kanaal blokkeerde, werd daarom gedacht minder Torsade de Pointes te geven. In het geremodeleerde hart bleek dit anti-arrhythmicum echter even veel Torsade de Pointes op te wekken als de klinisch gebruikte selectieve $\mathrm{I}_{\mathrm{K}}$ kanaal-blokker dofetilide. Het optreden van Torsade de Pointes was voor beide medicamenten geassocieerd met het ontstaan van vroege nadepolarisaties, ectopische activiteit vanuit de kamers van het hart, en een toegenomen repolarisatiedispersie.

Vanwege het feit dat additionele $\mathrm{I}_{\mathrm{Ks}}$ kanaalblokkade niet gunstiger was dan selectieve $\mathrm{I}_{\mathrm{K}_{r}}$ kanaalblokkade, werd het $\mathrm{I}_{\mathrm{Ks}}$ kanaal in het normale hondenhart, zowel op cellulair als in-vivo niveau, grondig bestudeerd. Hieruit bleek dat de werking van het kanaal sterk afhankelijk was van de adrenerge staat, en in de wakkere hond een belangrijke bijdrage levert aan de repolarisatie van de kamers. Vooral onder sterk adrenerge omstandigheden leidt blokkade van het kanaal waarschijnlijk tot het onvermogen om de repolarisatieduur te verkorten en juist tot Torsade de Pointes. Deze bevindingen geven verdere inzichten in aangeboren en verworven ziekten waarbij het $\mathrm{I}_{\mathrm{Ks}}$ kanaal betrokken is (Hoofdstuk 3).

Het anti-arrhythmicum amiodarone werd bestudeerd in Hoofdstuk 4 . Amiodarone is in de kliniek een effectief anti-arrhythmicum met een lage Torsade de Pointes incidentie. Het heeft echter veel, niet cardiale, bijwerkingen wat de klinische toepasbaarheid beperkt. Amiodarone gaf in het model, net als in de kliniek, geen Torsade de Pointes. Dit toont aan dat het model naast een hoge sensitiviteit ook een hoge specificiteit bezit voor het testen van medicamenten voor de bijwerking Torsade de Pointes. Daarnaast laat deze studie zien dat medicamenteuze QT-tijd verlenging in het geremodeleerde hart wel degelijk mogelijk is zonder Torsade de Pointes op te wekken. Torsade de Pointes treden niet op zolang geen vroege nadepolarisaties en ectopische slagen worden opgewekt en de repolarisatiedispersie niet toeneemt. Dus het blijkt dat de mate van QT-tijd verlenging niet de gouden standaard is om medicamenten te risikostratificeren voor Torsade de Pointes, ondanks dat deze parameter wel gebruikt wordt door de medicamenttoezichtscommissies.

Omdat de bestudering van elektrische eigenschappen van het hart die van belang zijn voor het ontstaan van ritmestoornissen tot nog toe alleen invasief, met catheters, bestudeerd kunnen worden, werd gekeken of deze gerelateerd konden worden met het ECG (Hoofdstuk 5). Het bleek dat de T-golf oppervlakte op het ECG als non-invasieve maat voor repolarisatiedispersie gebruikt kan worden. Mogelijk kan deze parameter dan ook gebruikt worden om patiënten te identificeren die een verhoogd risico hebben op medicament-geïnduceerde Torsade de Pointes.

Vanwege het feit dat de klasse-III-anti-arrhythmica in het model alleen bestudeerd werden onder anesthesie, en deze situatie niet overeenstemt met de patiëntsituatie, werden de medicamenten ook oraal onder wakkere omstandigheden toegediend. Met behulp van ECG telemetrie, Holter en implanteerbare-cardioverterdefibrillator opnamen, kon worden aangetoond dat het model ook een hoge sensiti- 
viteit bezat voor medicament geïnduceerde Torsade de Pointes en plotse hartdood onder wakkere omstandigheden (Hoofdstuk 6 en 7).

Verder werd het in het model mogelijk om op voorhand een onderscheid te maken tussen individuen die gevoelig zijn voor medicament-gerelateerde hartritmestoornissen en plotse hartdood, en degenen die dat niet zijn. Dit op basis van de lengte van de linker kamer repolarisatieduur en de mate van repolarisatiedispersie (Hoofdstuk 6).

Deze bevindingen maken in de toekomst identificatie, en mogelijk behandeling, van onderliggende genen of genproducten, die bepalend zijn voor medicament gerelateerde ritmestoornissen en plotse hartdood, mogelijk. 


\section{Dankwoord}


Het voor U liggende proefschrift is het resultaat van een jarenlange inspanning, welke door vele mensen werd verricht. Ik had het voorrecht dat het onderzoek kon plaatsvinden binnen de vakgroep Cardiologie te Maastricht met een wereldwijde bekendheid op het gebied van hartritmestoornissen. Alhoewel het onmogelijk is om iedereen te bedanken die bij het welslagen van het proefschrift betrokken is geweest, zou ik bij deze een poging willen wagen.

Prof. H.J.J. Wellens, de founding father van de Cardiologie te Maastricht, heeft al die tijd mijn onderzoek gestimuleerd en positief bekritiseerd. Prof. Wellens, het was een voorrecht om bij $U$ thuis het proefschrift zijn vorm te mogen geven, en het is een grote eer dat $U$ mijn promotor wilt zijn.

Dr. M.A. Vos, beste Marc, vanaf het moment dat ik kwam "binnenlopen" als student-assistent, heb jij je ingespannen voor een stimulerende en kritische begeleiding, zowel op als buiten de werkvloer. Jouw inzicht en juiste balans tussen wetenschap en pragmatisme, heeft er toe geleid dat de vakgroep Experimentele Electrofysiologie zich zowel binnen als buiten de Universiteit heeft gevestigd. Naast het bovenstaande ben je al die jaren in staat geweest om het beste uit mensen te halen en hen hun eigen verantwoordelijkheid te laten nemen, wat zowel het individu als de groep heeft doen groeien. Bedankt dat je mijn co-promotor wilt zijn en ik hoop dat ik ook na mijn promotie nog lang met je mag werken.

De leden van de beoordelingscommissie Prof. H.J.G.M. Crijns, Prof. M.A. Allessie, Prof. M.J. Janse en Prof. H.A.J. Struijker Boudier wil ik bedanken voor hun bereidheid om het manuscript kritisch door te lezen en tijdens de verdediging te opponeren. Pareil, je voudrais remercier Prof. D. Escande, pour avoir évalué cette thèse et pour faire le voyage à Maestricht.

Mijn paranimfen Bart Stubenitsky en Dirk Donker die me hebben bijgestaan tijdens het schrijven van het boekje en bij de organisatie van de promotie. Bart, het is al weer een tijdje geleden dat je zelf promoveerde, en nog langer geleden dat ik je er op een avond van af heb moeten houden om de Cardiologie in te gaan. Ik hoop nog veel speciale gelegenheden met je mee te maken. Dirk, sinds ik je tegenkwam in de Y-ruimte, hebben we veel dingen gedeeld. Als echte vriend stond je altijd klaar, en op de fiets hebben we samen het Ardennenoffensief herhaald. Nu de familie Donker weer wat groter wordt, hopen we binnenkort weer een glaasje Mirabelles te drinken in het Franse landschap.

Mijn collega's van de Experimentele Cardiologie groep hebben het werk lichter en plezieriger gemaakt: Jet, zonder jou geen proefschrift(en). Samen met Marc vorm je het fundament van de groep, en zorg je, naast een perfecte uitvoering van de experimenten, voor het dagelijkse management. Roel, naast je onbetwiste cellulaire vaardigheden en kennis, ben je ook degene die een idee vertaalt naar een werkelijk bruikbare illustratie. De fraaie figuren in dit proefschrift zijn dan ook van jou en Jet afkomstig. Marieke Schoenmakers, mijn kamergenoot van de laatste jaren, heb ik leren kennen als een goede collega met humor en altijd aandacht voor de ander, zelfs in voor haar zeer moeilijke tijden. Veel succes met de link vivo-moleculair en jouw 
promotie. Morten, actually I should write this in Danish, but unfortunately I am still following courses. Next to the fact that I could always bother you with questions on the pharmaceutical side, we had also some good discussions at the end of day. Keep the beers cold! Chris, de Amsterdamse tak, je hebt van een compleet onwetend moleculair iemand in ieder geval een leek gemaakt. Ik hoop dat we in de toekomst nog eens kunnen samenwerken. Jérôme, bedankt voor al je chirurgische expertise gedurende "kritische" momenten en veel succes met de afronding van je eigen promotie. Paul, ondanks je eigen drukke bezigheden, had je altijd tijd om manuscripten kritisch te bekijken en ideeën of protocollen te bediscussiëren. Uiteindelijk is er wat moois uitgekomen (hoofdstuk 3), en ik hoop ook in de toekomst nog veel van je te kunnen leren. Milan, for the real questions and answers, one has to come to you. Good luck with your career in Czechia. Cora, heeft mij gedurende de eerste schreden op het wetenschappelijke pad begeleid, en vormt mede de basis voor dit proefschrift. Bedankt! Michiel, gedurende het laatste jaar stond je als student-assistent altijd klaar om vlak voor deadlines nog presentaties klaar te maken. Maak er een leerzaam jaar van! Elke, na die vliegende start moet de rest van de thesis niet zo'n probleem meer zijn. Maaike, geadopteerd lid van de groep, wens ik veel succes met de verdediging van haar eigen proefschrift. Vivian Schellings, wil ik bedanken voor al de hulp rondom het proefschrift en de dagelijkse broodnodige secretariële ondersteuning.

Verder iedereen die de afgelopen jaren goede collega's waren binnen de experimentele cardiologie groep: Henny, Marieke, Xander, Ferenc, Mirella en Stephan.

Graag wil ik ook de stafleden van de vakgroep Cardiologie bedanken en met name Dr. Joep Smeets, die nauw betrokken is geweest bij de Holter studies. Bij diezelfde Holter studies waren ook de leden van de Hartfunctie betrokken, bedankt voor jullie inzet en betrokkenheid. De Instrumentele Dienst, en in het bijzonder Leon Dohmen was degene die de telemetrie studies mogelijk maakte. Leo Kretzers, Medtronic Bakken Research, voor het tot een succes maken van de ICD studies. Voor de ondersteuning van de computerzaken en het netwerk beheer aan Universitaire zijde was Charlie Bonnemayer altijd paraat.

De collega's van de vakgroep Fysiologie (onder leiding van Prof. M.A. Allessie) dank ik voor de intensieve samenwerking en discussies tijdens de werkbesprekingen.

Theo van der Nagel en Ruud Kruger voor de technische hulp tijdens de experimenten en de noodzakelijke afleiding.

De Centrale Proefdiervoorzieningen (onder leiding van Dr. Ton van den Boogaard) voor de goede verzorging van de honden.

Voor de noodzakelijke ontspanning en inspanning, waren met name Dirk, Birgit, Marijn, Mirto, Guy, Mascha, Bart, Annemieke, Tom en Annemarieke belangrijk.

Verder mijn eigen familie en mijn "schoonouders" die altijd met grote belangstelling de schrijfwerkzaamheden volgden. 
Mijn drie broers Robbert, Rurik en Jochgem, en schoonzus, voor hun steun, belangstelling en band door de jaren heen.

Mijn Oma en wijlen Opa, die mede de basis hebben gelegd voor deze mijlpaal. Mamma en Pappa, in een paar regels kan ik moeilijk alles kwijt wat jullie voor mij betekenen. Bedankt voor alles wat jullie gegeven hebben en voor het feit dat jullie altijd achter me staan en stonden.

Het laatste woord gaat naar diegene die altijd naast me staat, lieve Annelette, bedankt voor je onvoorwaardelijke steun en trouw door de jaren heen. 


\section{Curriculum Vitae}

2 november 1972 Geboren te Utrecht

1985-1991 Gymnasium, Gymnasium Beekvliet, St. Michielsgestel

1991-1998 Geneeskunde, artsexamen, Universiteit Maastricht

1994-1996 Student-assistent vakgroep Cardiologie

1998-2002 A.I.O., Cardiologie, Universiteit Maastricht

juli 2002-heden Arts-assistent Cardiologie, AZM, Maastricht 
Publications 


\section{ARTICLES}

1. SC Verduyn, MA Vos, HD Leunissen, JM van Opstal, HJJ Wellens. Evaluation of the acute electrophysiologic effects of intravenous dronedarone, an amiodarone-like agent, with special emphasis on ventricular repolarization and acquired Torsade de Pointes arrhythmias. J Cardiovasc Pharmacol. 1999 Feb;33(2):212-222

2. SC Verduyn, JM van Opstal, HDM Leunissen, MA Vos. Assessment of the proarrhythmic potential of antiarrhythmic drugs: an experimental approach. J Cardiovasc. Pharmacol. Therapeut. 2001; 6(1): 89-97

3. JM van Opstal, HDM Leunissen, HJJ Wellens, MA Vos. Azimilide and dofetilide produce similar electrophysiological and proarrhythmic effects in a canine model of Torsade de Pointes arrhythmias. Eur. J. Pharmacol. 2001;412:67-76

4. JM van Opstal, SC Verduyn, HDM Leunissen, SHM de Groot, HJ Wellens, MA Vos. Electrophysiological parameters indicative of sudden cardiac death in the dog with chronic complete AV-block. Cardiovasc. Res. 2001;50:354-61

5. JM van Opstal, M Schoenmakers, SC Verduyn, SHM de Groot, JD Leunissen, FF van der Hulst, MMC Molenschot, HJJ Wellens, MA Vos. Chronic amiodarone evokes no Torsade de Pointes arrhythmias despite QT lengthening in an animal model of acquired long QT syndrome. Circulation 2001; 104:2722-2727

6. MA Vos, JM van Opstal, HD Leunissen, SC Verduyn. Electrophysiological parameters and predisposing factors in the generation of drug induced Torsade de Pointes arrhythmias. Pharmacology \& Therapeutics 2001;92:109-122

7. JM van Opstal, SC Verduyn, SKG Winckels, H Leerssen, HD Leunissen, HJJ Wellens, MA Vos. The JT area indicates dispersion of repolarization in dogs with atrioventricular block. Journal of Interventional Cardiac Electrophysiology 2002;6:113-120

8. PGA Volders, JM van Opstal, M Stengl, RLHMG Spätjens, JDM Leunissen, KR Sipido, MA Vos. Probing the contribution of $\mathrm{I}_{\mathrm{Ks}}$ to canine ventricular repolarization. Submitted

\section{ABSTRACTS INTERNATIONAL}

1. SC Verduyn, MA Vos, JM van Opstal, J van der Zande, HJJ Wellens. Spontaneous termination of acquired Torsade de Pointes arrhythmias in dogs reveals causal relation between early afterdepolarizations with dispersion of repolarization. PACE 1995;18:830

2. JM van Opstal, SC Verduyn, MA Vos, J van der Zande, HJJ Wellens. Homogenization of ventricular repolarization by levcromakalim is responsible for suppression of Torsade de Pointes arrhythmias in dogs. Eur. Heart J. 1996;17:417

3. JM van Opstal, SC Verduyn, MA Vos, H Leersen, JD Leunissen, HJJ Wellens. Simple measurement of JTU area on the ECG indicates changes in interventricular dispersion of repolarisation in dogs. J Am Coll Cardiol 1998;31:2;253A 
4. SC Verduyn, MA Vos, JD Leunissen, JM van Opstal, HJJ Wellens. Evaluation of the electrophysiological effects of dronedarone i.v., an amiodarone like agent, with special emphasis on ventricular repolarization and acquired Torsade de Pointes arrhythmias. J Am Coll Cardiol $1998 ; 31: 4 ; 123 \mathrm{C}$

5. MA Vos, SC Verduyn, T Fazekas, FF van der Hulst, HDM Leunissen, JM van Opstal, HJJ Wellens. Antiarrhythmic drugs and Torsade de Pointes arrhythmias: an experimental approach. Fundam. Clin. Pharmacol. 1999;13 (1):71S

6. JM van Opstal, HDM Leunissen, HJJ Wellens, MA Vos. Azimilide and doferilide produce similar electrophysiological and proarrhythmic effects in a canine model of Torsade de Pointes arrhythmias. Pacing Clin Electrophysiol. 2000;23:732

7. JM van Opstal, MA Vos, HDM Leunissen, HJJ Wellens. The degree of interventricular dispersion in action potential duration determines susceptibility to sudden cardiac death and acquired Torsade de Pointes arrhythmias. J Am Coll Cardiol 2000;35:2:97

8. MA Vos, JM van Opstal, SC Verduyn, JD Leunissen, C Ramakers, P Doevendans, R Dumaine, C Antzelevitch, P Volders, K Sipido. Electrophysiological and molecular aspects of drug induced Torsade de Pointes (TdP). Br. J. Clin. Pharmacol. 2000;july;27

9. JM van Opstal, S Winckels, MA Vos, SC Verduyn, JDM Leunissen, HJJ Wellens. Changes in JTU area reflect interventricular dispersion of repolarization in chronic AV-block dogs. Eur. J Pacing Clin. Electrophys. 2000;2:b33

10. JM van Opstal, MA Vos, JDM Leunissen, HJJ Wellens. Susceptibility to sudden cardiac death and acquired Torsade de Pointes arrhythmias is determined by the degree of interventricular dispersion in action potential duration. Eur. J Pacing Clin. Electrophys. 2000;2:b27

11. M Schoenmakers, JM van Opstal, JDM Leunissen, SHM de Groot, RLHGM Spätjens, HJJ Wellens, MA Vos. Ventricular hypertrophy is not a prerequisite for short-term functional adaptation, electrical remodeling and arrhythmogenicity in the chronic AV-block dog. PACE 2001; 24:572

12. JM van Opstal, M Schoenmakers, SC Verduyn, SHM de Groot, HDM Leunissen, FF van der Hulst, MMC Molenschot, MA Vos. Absence of Torsade de Pointes arrhythmias despite QT-lengthening after oral amiodarone treatment in an animal model of acquired long QT. Eur. Heart J. 2001;22:449

13. JM van Opstal, M Schoenmakers, SC Verduyn, SHM de Groot, HDM Leunissen, FF van der Hulst, MMC Molenschot, HJJ Wellens, MA Vos. Chronic Amiodarone Evokes no Torsade de Pointes Arrhythmias despite QT lengthening in an Animal Model of Acquired long-QT Syndrome. Circulation 2001;104: II 47

14. M Schoenmakers, JD Leunissen, JM Van Opstal, HJ Wellens, MA Vos. Cardiac Hypertrophy and Electrical Remodeling Develop Asynchronously in the Chronic AV-block dog, Independently of AT1 blockade. J Am Coll Cardiol 2002;39 (5):104-105A

15. PGA Volders, M Stengl, JM Van Opstal, KR Sipido, MA Vos. Probing the contribution of $I_{\mathrm{ks}}$ to canine left and right ventricular repolarization. Biophysical Journal 2002;82:605a

16. JM van Opstal, M Truin, M Schoenmakers, M B. Thomsen, J Leunissen, MA Vos. Sudden cardiac death and Torsade de Pointes arrhythmias in the chronic AV-block dog are associated with large temporal- and temporospatial repolarization variance. Pacing Clin Electrophysiol. 2002; 25: 576 


\section{ABSTRACTS NATIONAL}

1. SC Verduyn, MA Vos, J van der Zande, JM van Opstal, HJJ Wellens. Torsade de Pointes arrhythmias: study of spontaneous termination reveals causal relation between afterdepolarizations and dispersion of repolarization in the mechanism of this arrhythmia. Pflugers Archiv 1995;460: R 176

2. SC Verduyn, JM van Opstal, HDM Leunissen, T Fazekas, FF van der Hulst, HJJ Wellens, MA Vos. Evaluation of the proarrhythmic effect of antiarrhythmic drugs in the dog with chronic complete AV-block: the relevance of multiple ectopic beats. Cardiologie jaargang 7, dec 2000

3. JM van Opstal, SC Verduyn, HDM Leunissen, HJJ Wellens, MA Vos. Sudden cardiac death and acquired Torsade de Pointes arrhythmias: key role for interventricular dispersion in action potential duration. Cardiologie jaargang 7, dec 2000 



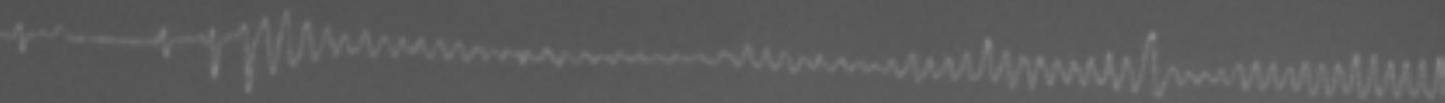

$+T_{1}+$ hom 